Florida International University FIU Digital Commons

FIU Electronic Theses and Dissertations

University Graduate School

10-28-2008

\title{
Global Factors Affecting Women's Participation in Leadership
}

Amanda M. Bullough

Florida International University, amanda.bullough@fiu.edu

DOI: $10.25148 /$ etd.FI10022504

Follow this and additional works at: https://digitalcommons.fiu.edu/etd

Part of the Business Administration, Management, and Operations Commons

\section{Recommended Citation}

Bullough, Amanda M., "Global Factors Affecting Women's Participation in Leadership" (2008). FIU Electronic Theses and Dissertations. 184.

https://digitalcommons.fiu.edu/etd/184

This work is brought to you for free and open access by the University Graduate School at FIU Digital Commons. It has been accepted for inclusion in FIU Electronic Theses and Dissertations by an authorized administrator of FIU Digital Commons. For more information, please contact dcc@fiu.edu. 


\title{
FLORIDA INTERNATIONAL UNIVERSITY
}

Miami, Florida

\section{GLOBAL FACTORS AFFECTING WOMEN'S PARTICIPATION IN LEADERSHIP}

\author{
A dissertation submitted in partial fulfillment of the \\ requirements for the degree of \\ DOCTOR OF PHILOSOPHY \\ in \\ BUSINESS ADMINISTRATION \\ by
}

Amanda M. Bullough

2008 
To: Dean Joyce Elam

College of Business Administration

This dissertation, written by Amanda M. Bullough, entitled Global Factors Affecting Women's Participation in Leadership, having been approved in respect to style and intellectual content, is referred to you for judgment.

We have read this dissertation and recommend that it be approved.

$\begin{array}{r}\hline \text { Sumit K. Kundu } \\ \hline \text { William Newburry } \\ \hline \text { Kevin B. Lowe } \\ \hline \text { Elisabeth Prugl } \\ \hline \text { K. Galen Kroeck }\end{array}$

Date of Defense: October 28, 2008

The dissertation of Amanda M. Bullough is approved.

Dean Joyce Elam

College of Business Administration

Dean George Walker

University Graduate School

Florida International University, 2008 


\section{ACKNOWLEDGMENTS}

The Ph.D. process is never completed in isolation without support and guidance from numerous others, and my journey was no different. While it is not possible to personally cite all those who have graced this process, I want to acknowledge many of the people that served as those guides and supporters. Without my professors, family, and friends, neither the Ph.D. nor this dissertation would have been possible.

I feel deep gratitude toward the professors who listened, supported, corrected, pushed, and encouraged me throughout my Ph.D. program. Here, I address each one in the order in which they came into my life throughout the course of my graduate studies. Doctor Elisabeth Prugl was the first person I met when coming to FIU. From the beginning she made quite an impression, and throughout my Masters program I was inspired by her to continue my work on women's issues around the world. While I pursued the Ph.D. in International Management, Lisa's feedback and guidance on my dissertation and the friendship we formed have been significant forces in my research focus. I thank her for her time, attention, and friendship and look forward to future opportunities for collaboration.

I thank Doctor Sumit Kundu for recognizing something in me and for proposing a Ph.D. in the Management and International Business Department. Dr. Kundu has been a tireless supporter of my progress and has never slacked in making me feel his encouragement. I will never forget his kindness and the reinforcement he provided me. 
To the one I worked the closest with throughout the entire Ph.D. program, Doctor K. Galen Kroeck, I am eternally indebted. Galen challenged me to critically evaluate prior research and literature, and more importantly, the minute details of my own work. I grew as a scholar because he pushed me, and I evolved as an individual as a consequence of what I learned from him. We are friends and I thank him and his family for the kindnesses they have always shown me.

Doctor Kevin Lowe and Doctor William Newburry have been critical to the quality of the dissertation. They put in countless hours to help me with background research, perspectives and options for the direction of the work, and editing. This dissertation is stronger because of their participation on the committee, and I am forever grateful for their time and attention.

To Dean Joyce Elam and the faculty in the College of Business, Professors Armagan, Carsrud, Chacar, Reynolds, Sanchez, Von Glinow, and Zanakis, thank you for everything you taught me for your guidance, for your support, and for challenging me, and making me a stronger academic. And, never to be forgotten, to Sarah Latham and Cassandra Alonso in the Management and International Business Department, thank you for all your help with administrative matters throughout the FIU system.

I also extend a heartfelt thanks to my friends in Tampa, too numerous to name, for distracting me from my work with their love and fun spirits. Without these friends, I may have burned out and never accomplished the goal. To my classmates and friends in Miami, thank you for your support and encouragement. Thank you to Borys Wenglowskyj for all the tech support and for your friendship. Doctor Maija Renko holds a special place in my heart as one of my best friends. Maija was about a year ahead of 
me in the program and played the role of big sister to me very well. Thank you to Maija and to my roommates and lifelong friends, Laura Calabria, Ivelina Pavlova, and Ati Abbasi for the countless hours of girl talk and for your stress-relieving spirit.

I also want to thank my family. My parents, Bill and Nancy Bullough, have spent my entire lifetime loving me and encouraging me to set goals that may be difficult, but that they knew I could achieve. More important than pushing me to strive for success, they always made sure I knew they had my back in case I failed or changed my mind. That support means more to me than they know. My brothers, Jimmy, Tommy, and my "sis" Ulrike are the coolest and sweetest anyone could hope for. I wish everyone in the world could have a family as awesome as mine; I couldn't possibly love them more. I am eternally grateful for my family and I Thank God for how fortunate we all are. The effort made by my Aunt Joan and Uncle Jim to proofread and edit the entire dissertation was an unforgettable gesture of love and kindness; this work is profoundly stronger for it.

Finally, I would like to thank Chuck for his love and support. Chuck has become a pillar that holds me up. I thank God for bringing him into my life at the perfect time, when I needed him the most, and when I was the most ready to meet the love of my life.

Moving on to the next stage of my life, I offer thanks to all the people mentioned here for preparing me for a fantastic job opportunity with Thunderbird School of Global Management, in Phoenix, Arizona. Thank you, Professor Bob Hisrich, for seeing something unique in me and my research, which has proven to be well-suited for my new position. I am inspired and humbled by the billions of women around the world who work harder and face more challenges than many of us ever will. I pray my research and my work allow me to leave this world, and the lives of some of the people in it, a better 
place than I found it. Kelly O, Marnie, Mecheline, and Fauzzia, you have my unending admiration and respect for the work you do in Afghanistan. Thank you as well to Katherine Hutton and Kellie Keiser for helping Chuck and me get settled in our new home in Phoenix.

Phoenix, AZ, November $26^{\text {th }}, 2008$

Amanda M. Bullough 


\title{
ABSTRACT OF THE DISSERTATION
}

\section{GLOBAL FACTORS AFFECTING WOMEN'S PARTICIPATION IN LEADERSHIP}

by

\author{
Amanda M. Bullough
}

Florida International University, 2008

Miami, Florida

\section{Professor K. Galen Kroeck, Major Professor}

This dissertation is a multi-level, cross-cultural study of women in leadership conducted with both macro-society data and individual-level data aggregated to the country level. The research questions are, "What macro and micro forces are hindering or advancing women into business or political leadership?" "How do these forces impact the level of women's involvement in business and political leadership in a particular country?" Data was collected from 10 secondary sources, available for 213 countries, and includes about 300 variables for business leadership $(\mathrm{N}=115)$ and political leadership $(\mathrm{N}=181)$. To date, most women in leadership research has been Western- or US- based, and little rigorous empirical, multi-level research has been done across countries. The importance of cross-cultural studies on women in leadership stems from the potential to better understand why some countries have more women in positions of both business and political leadership; and the factors that affect women's involvement in such positions in different countries. A "Levels of Women's Participation in Leadership" country model is tested using cluster and discriminant analyses. Results indicate that the factors that affect women's participation in leadership in countries with fewer women leaders are different from the factors that affect women's participation in countries with 
high levels of participation. This dissertation proposes that initiatives to increase participation of women in leadership need to consider the relevant factors that significantly affect countries at certain Levels of Women's Participation in Leadership. 


\section{TABLE OF CONTENTS}

CHAPTER

PAGE

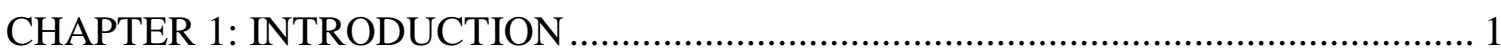

CHAPTER 2: LITERATURE REVIEW AND THEORY DEVELOPMENT .................... 8

Women in Leadership Research ....................................................................... 8

Moving Women in Leadership Research Forward ................................................ 28

Cross-Country Leadership Research............................................................................ 30

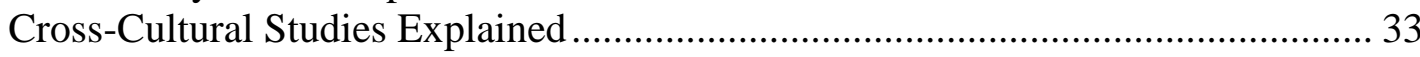

A Review and Critique of Recent Cross-Cultural Research..................................... 36

Directions for Future Research Recently Proposed by Scholars ................................ 43

Theory Development ........................................................................................ 47

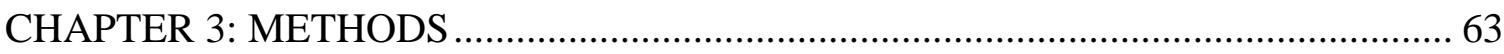

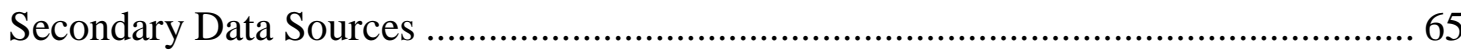

Sources for Dependent Variables: Women in Leadership ........................................... 66

Sources for Independent Variables: Business Environment ....................................... 68

Sources for Independent Variables: Societal Development...................................... 74

Sources for Independent Variables: Economy ......................................................... 79

Sources for Independent Variables: Technology and Physical Infrastructure.......... 80

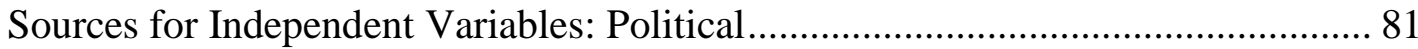

Sources for Independent Variables: Cultural ........................................................ 82

Cluster Analysis to Develop Dependent Variables ...................................................... 98

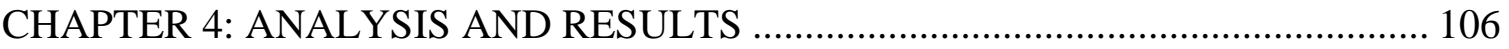

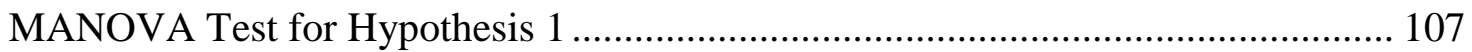

Discriminant Analysis Tests for Hypotheses 2-7 ...................................................... 109

Women in Business Leadership: Discriminant Analysis Results ............................... 111

Hypothesis 2: The Business Environment ....................................................... 112

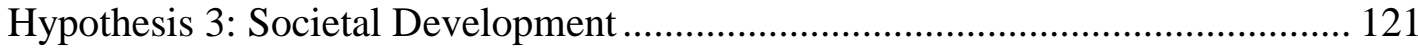

Hypothesis 4: Economics Factors ........................................................................ 129

Hypothesis 5: Technology and Physical Infrastructure ......................................... 134

Hypothesis 6: Political Freedom .......................................................................... 137

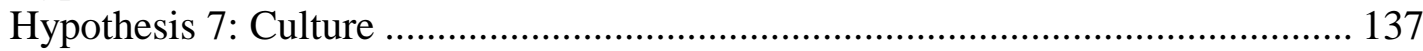

Women in Political Leadership: Discriminant Analysis Results ............................... 145

Hypothesis 2: The Business Environment ........................................................... 146

Hypothesis 3: Societal Development ................................................................. 155

Hypothesis 4: Economics Factors ...................................................................... 162

Hypothesis 5: Technology and Physical Infrastructure .......................................... 167

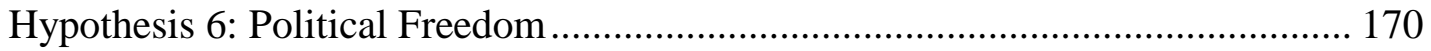

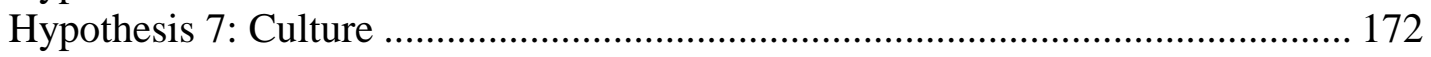




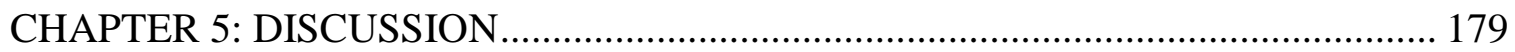

WOMEN IN BUSINESS LEADERSHIP DISCUSSION .................................... 182

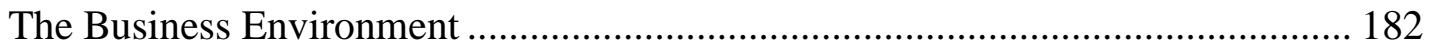

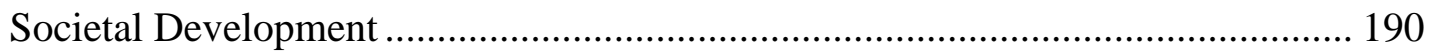

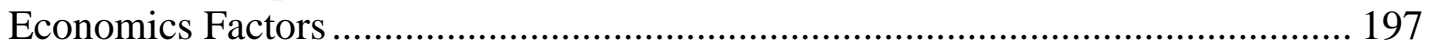

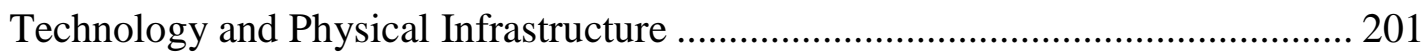

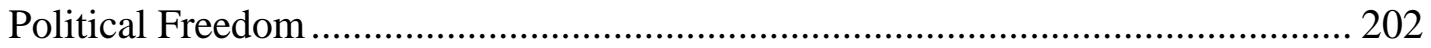

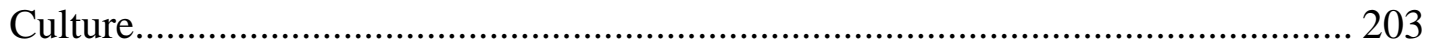

Conclusion to the Women in Business Leadership Findings............................... 212

WOMEN IN POLITICAL LEADERSHIP DISCUSSION .................................. 217

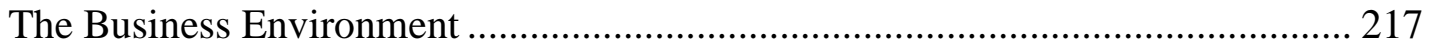

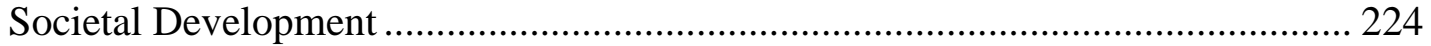

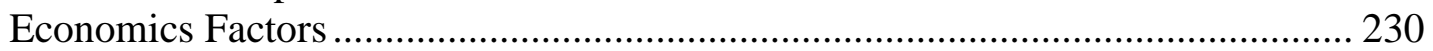

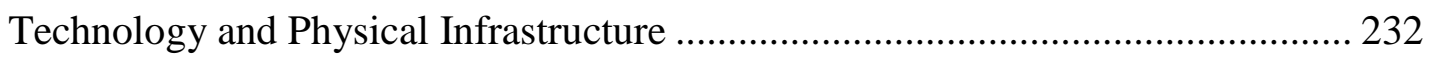

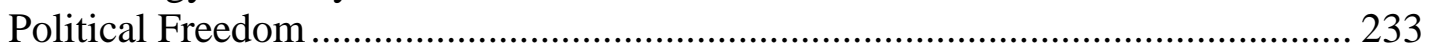

Culture................................................................................................ 234

Conclusion to the Women in Political Leadership Findings ............................... 246

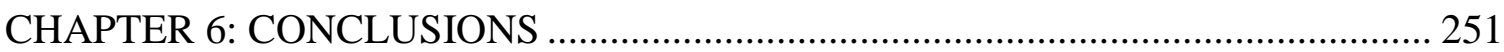

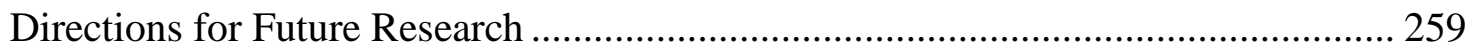

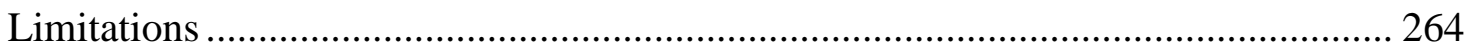

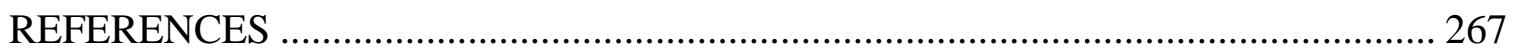

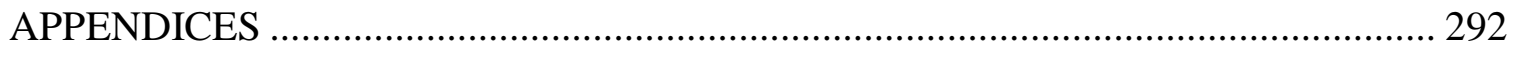

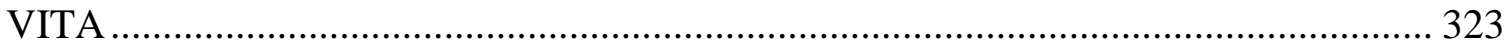




\section{LIST OF TABLES}

TABLE

PAGE

TABLE 1: Samples of Recent Empirical Gender Studies in Leadership..................12

TABLE 2: Samples of Recent Empirical Cross-Cultural Studies in Peer-Reviewed Journals...................................................... 38

TABLE 3: Samples of Recent Empirical Cross-Cultural Leadership Studies..............40

TABLE 4: K-Means Cluster Analysis Women in Political Leadership....................100

TABLE 5: K-Means Cluster Analysis Women in Business Leadership.................... 101

TABLE 6: MANOVA Test Distinct Clusters - Political Leadership .....................108

TABLE 7: MANOVA Test Distinct Clusters - Business Leadership..................108

TABLE 8: Business Enviornment H2 Discriminant Analysis Results Business

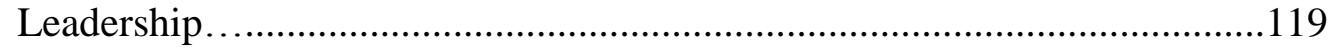

TABLE 9: Societal Development H3 Discriminant Analysis Results Business Leadership................................................. 127

TABLE 10: Economics H4 Discriminant Analysis Results Business Leadership........132

TABLE 11: Infrastructure/Technology H5 Discriminant Analysis Results Business

Leadership.................................................. 135

TABLE 12: Culture H7 Discriminant Analysis Results Business Leadership..............144

TABLE 13: Business Enviornment H2 Discriminant Analysis Results Political Leadership.

TABLE 14: Societal Development H3 Discriminant Analysis Political Leadership......160

TABLE 15: Economics H4 Discriminant Analysis Results Political Leadership.........166

TABLE 16: Infrastructure/Technology H5 Discriminant Analysis Results Political Leadership....................................................169

TABLE 17: Political H6 Discriminant Analysis Results Political Leadership............171

TABLE 18: Culture H7 Discriminant Analysis Results Political Leadership.............178 


\section{CHAPTER 1: INTRODUCTION}

The factors that affect women's participation in leadership roles are different across the world, changing with the dynamic nature of the environments in which they live (Bajdo \& Dickson, 2001; X.-P. Chen \& Li, 2005; D. N. Den Hartog, House, Hanges, Quintanilla, Dorfman, \& Associates, 1999; Erez \& Gati, 2004; Stelter, 2002). Women within a particular society are affected by: (a) the business environment, including taxes, procedures, corruption, labor, competition and finances (World Bank, 2007b, 2008a, 2008b; Bertrand, Djankov, Hanna, \& Mullainathan, 2007; Demirgüç-Kunt, LópezCórdova, Pería, \& Woodruff, 2007; Sharma, 2007); (b) fundamental social and developmental considerations like education, health, and the physical environment (Fagerberg, 1994; Hofstede, 1983, 1997; Lieb \& Thistle, 2005; Sachs, 1997, 2005; Van de Vliert, 2003); (c) economic factors and the level of development of a country, including the types of goods that are exported and services that provide a competitsive advantage (Hill, 2008b; Papamarcos \& Watson, 2006; M. E. Porter, 1990; UNDP, 2007); (d) technological and distribution infrastructure (Chan \& Qingyang, 2006; T. Friedman, 2005; UN, 2005b); (e) the political rights and civil liberties within a country (F. House, 2008; Puddington, 2008); and (f) the beliefs, norms, and expectations of the individuals within a particular culture (Fu, Kennedy, Tata, Yukl, Bond, Peng, Srinivas, Howell, Prieto, Koopman, Boonstra, Pasa, Lacassagne, Higashide, \& Cheosakul, 2004; K. Leung \& Bond, 2004; K. Leung, Bond, Reimel de Carrasquel, Muñoz, Herna'ndez, Murakami, Yamaguchi, Bierbrauer, \& Singelis, 2002). To date, insufficient attention has been given 
to the relationship between leadership and the structural elements related to culture (Farid, 2007).

Culture is a multi-layer construct that comprises an external global layer penetrating a society to indigenous layers, ultimately becoming a set of shared values at the group and individual level (Kwok Leung, Bhagat, Buchan, Erez, \& Gibson, 2005). Understanding cultural systems is critical for the advancement of research on leadership in varying contexts (Kirkman, Lowe, \& Gibson, 2006). The concept of leadership involves relationships deeply rooted in social settings (Bryman, 1996) requiring leadership theory and research to integrate leader attributes and behaviors within contextual aspects of leader emergence and effectiveness (G. Yukl, 1998; G. Yukl \& Howell, 1999). Javidan and Carl (2005) point out that leadership research emanating from the U.S. and Europe is important, but question its universality across cultures. For this reason, current leadership research is limited in cultural and contextual scope and very little empirically based multi-level theory development has been published across culture (i.e. Bajdo \& Dickson, 2001; Chow, 2005; D. N. Den Hartog et al., 1999).

A similar reservation can be held about research on women in positions of leadership. Most recent studies on women in leadership are based on American or Western theories, or typically compare women to men searching for individual differences or organizational effects based on gender (Hillman, Shropshire, \& Cannella, 2007; Kulich, Ryan, \& Haslam, 2007). Many of the studies continue to explore topics like stereotypes (Hoyt, 2005; Powell, Butterfield, \& Parent, 2002) and glass ceilings (Bartol, Martin, \& Kromkowski, 2003; Waldstrøm \& Madsen, 2007) or attempt to reveal significant female leadership traits and behaviors (Hansen \& Otero, 2006; Weikart, Chen, 
Williams, \& Hromic, 2006). There is little research on women leaders using a multilevel, cross-cultural perspective, and very few studies propose theory that is applicable outside the samples or settings being investigated. Since women's roles in leadership transpire in a multitude of settings and contexts, it is imperative that new research encompass multilevel frameworks that include both the macro and micro, and analysis across countries and institutional settings (deBruin, Brush, \& Welter, 2007; Minniti \& Nardone, 2007).

This study uses a cross-country, multi-level approach to emphasize leadership processes at both the individual and societal levels (Kevin B. Lowe \& Gardner, 2000) to better understand what affects women's involvement in leadership roles. Leaders impact their constituents through both their direct and indirect actions. A leader's constituencies include direct followers like employees and other subordinates, as well as indirect observers, business associates, and generational protégés who follow their lead and learn from their example. The GLOBE team of 54 researchers (R. J. House, Hanges, Javidan, Dorfman, \& Gupta, 2004) collectively defines leadership as "the ability of an individual to influence, motivate, and enable others to contribute toward the effectiveness and success of the organization of which they are members (p. 15)." Because the unit of analysis in this study is at the country level, "ability" is not tested. Leadership is therefore defined more broadly here as the influence an individual has, whether directly or indirectly, on followers or observers from her/his organization, community, or society. This study explores specifically business and political leaders, whereas leaders in other realms such as education or the non-profit sector are not included.

Women tend to occupy less visible positions of leadership through supportive roles, particularly in developing countries. Approximately 70 women have occupied 
prime minister or president positions around the world (Jalalzai, 2004; Zárate, 2008) and while these women have certainly set examples for all types of followers, observers, and admirers, they are a surprising minority and represent a very small percentage of women in leadership positions. Rather than spotlighting these extraordinary women and elucidating the influence of their achievements, this research examines women in lower levels of leadership, like business ownership and public office positions, because of the importance of their involvement in their economies and societies (Jones, Snelgrove, \& Muckosy, 2006). The importance of this research lies in the idea that attitudes toward women in leadership affect women's participation in leadership, and in turn, women in positions of leadership engage in policies that positively affect women (Caiazza, 2004). This reciprocal effect furthers the process of gender equality in the work force, and promotes an environment where women are supported to move into autonomous and independent activities. This process gradually leads to further acceptance of women in business or political leadership.

Traditional and persistent barriers have been shown to hinder the active pursuit of women to obtain positions of leadership (i.e. Bartol et al., 2003; Hoyt, 2005; Powell et al., 2002; Sczesny, 2003); this point is not contested here and is respected as a foundation of the field. However, because research and policy tend to view gender issues based on the premise that women are marginalized and a glass ceiling effect is still the major impediment to women's participation in leadership, other current yet authentic issues may go unnoticed or misunderstood. For example, women who have access to technology or fewer procedural obstacles to business ownership may have more opportunities for starting businesses (Fairlie, 2006; Koh, 2006), indicating that efforts 
focusing on related issues may prove more productive at this point. It is proposed here that with the globalization of business practices, opportunities, technologies, and cultures, women face new and different challenges that vary depending on the context of the environment in which they operate. Research can adapt from the idea that gender is a values-based impediment and move toward a discussion of the relationships among culture, context, and practice, with the goal of developing new applicable theories and frameworks (Earley, 2006).

The research questions examined here are, "What macro and micro forces are hindering or advancing women into business or political leadership?" "How do these forces change, depending on the level of women's involvement in business and political leadership in a particular country?" As will be shown in this study using data from 2002-2007, in very recent years there has been a considerable increase in education and socio-economic support for women in leadership in certain parts of the world. However, there are still obstacles facing women. These impediments, as well as the positive processes and developments that successfully move women forward into business and political leadership, are the focus of this study. If culture is changing, allowing more women to lead, what factors are stunting the progression of women into more leadership positions? What is holding women back from trying to become more independent? What is encouraging and supporting these efforts? The outcome of this study will elucidate the important factors that affect women's participation in leadership and result in recommendations for how the activity of women in the economy and in politics can be encouraged and promoted. 
This dissertation begins with a literature review in chapter 2 which includes two distinct fields of research applicable to this study: cross-cultural leadership studies and women in leadership studies. The first review is of both seminal research and current work done in cross-cultural leadership studies, highlighting the importance of this research. This review includes recommendations from scholars who have suggested valuable directions for future research to advance the field. This study fits with these recommended guidelines and therefore makes a significant contribution to the field of cross-cultural research. The second domain of literature to be reviewed is related to the field of women in leadership. Following the literature review is a theory section that proposes a levels model of women's participation in leadership roles, followed by the hypotheses that are tested empirically in subsequent chapters.

Chapter 3 presents the methods and analysis section. In this chapter, a brief description of the variables and the secondary sources from which they are gathered are presented. This study began with almost 300 variables, 213 countries, and 10 secondary sources and was reduced through further analysis. Chapter 3 also explains the two-step data analysis procedure chosen, including a cluster analysis of the dependent variables and discriminant analysis of the predictor variables.

Chapter 4 covers the quantitative results of the analysis and the tests of hypotheses, using multivariate analysis and discriminant analysis. Chapter 4 is presented in two separate parts. Since there are two dependent variables in this study, women's participation in business and women's participation in political leadership are analyzed and reported separately. Chapter 5 includes the discussion. The discussion section, like the results, is presented in two sections: one for women's participation in business 
leadership and the other for women's participation in political leadership. Chapter 6 presents overall conclusions to the study, recommendations, and limitations that are faced with regards to data and analysis. 


\section{CHAPTER 2: LITERATURE REVIEW AND THEORY DEVELOPMENT}

The following is a review of cross-cultural studies and research relating to women in leadership. This chapter begins with a review of past research in the field of women in leadership. Topics covered in this section include: international efforts toward the inclusion of women in leadership, work-family balance, glass ceiling effects, gender stereotypes, and gender-leader role incongruity. Following this review of the literature are recommendations for how future research on women in leadership can be improved. Next, this chapter will cover a review of both classic and recent work done in crosscultural studies and covers some important recommendations for future research. Studies in top quality, peer-reviewed journals will be evaluated against these suggested guidelines for impending research. This will lead to an explanation of how this dissertation complies with the suggestions made by prior scholars and the contribution of this study to cross-cultural research. Finally, a stage model of women's participation in leadership roles is proposed. The essence of this proposed model is a stage process through which countries go as women progress from generations of little to no involvement in leadership, to full societal acceptance and support for women at levels. Hypotheses are proposed following the stage model.

\section{Women in Leadership Research}

Encouraging women's roles in business leadership is critical to the growth of the economy (Afrin, 1999; Caputo \& Dolinsky, 1998; S. Coleman, 2004; Minniti, Arenius, \& 
Langowitz, 2004). Many organizations and government institutions (The hunger project, 2005; ILO, 2005b; UN, 2005a; UNIFEM, 2008) have long recognized the importance of women in both developed and developing nations to the process of increased development (I. Coleman, 2004). Women are credited with the role of primary caregiver, and their efforts outside the home to generate income positively affect a strong, burgeoning family (Afrin, 1999; Barnett, 1995; I. Coleman, 2004; S. Coleman, 2004; Dana, 2000; ILO, 2005a; Kantor, 2002; Mitra, 2002; Oppedisano, 2004; Shabbir \& Di Gregorio, 1996; UN, 2005a).

The United Nations' Millennium Development Goals (UN, 2003) specifically address women-related issues, promoting gender equality and the empowerment of women, and the UN Division for the Advancement of Women (DAW) (UN, 2005a) promotes equality with men across the world for sustainable development, peace and security, governance, and human rights. In the past decade, the number of people living in poverty has been reduced, the gender gap in education has narrowed, women have become more involved in political arenas, and women are a growing force in the economic labor market. However, inequalities remain and women are still a disappointing minority in education, and in parliament in particular, and are more likely to work in the lower paid, lower status, less reliable informal sector, and then get left behind with the progress of economic growth and trade liberalization (M. Chen, Vanek, Lund, Heintz, Jhabvala, \& Bonner, 2005). These findings support the timeliness of this project as globalization and focused efforts have made positive waves. Since women make up the majority of the informal working poor, a focus on women's leadership is 
needed to strengthen the organization of the working poor into a representative voice for effective policy making (M. Chen et al., 2005).

The participation of women in the workforce has been argued to bring particular gender-specific capabilities (relationship focused, open communication styles, motivating abilities toward followers, and the sharing of power) (Newburry, Belkin, \& Ansari, 2007) to the economic sector. A consequence of businesses operating in a globalized world is that modern, globalizing business values accommodate the advancement of women and lead individuals to associate the advancement of women with an increased capability to operate within the global economy. An increase in the acceptance of women in leadership may imply a recognition of the value of women-specific capabilities (Adler, 1999; Newburry et al., 2007) as well more opportunity for women to achieve gender equality and independence. However, while accommodating outside values has become recognized as important, these values may not have penetrated individual-level behaviors (Newburry et al., 2007). This dissertation aims to sort out exactly this point: some factors lead to an increase in women's participation in leadership, while others hinder women's advancement.

The topic of females as leaders in a cross-cultural context is still understudied in terms of rigorous, empirical research, though it has been increasing, and it is unclear if the reason for this dearth is because of a lack of interest in gendered leadership issues or because of a push toward a politically correct view that gender doesn't matter (Kevin B. Lowe \& Gardner, 2000). Table 1 shows a review of the empirical work done mostly since 2000 on the research juncture of gender and leadership. Most of the studies are U.S. or Western based, compare samples of women to men searching for individual 
differences or organizational effects based on gender, and examine hot topics like gender bias, stereotypes, and glass ceilings. Many of the studies are looking for significant leadership traits and behaviors in women. None of these studies attempt a multilevel, cross-cultural perspective and, with the exception of a few, most did not propose applicable theory outside the samples or settings being investigated. 


\begin{tabular}{|c|c|}
\hline $\begin{array}{l}\text { Hillman, Shropshire, \& } \\
\text { Cannella (Hillman et al., } \\
\text { 2007) }\end{array}$ & $\begin{array}{l}\text { Applied resource dependence theory to uncover } \\
\text { organizational predictors of women on corporate boards of } \\
\text { directors using panel data from the } 1,000 \text { largest U.S. firms } \\
\text { based on sales from } 1990 \text { to } 2003 \text { and found that } \\
\text { organizational size, industry type, firm diversification } \\
\text { strategy, and linkages to other boards with women directors } \\
\text { significantly influence the participation of females on } \\
\text { corporate boards of directors. }\end{array}$ \\
\hline $\begin{array}{l}\text { Kulich, Ryan, and } \\
\text { Haslam (2007) }\end{array}$ & $\begin{array}{l}\text { Extended prior research on the romance of leadership to men } \\
\text { and women and examined its impact on performance-based } \\
\text { pay. Conducted an experimental study with } 210 \text { men and } \\
\text { women and found that for female leaders, performance- } \\
\text { related bonuses are based on charisma and leadership ability } \\
\text { rather than performance, whereas for male leaders } \\
\text { performance leads to increased perceived charisma and } \\
\text { increased leadership ability, resulting in larger bonuses, } \\
\text { implying explanations for gender pay gaps. }\end{array}$ \\
\hline $\begin{array}{l}\text { Waldstrøm \& Madsen } \\
\text { (2007) }\end{array}$ & $\begin{array}{l}\text { Studied 1,500 Danish managers and found that older male } \\
\text { managers regard their nearest colleagues as friends more than } \\
\text { older female managers do. However, younger female } \\
\text { managers were more likely to have friends among their } \\
\text { nearest colleagues than younger male managers. Researchers } \\
\text { admitted that the implications of this are not particularly } \\
\text { clear. In addition, no gender differences were found on the } \\
\text { need to have social contact through the job. }\end{array}$ \\
\hline $\begin{array}{l}\text { Wolfram, Mohr, \& } \\
\text { Schyns (2007) }\end{array}$ & $\begin{array}{l}\text { Investigated } 81 \text { leaders and } 121 \text { followers from } 34 \text { German } \\
\text { organizations and found that female leaders receive less } \\
\text { professional respect from their followers than their male } \\
\text { leaders. }\end{array}$ \\
\hline Hansen \& Otero (2006) & $\begin{array}{l}\text { Examined American National Election Studies and found } \\
\text { that, in times of crisis, women politicians who can } \\
\text { demonstrate that they have toughness and management skills, } \\
\text { while simultaneously showing compassion, may have an } \\
\text { advantage. }\end{array}$ \\
\hline $\begin{array}{l}\text { Weikart, } \\
\text { Williams, \& } \begin{array}{r}\text { Chen, } \\
(2006)\end{array}\end{array}$ & $\begin{array}{l}\text { Explored } 192 \text { female and } 192 \text { male U.S. mayors. Results } \\
\text { showed no real differences on policy issues, the use of power, } \\
\text { and budget issues. However, women were more willing to } \\
\text { change the budget process, be more inclusive, seek broader } \\
\text { participation, and admit fiscal problems and discuss changes } \\
\text { in their goals. Men were less likely to believe that women } \\
\text { face gender-related barriers in leadership. }\end{array}$ \\
\hline Hoyt (2005) & $\begin{array}{l}\text { Examined the role of leadership self-efficacy as a moderator } \\
\text { of the think-leader-think-male stereotype. Manipulated } \\
\text { stereotypes in an experiment with } 85 \text { females and found that }\end{array}$ \\
\hline
\end{tabular}




\begin{tabular}{|c|c|}
\hline & $\begin{array}{l}\text { high levels of leadership efficacy demonstrated heightened } \\
\text { identification with the leadership domain after exposure to } \\
\text { negative stereotypes. This identification with leadership did } \\
\text { not happen to women with lower levels of leadership efficacy. }\end{array}$ \\
\hline $\begin{array}{lll}\text { Schyns } & \& & \text { Sanders } \\
(2005) & & \end{array}$ & $\begin{array}{l}\text { Studied } 58 \text { leaders and } 113 \text { followers and found no significant } \\
\text { relationship between transformational leadership and } \\
\text { occupational self-efficacy for women, but did for men. No } \\
\text { interaction effects were found for gender and transformational } \\
\text { leadership on leader occupational self-efficacy. }\end{array}$ \\
\hline Groves (2005) & $\begin{array}{l}108 \text { senior leaders and } 325 \text { of their direct followers were } \\
\text { examined to uncover the relationships between the gender of } \\
\text { the leader, their social and emotional skills, and charismatic } \\
\text { leadership. Female leaders scored higher on social and } \\
\text { emotional skills, and follower ratings of charismatic } \\
\text { leadership. In addition, social and emotional skills mediated } \\
\text { the relationship between leader gender and charismatic } \\
\text { leadership. }\end{array}$ \\
\hline $\begin{array}{l}\text { Neubert } \quad \& \quad \text { Taggar } \\
(2004)\end{array}$ & $\begin{array}{l}\text { Studied } 18 \text { manufacturing teams ( } 237 \text { participants) and found } \\
\text { that gender moderated the relationships between informal } \\
\text { leadership emergence in existing teams and conscientiousness } \\
\text { and emotional stability. When men fulfill expectations that a } \\
\text { leader be conscientiousness and emotionally stable, they arise } \\
\text { as informal leaders more than women who fulfill the same } \\
\text { expectations, because these characteristics are expected more } \\
\text { in women - possibly due to an incongruence between } \\
\text { leadership and gender stereotypes. }\end{array}$ \\
\hline Lucas (2003) & $\begin{array}{l}\text { Applied status characteristics theory in an experiment to test } \\
\text { the idea that institutionalizing women can legitimize } \\
\text { leadership for women in a structure that is predominately } \\
\text { male influenced. Initial results showed that males attained } \\
\text { higher influence than females. When institutionalized, } \\
\text { women leaders appointed on ability achieved influence as } \\
\text { high as men with ability. }\end{array}$ \\
\hline $\begin{array}{l}\text { Bartol, Martin, } \quad \& \\
\text { Kromkowski (2003) }\end{array}$ & $\begin{array}{l}\text { Investigated } 658 \text { middle managers and executives in a large } \\
\text { professional services business organization and found female } \\
\text { and male executives to share similar leader behaviors valued } \\
\text { by top management more than male and female middle } \\
\text { managers. However, both female middle managers and } \\
\text { female executives rated higher than males on interpersonal } \\
\text { behaviors. The females also engaged more in goals and task } \\
\text { leader behaviors. }\end{array}$ \\
\hline $\begin{array}{l}\text { Vinnicombe \& Singh } \\
(2002)\end{array}$ & $\begin{array}{l}\text { A study of } 363 \text { managers in a British/Australian insurance } \\
\text { company found significant gender differences in perceptions } \\
\text { of their own leadership style and that of successful leaders in } \\
\text { their organizations. Concluded that shifting perceptions in }\end{array}$ \\
\hline
\end{tabular}




\begin{tabular}{|l|l|}
\hline & $\begin{array}{l}\text { leadership styles leads to preferences of an androgynous } \\
\text { manager. }\end{array}$ \\
\hline Burke \& Collins (2001) & $\begin{array}{l}\text { In a sample of male and female accountants, found that } \\
\text { females are more likely than males to indicate that they use a } \\
\text { transformational leadership style. Females reported somewhat } \\
\text { higher perceived effectiveness on coaching, developing, and } \\
\text { communicating. }\end{array}$ \\
\hline
\end{tabular}

The following literature review is intended to set the foundation on which the study of women in leadership is built. The review begins with past research on international efforts made toward gender equality issues. Following this is a review of research done on topics related to work-family balance, glass ceiling effects, gender stereotypes, and gender-leader role incongruity. However, given the enormous amount of work done in some of these areas, this review is in no way meant to be exhaustive. In addition, considering the dynamic and rapidly changing nature of gender issues in today's globalized world, the majority of this literature review focuses on research published in approximately the last 10 years, with seminal pieces referenced where prudent. The theory development section following the literature review will stem from the recommendation that future research on women in leadership should provide a more complete examination of the degree to which culture, norms, and context (Kevin B. Lowe \& Gardner, 2000) influence women's involvement in positions of influence.

Research on Work-Family Balance: One of the hot topics in the gender literature is the tightrope that women walk in an effort to successfully balance their work and family lives. As women have joined the workforce and climbed into higher positions of influence, particularly in Western societies, they have increasingly been beset with mastering the task of wearing multiple hats at the same time. This multitasking 
characteristic is one that some may argue (i.e. Jennings \& McDougald, 2007; Ruderman, Ohlott, Panzer, \& King, 2002) women have mastered in order to juggle all the responsibilities of the home and each family member. The following is brief review of theory that has been proposed on this topic.

While much of the work family-balance research is Western-centric, it is important to review for its contribution to the field. Aldrich and Cliff (2003) demonstrate that major transformations have occurred in family composition and that these changes in roles and relationships can have a major influence on the working lives of both women and men. These scholars explain that in North America up until the 1950's and 60's, “'family' usually meant a nuclear two-generational group with parents and children sharing the same household ... when few women worked outside the home ..." (pg. 578). Over the next 50 years or so, the family system has changed because of transformations in the composition of households, including both family and non-family members, and in the roles and relationships among family members (Aldrich \& Cliff, 2003). In other words, family and business are embedded together and spillovers exist between the two realms. Applying this family embeddedness perspective to women in leadership, family systems influence the processes involved in women's decisions to engage in positions of leadership by affecting resources, family transitions, and ultimately the norms, attitudes, and values of each family member.

Women persistently face more household demands and family responsibility (Huang, Hammer, Neal, \& Perrin, 2004; Jurik, 1998; Milkie \& Peltola, 1999; Moen \& Yu, 2000; Rothbard, 2001) even when working outside the home because women are still expected to be the primary caregivers. This reduces time available for work and 
increases stress, leading to more work-family conflict and attitudes and behaviors that interfere with business leadership. Men on the other hand are expected to be good economic providers for their families and devote time to business. Therefore, as "breadwinners" men are better able to maintain their family and work demands at the same time than women (Jennings \& McDougald, 2007; Simon, 1995). Men tend to make greater sacrifices at home in order to maintain their work responsibilities whereas women do the opposite (Jennings \& McDougald, 2007; Martins, Eddleston, \& Veiga, 2002; Milkie \& Peltola, 1999; Moen \& Yu, 2000; Rothbard, 2001).

Female leaders will experience less work schedule autonomy and flexibility if they continue to work in the typical retail and personal services industries which have either inflexible hours or demanding clients (Bates, 2002; Cliff, 1998; Kim \& Ling, 2001) leaving women less control over their work environments and higher levels of workfamily conflict. Family-work constraints can lead women to pull double duty with home and work responsibilities, and in turn restrict business growth rather than encourage it, give higher priority to their spouse's careers and make sacrifices in their own. This results in smaller employment size, revenues, and income levels of women-led businesses. (Jennings \& McDougald, 2007),

Individuals experience the work-family interface when there is conflict from incongruity between the two spheres because of stress, time, and incompatible behaviors required for each. These work-family interface factors offer a more robust explanation for differences between men and women (on factors like human capital, social capital, financial capital, growth orientations, and industry choice). The different life experiences that women face will cause women-led businesses to face more challenges compared to 
men-led businesses (Jennings \& McDougald, 2007), to respond differently to their environment, and in turn lead differently than men (Weikart et al., 2006) and for different reasons.

Individuals also experience the work-family interface in more positive ways through the benefits and enriching properties of both work and family and the effects that both realms simultaneously have on each other (Jennings \& McDougald, 2007). Ruderman, Ohlott, Panzer, and King (2002) counter the role scarcity argument (Goode, 1960) that women have a fixed amount of time and energy sectioned into pieces of a figurative pie and that for more time or energy to be allocated to one slice, another slice needs to be reduced. They argue, alternatively, that the roles present in women's personal lives psychologically enhance their effectiveness in business roles. In other words, emotional abilities, multitasking, interpersonal skills, and leadership activities involved in women's personal spheres positively spill-over into professional realms. Ruderman et al. (2002) refer to this as the role accumulation perspective - the idea that multiple roles provide some people with more energy, rather than deplete a set reserve (Marks, 1977; Sieber, 1974), although certainly role overload and role stress can stretch a person's limits and become burdensome. Role accumulation can be beneficial because of available enhanced psychological resources, social resources, and learning opportunities (Ruderman et al., 2002).

The Glass Ceiling: Context plays a crucial role in women's involvement in positions of leadership, in that, if women feel alienated from leadership positions, they are discouraged from participating (Vinnicombe \& Singh, 2002). Powell and Butterfield (1994) combined prior definitions (Labor, 1991; A. M. Morrison, White, \& Van Velsor, 
1987) to describe the glass ceiling for women as "a barrier to entry into top-level management positions ... based on attitudinal or organizational bias ... simply because they are women rather than because they lack the ability to handle jobs at higher levels" (pg. 68). Because this is such a popular topic in modern gender discussions, a tremendous amount of work has been done. This review of the glass ceiling debate is in no way intended to cover the enormity of the topic. Rather, the goal is to scratch the surface in an attempt to point out the discrepancies in findings and possible biases some researchers might have toward either the idea of women as victims or the opposite idea that gender doesn't matter at all. The real story is much more complicated than either of these ends of the spectrum.

There have been some inconsistencies in findings related to the validity or severity of the glass ceiling effect. For example, one study found that while women make up half of the work force in developed countries these days, there are still visible glass ceiling effects that keep women from moving into middle- and senior-level management positions - long working hours and male-dominated networks in particular (Ogden, McTavish, \& McKean, 2006). Similarly, women are still less likely to run for political office than men, which explains the under-representation of women in politics. Reasons for this include a lack of political confidence, family responsibilities, gender role socialization (subtle socialization processes that politics is a man's world), and a lack of other women politicians to emulate (which may explain the gender role socialization finding) (Elder, 2004).

On the other hand, prior research (Burrell, 1996; Darcy, Welch, \& Clark, 1994; Seltzer, Newman, \& Leighton, 1997; E. Smith \& Fox, 2001) has also shown that voter 
bias is not a significant factor and that women political candidates receive equal party and financial support. In addition, Powell and Butterfield (1994) were the first to explore promotion decisions for top management positions to determine if they displayed the glass ceiling trend. The findings did not indicate a bias against women's advancement to higher levels, and in fact suggested that gender may work in women's favor.

The discrepancies at play here are most likely due to the context within which the glass ceiling effects operate. For example, the more a country has reached higher levels of gender empowerment and equality, the less likely it may be that women will face glass ceiling obstacles. Context also matters in terms of mediating and moderating variables that may affect the relationship between gender and the glass ceiling. For example, in organizations or societal cultures where women are generally accepted at higher levels of leadership, glass ceiling effects may be considerably minimized. The opposite may be true in places where women are severely marginalized and the proverbial "glass" ceiling is actually made of steel. In these cases, women not only cannot attain levels of leadership, they can't even envision them. In other words, the level that an organization or society falls on a women-in-leadership spectrum, from low to high participation of women in leadership, can moderate the effect of the glass ceiling. Because a glass ceiling measure does not exist at the country level and the concept is theoretical in nature, a hypothesis cannot be tested empirically, however, the following proposition can be offered: the effect of the glass ceiling in corporations and in politics on women's participation in leadership in a country is moderated by the characteristics of the political, economic, social, technological, infrastructural, business, and cultural contexts. 
In addition, glass ceiling issues may be less present in organizations started by women themselves. Women often start their own businesses in an effort to circumvent the old boy's network or glass ceiling issues faced with traditional, large organizations where higher positions have been held predominately by men. Although owning a business is understood to be challenging, it is nonetheless preferred to working in other organizations. This leads to a motivation toward women leading their own businesses based on both an inflexibility of employers toward working women with family responsibilities, and women's desires to run their own businesses (Jennings \& McDougald, 2007). Another reason men and women aim to lead their own businesses is to have the control to choose the flexible hours associated with this in an effort to achieve better balance between work and family (Walker \& Webster, 2007).

Individual Differences, Stereotypes, and Role Congruity Studies: This section of the leadership and gender literature review covers past research that has been done on individual differences between men and women in leadership style, stereotypes based on assumed gender differences and the traits specific to both genders, and the incongruity with these stereotypes with expectations about leader characteristics. As will be shown, many of the findings in this research are inconsistent and sometimes contradictory, illuminating the importance of evaluating context (economic, business, social, technological, political, and cultural) when proposing such research.

Eagly and Carli (2004) offer several explanations for women's lesser occupancy of high-level leadership positions in the United States. One explanation is that women make less of an investment in human capital, although not necessarily in terms of education or work experience. Because of women's greater involvement in domestic 
work, their attention is often diverted from training and efforts made toward paid work, causing them to experience interruptions in their work history, more than men. Another explanation is that women and men lead differently and these styles are inconsistent with the role expectations of leaders and therefore lead to a potential prejudice and discrimination against women in leadership roles (Eagly \& Carli, 2004).

The role congruity theory of prejudice toward female leaders proposes that a perceived incongruity between the female gender role and the leadership role leads to prejudice (Eagly \& Karau, 2002) or a glass ceiling. One form of this prejudice involves the perception of women less favorably than men as potential occupants of leadership roles. A second form of prejudice includes evaluating behaviors that fulfill the prescriptions of a leader role less favorably when it is enacted by a woman. Consequently, attitudes are less positive toward female leaders, making it more difficult for women to become leaders and to achieve success in leadership roles. Because the requirements of leadership roles have been argued to be generally constructed in masculine terms, there is some degree of inconsistency between these expectations and those of the female gender role (Eagly \& Karau, 2002).

If perceivers often observe a specific group of people engaging in a particular activity, they are likely to believe that the abilities and personality attributes required to carry out that activity are typical of that group of people (Osborn \& Vicars, 1976). Stereotyping happens when individuals cognitively categorize people into groups and then acquire beliefs that certain attributes are common among members of those groups, including their own. Some stereotypes are exceptionally persistent in some cultures over time, even as feelings about women's roles have evolved (Powell et al., 2002). Sex-role 
stereotyping depicts men as superior in leadership pursuits because they are considered to possess the masculine, agentic qualities (e.g., men are more assertive, competitive, daring, and courageous) that are needed to gain the necessary level of respect for the successful supervision of followers (Eagly \& Mitchell, 2004). Women are expected to display relatively feminine, communal values by acting affectionate, cooperative, and compassionate. Women are generally not expected to exhibit the characteristics typically associated with men and leaders, such as being assertive, ambitious, dominant, strong, independent, and self-confident (Eagly \& Mitchell, 2004).

Contrary to research findings on gender stereotypes and biases (Alice H Eagly \& Linda L Carli, 2003; Alice H. Eagly \& Linda L. Carli, 2003; Eagly \& Johnson, 1990; Eagly \& Karau, 2002; Eagly, Karau, \& Makhijani, 1995; Eagly \& Mitchell, 2004; Eagly \& Steffen, 1984), Jennings and McDougald (2007) explain that while past research has shown differences between men and women on several factors (human capital, social capital, financial capital, growth orientations, and industry choice), these have not necessarily accounted for the smaller size of female-headed firms or for discrimination problems toward women trying to secure funding (Fabowale, Orser, \& A., 1995; Loscocco \& Leicht, 1993; Rosa, Carter, \& Hamilton, 1996; Watson \& Robinson, 2003).

In a review of the "female advantage" versus the "male advantage," Vechio (2002) refutes these stereotypical studies in male versus female research. The idea of the "female advantage" (Helgesen, 1990; G. Yukl, 2002) that women are better at inclusiveness, interpersonal relations, power sharing, and being nurturing to followers and therefore make better leaders is debunked, as is the old male advantage (Vecchio, 2002). The "masculine advantage" presumed that men are inherently more skilled 
leaders because they tend to be directive and have a greater task focus and are less emotional. Vechio argues that the old masculine advantage debate was quieted long ago but has been "reincarnated" in recent years to a female advantage argument based on different skill sets. While there are social gender differences, such as those mentioned here, these do not automatically translate to an advantage for either sex. There are benefits to all of these types of skills for effective leadership and considerable overlap between genders in relation to who possesses these skills, be it men or women. Research built on gender behavior differences in leadership continues to run the danger of producing extremely ambiguous results for the study of leadership.

Perhaps the discrepancy in findings related to the glass ceiling effect and stereotypes can be shifted to an examination of women who have successfully ascended the laborious ladder to senior leadership. An explanation toward reconciling some inconsistencies may lie in a narrow stereotype, called a subtype, which distinguishes a group of people from a generally accepted stereotype (Rosette, Leonardelli, Tost, \& Phillips, 2006). In other words, it is plausible that women leaders have acquired exceptional abilities in order to have achieved their high level positions and can be studied as an atypical group of women. There may even be a reactive response to stereotypes in that when individuals' freedoms are threatened, they react in a way to reassert their power. This happens when members of a social group act in a way opposite of the stereotyped behavior, leading women to covet positions of leadership, shown particularly in people with leadership self-efficacy (Hoyt, 2005).

Rather than focusing on the differences between men and women and the ways in which they lead, some scholars (i.e. Foels, Driskell, Mullen, \& Salas, 2000; N. Porter, 
Geis, Cooper, \& Newman, 1985; Sargent, 1981) have recognized the obvious benefits of combining both male and female leadership styles. In this way, leaders are nurturing, supporting, inclusive, assertive, decisive, and competitive all at the same time and depending on any given circumstance. In a study of politician characteristics in the U.S., it was found that toughness and management skills in times of crisis are valuable traits and that women politicians who can demonstrate that they have these skills, while simultaneously taking advantage of the perceived female edge in compassion, may have an advantage (Hansen \& Otero, 2006). Similarly, in another study of perceptions of leadership styles it was found that an androgynous management style with both instrumental and expressive traits was favored (Vinnicombe \& Singh, 2002).

International Efforts and Research on the Inclusion of Women: As economic development brings an increase in the specialization of labor, improved and more accessible machinery and infrastructure, and better education and training to the workforce, work is no longer performed in the household and production is increasingly supplied by specialized enterprises with wage labor and management jobs. As decision makers who are more educated and better trained, and less burdened with family and household responsibilities, men have been more likely to reap the benefits of economic growth than women. Extending education and training to women for them to become more active in the paid and productive workforce has shown to enhance economic development efforts further (Boserup, 1986). Brown (2006) explains that "gender planning" involves projects and programs intended for Third World development and recognizes that the involvement of women is significant and that women are affected differently than men by modernization, development, and social change. Initiatives such 
as these aim to not only effectively facilitate development efforts, but at the same time ensure that the process is equitable (Currie, 1999). As is characteristic of any development effort originating in the developed world, the women in development (WID) movement holds modernization as its central tenet, viewed as a linear process that is measured in economic terms (Chowdhry, 1995), even though much of the modernization of the colonial era had marginalized women when new technology and innovation had been targeted toward men (Boserup, 1970, 1986).

Even though one of WID's central goals was the incorporation of women into capitalist models of development, this era spawned pushback against First World feminist ideas that were not applicable in the Third World (Brown, 2006; Ghodsee, 2003) and stimulated demands from feminists that women are to be included in development efforts, and the international community listened and responded (World Bank 2004; UN, 2004; UNDP, 2003, 2004, 2005, 2006). The response has been a gender and development approach (GAD) which switched the focus from women and women's roles, to the gender relations between women and men and the interaction of women's and men's roles together at all levels of the social, political, and economic spectrum. This movement includes Third World women's organizations as well as efforts proposed by the developed world. GAD is a more sensitive, varied, and flexible approach to complex gender structures and addresses the shortcomings in the WID approach. ${ }^{1}$ The GAD approach is more ambitious in its challenge of long-standing social forces, and therefore difficult to implement. The WID projects tended to be politically and practically easier to implement (Brown, 2006; Chowdhry, 1995; Ghodsee, 2003; Vavrus \& Richey, 2003).

\footnotetext{
${ }^{1}$ For a comparison between the two approaches, see Brown, 2006.
} 
A combination of the two approaches - a GAD approach to WID policies - may be more effective and easier to implement while still focusing on social, economic, and political factors that affect both genders - "a programmatic shift toward a 'gender mainstreaming' paradigm that integrates a gender analysis into all aspects of sustainable development" (Silber, 2007 p. 171). The women participating in WID programs themselves can then shape these efforts over time in the direction of their choosing to become more in line with both practical and strategic benefits - development with a gradual transformation of gender relations (Brown, 2006).

Micro-credit has been described as dramatically increasing social benefit (Ricart, Enright, Ghemawat, Hart, \& Khanna., 2004). It is designed to give very small loans to poor people, often women, to assist them in launching small businesses (Anthony, 2005; Temtime, Chinyoka, \& Shunda, 2004). This is often done through a collective gathering of borrowers within a community who together offer collateral that individuals alone do not have. These group members are then responsible for screening other borrowers, whom they know based on previous personal relationships within the community, and overseeing repayment of the loans (Anthony, 2005) even through intense pressure by the collective on individual women borrowers (Rahman, 1999).

While micro-credit has been criticized for its imperfections, such as unemployment due to a reduction in public-sector employment as job opportunites have shifted to small businesses, the removal of welfare provisions, and the American bootstrap ideology that anyone can make it through entrepreneurship if they work hard (Isserles, 2003), numerous positives have resulted. Studies have shown that access to micro-credit helps reduce poverty for women borrowers and their villages, and thus 
benefits poor participants and the local economy simultaneously (Khandker, 2005). In addition, micro-enterprise training has empowered women to achieve economic selfsufficiency, develop management skills, build new homes, and create new jobs through small-scale businesses that have grown into larger enterprises (Andaleeb \& Wolford, 2004; Dumas, 2001; Isserles, 2003).

Micro-credit initiatives are widely used to help establish small-scale industries which consist of responsible individuals with the training to economically move a community or country toward further growth through trade with the international community (Mujtaba, 2005). Small-scale industry involves the coming together of firms and the subsequent competitive advantage derived from local economies and efficiencies produced by the collective (Schmitz, 1995). Small-scale industries in Japan, for example, have included cotton and silk weaving, silk reeling, pottery manufacture, the machine industry, and brewing, and offer an alternate path to industrialization (Tanimoto, 2006). As another example, in the past, because of conflict and the Taliban in Afghanistan, women typically engaged in handicrafts and carpet weaving, and more recently, women have entered the service industry, operating hair salons, clothing boutiques, and guesthouses. Women in Kabul are now acquiring computer, networking and IT training (Mujtaba, 2005). Large multinational enterprises (MNE's) have begun to recognize the benefit of supporting small business training initiatives in developing countries for the purposes of training employees to be productive in other industries once their labor is no longer useful to the MNE This includes trade training for women, micro-credit, and business development in an effort to promote self-help enterprise development (Eweje, 2006; Mujtaba, 2005). 


\section{Moving Women in Leadership Research Forward}

While these lines of research are important for forming the foundation of the field of study regarding women in leadership, the problem is that there are other factors that can influence follower evaluations of a leader that have little to do with male or female traits. Biases and glass ceiling issues also may not apply as much to the developed societies with more gender equality, because women in positions of leadership is not as uncommon as perhaps even 10-20 years ago. This is perhaps because idea of women in leadership has become institutionalized (Lucas, 2003). However, status remains a real issue and the institutionalization of people in their societies to the idea of women in leadership becomes an important factor, especially for women who currently are breaking new ground in countries where they are the first generation of women in leadership roles.

When the idea of women successfully leading organizations becomes institutionalized and commonplace, then women can achieve influential levels equal to men (Lucas, 2003). Perhaps the best way for institutionalization of the idea of women in leadership happens through the growth of schools and education for girls, and can be seen in the promotion of women to government, professional and technical positions, and business ownership. Institutionalization is possible because we already know that culture is not only a stable characteristic of society (Berry, Poortinga, Segall, \& Dasen, 2002; Kitayama, 2002; Schein, 1992), it is also evolving, allowing for the co-mingling of traditional with modern values (Kwok Leung et al., 2005; Marsella \& Choi, 1993). Lucas (2003) explains that institutionalization happens through social processes developing into a regime of social thought and action (Ingram \& Clay, 2000). Rules, requirements, and norms govern environments and, in turn, provide support and legitimacy (Scott, 1987). 
The idea of isomorphism is that institutional forces cause organizations to become similar, and conforming to norms is a consequence of efforts to increase legitimacy (DiMaggio \& Powell, 1983). Institutions (i.e., women in leadership) gain legitimacy when social practices become accepted into the structure in such a way that these institutions become collectively expected as an obvious course of action (Lucas, 2003; Montgomery \& Oliver, 1996). It can be proposed here that as women in positions of leadership and influence becomes more commonplace, women in leadership positions will become an accepted fabric of societal structure. Lucas proposes that legitimacy is achieved as one group recognizes the success of women leaders in another group. This proposition may even be extended in that as societies recognize the success of the growth of other nations that incorporate women into leadership and into the economy, legitimacy of the institution of women in leadership is reinforced.

These comparisons between women and men leaders and the expectations imposed on each gender have been debunked by some (i.e., Vechio 2002), while others have proposed important moderators or mediators to better explain the differences (Hoyt, 2005; Jennings \& McDougald, 2007; Martins et al., 2002). It is not enough to simply find a few direct dependent variables to explain perceptions of individuals in complex social settings, like female versus male leaders. It is more worthwhile to study settings and circumstances that affect these stereotypes or perceptions.

A better understanding of the factors that affect women involvement in leadership can assist and improve current international efforts to include women in the economic and political sectors. The following is a review of past cross-cultural research on leadership. National culture and the context within which women operate will affect the 
values, beliefs, norms, and behavioral patterns related to women's participation in leadership roles. Therefore, a cross-country study of the factors that affect women's participation in leadership requires an understanding of past efforts in the study of crosscultural leadership. Scholars in the cross-cultural discipline have set the stage for further research and offer valuable recommendations for the advancement of the field.

\section{Cross-Country Leadership Research}

It is proposed in this study that the factors that influence leadership may vary depending on circumstance and may change due to the dynamic nature of any given context (Kevin B. Lowe \& Gardner, 2000). Javidan and Carl (2005) argued that the issue of universality of leadership across cultures is important, however inadequate. They point out that there is a great deal of research on leadership in the US and Europe, but ask how generalizable this is in other cultures. To the extent that leaders in different cultures share similar values and expectations, they will also display similar leadership behaviors. Leaders act the way they do because followers accept and expect it (Collinson, 2006). In particular in the business world, across cultures there is a convergence of administrative, training, and interaction styles due to globalized business practices. In an increasingly capitalist system across nations, Javidan and Carl (2004) suggest that these commonalities in leadership behaviors and characteristics are the result of a shared need for achievement and self-actualization. These motivational drivers direct leaders to act in certain universal ways and these findings are supported by 
numerous prior studies (Bass, Burger, Doktor, \& Barrett, 1979; Haire, Ghiselli, \& Porter, 1966; Schwartz \& Bilsky, 1990).

One of the purposes of this study is to uncover the cultural factors that affect women's participation in leadership. The GLOBE team (R. J. House et al., 2004) collectively defines culture as "shared motives, values, beliefs, identities, and interpretations or meanings of significant events that result from common experiences of members of collectives that are transmitted across generations" (p. 15). The similar but more broad definition of national culture used by Leung, Bhagat, Buchan, Erez, and Gibson (2005) as "values, beliefs, norms, and behavioral patterns of a national group" (p. 357) is used here, as this study examines culture at the national level. Leung et al. attribute the growth of importance in the last 20 years to the study of national culture to the classic work of Hofstede (1980). In addition, these same two prior to decades have brought the onslaught of globalizational forces that increasingly call for the study of national culture (M. W. Dickson, Hanges, \& Lord, 2001; Erez \& Gati, 2004; Hill, 2008b). These forces will affect the values, beliefs, norms, and behavioral patterns related to women's participation in leadership roles. National culture in this study in a broad sense also involves the macro-level societal, political, economic, infrastructural context within a country that affects and changes values, beliefs, norms, and behavioral patterns.

A key to leadership research across cultures is to try to sort out the characteristics of leadership that are partially or completely universal (etic) from those that are specific to a particular culture (emic) (M. W. Dickson et al., 2001; Marcus W. Dickson, Hartog, \& Mitchelson, 2003; Graen, Hui, Wakabayashi, \& Wang, 1997; K. Leung \& Bond, 2004; K. Leung et al., 2002; Scandura \& Dorfman, 2004). Implicit leadership theory (R.G. 
Lord \& Maher, 1991), which suggests that individuals hold personal beliefs and assumptions about what constitutes leader and non-leader characteristics, becomes an important focus because individuals' behaviors are shaped by their experiences, values, traits, and other social-cultural influences (Javidan \& Carl, 2005). Individuals process information based on inputs and abilities that affect their rational application of information, informal cognitive heuristics, expert knowledge structures in particular contexts, plus the continuous and reciprocal processing of dynamic information (Robert G. Lord \& Maher, 1990). Leadership theory and research should reflect leader attributes and behaviors in combination with contextual aspects of leader emergence and effectiveness (G. Yukl, 1998; G. Yukl \& Howell, 1999) because leadership is made up of relationships entrenched in social settings (Bryman, 1996). Therefore, it can be assumed from this that people are affected differently by the contexts in which they operate and from which they come. In other words, context helps shape what is expected from leaders, as well what leaders are affected by (Stelter, 2002), including the setting, norms, and other individuals (Kevin B. Lowe \& Gardner, 2000).

In Dickson, Den Hartog, and Mitchelson's (2003) review of cross-cultural leadership, they argue that "still today, few scholars publishing in the field would characterize themselves as 'cross-cultural leadership researchers,' and most cross-cultural leadership research has been conducted by leadership researchers who apply a cultural lens to extant leadership theories" (p. 748). For this reason, current leadership models are rather limited in their consideration of these types on nuances. Javidan and Carl's (2005) study detracts from the norm and, rather than controlling similarities in order to isolate differences by matching samples on as many dimensions as possible, they "exacerbated 
differences" of the respondents in their sample, allowing for better interpretation of the similarities. The models proposed by Javidan et al. (Javidan \& Carl, 2004; Javidan \& Carl, 2005; Javidan \& House, 2001; Javidan, House, Dorfman, Hanges, \& deLuque, 2006) explore a multitude of attributes (based on leadership literature related to traits, behaviors, leader-member exchanges, transformational and charismatic leadership theories) in an effort to form an integrative conceptual model. While these endeavors are extremely valuable to advance the understanding of leadership in the cultural context, particularly from the standpoint of cognition, studies such as these ignore numerous other nuances that impact leadership, such as, for instance, the changing of the external economic, technological, infrastructural, societal, and development contexts of their surroundings. Lowe and Gardner (2000) argue that multi-level approaches to research need to emphasize leadership processes at the individual (leaders and followers), dyad, group, and organizational levels, and this study extends this further to include the country level as well. This research effort will concentrate in particular on the individual and societal levels.

\section{Cross-Cultural Studies Explained}

Cross-cultural research has become a well-respected and advancing field of research in international business literature (Kwok Leung et al., 2005). Leung et al. argue that culture is a multi-layer construct that exists from global to individual layers, beginning with the most external layer and penetrating a group until it becomes a shared value that characterizes the aggregated unit, in a continuous, reciprocal process. Schein (1992) explains that levels of culture range from the deeply embedded, unconscious, 
basic assumptions that define the essence of a particular culture, to the external manifestations that are tangible and overt and can be seen and felt by outsiders. The middle layers that fall within these two extremes are the beliefs, values, norms, and rules of behavior that members of the culture abide by and partake in as a way of depicting these cultures within the cultural group and to others. The meanings of these overt and tangible influences can be studied and uncovered. According to Schein, researchers need to go deeper and pay closer attention to the values, norms, and rules that dictate the basic operating principles by which the members of the group guide their behavior. If these beliefs and values are reasonably congruent with underlying assumptions, then they can be articulated into a philosophy that brings the group together and serves as a source of identity and core mission. Researchers must be careful, however, to discriminate carefully between those values and beliefs that are congruent with actions from those that are mere rationalizations or only aspirations for the future (R. J. House et al., 2004; Schein, 1992).

Schein goes on to explain that there are basic assumptions that actually guide behavior, are usually not challenged or debated, and are often nearly impossible to change without high levels of anxiety among constituents. People are most comfortable with others who operate under the same basic assumptions, feel the most disconnected to those who do not, and vulnerable and uncomfortable in systems where different assumptions operate. "The essence of a culture lies in the pattern of basic underlying assumptions, and once one understands those, one can easily understand the other more surface levels and deal appropriately with them" (p. 36). Schein recommends that "the two keys to successful culture change are (1) the management of the large amounts of 
anxiety that accompany any relearning at this level and (2) the assessment of whether the genetic potential for the new learning is even present" (p. 32). In line with McGregor (1960), Schein argued that if people are treated repeatedly according to certain basic assumptions, they eventually behave according to those assumptions in order to operate in a stable and predictable manner. Because these assumptions are shared, culture is powerful because the assumptions are mutually reinforced. Here, a third party or outside influences ( i.e., globalization, modernization, technology, Western business practices) could offer a scenario where both parties could bring their sets of assumptions to the table in an effort to find some common ground within which to operate. As the new party or influence develops, it creates its own assumptions based on a shared history and critical experiences.

Leadership of cultural change is extremely difficult because it requires changing basic assumptions and getting at the deeper levels of culture and dealing with the anxiety associated with those assumptions (Schein, 1992). Applying Schein's arguments, indigenous women who operate within the confines of their cultures to increasingly embark on positions of leadership may prove more effective for the purposes of development. These women understand the nuances of their societies and can slowly offer examples of leading small groups and organizations while simultaneously changing the deeper level assumptions underlying their culture.

Culture is seen as a multi-level construct, one that operates in a reciprocal topdown, bottom-up fashion (Erez \& Gati, 2004; Kwok Leung et al., 2005; Schein, 1992). More specifically, these authors view globalization as a macro-level culture that affects behavioral changes of individuals, and in turn, the behaviors of members within a culture 
become shared behavioral norms and values that affect the macro-level. Therefore, culture in this regard is seen as a dynamic force, rather than static, that needs to be evaluated among these different levels. Their multilevel approach involves lower levels of cultures nested within higher levels; change at any level can affect other levels. In other words, "we are witnessing the emergence of a global culture as a new (top) layer of culture that affects the nested levels of culture below, and is reciprocally affected by them" (p. 587). For example, a societal context can push contact among disparate cultures and require individuals to adapt to more than one context. The level of cultural diffusion depends on both the level of attraction to the new culture and the importance of preserving an original culture. This leads to a level of adaptation at the societal and individual levels. Cross-level research examines the congruence between two or more levels. For this reason, because of globalizing forces that are more acceptable of women the cultural aspects that may have prevented or discouraged women from being more involved in the formal economy in the past may have changed slightly in more recent years.

\section{$\underline{\text { A Review and Critique of Recent Cross-Cultural Research }}$}

Although research has been advancing, in very recent years there remains a surplus of dichotomous cross-cultural studies comparing one country to another. In addition, there are recent studies that use a vast number of countries, or samples of people from numerous cultural backgrounds, but that test a handful of variables. Table 2 shows the most current empirical research since 2000, primarily from two premier international business journals (Journal of International Business Studies and Management 
International Review), to provide merely an example of the types of cross-cultural research being published in recent years. ${ }^{2}$ Missing are multilevel theories (e.g. Niederman, Kundu, \& Salas, 2006), that employ country-level data combined with individual-level data, and studies that examine multiple layers of contextual factors, like economics, business environments, societal development, technology, and changes in these contexts over time. Many of the cross-cultural studies in international management literature, and leadership literature specifically, have involved a few countries which offer findings that may be inapplicable to other cultures and contexts (Marcus W. Dickson et al., 2003) without analysis of layers that affect each other.

Table 3 is a similar review of recent empirical cross-cultural studies, specific to leadership, from a variety of journal titles and shows that research in this field in particular is severely lacking. A commonality running among these studies is the finding that leadership attributes and styles are at least partially culturally determined, while some skill sets and styles may be applicable across cultures. These studies predominately examined culture and individual-level variables, but did not include factors relating to the environment or context within which the participants operate.

\footnotetext{
${ }^{2}$ The purpose of this table is not to show a comprehensive list of all cross-cultural research done in the international business literature. The intent is merely to the show the nature of the most recent empirical publications coming out of the two top IB journals. Conceptual papers were not included in the table.
} 


\begin{tabular}{|c|c|}
\hline Chen and $\mathrm{Li}$ (2005) & $\begin{array}{l}\text { Performed cross-national experiments to compare } 184 \\
\text { Chinese and Australian people to see which group would be } \\
\text { more or less cooperative depending on the motive of the } \\
\text { business situation or the foreignness of business partners. } \\
\text { Also looked for mediators and found that individual cultural } \\
\text { orientation on individualism mediates how nation affects } \\
\text { cooperative decision-making style. }\end{array}$ \\
\hline $\begin{array}{l}\text { Friedman, Chi, and Liu } \\
\text { (2006) }\end{array}$ & $\begin{array}{l}\text { Conducted a conflict scenario experiment with } 308 \\
\text { Taiwanese and American individuals to develop an } \\
\text { expectancy model for differences in conflict management } \\
\text { and regard for preserving the relationship with the other } \\
\text { party. }\end{array}$ \\
\hline $\begin{array}{l}\text { Fu, Kennedy, Tata et al. } \\
(2004)\end{array}$ & $\begin{array}{l}\text { Directed a 12-nation study with } 1,764 \text { participants to } \\
\text { examine societal cultural values, individual social beliefs, } \\
\text { and the perceived effectiveness of different influence } \\
\text { strategies. Found that the perceived impact of people's } \\
\text { different styles influencing others can be predicted by } \\
\text { individual social beliefs. The strength of this relationship is } \\
\text { moderated by cultural values such as in-group collectivism, } \\
\text { uncertainty avoidance, and future orientation from the } \\
\text { GLOBE study. }\end{array}$ \\
\hline Hui, Au, and Fock (2004) & $\begin{array}{l}\text { Conducted three different studies to examine cross-cultural } \\
\text { variations in the effect of empowerment by testing the } \\
\text { moderating effects of power distance using World Values } \\
\text { Survey data in } 33 \text { nations, and by comparing hotel } \\
\text { employees in Canada to those in China through a role play } \\
\text { scenario experiment and survey methodologies. Found } \\
\text { moderating effects of power distance for the impact of } \\
\text { empowerment on job satisfaction. }\end{array}$ \\
\hline $\begin{array}{l}\text { Lee, Yang, and Graham } \\
\text { (2006) }\end{array}$ & $\begin{array}{l}\text { Examined the antecedents and consequences of tension on } \\
\text { business negotiations through experiments with } 176 \\
\text { American and Chinese executives. }\end{array}$ \\
\hline $\begin{array}{l}\text { Newburry and Yakova } \\
(2006)\end{array}$ & $\begin{array}{l}\text { Tested employee standardization preferences depending on } \\
\text { cultural context using a global firm with approximately } 400 \\
\text { employees headquartered in the UK, with regional offices in } \\
\text { Europe, North America, and Asia. }\end{array}$ \\
\hline $\begin{array}{l}\text { Papamarcos \& } \quad \text { Watson } \\
\text { (2006) }\end{array}$ & $\begin{array}{l}\text { Empirically studied the role of culture in encouraging or } \\
\text { discouraging country level economic performance. Results } \\
\text { indicate that cultural values have economic effects. }\end{array}$ \\
\hline $\begin{array}{l}\text { Pellegrini and Scadura } \\
(2006)\end{array}$ & $\begin{array}{l}\text { Studied } 185 \text { employees from Turkish companies and found } \\
\text { that the paternalism cultural dimension mediated the effect } \\
\text { of LMX on job satisfaction. }\end{array}$ \\
\hline $\begin{array}{l}\text { Marshall and Boush } \\
(2001)\end{array}$ & $\begin{array}{l}\text { Investigated } 185 \text { export managers from Peru and the US to } \\
\text { understand cultural differences toward in-group and out- }\end{array}$ \\
\hline
\end{tabular}




\begin{tabular}{|c|c|}
\hline & $\begin{array}{l}\text { group members, and found that cultural differences declined } \\
\text { as business associates developed relationships with one } \\
\text { another. }\end{array}$ \\
\hline $\begin{array}{l}\text { Pereira, Hsu, \& Kundu } \\
(2002)\end{array}$ & $\begin{array}{l}\text { Based on the cultural diversity in a sample of } 298 \text { Chinese, } \\
\text { Indian, and Taiwanese managers and business students, } \\
\text { measured ethnocentrism in order to validate the multi-item } \\
\text { Consumers' Ethnocentric Tendencies Scale in China, India, } \\
\text { and Taiwan among consumers. }\end{array}$ \\
\hline $\begin{array}{l}\text { Skarmeas, Katsikeas, and } \\
\text { Schlegelmilch (2002) }\end{array}$ & $\begin{array}{l}\text { Studied } 216 \text { overseas distributor-manufacturer relationships } \\
\text { around the world to understand the role that commitment } \\
\text { plays in buyer-seller associations, and found that } \\
\text { commitment has a positive impact on performance in the } \\
\text { relationship. }\end{array}$ \\
\hline Van de Vliert (2003) & $\begin{array}{l}\text { Used World Economic Forum data to conduct a 58-nation } \\
\text { study with } 3,934 \text { senior business leaders and government } \\
\text { officials to examine over- and under-payment of employees } \\
\text { and found that temperate climates are associated with } \\
\text { mastery-oriented behavior, which is also associated with } \\
\text { wealth-referenced overpayment. }\end{array}$ \\
\hline Chiang and Birtch (2006) & $\begin{array}{l}\text { Engaged in a cross-national study of reward preferences of } \\
441 \text { employees in the banking industry in } 60 \text { companies in } \\
\text { Finland and Hong Kong and found that a mix of financial } \\
\text { and non-financial rewards is more beneficial and highlights } \\
\text { the importance of employee characteristics and contextual } \\
\text { factors beyond culture. }\end{array}$ \\
\hline Husted (2005) & $\begin{array}{l}\text { Examined } 122 \text { countries from data provided by the Global } \\
\text { Leaders of Tomorrow Environment Task Force of the } \\
\text { World Economic Forum and applied Hofstede's cultural } \\
\text { measures to argue that sustainability of the physical } \\
\text { environment requires examination beyond economic factors } \\
\text { to include those cultural in nature. }\end{array}$ \\
\hline $\begin{array}{l}\text { Parboteeah, Cullen, } \\
\text { Victor, and Sakano (2005) }\end{array}$ & $\begin{array}{l}\text { Studied the effects of culture on ethics among } 250 \\
\text { American and Japanese accountants and found that } \\
\text { institutional norms and regulations along with national } \\
\text { culture led to differences in ethical climate. }\end{array}$ \\
\hline $\begin{array}{l}\text { Wang, Lin, Chan, and Shi } \\
(2005)\end{array}$ & $\begin{array}{l}\text { Conducted large-scale survey research on } 463 \text { joint venture } \\
\text { managers in China, other East Asian countries, the US, and } \\
\text { Western Europe in } 19 \text { countries to examine the cross- } \\
\text { cultural and cross-national differences in conflict handling } \\
\text { styles. }\end{array}$ \\
\hline $\begin{array}{l}\text { Javidan and Carl (2005) } \\
\text { MIR }\end{array}$ & $\begin{array}{l}\text { Identified leadership behaviors and attributes that have } \\
\text { merit across cultures, as well as those that are culture- } \\
\text { specific, by comparing the leadership profiles of } 1,307 \\
\text { senior and middle level managers from different industries } \\
\text { in two culturally dissimilar countries, Taiwan and Canada. }\end{array}$ \\
\hline
\end{tabular}




\begin{tabular}{|l|l|}
\hline Inglehart and Baker (2000) & $\begin{array}{l}\text { Used data from the World Values Survey on 65 countries } \\
\text { and found the coexistence of mass cultural change along } \\
\text { with the persistence of distinct traditional values. Economic } \\
\text { development brought about by industrialization and } \\
\text { modernization was associated with cultural shifts away } \\
\text { from absolute norms and values toward those that are more } \\
\text { rational, tolerant, trusting, and participatory. Also, broad } \\
\text { cultural heritage of a society left a lasting imprint on values, } \\
\text { which endure despite the move toward modernization. }\end{array}$ \\
\hline
\end{tabular}

\begin{tabular}{|c|c|}
\hline Ardichvili (2001) & $\begin{array}{l}\text { Assessed groups of } 2,900 \text { managers and employees in } 9 \\
\text { manufacturing firms in Russia, Georgia, Kazakhstan and } \\
\text { Kyrgystan and found that all four cultures were significantly } \\
\text { different on paternalism, masculinity, and leadership } \\
\text { attributes, while fatalism and long-term orientation had } \\
\text { similar effects. }\end{array}$ \\
\hline $\begin{array}{l}\text { Brodbeck, } \\
\text { Akerblom, } \\
\text { Bakacsi, Bendova, } \\
\text { et al. }(2000)\end{array}$ & $\begin{array}{l}\text { Studied the cultural variation in leadership prototypes of } \\
6,052 \text { managers among } 22 \text { European nations and found that } \\
\text { inspirational, visionary, integrity, performance-orientation, } \\
\text { decisiveness and team-integrator leadership attributes were } \\
\text { important across all countries, except for France, while self- } \\
\text { centeredness and malevolence were impediments to } \\
\text { effective leadership in all nations, including France. } \\
\text { Findings indicate a relationship between leader attributions } \\
\text { and culture. }\end{array}$ \\
\hline $\begin{array}{l}\text { Robie, Johnson, Nilsen, \& } \\
\text { Hazucha (2001) }\end{array}$ & $\begin{array}{l}\text { Studied over } 9,000 \text { US and European managers and found } \\
\text { that a drive for results and analyzing issues, on the part of } \\
\text { managers, were universally effective leader behaviors and } \\
\text { the best predictors of managerial performance, as rated by } \\
\text { supervisors. }\end{array}$ \\
\hline $\begin{array}{l}\text { Mehta, Larsen, } \\
\text { Rosenbloom, Mazur, \& } \\
\text { Polsa (2001) }\end{array}$ & $\begin{array}{l}\text { Studied } 350 \text { leaders from the U.S., Finland, and Poland, and } \\
\text { found positive and inconsistent relationships between } \\
\text { participative, supportive and directive leadership styles and } \\
\text { levels of cooperation among followers. }\end{array}$ \\
\hline Chow (2005) & $\begin{array}{l}\text { Found that Hong Kong ranked high in gender egalitarianism } \\
\text { among } 61 \text { GLOBE countries, but, in professional and } \\
\text { managerial occupations, the relative proportion of men to } \\
\text { women is still unequal. }\end{array}$ \\
\hline Bajdo and Dickson (2001) & $\begin{array}{l}\text { Found that organizations that report high humane } \\
\text { orientation and high gender equity, high performance } \\
\text { orientation, and low power distance, also reported higher } \\
\text { percentages of women in management relative to other } \\
\text { organizations in society and relative societal norms, and that }\end{array}$ \\
\hline
\end{tabular}




\begin{tabular}{|l|l|}
\hline $\begin{array}{l}\text { Den Hertog, House, } \\
\text { Hanges, et al. (1999) }\end{array}$ & $\begin{array}{l}\text { Used the GLOBE study to argue that attributes associated } \\
\text { women in management. } \\
\text { with charismatic and transformational leadership are } \\
\text { universally endorsed as contributing to outstanding } \\
\text { leadership at high and lower levels of leadership. Applied } \\
\text { implicit leadership theory and suggested that these } \\
\text { leadership characteristics are implicit because of cultural } \\
\text { norms, which leads to certain leadership prototypes. } \\
\text { Implied an element of role congruity in which perceivers } \\
\text { match attributes of the potential leaders, based on cognitive } \\
\text { categorization processes, that categorizes particular } \\
\text { prototypes of leadership. }\end{array}$ \\
\hline
\end{tabular}

As can be seen in the reviews of literature in Tables 2 and 3, cross-cultural research in the international business literature, as well as the subfield of Cross-Cultural Leadership within the greater Leadership discipline, has predominately focused on leadership within organizations and industries and is confounded with research at the MNE level. This study differs in that the basis for cultural variables is national culture using data on individuals' beliefs, values, norms, and behaviors (Kwok Leung et al., 2005), aggregated to the country level.

One of the most recent and impressive in the advancement of cross-cultural leadership studies is House and associates' (R. J. House et al., 2004) groundbreaking endeavor that examined 27 hypotheses with over 17,000 middle managers who worked in 951 organizations. While prior leadership research was predominately U.S.-based, the Global Leadership and Organizational Behavior Effectiveness (GLOBE) study was conducted over a 10-year period in 62 societies for the purposes of understanding societal culture along with organizational and leadership effectiveness. This included survey 
research, archival data, media analyses, individual and focal group interviews, and observational tactics.

In an obvious display of esteem for Hofstede's (1980; 2001) prior work to create testable cultural dimensions, the GLOBE study built on and extended Hofstede's five measures to nine. Five of these dimensions are submitted as enhanced versions of Hofstede's power distance, uncertainty avoidance, future orientation, and individualismcollectivism which is broken into two sub-dimensions: institutional collectivism and ingroup collectivism. The remaining four represent an effort to extricate discrete elements in Hofstede's masculinity-femininity dimension: performance orientation, gender egalitarianism, assertiveness, and humane orientation. Large-scale studies resting on Hofstede's original framework are clearly relevant for cross-cultural research (Kirkman et al., 2006). The GLOBE research is theory driven, beginning with more general constructs, and later writing items and developing scales (Javidan et al., 2006).

Earley (2006) praises the GLOBE study for applying country practices by the people in a particular society using aggregate measures in determining country-level indicators of cultural values measured at the individual level unit of analysis. These cultural values could then associate country-level outcomes with individual-level perceptions. This "sophisticated research design" was achieved by operationalizing and measuring constructs at different levels of analysis and linking these levels together, allowing for an examination of how micro-level constructs influence the macro-level, and vice versa, made possible by sampling across many nations.

Criticisms of both Hofstede's and Project GLOBE have argued that these conceptualizations focus too much on culture alone and miss the benefits of examining 
across cultural levels (Kirkman et al., 2006; P. B. Smith, 2002). Earley (2006) warns against the mistake of misunderstanding the construct validity and generalizability of constructs developed in one setting and attempting to apply the same constructs to other settings. Unfortunately, aggregate measures of culture at the societal level may mask some within-society differences. Whereas the GLOBE study is a multi-phase, multimethod project that spans organizational behavior and leadership effectiveness across a vast number of countries, resting mostly on social factors, it does not incorporate economic, political, or infrastructural factors into the study.

A study is needed that includes all these various aspects that affect culture (Farid, 2007), and in turn affect individuals' roles in leadership positions. In addition, both the Hofstede and GLOBE studies are limited to a sample of mid-level managers (mostly men in Hofstede's original study) in a fixed set of organizations (Moulettes, 2007). This means that the study did not capture the cultural perceptions of people at different levels of the social and economic strata. These types of concerns may be addressed by the kind of work proposed in this study, which attempts to categorize countries in a quantitative analysis to uncover certain factors that impact countries in different ways. Hofstede's and the later GLOBE study can be used as a foundation for further investigation in the multi-level dynamics affecting women's participation in leadership.

\section{Directions for Future Research Recently Proposed by Scholars}

Kirkman, Lowe, and Gibson (2006) argue that there has been a lack of research at multiple levels and urge researchers to formulate theory for testing the impacts of culture across levels. They also find that past research has, for the most part, failed to separate 
cultural effects from country-level effects across countries. Country effects based on culture are valuable, as are culture effects alone on outcome variables. These differing relationships among cultural values (which are not isomorphic with country) and outcome variables depending on country may have competing and compelling theoretical explanations. What is needed is sufficient theory to explain how country and cultural effects vary across and within countries at the individual level. In other words, in support of this study, how do cultural-level effects based in tandem with country differences affect individuals?

Culture constantly adapts to ecological and socio-political changes in the environment and individual psychological characteristics can evolve within the context in which they operate (Berry et al., 2002). People's psychological characteristics will evolve not only flexibly and seemingly unnoticeably in response to changing environments, but there is also an active effort to coordinate old psychological tendencies with new pertinent cultural practices and public meanings (Kitayama, 2002). Although culture has been treated as a very stable characteristic of a society, it is constantly evolving. Strong, traditional values can co-exist with modern values of individual achievement and competition (Kwok Leung et al., 2005). Leung et al. argue that there may be a simultaneous merging of Western and Eastern cultures. For example, just as there is a spread of Western values and practices, there may be an Eastern response to modernity-consumption aspects of globalization (Marsella \& Choi, 1993).

Inglehart and Baker (2000) found the coexistence of mass cultural change along with the persistence of distinct traditional values. In other words, economic development brought about by industrialization and modernization, is associated with cultural shifts 
away from absolute norms and values toward those that are more rational, tolerant, trusting, and participatory. At the same time, the broad cultural heritage of a society leaves a lasting imprint on values, which endure despite the move toward modernization. In addition, cross-national differences become part of the national culture as a result of rising education levels, the influence of mass media, occupational specialization, and rising income levels. This brings about unforeseen changes such as changing gender roles, attitudes toward authority, broader political participation, and a more sophisticated public body. While these changes occur, there remain enduring cultural traits that do not necessarily lead to increasing uniformity, but rather to the persistence of diversity among civilizations through a reinterpretation and inclusion of traditional patterns (Hamilton, 1994). Because it seems like cultures in a globalized world are becoming more similar, it is less apparent, although very real, that there are very strong, persistent values and norms still in place.

Persistent and changing culture can also be reflected in particular artifacts that show fundamental cultural differences and similarities throughout time. Including artifacts in a cultural analysis allows researchers to capture a real assessment of what is actually valued in society (Earley, 2006). The blending of traditional with modern values may be uncovered by observing the merging of new and old in certain cultures. Earley (2006) proposed that often researchers focus too much on values in a culture and then misinterpret the culture as being defined by those values, instead of by meaning. More important than values, which vary from person to person, is the awareness of a shared understanding of the meaning of a particular circumstance. Earley suggests that researchers move beyond grand surveys of values and toward research that focuses on the 
linkages between culture, perception, action, and practice, with the goal of developing theories and frameworks applicable to these linkages - the study of how culture and context affect practice.

This review of culture and cross-cultural studies points to multi-layer, multi-facet, contextual, and dynamic views of culture. This suggests that the philosophy of cultural research entails much more than cultural dimensions, and that culture is manifested through many levels and domains. Some cultural elements are dynamic and changing, while others are stable. A major challenge for the field is to develop dynamic frameworks of culture that portray the sensitivities of cultural nuances in different contexts (Kwok Leung et al., 2005). 


\section{Theory Development}

This study attempts a cross-country, multi-level approach to further understand the factors that affect women's involvement in business and political leadership roles. The active pursuit of women to obtain positions of leadership has been stunted by barriers (i.e. Bartol et al., 2003; Hoyt, 2005; Powell et al., 2002; Sczesny, 2003). With this understanding as the base for further research, it is proposed here that women face new and different challenges and opportunities that vary depending on the context of the environment in which they operate. This theory development section proposes testable hypotheses to uncover these forces. Proposed here is a global levels theory of women in leadership (see Figure 1). These different levels of participation of women in leadership roles can be distinguished both quantitatively and qualitatively, by factors related to the business environment, societal development, economics, technology and infrastructure, political freedom, and cultural factors. 


\section{Figure 1 - Levels of Women's Participation in Leadership}

\begin{tabular}{|c|c|c|}
\hline Level & Level Title & Level Description \\
\hline Level 1 & $\begin{array}{l}\text { Minimal } \\
\text { Participation }\end{array}$ & $\begin{array}{l}\text { Virtually no women in independent positions of influence in } \\
\text { business or politics }\end{array}$ \\
\hline$\underset{\downarrow}{\downarrow}$ & $\begin{array}{l}\text { Moderate } \\
\text { Participation }\end{array}$ & $\begin{array}{l}\text { A few women gain independence based on need with a } \\
\text { simultaneity of backlash and cultural acceptance, but } \\
\text { leadership in business politics remains low }\end{array}$ \\
\hline$\underset{\mid}{\downarrow}$ & $\begin{array}{l}\text { Substantial } \\
\text { Participation }\end{array}$ & $\begin{array}{l}\text { Considerably more women follow their predecessors into } \\
\text { leadership roles and can start businesses and/or participate in } \\
\text { political leadership }\end{array}$ \\
\hline$\underset{1}{1}$ & $\begin{array}{l}\text { Pronounced } \\
\text { Participation }\end{array}$ & $\begin{array}{l}\text { Women achieve equality at lower and middle levels of formal } \\
\text { business and political organizations and a few reach the } \\
\text { highest levels of leadership }\end{array}$ \\
\hline $\begin{array}{l}\vee \\
\text { Level } 5 \\
\text { (Unrealized) }\end{array}$ & $\begin{array}{l}\text { Widespread } \\
\text { Participation }\end{array}$ & $\begin{array}{l}\text { Complete equality of women and men across industry or } \\
\text { occupational roles as well as at the highest levels of business } \\
\text { and political leadership }\end{array}$ \\
\hline
\end{tabular}

This proposed model of the Levels of Women's Participation in Leadership is similar to 1) Rostow's (1960; 1990) Stages of Economic Growth, and 2) the widely accepted range of least integrated to most integrated Levels of Economic Integration (Hill, 2008a; Mirus \& Rylska, 2001; Sampson \& Woolcock, 2003). These two frameworks are presented in the model only for conceptual purposes, but are not isomorphic with the levels that are tested in this study. The dotted line from Level 4 to Level 5 indicates that Widespread Participation of women at all levels of leadership with complete equality of men and women in top levels of business and political leadership has not been achieved at this point in history. ${ }^{3}$

\footnotetext{
${ }^{3}$ As can be seen by the proportions of women in business and political leadership data used in the analysis
} 
The difference between Rostow's model and the one proposed here is that Rostow offered his stages based on experience and expertise, "a spontaneous and protracted effort." The theory of global levels of women's participation in leadership is derived from an integration of literature, but intended for empirical testing. Boserup (1970; 1986) too recognized countries moving through stages of economic development both occupationally and geographically - from village to town and from agricultural to nonagricultural economic systems. The concept of qualitatively different levels can be seen in other stage theories that are not at the international or country level: Beck's (2000) stages of social development, Piaget's (1954) stages of cognitive development, Erikson's (1964) stages of social-emotional development, and Kohlberg's (1973) stages of moral development. By examining the similarity of the Levels of Women's Participation in Leadership to other stage theories with qualitatively different levels, 5 levels are proposed because theoretical breaks can be logically detected, as seen in the description on each level in Figure 1. Because level 5 is figurative in nature at this point in history, only 4 levels are testable empirically.

Important to note here is that although Rostow's and Boserup's models are of economic growth and modernization, the proposed theory of global levels of women's participation in leadership tested in this study is not intended to be a mirror of Rostow's model. That said, there is expected to be a positive relationship between economic development/modernity and women's participation in leadership. The global levels of women's participation in leadership are developed based on a synthesis of prior research from cross-cultural leadership and women in leadership. The similarity of this levels 
theory to comparable stage models lies in the process of qualitative change, as a progression from one stage to the next. The term "levels" is used, as opposed to "stages," because this is not a longitudinal study following countries over time to test progression from one stage to the next. This project captures the empirically validated level of a country at a point in time with regard to women's participation in leadership.

It is expected that many of the factors that affect countries with lower levels of women's participation in business and political leadership may be different from those that affect women in countries with higher levels of participation. In countries with fewer women in positions of leadership, two paradigms remain less affected: 1) general societal acceptance remains lower because of confusion when grappling with the combination of long-standing cultural norms and the addition of modern movements (Inglehart \& Baker, 2000); and 2) there are fewer role models (Bandura, 1977) and mentors for women to follow and policies that encourage women to attempt to hold positions of influence. The data show (World Bank, 2007e, 2008a; UN, 2004) that in societies with lower participation of women in leadership, very few women have advanced to political or business leadership. As the idea of women in leadership becomes less foreign and societies become institutionalized to the idea (Lucas, 2003), more women progress into positions of leadership. In countries with more participation of women in leadership, gender equality in the work force is visible and increasingly more women are seen in business ownership and political leadership positions. 
In addition, countries with high proportions of women in political leadership do not necessarily have high proportions of women in business leadership. ${ }^{4}$ Combining these two constructs would compromise the sensitivity required for understanding the macro and micro factors that affect women's participation in both political and business leadership.

H1: Countries can be categorized into significantly different clusters based on the levels of women's participation in business and political leadership.

\section{Independent Variables}

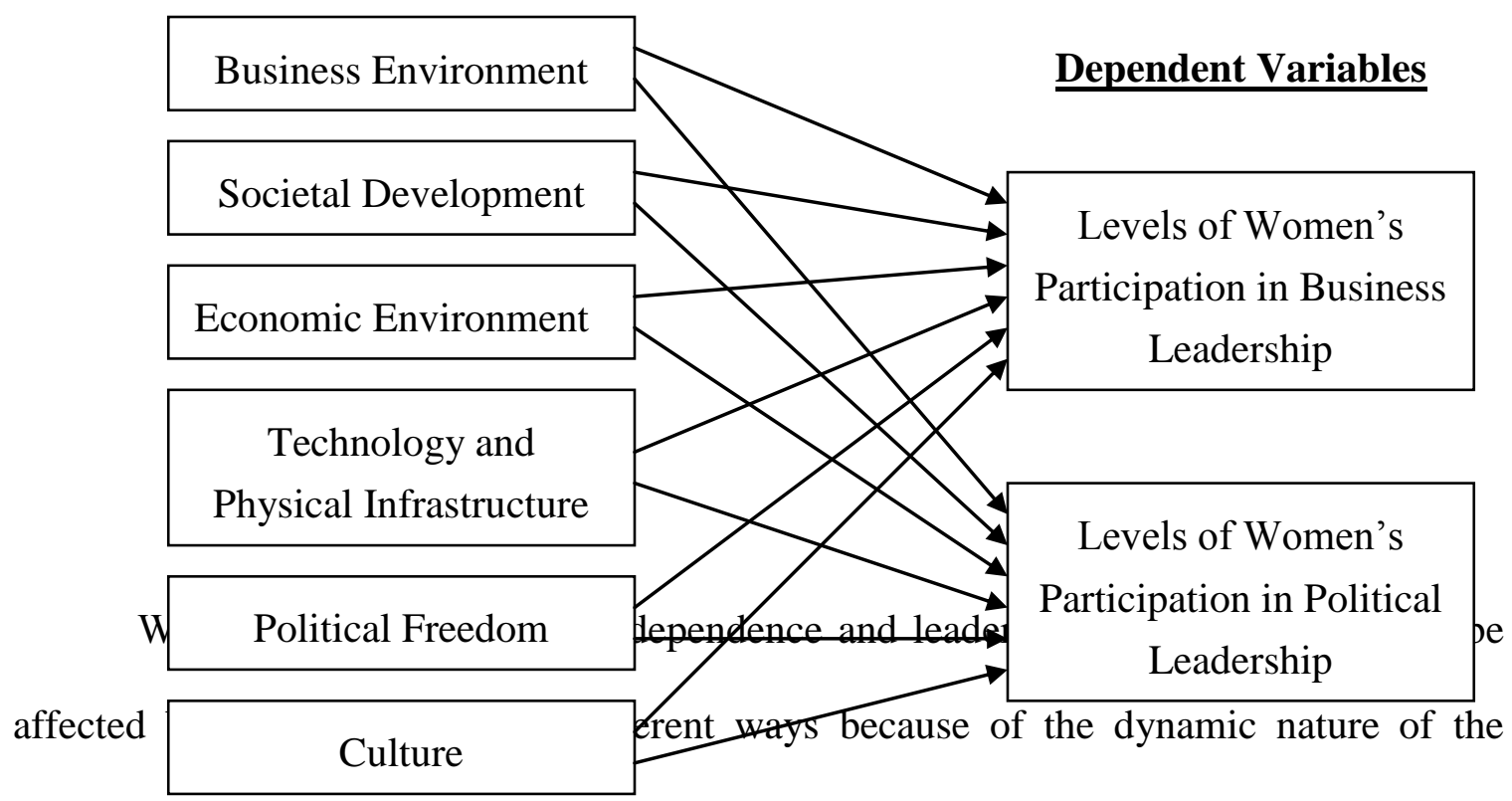

environments in which they live (Bajdo \& Dickson, 2001; X.-P. Chen \& Li, 2005; D. N.

Den Hartog et al., 1999; Erez \& Gati, 2004; Stelter, 2002). Certain institutions are more or less supportive of women in leadership roles. Huntington $(1965 ; 1968)$ argued for the importance of institutions and the creation of structures with formal government institutions. Institutional theory is used here to explain how societal level institutions -

\footnotetext{
${ }^{4}$ As can be seen by the proportions of women in business and political leadership data used in the analysis of this paper - see Cluster Analysis section.
} 
business environment, societal development, economics, technology and infrastructure, political freedom, and culture (Ghemawat, 2001; Hill, 2008b; Hofstede, 1980; R. J. House et al., 2004; M. E. Porter, 1980, 1990) - can promote or impede women's participation in business or political leadership.

A PEST (Political, Economic, Social and Technological institutions) analysis is a tool for understanding market growth or decline, and is used to assess the market for a business or organizational unit (Aguilar, 2006; M. Morrison, 2008). A PEST is a framework for reviewing a situation, a strategy or position, the direction of a company, a marketing proposition, or an idea. The PEST analysis has also been extended to a PESTEL, adding environmental and legislative institutions (Havergal \& Edmonstone, 1999; J. Rogers, 1999), and a STEEPEL analysis, adding an ethical institution (12Manage, 2008). The current analysis adds the institutions of culture and the business environment. Another such analysis is the Ghemwalt's CAGE analysis of distances, by examining cultural, administrative, geographic, and economic distances between societies for the purposes of strategic development (Ghemawat, 2007).

There are two ways to view institutions, economic (North, 1990) and sociological (DiMaggio \& Powell, 1983) Institutions provide a structure for shared skills, knowledge, and opportunities to produce growth and development (North, 1990). The central tenent to institutional theory is that rules, requirements, and norms govern environments, and in turn provide support and legitimacy (Scott, 1987) for, in this case, women in leadership. In this case, the business environment, societal development, economics, technology and infrastructure, political freedom, and culture affect women's participation in leadership. This study fouces on the influence of these six systems surrounding the environment that 
shapes the behavior (Hoskisson, Eden, Lau, \& Wright, 2000; Scott, 1987) to engage in leadership.

The concept of isomorphism implies that institutional forces cause organizations to become similar and that conforming to norms is a result of an attempt at increased legitimacy. Agreeing to rules and requirements also allows greater access to resources and strengthens survival capabilities (DiMaggio \& Powell, 1983; Kostova \& Zaheer, 1999; Oliver, 1991). The normative approach to institutional theory implies that actors function within institutions because of normative standards and social values that are inherent within the environment (March \& Olsen, 1984, 1989, 1996). Rational choice institutionalism maintains that members of institutions respond to rules and incentives but that individuals take their own priorities under consideration while interacting within the institution (Peters, 2000). Either way, when institutionalism increases and provides greater uniformity (Zucker, 1988), an infrastructure for women in leadership can prosper (Lucas, 2003).

Business Environment: The role of business institutions in shaping the macroenvironment of a country is intertwined with globalizing and modernizing forces. Country business environments respond to the institution of modern, global business practices and conform for the purposes of legitimacy (DiMaggio \& Powell, 1983, 1991; Kostova \& Zaheer, 1999). Multinational corporations operate in transnational networks, therefore influencing institutional development (Dahan, Doh, \& Guay, 2006). Emerging economies begin with a more informal relationship-based transactional arrangement and eventually evolve into a more rules-based organization (Peng, 2003). When these more informal relationships lead to a decrease in transaction costs, then the benefits of the 
relationship bread new opportunities. The expansion of the network then begins to require more formal rules and procedures to cope with the further complex structure. These informal networks allow existing parties access to limited information, however sometimes may discourage evolution into a broader network with new trading partners.

The business environment institution and the factors that affect doing business affect business culture and productivity. These same factors therefore affect a modernizing culture that allows women into positions of leadership (World Bank, 2007b, 2008a, 2008b; Bertrand et al., 2007; Demirgüç-Kunt et al., 2007; Farid, 2007; Jackson \& Sorensen, 2003; Navari, 1989; Sala-i-Martin, Blanke, Hanouz, Geiger, Mia, \& Paua, 2007; Sharma, 2007; Toye, 1987; Weiss, 1988; White, 1984). Certain business institutional forces, such as the skill level of workers, access to tools to finance a business, global business competitiveness, and a strong entrepreneurial environment, facilitate women's participation in leadership. For example, a positive entrepreneurial environment that encourages individual innovation and business growth makes it easier for individuals to learn business skills and gain respect from others for launching new businesses. This innovation and creativity spawned from the generation of business (Schumpeter, 1934) brings with it modernity and an acceptance of women in leadership positions.

Other business institutional forces inhibit women's participation in leadership, such as giving gifts to bureaucratic officials, costs associated with crime and corruption, obstacles to international trade, arduous tax systems, and cumbersome bureaucratic procedures for licenses and permits, enforcing contracts, or starting a business. For example, cumbersome bureaucratic procedures can discourage business leadership for 
those who find that the system causes bottlenecks and hinder their business growth. Similarly, crime and corruption may inhibit political leadership for those who fear for their safety or don't trust the government system.

H2: Business institutional variables distinguish among qualitatively different levels of women's participation in positions of leadership.

H2a: Business facilitating institutional forces are positively related to the levels of women's participation in positions of leadership.

$\underline{\mathrm{H} 2 \mathrm{~b}}$ : Business inhibiting institutional forces are negatively related to the levels of women's participation in positions of leadership.

Societal Development: A society's preoccupation with severe health problems, a lack of medical care, and land and environmental issues can stunt economic growth. Fundamental societal development issues like education, a more modern non-agricultural employment and an urban population, gender equality, family health and medical capabilities, and environmental issues can also affect the culture and the economic prosperity of a country, and consequently affect opportunities for women's involvement in leadership (Boserup, 1986; Forum, 2008; Hofstede, 1983, 1997; Jackson \& Sorensen, 2003; Lieb \& Thistle, 2005; Navari, 1989; Sachs, 1997, 2005; UNDP, 2003; UNESCO, 2001; UNIFEM, 2008; Van de Vliert, 2003).

Societal development institutional forces facilitate women's participation in leadership, such as burgeoning employment, gender equality, literacy and education, a young and urban population, and human health and environmental development. For example, women who have an education and work experience in social institutions with less concern for basic safety and nourishment for their families will have more opportunity to engage in leadership, than women who must be preoccupied with fundamental health and survival needs. Investments in girls' education have been found 
to benefit the home and workforce development and female participation then maintains regardless of income at the country level (Lincove, 2008).

H3: Societal institutional variables distinguish among qualitatively different levels of women's participation in positions of leadership.

H3a: Societal development is positively related to the levels of women's participation in positions of leadership.

Economic Environment: Economic institutional factors, including imports and exports and the types of goods and services that are produced and exported, services that provide a competitive advantage to a country, the level of economic development in a country, economic freedoms experienced by citizens, taxes, and investment in the private sector through credit can create opportunities and positively affect women's roles in leadership (World Bank, 2007c, 2007e; Farid, 2007; Forum, 2007; Hill, 2008b; Neumayer \& deSoysa, 2007; Papamarcos \& Watson, 2006; M. E. Porter, 1990; UNDP, 2007).

Certain economic institutional forces that are likely to enable economic development facilitate women's participation in leadership, such as economic freedom, macroeconomic stability, economic development, domestic credit provided to the private sector, and inflows and outflows signifying international trade. Economic growth and credit for new business development brings modernity to business management and cultural practices that are open to women. The types of goods and services produced and sold can have a positive impact on women's participation in positions of leadership because international trade in general advances global norms and hence the acceptance of women in society (D. Chen, Newburry, \& Park, Forthcoming). Other economic institutional forces inhibit women's participation in leadership, such as non-performing 
bank loans, taxes, and inflation. For example, delinquency on credit can adversely affect lending institutions and cripple economic growth, cause inflation, and hinder institutional practices and women's advancement to leadership.

H4: Economic institutional variables distinguish among qualitatively different levels of women's participation in positions of leadership.

H4a: Economic facilitating institutional forces are positively related to the levels of women's participation in positions of leadership.

H4b: Economic inhibiting institutional forces are negatively related to the levels of women's participation in positions of leadership.

Technology and Physical Infrastructure: Technology, like access to the use of computers, the internet, and cell phones, and other infrastructural capabilities that affect the distribution systems and productivity of a country, like roads, electricity, and railways can all significantly impact the culture and the advancement of women in a country (Chan \& Qingyang, 2006; T. Friedman, 2005; Hill, 2008b; Lieb \& Thistle, 2005; UN, 2005b; UNDP, 2007). These institutional capabilities lend to exporting, importing, and distributing goods and supplies and spread learning and know-how from other cultures and systems around the world. Technology and innovation do not merely add something to a culture, but can change everything about it (Postman, 1993; Schumpeter, 1934). Technology and physical infrastructure institutional forces facilitate women's participation in leadership. For example, cellular technology and access to the internet signify development and connect societies to the outside world. This facilitates economic growth from international trade and advances global norms, creating a hospitable institutional environment for women in leadership (D. Chen et al., Forthcoming).

H5: Technology and physical infrastructure institutional variables distinguish among qualitatively different levels of women's participation in positions of leadership. 
H5a: Technological advancements and physical infrastructure are positively related to the levels of women's participation in positions of leadership.

Political Freedom: Political freedom can also have an impact on women's participation in positions of leadership. Political factors can influence female participation as much as social, cultural, and economic factors (Lincove, 2008; Sen, 1996). Noneconomic obstacles to female participation vary with political institutions (Smock, 1981; Youssef, 1974). Countries that are politically free benefit from open political competition, respect for civil liberties, an independent media, low levels of corruption, a strong rule of law, and a lack of ethnic and religious strife (Puddington, 2008). Women will have higher levels of participation in leadership in countries where citizens can be instinctive and take advantage of opportunities in areas outside the control of the government and participate in political institutional processes that affect them (Freedom house, 2008). The institution of political freedom facilitates women's participation in leadership through respect for their civil liberties and their right to engage in the political process and engage in business relationships.

H6: Political institutional variables distinguish among qualitatively different levels of women's participation in positions of leadership.

H6a: Political rights and civil liberties are positively related to the levels of women's participation in positions of leadership.

Culture: Cultural indicators in this study relate to specific individual perceptions such as beliefs, norms, and expectations of individuals within a society that affect the culture of that society (Fu et al., 2004; Hofstede, 1983, 1997; K. Leung \& Bond, 2004; K. Leung et al., 2002), and in turn affect the advancement of women into positions of leadership. Specifically, certain cultural institutional forces facilitate women's 
participation in leadership, such as societal comfort with uncertainty and breaking the rules (uncertainty avoidance), rewards for performance and individual achievement (performance orientation), planning for the future (future orientation), gender equality (gender egalitarianism), societal affinity for other people and the environment (humane orientation), societal inclinations toward assertive behavior (assertiveness) (Hofstede, 1980, 2001; R. J. House et al., 2004), external locus of control (fate control), flexible religious values (religiosity), societal belief in hard work, experience, and a sensible strategy (rewards for application), and societal belief that there are numerous opportunities to achieve outcomes (complex social systems) (K. Leung \& Bond, 2004). For example, women who want to achieve leadership positions or independence to care for themselves and their families will mostly like look ahead and plan for their futures, believe in hard work in order to achieve such positions, and be willing to debunk norms and societal expectations that might provide a little uncertainty.

Other cultural institutional forces inhibit women's participation in leadership, such as sense of group belonging and responsibility (collectivism), regard for hierarchy (power distance) (Hofstede, 1980, 2001; R. J. House et al., 2004), and pessimism, prejudices, and stereotypes (cynicism) (K. Leung \& Bond, 2004). Cultural obstacles to female participation, for example, some religions have been argued to be associated with lower female labor force participation or the relegation of women to specific employment sectors vary (Lincove, 2008; Robbins, 2007; Smock, 1981; Youssef, 1974). Therefore, it can be hypothesized that strong power distance and collectivistic tendencies in a society may inhibit women's progression into leadership. 
H7: Cultural institutional variables distinguish among qualitatively different levels of women's participation in positions of leadership.

H7a: Liberal and open cultural institutional forces are positively related to the levels of women's participation in positions of leadership.

H7b: Constraining and restrictive cultural institutional forces are negatively related to the levels of women's participation in positions of leadership.

In addition, certain institutional leadership skills and abilities are culturally recognized to facilitate women's participation in leadership, such as inspirational, motivational, and performance-oriented leadership (charismatic and visionary leadership), goal attainment through team building (team-oriented leadership), democratic and inclusive leadership (participative leadership), leadership that is considerate, compassionate, and supportive (humane-oriented leadership), individualistic leadership with independence from superiors (autonomous leadership). Other institutional leadership skills and abilities are culturally recognized to inhibit women's participation in leadership, such as self-serving leadership interested in security only for the leader and the leader's friends (self-protective leadership) (Dorfman, Hanges, \& Brodbeck, 2004; R. J. House et al., 2004).

Women face problems of resistance and legitimacy that limit their influence through directive or assertive behavior (Berger, Ridgeway, Fisek, \& Norman., 1998; Butler \& Geis, 1990; Eagly, Makhijani, \& Klonsky, 1992) and therefore, may encourage their use of more democratic and participative leadership traits. Because of the low external status women and minorities to leadership positions, concerns about legitimacy affect the strategies they employ to gain influence (Berger et al., 1998; Carli, 1991; Ellyson, Dovidio, \& Brown, 1992; Ridgeway, Johnson, \& Diekema, 1994). Finally, a transformational leadership style has been found to be a positive force across countries 
(De Hoogh, Den Hartog, Koopman, Thierry, Van den Berg, Van der Weide, \& Wilderom, 2005; D. N. Den Hartog et al., 1999), so it is expected that women who utilize charismatic and transformational leadership characteristics are positively related to women's advancement into leadership positions.

H7c: Transformational, participative, humane, and collaborative leadership skills and abilities are positively related to the levels of women's participation in positions of leadership.

H7d: Self-serving leadership skills and abilities are negatively related to the levels of women's participation in positions of leadership.

Rostow (1990) breaks countries into two kinds of cases. The first he refers to as the general case of countries with extremely long histories, like most of Europe, a great part of Asia, the Middle East, and Africa, where preconditions for movement from the traditional stage "required fundamental changes in a well-established traditional society" (p. 17). The other case of countries represent a small group of nations that were 'born free', such as the U.S., Australia, New Zealand, and Canada, which evolved mainly from non-conformist individuals. These differences in country history may also affect longstanding cultural norms and explain how one country moves from one stage differently than another country in the freedom of women to achieve higher levels of leadership. Because these younger countries were "born free," the members of these societies do not as much face the long-standing cultural norms and expectations that remain present in countries with a longer historical base, and are therefore more open to the freedom of expression for members of society, and women can access leadership roles with more ease. 
This study aims to explore several factors that affect women getting involved in leadership positions. The findings from this study will change over time. These factors are dependent on context and change in time with the spread of globalization and the comingling of the traditional with the modern, to varying degrees. The lesson to be learned form this research is that discrepant findings or less-than-productive research on differences among women and men can be explained by the complex and dynamic nature of context. Varying contextual factors affect women at different levels of participation in leadership. The varying contextual factors that affect women's participation in leadership positions determine the level in which a country falls in the process toward an increase in women in leadership. 


\section{CHAPTER 3: METHODS}

Roberts, Hulin, and Rousseau (1978) define aggregation as "the use of some combination of ... unit characteristics to reflect something about the immediately more macro unit of analysis (p. 82)." A downside to aggregate data is that it can obscure understanding if alternative meanings of a construct have not been accounted for. For example, any surplus meaning of a variable beyond that associated with its original level of assessment may be missed or misunderstood when aggregating data. However, aggregation allows for measure error and individual levels of description to be averaged out, thereby offering a more representative measure than possible through a reliance on one's individual's perception. Where whole-unit data cannot be assessed as a whole unit, aggregates can be substituted, as long as the researcher explains the relationship between the aggregated data and the global concept. Data aggregated across geographical areas is common in the use of census data (Roberts et al., 1978); i.e., women leaders nested within countries. This is necessary when the aerial unit is the unit of analysis - in this case, the aerial unit "country" is the unit of analysis.

This research study will provide a multilevel, cross-country analysis using macroeconomic and macro-social data as well as individual-level business environment data from institutions including the World Bank (2007a, 2007e, 2008a) the United Nations (UNDP, 2006), the OECD (2008), Freedom House (2008), and the Heritage Foundation (2008), all totaling approximately 200 countries, and individual-level cultural survey data from GLOBE (R. J. House et al., 2004) for approximately 62 countries; the Global Entrepreneurship Monitor (P. Reynolds, Bono, \& Autio, 2003) for about 40 countries; 
and the Social Axioms Survey (K. Leung \& Bond, 2004; K. Leung et al., 2002) for approximately 40 countries, all aggregated to the country level using country means. This will be done through a two-part analysis. The first step involves cluster analysis of the women in business and political leadership variables to arrive at the two final categorical dependent variables. The second represents the main hypothesis testing, conducted with discriminant analysis.

The years chosen for study in this project represent, in most cases, the most recent data available, particularly for the dependent women in leadership variables. There are two specific explanations of years chosen that merit attention. First, the dependent variables are made up of data from the OECD in 2004 and from the World Bank Enterprises Survey from 2002-2007. Each of the countries in the World Bank Enterprises Survey 2002-2007 database represented a mixture of 1, 2, or 3 years, seemingly completely at random. For example, data are reported for Nicaragua in 2003 and 2006, Costa Rica only for 2005, and Lithuania in 2002, 2004, and 2005. Therefore, for any individual year, far fewer countries are represented - anywhere from 3 to a maximum of 40 countries of data in each year. In an attempt to maximize the use of this rich and important data, an average of the years for each country is taken and used as a representative score from the years of 2002-2007. For example, the 2 scores for Nicaragua in 2003 and 2006 are averaged for a final score from this time period.

The second issue regarding years chosen for analysis that merits attention relates to the reality that some sources (i.e., The Heritage Foundation's Index of Economic Freedom) provided extremely current data. In such a case, the most recent data would have been inappropriate considering the older, albeit still timely, nature of the dependent 
variable, and therefore a year closer to that of the DV chosen for analysis. In other cases, the most recent data are used when the most readily available from a source's publicly available website. Therefore, in cases where only the most recent data are publicly available, those are the data used in the current study. This 5-year range of data do not pose a problem for analysis because the current project supports the belief that macrolevel changes at the country level do not typically have broad sweeping and swift effects detected from year to year.

\section{$\underline{\text { Secondary Data Sources }}$}

This section relates to the variables chosen for this study. A dataset of about 300 variables for 213 countries are collected from ten secondary data sources, including: the World Bank World Development Indicators, the United Nations Human Development Indicators, the Organization for Economic Cooperation and Development, the World Bank Doing Business Project, the World Bank Enterprises Survey, the Heritage Foundation, Freedom House, Global Leadership and Organizational Behavior Effectiveness Research Project, the Social Axioms Survey, and the Global Entrepreneurship Monitor. While suggestions for other additional outside data sources

could be made, given the large number of variables and the comprehensiveness of the secondary sources used in this study, each of the hypothesis categories is well represented 
with variables to test each hypothesis. Any supplementary variables beyond the vast number included here would be redundant and not necessarily add to the analysis. ${ }^{5}$

The following discussion is organized according to the variables presented in the hypotheses section, beginning with the dependent women in leadership variables and proceeding to each of the groups of independent variables: business environment, societal development, economic, technology and physical infrastructure, political, and cultural variables. Each secondary data source is described in detail one time, in the section where that source makes the largest contribution to the number of variables presented. For example, the World Bank Enterprises Survey provides data for two of the dependent variables; however, the majority of the variables gathered from the Enterprises Survey fall in the next business environment section - and this is where the details of the Enterprises Survey can be found. A table that shows the variables, sources, and final sample sizes, organized by hypothesis and into subcategories can be found in Appendix 1.

Sources for Dependent Variables: Women in Leadership

Women in Business Leadership: The Organization for Economic Cooperation and Development (OECD, 2008) reports a measure called Employers and Persons Working On Their Own Account which represents individuals who operate their own economic enterprise or follow a profession or trade on their own account, whether they employ

\footnotetext{
5 i.e. Gender-specific variables were well represented by the employment, education, and gender equality measures provided by the World Bank World Development Indicators, United Nations Development Program, and World Economic Forum Gender Gap, outlined below. Therefore, Cingranelli and Richard's (2004) variable for women's economic rights was not necessary since many of its components overlap with variables already included in the dataset.
} 
other people or not. The data are provided in thousands for women, men, and the combined total of both, for each of the 29 countries covered in $2004 .^{6}$ For the purposes of this study a women-to-total proportion is used, for a final variable called Proportion of Firms with Female Employers \& Own Account Workers. The World Bank Enterprises Survey (World Bank, 2008a) ${ }^{7}$ provides information about women's entrepreneurship and economic participation in the labor force, including the percent of firms with women in ownership and the percent of firms with women in senior positions from 2002-2007. These variables are converted to proportions to maintain consistency with the other dependent variables, and the two final variable names are: Proportion of Firms With Females in Ownership Developing Countries and Proportion of Women in Senior Positions Developing Countries.

Women in Political Leadership: The World Bank World Development Indicators (WBWDI) (World Bank, 2007e) is an annual compilation of data about development and includes over 800 indicators in 153 countries. 2004 is the year of chosen data for this project because at the time of compiling the data this is the most recent and most complete data across countries. The WDI provide a measure for women in public sector leadership, Proportion of seats held by women in national parliament, and this variable is used here. Similarly, the United Nations Development Program (UNDP) provides the variable, Seats in parliament held by women (\% of total), which is used here. The United Nations Development Program (UNDP, 2005, 2006, 2007) produces, every year, the

\footnotetext{
${ }^{6}$ For more information of methodology, see www.stats.oecd.org. Data were accessed through the Florida International University Library Database

${ }^{7}$ See discussion explaining the World Enterprises Survey below in the Sources for Independent Variables: Business Environment section.
} 
Human Development Report which provides data on a plethora of measures related to human development in up to 177 countries. $^{8}$

\section{$\underline{\text { Sources for Independent Variables: Business Environment }}$}

Two World Bank sources are used to collect data for items related specifically to the business environment in each country: the World Bank Doing Business Project and the World Bank Enterprises Survey. In addition, two other sources, the World Economic Forum and the Global Entrepreneurship Monitor also provide information on the business environment in each country. Each of these will be discussed in the following paragraphs.

Doing Business Project: The World Bank Doing Business Project (World Bank, 2007a) gauges business regulations and the enforcement of those regulations in 178 countries in 2007 for the purposes of assessing which regulations have the greatest effect on economic growth, understanding business related laws, and ascertaining effective modification practices. The data are gathered through lawyers, business consultants, accountants, government officials, and other professionals considered to be local experts who consistently oversee or counsel on legal issues and regulations. The Doing Business group catalogues activities required for starting a new business and conducting business in general, by measuring procedures, time, sequence, or costs associated with: Licenses and permits, employing workers, getting credit, protecting investors, paying taxes, trading across borders, and enforcing contracts. To make data comparable across

\footnotetext{
${ }^{8}$ See discussion explaining the UNDP and Human Development Indices in more detail in the Sources for Independent Variables: Societal Development section.
} 
countries, Doing Business gauges business practices under normal conditions and requires participants to meet certain characteristics to be included in the survey. ${ }^{9}$

Enterprises Survey: The World Bank Enterprise Survey questions a random sample of over 70,000 firms about their perceptions of the quality of the business environment in 104 developing countries. ${ }^{10}$ The survey is designed to uncover the most significant impediments to venture growth and to increasing employment and productivity, and the effects of these on international competitiveness. To ensure confidence and participation of respondents, private contractors with the World Bank, rather than government agencies, conduct the surveys. The survey seeks to uncover productivity measures and managers' opinions of the most important obstacles to the business environment and is administered to managing directors, accountants, human resource managers, and other company staff. Data are collected from 2002-2007 and topics in the survey include:

Regulations and Tax: including time spent with tax officials and paying taxes and the percent of firms that identify tax rates and administration as major constraints.

Permits and Licenses: including the time required to obtain various licenses and permits, the effects of excessive bureaucratic procedures, and the percent of managers that feel this is a major constraint.

Corruption: including additional costs associated with making unofficial payments or gifts to "get things done" in areas related to customs, taxes, licenses, regulations, services, etc.

\footnotetext{
${ }^{9}$ For more information on methodology, see http://www.doingbusiness.org/MethodologySurveys/.

${ }^{10}$ Data from emerging markets only were collected by the World Bank Enterprises Survey team.
} 
Crime: including the percent of firms paying for security, losses due to theft, vandalism, and arson, the percent of firms identifying crime, theft, and disorder as a major constraint, and security costs.

Informality: including the percent of firms that claim there is an under-reporting of sales, the percent of firms reporting competition with unregistered firms, the percent of firms not formally registered at the start of operations, and number of years firms operated without formal registration.

Financing: including the percent of firms with line of credit or loans from financial institutions, the percent of firms using banks to finance investments and expenses, the value of collateral needed for a loan, and the percent of firms identifying access to finance as a major constraint.

Trade: including time spent waiting for imports and exports to clear customs and the percent of firms identifying this as a major constraint.

Workforce: including the percent of firms offering formal training, seasonal/temporary fulltime employees, permanent fulltime employees, and the percent of firms identifying labor regulations as a major constraint.

Global Competitiveness: The World Economic Forum Global Competitiveness Network (Forum, 2007) conducts an annual study to help influence investment decisions and direct economic policy by ascertaining obstacles to growth and stimuli for economic progress. This is done by gathering publicly available data, working with leading academics and a global network of research institutes, and survey data from over 11,000 business executives to compile subindexes that ultimately make up a Global Competitiveness Index (Sala-i-Martin, 2007). Data for this study come from 2007 and 
cover 131 countries. A high score on global competitiveness indicates functioning institutions, business sophistication, labor market efficiency, financial market sophistication, and efficient goods market, strong market size, sufficient health and primary education, available higher education, macroeconomic stability, basic infrastructure, and technological readiness. The index is calculated based on 12 pillars, which are each calculated from individual items from the executive questionnaire and made into scales. The 7 the pillars included in the present study are: global competitiveness of institutions, business sophistication, innovation, labor market efficiency, financial market sophistication, goods market efficiency, and market size. The remaining 5 pillars can be found in later Sources for Independent Variables section

Entrepreneurial Framework Conditions: The Global Entrepreneurship Monitor research program is made up of a consortium of researchers in over 40 countries aimed at increasing the understanding of factors that affect individuals starting new businesses. Part of this objective is targeted with questionnaires answered by experts on entrepreneurship in each country, for a sample size of approximately 4,000. Experts were chosen by GEM team members in each country based on personal and professional social networks, including individuals from government agencies, universities, consulting firms, the financial sector, mass media and even experienced, established entrepreneurs from all geographic regions and in different industry sectors (P. Reynolds, Bosma, Autio, Hunt, Bono, Servais, Lopez-Garcia, \& Chin, 2005; P. D. Reynolds \& Hechavarria, 2007). ${ }^{11}$ Based on raw scores from the expert data, 14 scales are created $(.62<r>.94$.) each on a

\footnotetext{
11 For complete methodology and publicly available data, go to the Global Entrepreneurship Monitor website located at www.gemconsortium.org/.
} 
1-5 scale (completely false to completely true) based on a factor analysis of 62 individual questions in 32 countries in 2003. The 14 Entrepreneurial Framework Condition scales are:

Good Infrastructure and Communications (2 items, $r=.81$ ) relating to roads, utilities, phones, internet, etc.;

Respect for Individualistic and Innovative Entrepreneurs (5 items, $r=.94)$ relating to societal emphasis on individual success achieved through personal efforts, self-sufficiency, autonomy, personal initiative, entrepreneurial risk-taking, creativity and innovativeness, and individual (rather than the collective) responsibility in managing personal life;

Social Acceptance and Respect for Entrepreneurs (4 items, $r=.89$ ) relating to respect for becoming an entrepreneur and becoming rich through new venture creation, valuing entrepreneurs as competent and resourceful individuals, and media attention on successful entrepreneurs;

Supportive Environment for Women (5 items, $r=.87$ ) relating to sufficient social services available for women to work after starting a family, social support for women starting new businesses, encouragement of women to become self-employed or start a new business, equality in the number of good opportunities for both genders, and equality in the level of knowledge and skills among both genders;

Business Opportunity Environment \& Entrepreneurial Ability (9 items, $r=.91$ ) relating to accessible information to assess business opportunities, the idea that there are many good opportunities for new firm creation and sometimes too few people to capitalize on these good ideas, plenty of high growth opportunities, the idea that creating 
new or high growth businesses is easy, small business management know-how, new business experience, quick reaction times to capitalize on new opportunities, and resource accumulation to launch a new business;

Positive Impression of Government Support (7 items, $r=.84$ ) relating to the priority of new and growing firms for national government policy, and the efficiency, competence, availability, effectiveness, adequacy, and scope of government agencies aimed at supporting new and growing firms;

Accessible \& Affordable Business Services \& Suppliers (6 items, $r=.89$ ) relating to the affordability of market entry, and the affordability, quality, accessibility, and sufficient number of subcontractors, suppliers, consultants, professional legal, accounting, and banking services;

Sufficient New Venture Funding (6 items, $r=.81$ ) relating to debt, equity, private sector, and venture capitalist funding, government subsidies, and initial public offerings (IPOs) for new and growing firms;

Strong Intellectual Property Rights (5 items, $r=.85$ ) relating to comprehensive and efficiently enforced legislation on IPRs, copyrights, or trademarks;

Grade School Entrepreneurial Education Focus (3 items, $r=.91$ ) relating to the emphasis of education on creativity, self-sufficiency, and personal initiative, market economic principles, and entrepreneurship and new firm creation;

Good Market Opportunity and Controls (5 items, $r=.74$ ) relating to the idea that markets for consumer and business-to-business goods and services change drastically from year to year, ease of market entry, and anti-trust legislation; 
Positive Research and Technology Environment (4 items, $r=.74$ ) relating to universities, public research centers, and government support for new and growing firms gaining access to new technologies, science, and other knowledge;

Timely Access to Utilities, Communications, and Permits/Licenses (3 items, $r=$ .62) relating to good access to utilities, phones, internet, etc. and quick access to permits and licenses;

Good Available Entrepreneurship Training ( 3 items, $r=.69$ ) relating to sufficient and quality university entrepreneurship programs, business and management education, and vocational, professional, and continuing education for self-employment.

\section{$\underline{\text { Sources for Independent Variables: Societal Development }}$}

Three sources are used to collect data for items related to societal development: the World Bank World Development Indicators, the United Nations Human Development Program, and the World Economic Forum. Each of these is discussed in the following paragraphs.

The World Bank World Development Indicators (World Bank, 2007e): An introduction to the World Development Indicators is provided in the "Sources for Dependent Women in Leadership Variables" earlier section. 2004 is the year of chosen data (unless otherwise noted) for this project because at the time of compiling the data this is the most recent and most complete data across countries. The societal development indicators chosen for this study from the WDI are organized into categories, including: 
Employment: female unemployment (percent of female labor force), male unemployment (percent of male labor force), total unemployment (percent of total labor force), share of women employed in the nonagricultural sector (percent of total nonagricultural employment), employees in agriculture, industry, and services (all as a percent of total employment), female employees in agriculture, industry, and services (all as a percent of female employment), male employees in agriculture, industry, and services (all as a percent of male employment), female labor force (percent of total labor force), female labor force participation (percent of female population ages 15-64), male labor force participation rate (percent of male population ages 15-64), total labor force participation rate (percent of total population ages 15-64), proportion of seats held by women in national parliament, ratio of estimated female to male earned income 2003;

Education: primary education, secondary education, public spending on education, and female and male children out of school;

Population: population ages $0-14,15-64$, and 65 and above (\% of total), population of females (percent of total population), and rural and urban population (percent of total population);

Health \& Development: birth rate (per 1,000 people), death rate (per 1,000 people), fertility rate (births per woman), improved sanitation facilities percent of population with access), improved water source (percent of population with access), outof-pocket health expenditure (percent of private expenditure on health), physicians (per 1,000 people), prevalence of undernourishment (percent of population). 
The World Bank Enterprises Survey (World Bank, 2008a) ${ }^{12}$ provides information about women's economic participation in the labor force, including the percent of fulltime female workers from 2002-2007.

The United Nations Development Program (UNDP, 2005, 2006, 2007) produces, every year, the Human Development Report which focuses on people as the epicenter of development progress and gathers data on up to 177 countries regarding: social progress, economics, efficiency, equity, participation and freedom, sustainability, and human security. All data used in the current study are from the 2006 Human Development Report, which has a two-year lag, and therefore reported data are from 2004. In some cases, the data from 2004 in the 2006 Report are incomplete and the UNDP reports 2003 numbers. Unless otherwise noted, the data below are from 2004. The following are the variables used, again organized into groups of societal development: ${ }^{13}$

Employment: percent of male and female contributing family workers (people working without pay for a related person living in the same household), percent of female and male employment in industry, agriculture, or services (percent of female, male, and total employment in each sector), female and male estimated earned income (the ratio of female to male nonagricultural wage, the female and male economically active population, total female and male population, and GDP per capita - in purchasing power parity terms in US dollars), female economic activity rate (the share of the female population ages 15 and older who are available to supply labor for the production of

\footnotetext{
${ }^{12}$ See discussion explaining the World Enterprises Survey in the Sources for Independent Variables: Business Environment section.

${ }^{13}$ For more detailed information on the calculation of the indices from the Human Development Report, see the Technical Notes pdf document on the HDR website http://hdr.undp.org/en/media/ techinical_notes12.pdf or in the full Report.
} 
goods and services), female legislators, senior officials, and managers (includes the percent of total legislators, senior government officials, traditional chiefs and heads of villages, senior officials of special-interest organizations, corporate managers, directors and chief executives, production and operations department managers and other department and general managers), female professional and technical workers (includes the percent of total physical, mathematical, engineering science, life science and health, teaching, and other professionals and associate professionals)

Gender Equality: the Gender Empowerment Measure (a composite index of empowerment including female and male seats in parliament, estimated earned income, shares of legislators, senior officials, and managers, and shares of professional and technical workers), the Gender-Related Development Index (a composite index of female and male life expectancy at birth, adult literacy rate, and estimated earned income)

Education: adult literacy rate female, male, and total (percentage of people ages 15 and over who can read and write a short, simple statement), female and male education combined primary, secondary and tertiary (primary $=$ the basic elements of education at elementary schools, secondary $=$ general or specialized instruction at middle schools, secondary schools, high schools, teacher training schools, and vocational or technical schools, tertiary $=$ universities, teachers colleges and higher level professionals), combined gross enrolment ratio for primary, secondary and tertiary schools (as a percentage of the population of official school age for the three levels), Education Index (a composite index of the adult literacy rate and the combined gross enrolment ratio for primary, secondary and tertiary schools) 
Health \& Development: the Human Development Index (a composite index of life expectancy at birth, education index, GDP per capita PPP US\$), female and male life expectancy at birth (number of years a newborn infant would live).

The World Economic Forum (2008) produces an annual Gender Gap Index which measures the difference between men and women with regard to access to resources and opportunities in 128 countries -2007 data are used in the current study. By using data from the other partner institutions, the Gender Gap Index is an equality measure that comprises composite scores from the gender gap in the following areas: economic participation and opportunity, educational attainment, political empowerment, and health and survival. A perfect score of 1 indicates complete equality. The goal of this World Economic Forum is to gauge if the Gender Gap in these areas is narrowing, or decreasing, over time (Hausmann, Tyson, \& Zahidi, 2007). ${ }^{14}$

As mentioned in the previous Sources for Independent Business Environment Variables section, the World Economic Forum also produces the Global Competitiveness Index, which is built on 12 pillars, each calculated from individual items from the executive questionnaire and made into scales. The two component scores specifically related to societal development included in the present study are country competitiveness in terms of health and primary education and higher education and training.

\footnotetext{
${ }^{14}$ For more detailed information on the calculation of the Global Gender Gap Index, see Hausmann, Tyson, and Zahidi's Gender Gap Explanation pdf found on the World Economic Forum website.
} 


\section{Sources for Independent Variables: Economy}

Economic Freedom: The Heritage Foundation (2008) creates an empirical measure of economic freedom for policy makers and investors each year in 161 countries, called the Index of Economic Freedom. The Heritage Foundation defines economic freedom as the production, distribution, or consumption of goods and services without coercion or constraint from the government beyond what is necessary for citizens to protect and maintain liberty. Findings from the study indicate strongly that economic freedom is positively related to long-term economic growth, prosperity, and standard of living. The 2005 index used in this study covers data from the second half of 2004 through the first half of 2005 and is compiled using 50 independent variables divided into 10 factors: trade policy, fiscal burden of government, government intervention in the economy, monetary policy, capital flows and foreign investment, banking and finance, wages and prices, property rights, regulation, and informal market activity (Beach \& Kane, 2008).

Other Economic Indicators: Three more sources provided economic measures used in this study: The World Economic Forum, the UN, and the World Bank. The World Economic Forum's Global Competitiveness Report provides a measure of country competitiveness with regards to macroeconomic stability used in the present study as an economic indicator. This measure is one of the 12 pillars that make up the Global Competitiveness Index, as discussed earlier in the Sources for Independent Business Environment Variables section. The United Nations Human Development Programme (UNDP, 2006) provided a measure for gross domestic product - GDP per capita (PPP US\$) 2004. 
The economic indicators chosen for this study from the World Bank's World Development Indicators (World Bank, 2007e) are: bank non-performing loans (percent of total gross loans), domestic credit provided by banking sector (percent of GDP), domestic credit to private sector (percent of GDP), the final consumption expenditure, the general government final consumption expenditure, the household final consumption expenditure (all expressed in the percent of GDP), inflation of consumer prices, aid per capita, tax revenue, the official exchange rate (LCU/US\$), purchasing power parity conversion, and the highest marginal tax rate. In addition, included is a sub-grouping of economic indicators related specifically to exports and imports, and these are: arms imports, net foreign direct investment inflows (percent of GDP), imports of goods and services (percent of GDP), exports of goods and services, international tourism (percent of total exports), high-technology exports, consumer services exports including insurance, financial, computer, communications and other services, and merchandise exports including manufactures, ores and metals, food, agricultural and raw materials, and fuel.

Sources for Independent Variables: Technology and Physical Infrastructure

The World Bank World Development Indicators (World Bank, 2007e) also offer secondary use of variables related to the physical infrastructure of a country that affect a country's development in terms of functionality and transportation capabilities, including: paved roads, railways, telephone lines, and electric power. The WDI indicators also provide measures of the technological infrastructure that affect a country's level of development and domestic connection to each other and to the outside world, including: internet users and broadband subscribers, mobile phone subscribers, and personal 
computers (all per 1,000 people), percent of households with televisions, information and communication technology expenditure, and internet bandwidth per person. In addition, as mentioned in the Sources for Independent Business Environment Variables section, the Global Competitiveness Index is built on 12 pillars, each calculated from individual items from the executive questionnaire and made into scales. The two component scores relate specifically to technology and infrastructure and included in the present study are country competitiveness in relation to basic infrastructure and technological readiness.

\section{$\underline{\text { Sources for Independent Variables: Political }}$}

Freedom House (2008) conducts an annual Freedom in the World survey to provide a political freedom score for 193 countries, called the Political Freedom Index. For the purposes of the present study, the two component measures that make up the political freedom index - political rights and civil liberties - are used. The political rights questions comprise: free and fair electoral processes; political pluralism with competitive and open participation; and functioning of government with freely elected officials and little corruption. The civil liberties questions comprise: freedom of expression and belief in the media, religious institutions, educational systems, and in public; associational and organizational rights and freedom of assembly and demonstration; rule of law and functioning and just judicial, civil, and criminal legal systems; and personal autonomy and individual rights. Raw points from the 2005 dataset

are used for analysis in the current study. The highest number of points that can be 
awarded to political rights is 40 and the highest number of points that can be awarded to civil liberties is $60 .^{15}$

\section{$\underline{\text { Sources for Independent Variables: Cultural }}$}

Two sources are used for measures of culture in this study - Project GLOBE and Leung and associates Social Axioms. Both are survey research conducted around the world in an attempt to provide measures for "culture," a confounded construct. The details of each of these are provided in the following paragraphs.

Project GLOBE: The Global Leadership and Organizational Behavior Effectiveness Research Program (GLOBE) surveyed 17,000 middle managers in 62 societies in 3 industries and developed nine quantitative dimensions of culture - all questions are framed on a 1-7 scale. Project GLOBE operationally defined culture with indicators of two kinds of cultural manifestations: the first, a commonality among members of collectives on particular psychological attributes, and the second, a commonality of practices of families, schools, work organizations, economic and legal systems, and political institutions (R. J. House et al., 2004). ${ }^{16}$ In other words, the GLOBE group studied cultural "values" by asking respondents" judgments of "what should be" versus "practices" by asking about respondents to answer questions regarding "what is." Therefore, there are two sets of data for each of the nine dimensions, which are: future orientation, in-group collectivism, institutional collectivism, power distance,

\footnotetext{
${ }^{15}$ For more methodology information on the collection of data, research team input, and final ratings for each measure, see the Freedom House index at www. FreedomHouse.com.

${ }^{16}$ For complete project information and data, see House, Hanges, Javidan, Dorfman, and Gupta's (2004) book.
} 
uncertainty avoidance, gender egalitarianism, performance orientation, assertiveness, and humane-orientation - each discussed in more detail below.

The GLOBE team (Dorfman et al., 2004; R. J. House et al., 2004) also identified six global leader behaviors that constitute effective leadership, called Culturally Endorsed Implicit Leadership Theories (CLTs). The six CLTs are: charismatic/value-based leadership, team-oriented leadership, participative leadership, humane-oriented leadership, autonomous leadership, and self-protective leadership - each described in more detail following the nine cultural dimensions.

The final sample used for the current research project is 56 countries. Some important remarks are necessary about this final sample. First, there are 56 countries that provided scores for the women in political and business leadership dependent variables. Second, because the GLOBE team feels that there are meaningful cultural differences for distinct societies within some countries, there are a few countries that GLOBE broke into 2 separate societies: 1) for Germany, separate country means are provided for East and West Germany, 2) for South Africa, separate country means are provided for Black and White South Africa, 3) for Switzerland, separate country means are provided for FrenchSpeaking and Non-French-Speaking Switzerland, and finally, 4) Canada is simply representative of English-Speaking Canada. ${ }^{17}$ While this separating of the countries into culturally different societies is invaluable for increased understanding of related phenomena, unfortunately, it is not usable in the current study because of the multitude of other data sources that do not provide data on these subcultures. To deal with these 3

\footnotetext{
${ }^{17}$ For more specific information on each country's sample, see the Special Issue in the Journal of World Business (2002) Vol. 37 accessible through the GLOBE website http://www.thunderbird.edu/wwwfiles/ms/globe/ and the Chhokar, Brodbeck, and House (2007) GLOBE book.
} 
countries with separate society scores, these GLOBE societies are combined into one country mean score by using weighted samples of the GLOBE collected data where available, or by using weighted samples of total population percentages. For Germany, GLOBE sample sizes for both West and East are readily available and these are used to calculate a combined weighted country mean score (Felix C. Brodbeck \& Frese, 2007; Szabo, Brodbeck, Hartog, Reber, Weibler, \& Wunderer, 2002). For Switzerland, no sample size was reported for the French-speaking sector; however, Weibler and Wunderer (2007) reported that the German-speaking area of Switzerland accounted for nearly two-thirds of the population, so this weight is used to calculate a combined weighted country mean score for Switzerland. For South Africa, no sample size was reported for either subculture, but Booysen and Vanwyk (2007) reported population percentages for both groups, and these are used to calculate a combined weighted country mean score for South Africa.

Performance Orientation: Performance orientation (PO) reflects the degree to which a society encourages and rewards individuals for improvements, innovation, high standards, or excellence. High performance-oriented cultures tend to: appreciate training and development, focus on results, reward performance and individual achievement, appreciate competitiveness, assertiveness, and materialism, have productive attitudes, have performance appraisal systems that reward achieving results, value feedback and taking initiative, be motivated by success, and have a sense of urgency. Low performance-oriented cultures tend to: value family and relationships, focus on loyalty and belonging, respect quality of life, have performance appraisal systems that reward integrity, loyalty, and cooperation, are less motivated by money or success, value 
sympathy, respect individual people, and have a low sense of urgency (R. J. House et al., 2004; Javidan, 2004).

Javidan (2004) found a significant negative relationship between PO practice (as is) and PO values (should be). In other words, societies with weaker PO practices tend to value a PO style more, and vice versa. This may be that weaker performance-oriented societies value more feedback and rewards for success. Javidan also found that societies that are more performance-oriented in practice tend to be more politically advanced, have more flexible labor regulations, have a more economically savvy population, have regulations in place that favor a competitive business environment, and value private enterprise. Societies that show higher PO values tend to experience weak economic prosperity, be less competitive, and do not benefit from high human development. Finally, PO is positively related to charismatic/value-based, team-oriented, and humaneoriented leadership attributes and negatively related to autonomous and self-protective leadership styles. ${ }^{18}$

Future Orientation: Future orientation (FO) refers to the extent to which individuals in a society engage in planning, investing in the future, delaying gratification, and believe that their current actions will influence the future. High future orientation cultures tend to: have an affinity for recognizing future events, make goals, prioritize strategies for meeting objectives, may neglect present relationships while focusing on the future, maintain self-control in order to enrich life, achieve economic success, save for the future, be intrinsically motivated, be psychologically healthy and well-accustomed to

\footnotetext{
${ }^{18}$ For more specific details and background information on the performance-orientation dimension, see Javidan's chapter in the House et al. (2004) GLOBE book.
} 
social settings, be strategically oriented, flexible and adaptable. Low future orientation cultures tend to: enjoy the moment and be spontaneous, be free of worry and anxiety about the future, may seek hedonistic pleasures, be virtually incapable or unwilling to plan, not notice warning sign of negative outcomes, simplify life, depend on others, have lower levels of economic success, not save for the future, be psychologically weak and socially maladjusted, be less intrinsically motivated, and value instant gratification (Ashkanasy, Gupta, Mayfield, \& Trevor-Roberts, 2004; R. J. House et al., 2004).

The GLOBE team (Ashkanasy et al., 2004) found a significant negative relationship between FO practice (as is) and FO values (should be). In other words, societies with weaker FO practices tend to value a FO style more, and vice versa. This means that societies that are less future-oriented in practice actually aspire to be more cognizant of planning for the future and suffer more from the uncertainty with neglecting long-term issues. ${ }^{19}$ Findings also indicate that FO practices are positively related to economic and social well-being, scientific progress, gender equality, and fiscal savings and negatively associated with current family and friend relationships, whereas the opposite is found for most of these constructs with FO values.

Gender Egalitarianism: Hofstede's (1980; 1998; 2001) original masculinityfemininity dimension is criticized for problems with replication, for inaccurate interpretation of findings, and for confounding other more independent constructs, ${ }^{20}$ leading Project GLOBE to revise the dimension by breaking it into four separate

\footnotetext{
${ }^{19}$ For more specific details and background information on the future-orientation dimension, see Askanasy, Gupta, Mayfield, and Travor-Roberts's chapter in the House et al. (2004) GLOBE book.

${ }^{20}$ For more specific details and background information on Hofstede's original MAS measure and the GLOBE team's gender egalitarianism dimension, see Emrich, Denmark, and Den Hartog's chapter in the House et al. (2004) GLOBE book.
} 
measures - gender egalitarianism, performance orientation, assertiveness, and humane orientation. Gender egalitarianism (GE) reflects individuals' ideologies with regard to men and women. It relates to the extent to which a society either minimizes gender role differences while promoting equality, or believes that biological sex should determine individual roles in the home, work, or community. More gender-egalitarian cultures tend to: depend less on biological sex to determine role appropriateness, have more women in the labor force and in authoritative positions, bestow women a high position in society and respect their roles in decision making, have less gender segregation in the workplace, and have more literate and educated women. Less gender-egalitarian cultures tend to: discriminate on the basis gender, have fewer women in the labor force and in authoritative positions, bestow upon women a lower position in society and suppress their roles in decision making, have more gender segregation in the workplace, and have fewer literate and educated women (Emrich, Denmark, \& Den Hartog, 2004; R. J. House et al., 2004).

Analysis by Emrich, Denmark, and Den Hartog (Emrich et al., 2004) revealed a significant positive relationship between GE practices (as is) and GE value (should be), indicating perhaps that those societies that are more gender egalitarian value such practices, and those societies that are less gender egalitarian value a separation for male and female roles and do not look for a change in that structure. This research team also found that societies that scored higher on gender egalitarianism in practice and in value have the following combined characteristics: higher levels of human development, including longer life expectancy, higher economic development, higher education and literacy, experience greater general satisfaction, prefer government take a less active role 
in the private sector, and are more adaptable to change. By examining correlations between gender egalitarianism and women in leadership positions, not surprisingly, positive relationships are found for women's economic activity, purchasing power, positions in government and public office. Finally, higher GE societies are more likely to endorse charismatic/value-based, team-oriented, and participative leadership attributes and reject a self-protective leadership style.

Assertiveness: The assertiveness dimension relates to the extent to which individuals believe that people in a society should be assertive, confrontational, tough, or aggressive versus nonassertive, conciliatory, and tender in social relationships. Highly assertive cultures tend to: sympathize with the strong, value competitiveness, taking initiative, ambition, confidence, direct and explicit communication, performance, results over relationships, and are weary of opportunistic behavior. Cultures that are less assertive tend to: sympathize with the weak, value cooperation, warm relationships, facesaving actions, subtlety and indirect communication, harmony, equality and quality of life, seniority and experience, and are generally trustworthy (Deanne N. Den Hartog, 2004; R. J. House et al., 2004).

Den Hartog (2004) found a significant negative relationship between assertiveness practices (as is) and assertiveness values (should be). This means that in some countries where there is a good amount of assertive behavior in practice, a less threatening and aggressive society is desired, whereas countries with less assertive behavior in practice, value more direct and assertive behavior, although only about a third of the countries would like more assertiveness. Findings also indicate that more assertive cultures tend to excel in science and technology, respect kinships more, and are 
less egalitarian. In addition, assertiveness values and practices are found to be negatively correlated with team-oriented, participative leadership, and positively correlated with autonomous and human-oriented leadership (Deanne N. Den Hartog, 2004).

Institutional \& In-Group Collectivism: Hofstede (1980) defined individualism as the degree to which society expects ties between individuals to be loose and that individuals are only expected to care for themselves and their families. Hofstede defined collectivism as the degree to which society believes that people integrated into formidable and interconnected groups that protect and offer security throughout life. Individualistic cultures tend to: view individuals as autonomous and independent beings, value individual goals over group goals, believe that behavior is mostly determined by attitude and need and that people are rational beings, have industrial and wealthy ecological systems with a more stressful and faster pace of life, believe in the nuclear family unit, focus on love in the decision to marry and have higher divorce rates, have direct communication styles, engage in more but shorter social interaction while respecting an individual's right to be alone, and have less explicit distinctions between ingroups and out-groups. Collectivistic cultures tend to: be made up of developing countries, view individuals as interdependent within groups, value group goals over individual goals, believe that behavior is mostly determined by duties and obligations, have agricultural ecological systems, have a less stressful and slower-paced life, believe in extended family structures, disregard love in the decision to marry and have lower divorce rates, have indirect communication styles, engage in fewer but longer social interaction mostly with members of the in-group, and have well-defined distinctions between in-groups and out-groups (Gelfand, Bhawuk, Nishi, \& Bechtold, 2004). 
The GLOBE team (Gelfand et al., 2004) critically reviewed past research in the individualism-collectivism dimension and argued that past research has focused solely on values and missed any analysis of actual practice, and has applied individual-level items to the societal level. Project GLOBE attempted to reconcile these omissions by applying a multi-level approach to the individualism-collectivism construct. In other words, the extent to which an individual within a society is more individualistic or collectivistic depends on context. Therefore, GLOBE gauged Institutional Collectivism by measuring practices at the societal level and In-Group Collectivism by measuring practices within the family. Institutional collectivism assesses the extent to which society, in the form of laws, social programs, and institutions, values group loyalty over individual achievement, economic systems that underscore collective versus individual interests, and group cohesion over individualism. In-group collectivism assesses the extent to which individuals are proud of, loyal to, and dependent on the families. ${ }^{21}$

Power Distance: Power distance (PD) reflects the extent to which members acknowledge and support authority, power distinction, and status privileges of a society feel and that power should be stratified and reserved for higher levels in a hierarchy. High power distance cultures tend to: distinguish society into classes with limited upward mobility, have delineable and consistent power bases, view power positively with respect to social order, harmony, and stability, not have equal opportunity for involvement of all groups, have grown from nonnative influence and recently gained independence, have weak civil liberties and high political corruption, have low human development and lack

\footnotetext{
${ }^{21}$ For more specific details and background information on the individualism-collectivism dimension, see Gelfand, Bhawuk, Nishi, \& Bechtold's chapter in the House et al. (2004) GLOBE book.
} 
resources for all members of society, and withhold information and use technology to maintain power distances. Low power distance cultures tend to: have a large middle class with flexible social mobility and ephemeral and transferable power bases, view power negatively as corruptive, have equal opportunity for involvement of all groups, have historically strong native influence and long-standing independence, have strong civil liberties and low political corruption, have high human development and resources available for all members of society, and share information and use specialized technologies that adapt to multiple users (Carl, Gupta, \& Javidan, 2004; R. J. House et al., 2004).

Carl, Gupta, and Javidan (2004) found a significant negative correlation between PD practices (as is) and PD values (should be). Societies with higher PD practices would prefer a more equitable distribution of power, and societies with lower PD practices tend to value a more hierarchical division of power. In addition, higher power distance societies tend to value humane-oriented and self-protective leadership and find charismatic/value-based and participative leadership to be less effective. On the other hand, higher power distance society practices indicate an affinity toward team-oriented and self-protective leadership styles and hold less regard for participative leadership.

Humane Orientation: Humane orientation (HO) reflects the degree to which individuals in societies encourage and reward fairness, altruism, friendliness, generosity, caregiving, and kindness expressed both in individual treatment of others and in societal institutions. Highly humane-oriented societies tend to: be more fair, benevolent, friendly, generous, have fewer psychological and pathological problems, treat others as important and have a need for belongingness and affiliation, offer all forms of support to those in 
one's close circle and even to others in general, and promote well-being, fairness, and humane labor practices. Societies that are less humane-oriented tend to: have more psychological and pathological problems, value personal pleasure, self-enjoyment, and comfort, be motivated by money and power, not support others and promote selfprotection and self-enhancement, discriminate against those who are different, and solve personal problems individually (R. J. House et al., 2004; Kabasakal \& Bodur, 2004).

Kabasakal and Bodur (2004) found a significant negative relationship between $\mathrm{HO}$ practices (as is) and HO values (should be). In other words, societies with lower humane orientation practices would like to see more benevolence, fairness, and altruism. The more humane-oriented a society in practice, the more likely the society is going to be collectivistic and performance-oriented in an unassertive manner and value assertiveness, power distance, future orientation, and uncertainty avoidance. It is also found that $\mathrm{HO}$ practices are negatively correlated with life expectancy, human development, economic growth, and left-wing political ideology, whereas HO values are less likely to have unjust legal systems and discriminate against others. Finally, high $\mathrm{HO}$ values are associated more with participative leadership and less with self-protective leadership and the higher the HO practices in a society, the higher the likelihood of engaging in humane-oriented leadership practices. ${ }^{22}$

Uncertainty Avoidance: Uncertainty avoidance (UA) relates the degree to which members of a society are threatened by ambiguous situations and aim to evade uncertainty by relying on established social norms, rules, order, rituals, and bureaucratic

\footnotetext{
22 For more specific details and background information on the humane-orientation dimension, see Kabasakal \& Bodur's chapter in the House et al. (2004) GLOBE book.
} 
practices. Uncertainty avoidance refers to members of society being most comfortable with orderliness, consistency, structure, formalized procedures, and laws. High uncertainty avoidance cultures tend to: actively seek to decrease the probability of unpredictable future events that could have adverse affects, formalize their interactions with others, operate under contractual legal systems, keep meticulous records, verify communications in writing, establish regulations and procedures, take calculated risks, sometimes stunt innovation but maintain tight controls on implementation, resist change, prefer established rules that allow for predictability, and be intolerant of rule breaking. Low uncertainty avoidance cultures tend to: have less formal interactions with others, be more trusting, be less concerned with orderliness, rarely document and keep detailed records, function under informal norms, and have less structured policies and procedures, take less calculated risks, initiate new product development and take higher risks with less planning, be less resistant to change, show less desire for rules and regulations to govern behavior, and be more tolerant breaking rules (R. J. House et al., 2004; SullydeLuque \& Javidan, 2004).

Sully de Luque and Javidan (2004) found a significant negative relationship between the UA practice (as is) and UA values (should be). This means that societies with weaker UA practices tend to value a UA style more, and vice versa. These researchers also speculate that perhaps societies with low UA practices value more regulation and would like to have more formalized procedures in order to avoid risks and uncertainty. These researchers also examined the uncertainty avoidance dimension in relation to other variables and found that societies with higher UA practices tended to benefit from more civil liberties, are more competitive, had greater security, life 
expectancy, and general satisfaction, and engaged more in science and research. Higher UA values are related to higher team-oriented, humane-oriented, and self-protective leadership. $^{23}$

6 Globally Endorsed Culturally Implicit Leadership Dimensions: These dimensions represent skills and abilities that are culturally recognized as either contributors to effective leadership or as impediments (Dorfman et al., 2004; R. J. House et al., 2004). Charismatic/Value-based leadership refers to a leader's affinity toward inspirational, motivational, and performance-oriented leadership based on a set of strong core values and is based on the following leadership characteristics: visionary, inspirational, self-sacrificial, integrity, decisiveness, and performance-oriented. Teamoriented leadership reflects a leader's emphasis on building teams for the purpose of implementing mutually agreed upon goals and is made up of the following characteristics: collaborative team orientation, team integration, diplomacy, benevolence, and administrative competence. Participative leadership indicates the extent to which leaders include others in decision making and implementation and is comprised of democratic and participative leader characteristics. Humane-oriented leadership emphasizes leadership that is considerate, compassionate, generous, modest, and supportive. Autonomous leadership reflects independence from superiors and individualistic leadership with a tendency to work alone and keep social distance from subordinates. And finally, self-protective leadership represents a leader's attention to guaranteeing safety and security for himself or herself or for a fellow group member and

\footnotetext{
${ }^{23}$ For more specific details of the uncertainty avoidance dimension, see Sully de Luque and Javidan's chapter in the House et al. (2004) GLOBE book.
} 
is made up of the following subscales: self-centered, status-conscious, conflict inducer, face saver, and procedural (Dorfman et al., 2004).

Social Axioms: Leung et al. (K. Leung \& Bond, 2004; K. Leung et al., 2002) define social axioms as general beliefs at a higher level that are likely to relate to social behaviors in a variety of contexts. Social Axioms are "general beliefs [that] are pitched at a high level of abstraction and hence are likely to relate to social behaviors across a variety of contexts, actors, targets, and time periods (K. Leung et al., 2002, p. 288).” These are the generalized expectancies people hold that guide behavior within a particular culture. Social Axioms represent "a pan-cultural structure of broad, contextfree beliefs ... [and apply] this structure to a wide range of social behavior (K. Leung \& Bond, 2004, p.127).” These include: fate control, religion, rewards for effort, social complexities, and cynicism (K. Leung \& Bond, 2004). Used for analysis in the current study, Leung and Bond (K. Leung \& Bond, 2004) ${ }^{24}$ conducted an around-the-world study of college students and adults in over 40 cultures to collect countries to derive a "citizen axiom profile" scores for each country based. The following are descriptions of Leung et al.'s five social axiom factors.

Social Cynicism represents a pessimistic image of human nature, a prejudiced opinion or stereotypes of people from other groups, a suspicion of social institutions, and a lack of attention to ethics. Cynicism relates to the negative effects of power or hierarchy associated with wealth and age and leads people to become self-involved and unconcerned with others' well-being. Cynical people tend to feel that charity and

\footnotetext{
${ }^{24}$ The Leung et al. (2002) journal article covers the development and testing of the social axioms instrument and the subsequent 5 -factor structure. Complete data and methodology for each of the 5 dimensions with means for all countries surveyed can be found in Leung \& Bond's (2004) book chapter.
} 
goodwill are useless actions based on a view that the social world is uncaring and apathetic. This axiom is significantly and negatively related to affluence (measure by GDP per capita), life satisfaction, satisfaction toward one's company, hedonic balance, conscientiousness, achievement via conformity, charismatic/values-based leadership, team-oriented leadership, and church attendance, and is positively related to in-group disagreement and a business/transaction-oriented pace of life (K. Leung \& Bond, 2004).

Social complexity relates to the idea that human behavior is often complex and inconsistent and therefore there are numerous methods to achieve any outcome and few standards exist. Predictability of outcomes is difficult and people deal with circumstances and situations as they come because the underlying logic for certain events can seem opaque. Social complexity has a significant positive relationship with affluence and economic growth, percent of GDP spent on health, voter participation and interest in politics. However, Leung and Bond (2004) argue that the interpretation they offer for these correlations is speculative and tentative and more analysis is needed.

Reward for application represents a general expectancy that hard work, experience, and a sensible strategy will lead to positive outcomes. This dimension somewhat resembles locus of control (Rotter, 1966) and self-efficacy (Bandura, 1977), but the questions in the survey did not ask respondents about their own internality or their belief in their own personal ability. Alternatively, Social Axioms Survey items asked respondents about their impression of the relationship between human action, in general, and resultant outcomes. Reward for application has been found to be significantly and negatively related to GDP per capita, life expectancy at birth, health expenditures, human development, human rights, political freedom, gender equality, alcohol consumption, and 
tolerance for divorce. Reward for application is positively related to population growth, working hours per week, agreeableness, an affinity toward superiors, humane leadership, scientific advances for the betterment of humankind, and comparing performance to that of others. Leung and Bond (2004) speculate that these associations may indicate that difficult socioeconomic conditions are related to an intense belief in reward for application as a strategy to cope with hardships, and that hard work and determination leave little attention paid to more frivolous activities.

Religiosity refers to the presence of mystical or spiritual forces and religious belief. This dimension relates to a belief that religion helps with understanding the meaning of life, and leads to good mental health, good citizenship, and an adherence to moral standards, while religion also contributes to unscientific thinking and an escape from reality. Religiosity is negatively related to affluence, life expectancy, urbanism, health expenditures, environmental sustainability, human development, human rights, political freedom, gender equality, alcohol consumption, and pace of life. Religiosity is positively related to population growth, working hours per week, positive and negative affect, hedonic balance, agreeableness, humane-oriented leadership, scientific advancement, and church attendance and prayer. Leung and Bond (2004) interpret these correlations in a way that religiosity is related to a life with socioeconomic hardships and under such conditions individuals tend to find relief in religious action, while at the same time value humane leadership, are more agreeable by nature, experience more affect, at a slower pace of life.

Fate control, similar to but broader than locus of control, represents a belief that circumstances in life are both predetermined and predictable and people can in some way 
control outcomes. People high in fate control (external locus of control) tend to take less action in the control of life events and tend to be more passive. High fate control was found to be related to less affluence, lower life expectancy, lower urbanism, lower health expenditures, less environmental sustainability, lower human development, less human rights, less gender equality, lower voter participation, less job and company satisfaction, introversion, lower work ethic, less charismatic/value-based leadership, less humanoriented leadership, and less team-oriented leadership. Lower fate control is related to a lower heart disease death rate, a lower suicide rate, and a more hedonic balance.

\section{Cluster Analysis to Develop Dependent Variables}

Cluster analysis is used for this study to categorize a large number of countries into smaller groups so that the countries within each cluster would be significantly homogenous and distinct groupings based on women's participation in political and business leadership (Lattin, Carroll, \& Green, 2003a). Cluster analysis takes a largely heuristic approach based on algorithms that are reasonably close to the best possible solution of naturally occurring, homogenous subsets of countries. Since the goal of this study is to divide the countries into four non-overlapping groups or clusters according to the global levels of women's participation in leadership, with countries in each group being similar and counties between groups dissimilar, the method used is $K$-means Cluster Analysis.

$K$-means clustering allows for finding within group similarities and between group differences based on the predetermined number of clusters instructed by the 
researcher. ${ }^{25}$ Euclidean distance, which calculates the distances between each pair of countries, is used with $K$-means cluster analysis to compute distances by essentially assigning equal weight to each standardized variable for determining the relative closeness of the countries in each cluster (Lattin et al., 2003a). Ultimately, cluster analysis in this case sorts countries into clusters so that the degree of association is strong between member countries of the same cluster and weak between member countries of different clusters (Wishart, 1998). Based on the number of clusters chosen by the researcher, $K$-means cluster analysis then specifies seed points that act as cluster centroids. Each country is then cycled through the clustering process of analyzing the Euclidean distance to determine placement into the cluster with which each country has the closest seed point. This partitioning process continues until each country is correctly classified to a cluster with its best possible distance from the centroid (Arnott, 2003; Sclove, 2001). This method has been called "ANOVA in reverse" because the program tries to move countries in and out of clusters, with cluster means that are the most different from each other, until final clusters centers are determined based on the best the analysis (StatSoft, 2008).

Because political leadership and business leadership are distinct phenomena, stemming from both public and private sectors, these two constructs are analyzed as separate dependent variables. Therefore, cluster analysis was used to provide two final dependent variables - one for women in business leadership and one for women in political leadership. Each type of leadership is discussed here. As discussed earlier in the

\footnotetext{
${ }^{25}$ In order to avoid issues with case ordering, an option to use running means to recalculate cluster centers in the clustering process was not used. Therefore the ordering of countries in the dataset was not an issue.
} 
description of secondary data used, for women in political leadership, two variables are entered into a $K$-means cluster analysis: Proportion of seats held by women in parliament WDI and Proportion of seats in parliament held by women UNDP. Table 4 shows the final cluster centers in sequential order and the number of countries in each cluster. The final 4-cluster variable is called K-Means Cluster Political Leadership with a final sample size of 181 countries $(\mathrm{N}=181)$.

Table 4: $K$-Means Cluster Analysis Women in Political Leadership

\begin{tabular}{|lr|c|c|c|c|}
\hline \multirow{2}{*}{$\begin{array}{l}\text { Ownership Variable Clusters } \\
\text { Proportion of seats held by women in parliament WDI }\end{array}$} & \multicolumn{3}{|c|}{ Cluster: } & \multicolumn{3}{|c|}{2} \\
\cline { 2 - 6 } & Center: & 0.059 & 0.126 & 0.217 & 0.353 \\
\hline Proportion of seats in parliament held by women UNDP & Center: & 0.072 & 0.153 & 0.244 & 0.362 \\
\hline Total N = 181 & $\mathrm{N}:$ & 69 & 60 & 36 & 16 \\
\hline
\end{tabular}

For the women in business leadership cluster variable, two $K$-means cluster analyses are conducted on three continuous dependent variables: Proportion of Firms with Female Employers \& Own Account Workers (OECD 2004, 29 developed countries), Proportion of Firms With Females in Ownership Developing Countries (World Bank Enterprises Survey 2002-2007, 76 developing countries), and Proportion of Women in Senior Positions Developing Countries World Bank Enterprises Survey 2002-2007, 66 developing countries).

Because of missing data dispersed differently among these three variables, it was not possible to run a cluster analysis on the three variables together. Therefore, the first cluster analysis was conducted on the two women in ownership variables - the developed countries and the developing countries. The second cluster analysis was conducted on the two developing country variables - women in ownership and women in senior positions. Table 5 shows the raw data variables with proportions and the final Women in Business Leadership 4-cluster variable. 
Table 5: $K$-Means Cluster Analysis Women in Business Leadership

\begin{tabular}{|c|c|c|c|c|c|}
\hline Ownership Variable Clusters & Cluster: & 1 & 2 & 3 & 4 \\
\hline Firms with Female Employers \& Own Account Workers Developed & Center: & 0.145 & 0.244 & 0.344 & 0.418 \\
\hline Firms With Females in Ownership Developing & Center: & 0.099 & 0.278 & 0.228 & 0.353 \\
\hline Total $\mathrm{N}=95$ & $\mathrm{~N}:$ & 14 & 35 & 22 & 23 \\
\hline Developing Country Variable Clusters & Cluster: & 1 & 2 & 3 & 4 \\
\hline Firms With Females in Ownership Developing & Center: & 0.100 & 0.275 & 0.430 & 0.440 \\
\hline Women in Senior Positions Developing & Center: & 0.031 & 0.107 & 0.189 & 0.048 \\
\hline Total $\mathrm{N}=97$ & $\mathrm{~N}:$ & 37 & 26 & 18 & 16 \\
\hline
\end{tabular}

From these two new $K$-means 4 -cluster variables, a new single 4-cluster Women in Business Leadership variable was created. This was done by combining these two variables into one by relying on close securitization of the variables through expert rational evaluation of each country's relation to its cluster center. The final sample size of the Women in Business Leadership Clusters was $115(\mathrm{~N}=115)$. A couple of decision rules are devised to deal with a small number of discrepancies in matching the two $K$ means cluster variables into one.

Decision Rule One: Toward Centrality - Where there are discrepancies, the decision rule was "toward centrality," a more conservative approach. "Toward centrality" means that the distances from each cluster centroid of the two cluster variables are examined and the conservative approach of choosing the cluster for the variable whose "distance from center" was closer to its cluster centroid was used. For example, Croatia fell into cluster 2 for the ownership cluster variable (distance from centroid = .4432) and into cluster 1 for the developing country variable (distance from centroid = 4059). Since the latter distance is shorter, this country was assigned to cluster 2 of the final combined Women in Business Leadership Clusters variable. This decision rule was only required for a handful of countries (Tanzania, Slovak Republic, Poland, Ireland, 
Germany, Gambia, Ethiopia, and Croatia) as the majority of cluster numbers between the two $K$-means 4-cluster variables matched nicely.

Decision Rule Two: Because the proportions of women in senior positions are so much lower than women in ownership, in cases where only women in senior positions are reported for a country, and no ownership data are available, these countries are clustered in group 1 of the final Women in Business Leadership Clusters. (This decision rule is applied specifically only to the Philippines, Oman, and Cambodia.).

Appendix 2 provides a large table that shows, for every country in the data set, the two K-Means cluster variables, the distances from the centroid, the raw data variables with proportions, the final K-Means Cluster Political Leadership variable and the final Women in Business Leadership Clusters variable based on matching cluster assignments and the two decision rules. This table also provides GDP for every country and the Gender Gap Index for comparison purpose to aid in understanding individual country characteristics. Figures 2 and 3 are scatterplot graphic depictions of the countries for both women in business leadership and women in political leadership with lines to show cluster centers. The frequencies for each of the clusters are as follows:

\section{Political Leadership Business Leadership}

$\begin{array}{lll}\text { Cluster } 1 \text { Minimal }= & 69 & 38 \\ \text { Cluster } 2 \text { Moderate }= & 60 & 32 \\ \text { Cluster } 3 \text { Substantial }= & 36 & 22 \\ \text { Cluster } 4 \text { Pronounced }= & 16 & 23\end{array}$

The first test (Hypothesis 1) is thus concerned with whether these clusters are significantly different from one another. This test is necessary to determine whether there truly are distinct levels of women's participation in business leadership and political 
leadership. Furthermore, the significant distance of these clusters from one another is necessary to determine if clusters of countries can be used as the dependent variable to test all other hypotheses. 
Figure 2 - Scatterplot of Country Levels of Women in Business Leadership

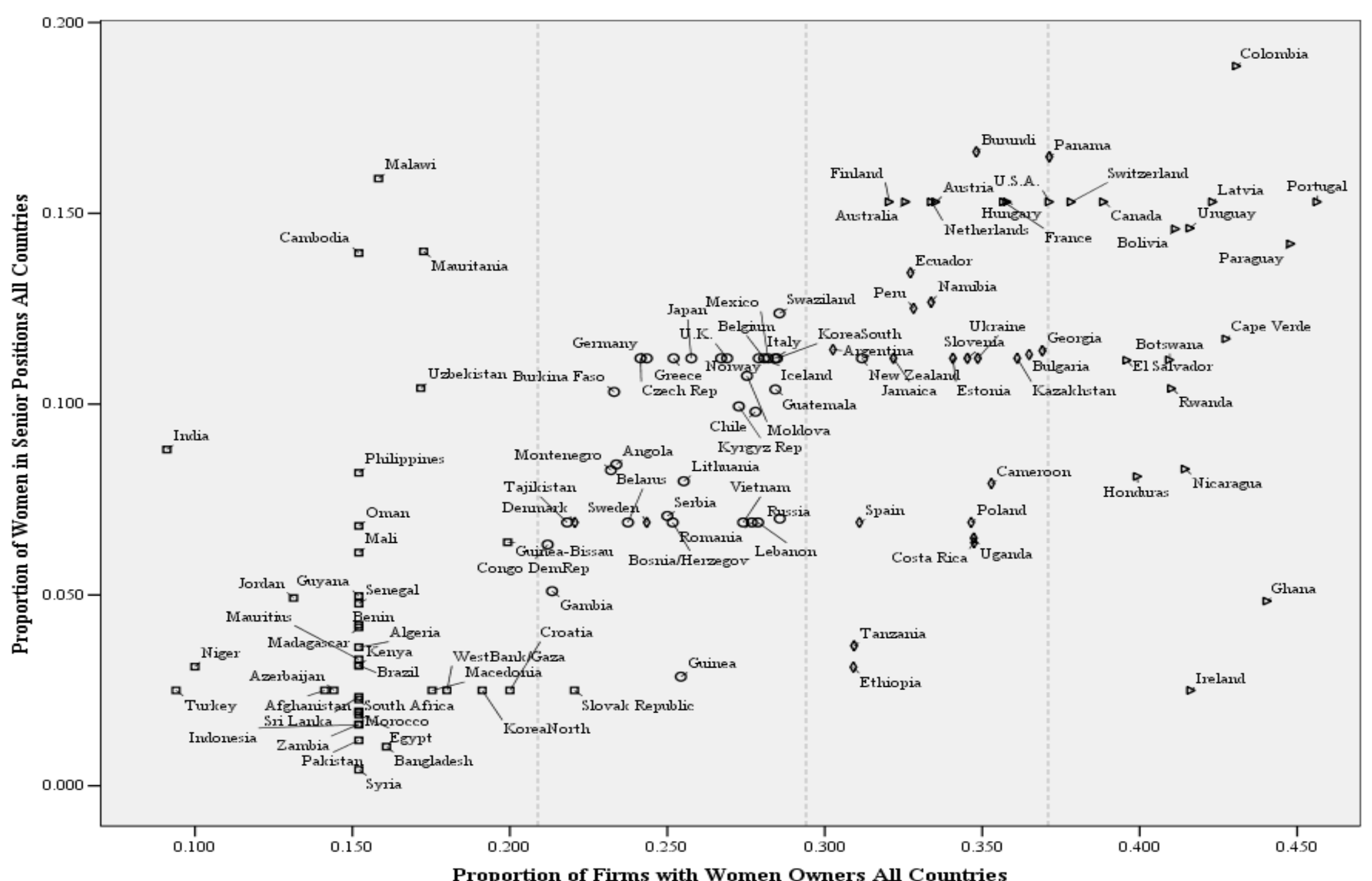

Proportion of Firms with Women Owners All Countries 
Figure 3 - Scatterplot of Country Levels of Women in Political Leadership

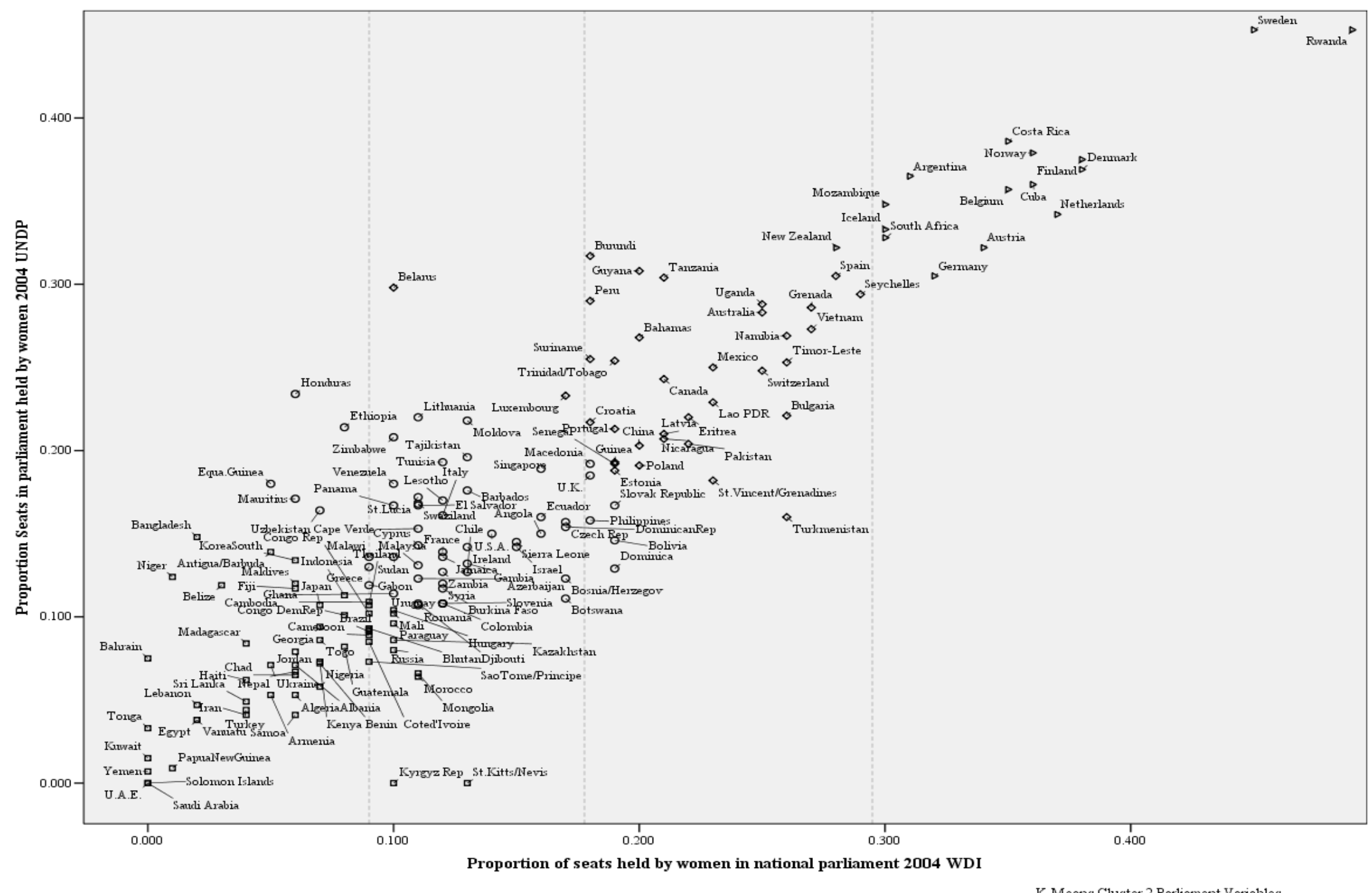

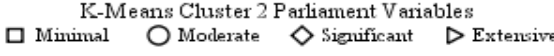




\section{CHAPTER 4: ANALYSIS AND RESULTS}

Initial categorization of the women in leadership variables into clusters of countries has been completed. This chapter begins with the test of hypothesis 1 that these 4 clusters are significantly different from one another. Discriminant analysis will be used to test hypotheses 2-7. Discriminant analysis will: 1) discern what variables affect women's participation in leadership, 2) negatively or positively, 3) at each stage, and 4) how many country cases are able to be classified correctly into the defined cluster levels of women's participation in both business and political leadership. Findings are expected to show that, depending on the level of participation of women in leadership, 1) certain factors affect countries in one level differently than they affect countries in a different level, 2) that some factors will affect countries in one level and have no significant affect on other levels at all, and 3) that some factors are important for countries in all 4 levels. For example, whereas one variable may have a positive effect on countries in level 1 , that same variable may not be a significant factor at all for countries in level 4. Because of this expectation, discriminant analysis is used to determine which factors are able to distinguish between each set of 2 levels separately - levels 1 and 2, levels 2 and 3, and levels 3 and 4 - and among all levels 1 through 4 together. In addition, it will be clear which factors are most important at each stage. 


\section{MANOVA Test for Hypothesis 1}

The test for Hypothesis 1, which stated that countries can be categorized into significantly different clusters based on women's participation in business and political leadership, is conducted with a multivariate ANOVA. MANOVA is used to test for significance differences between the proposed levels. Results indicate that indeed countries can be categorized into clusters with strong within group membership and weak between group association. The MANOVA Table 6 shows the analysis of clusters for the K-Means Cluster Political Leadership cluster variable, the error, and the corrected total (Proportion of seats held by women in parliament WDI, F = 306.39, p<.001) (Proportion of seats in parliament held by women UNDP, $\mathrm{F}=319.64, \mathrm{p}<.001$ ). The MANOVA Table 7 shows the analysis of K-Means Cluster Firms With Women Owners Developed and Developing cluster variable, the error, and the corrected total (Firms with Female Employers \& Own Account Workers Developed, F = 10.39, p <.01) (Firms With Females in Ownership Developing, $\mathrm{F}=14.34, \mathrm{p}<.01$ ). The MANOVA Table 7 also shows the analysis of K-Means Cluster Firms with Women Owners and Senior Positions Developing cluster variable, the error, and the corrected total (Firms With Females in Ownership Developing, $\mathrm{F}=166.93, \mathrm{p}<.01$ ) (Firms with Women in Senior Positions Developing, $F=2.96, \mathrm{p}<.05)$. Both Tukey's and Sheffe post hoc tests indicate all 4 clusters for both the women in political leadership and the women in business leadership cluster dependent variables are significantly different from each other $(p<.001)$, confirming the cluster analysis that partitioned the countries into groups with insignificant within-group differences but distinct between-group properties. 
Table 6: MANOVA Test Distinct Clusters - Political Leadership

\begin{tabular}{|c|c|c|c|c|c|c|}
\hline Source & Dependent Variable & $\begin{array}{c}\text { Type III Sum } \\
\text { of Squares }\end{array}$ & df & \begin{tabular}{|l|} 
Mean \\
Square
\end{tabular} & $\mathrm{F}$ & Sig. \\
\hline \multirow{2}{*}{$\begin{array}{l}K \text {-Means Cluster } \\
\text { Political Leadership }\end{array}$} & Proportion of seats held by women in parliament WDI & 1.322 & 3 & 0.441 & 306.39 & 0.000 \\
\hline & Proportion of seats in parliament held by women UNDP & 1.358 & 3 & 0.453 & 319.64 & 0.000 \\
\hline \multirow{2}{*}{ Error } & Proportion of seats held by women in parliament WDI & 0.233 & 162 & 0.001 & & \\
\hline & Proportion of seats in parliament held by women UNDP & 0.229 & 162 & 0.001 & & \\
\hline \multirow{2}{*}{ Corrected Total } & Proportion of seats held by women in parliament WDI & 1.555 & 165 & & & \\
\hline & Proportion of seats in parliament held by women UNDP & 1.588 & 165 & & & \\
\hline
\end{tabular}

Table 7: MANOVA Test Distinct Clusters - Business Leadership

\begin{tabular}{|c|c|c|c|c|c|c|}
\hline Source & Dependent Variable & $\begin{array}{c}\text { Type III Sum } \\
\text { of Squares }\end{array}$ & $\mathrm{df}$ & $\begin{array}{l}\text { Mean } \\
\text { Square }\end{array}$ & $\mathrm{F}$ & Sig. \\
\hline \multirow{2}{*}{$\begin{array}{c}K \text {-Mean Cluster Firms } \\
\text { With Women Owners } \\
\text { Developed \& } \\
\text { Developing }\end{array}$} & $\begin{array}{l}\text { Firms with Female Employers \& Own Account } \\
\text { Workers Developed }\end{array}$ & 0.057 & 3 & 0.019 & 10.39 & 0.006 \\
\hline & Firms with Females in Ownership Developing & 0.128 & 3 & 0.043 & 14.34 & 0.002 \\
\hline \multirow{2}{*}{ Error } & $\begin{array}{l}\text { Firms with Female Employers \& Own Account } \\
\text { Workers Developed }\end{array}$ & 0.013 & 7 & 0.002 & & \\
\hline & Firms with Females in Ownership Developing & 0.021 & 7 & 0.003 & & \\
\hline \multirow{2}{*}{ Corrected Total } & $\begin{array}{l}\text { Firms with Female Employers \& Own Account } \\
\text { Workers Developed }\end{array}$ & 0.070 & 10 & & & \\
\hline & Firms with Females in Ownership Developing & 0.149 & 10 & & & \\
\hline \multirow{2}{*}{$\begin{array}{c}K \text {-Means Cluster Firms } \\
\text { with Women Owners } \\
\text { and Senior Positions } \\
\text { Developing } \\
\end{array}$} & Firms with Females in Ownership Developing & 0.378 & 3 & 0.126 & 166.93 & 0.000 \\
\hline & Firms with Women in Senior Positions Developing & 0.013 & 3 & 0.004 & 2.96 & 0.044 \\
\hline \multirow{2}{*}{ Error } & Firms with Females in Ownership Developing & 0.031 & 41 & 0.001 & & \\
\hline & Firms with Women in Senior Positions Developing & 0.061 & 41 & 0.001 & & \\
\hline \multirow{2}{*}{ Corrected Total } & Firms with Females in Ownership Developing & 0.409 & 44 & & & \\
\hline & Firms with Women in Senior Positions Developing & 0.074 & 44 & & & \\
\hline
\end{tabular}




\section{Discriminant Analysis Tests for Hypotheses 2-7}

Discriminant analysis works with categorical dependent variables and therefore is used for this study for the purposes of determining which independent variables would be able to distinguish between the 4-cluster variables representing the levels of women's participation in business and political leadership. The objective is to apply the independent variables in order to achieve the most accurate discrimination between groups. In other words, the intention is to exploit the independent variables (business environment, societal development, economics, infrastructure and technology, political freedom, and culture) for as much of the variation in the women's participation in leadership dependent variable as possible, similar to multiple regression (Lattin, Carroll, \& Green, 2003b). The objectives of discriminant analysis are to: 1) show the DV groups with respect to the IV's, 2) determine if the differences across groups are significant, and 3) predict DV group membership with a set of IVs based on the discriminant function scores. Essentially, DA can be used to either predict group membership by classifying countries into groups on the basis of some or a few measures, or DA can be used to distinguish the 4 levels of women's participation in leadership based on a linear combination of measures (Green \& Salkind, 2005); this study attempts the latter.

Since this analysis works with two dependent 4-cluster categorical variables with countries classified into groups according the level of women's participation in business and political leadership, discriminant analysis is used here for the purposes of describing differences among these groups based on the independent variables (Mertler \& Vannatta, 2002) - to uncover a description of countries in the 4 different levels of women's 
participation in leadership based on the business environment, economics, societal development, infrastructure and technology, political freedom, and culture. Women's participation in business leadership is significantly correlated with women's participation in political leadership, (K-Means Cluster Political Leadership and Women in Business Leadership Clusters, $r=.346, \mathrm{p}<.01$ ), however only about $10 \%$ of the variance is explained. Therefore, due to the substantial amount of variance these constructs do not share, hypotheses 2 through 7 are tested for both business and political leadership separately.

Because this analysis employed a step-wise method, the most discriminating variable is entered in steps. Those variables that do not add any unique explanatory contribution do not make it into the model. Therefore, multicolinearity is not a problem because only the variables that add unique distinguishing power to predicting membership in the levels of women's participation in leadership are used, while others are excluded. 


\section{$\underline{\text { Women in Business Leadership: Discriminant Analysis Results }}$}

In this section, results are presented for the women in business leadership dependent cluster variable only - women in political leadership are discussed separately in the next section. This section proceeds from here with an ordering of the results by hypothesis. A discriminant analysis was run on the business leadership dependent variable separately for each category of variables in each hypothesis: the business environment (H2), societal development (H3), economics (H4), technology and infrastructure (H5), political freedom (H6), and culture (H7). Four analyses are run for each hypothesis section to uncover the variables that could discriminate among women in business leadership from: levels 1 and 2, levels 2 and 3, levels 3 and 4, and finally overall from levels 1 through 4 to reveal the factors that can distinguish among countries with low and high levels of participation of women in business leadership. Tables 8-12 show the discriminant analysis results for all hypotheses and sub-hypotheses for $\mathrm{H} 2$ through $\mathrm{H} 7$ for all combinations of levels - 1 and 2, 2 and 3,3 and 4, and all levels 1 through 4.

Reported in this section are Lambda $(\lambda)$, sample size $(N)$, significance (p-value), and the percent of the countries correctly classified in the cross-validated analysis. When interpreting the significance of the percent correctly classified, it is important to note that when examining discriminating ability between two levels ( 1 and 2, 2 and 3, 3 and 4), by chance alone $50 \%$ of the countries can be correctly classified, and when distinguishing among all levels 1 through 4 , by chance alone $25 \%$ of the countries can be correctly classified. Therefore, the higher the percent of the correctly classified countries beyond these two benchmarks, the more impact that variable has. Finally, to determine direction 
only, a Pearson's correlation is reported for each significant function variable found in the discriminant analysis (the significance of the correlation is not considered as important as the significant discriminant analysis results.) Appendix 3 shows the correlations with both women in business leadership and political leadership dependent cluster variables.

Hypothesis 2: The Business Environment

Hypothesis 2 stated that business institutional variables can distinguish among qualitatively different levels of women's participation in positions of leadership. To test this hypothesis, a stepwise discriminant analysis was run on 11 sub-categories of the business environment to determine which of the variables in each of these categories can distinguish between levels 1 and 2, 2 and 3, 3 and 4, and among all levels 1 through 4 of women in business leadership. Correlations are provided to show the positive or negative relationship between each significant dependent and independent variable. Table 8 shows the results of these analyses.

Hypothesis 2 a stated that business facilitating institutional forces are positively related to the levels of women's participation in positions of leadership. Hypothesis $2 b$ stated that business inhibiting institutional forces are negatively related to the levels of women's participation in positions of leadership. As can be seen in the following review of the results, both hypotheses $2 \mathrm{a}$ and $2 \mathrm{~b}$ are supported.

Gift Giving: As can be seen in Table 8, giving gifts to bureaucratic officials to facilitate business is able to distinguish between levels 2 and 3 only. A significant function was generated $(\lambda=.87, \quad \mathrm{~N}=40, \quad \mathrm{p}<.05) \quad$ indicating that 
PayingInformalPaymentToGetThingsDone is able to accurately classify $63 \%$ of the countries in the cross-validated analysis, with a negative association $(r=-.35)$. Making informal payments to bureaucratic officials is negatively related to women's participation in business leadership.

Crime and Corruption: As can be seen in Table 8, no costs associated with crime and corruption are able to distinguish between levels 1 and 2,2 and 3,3 and 4, or among all levels 1 through 4 and are not related to women's participation in business leadership.

Skill Level of Workers: As can be seen in Table 8, worker skills are able to distinguish between all levels of women's participation in business leadership. In distinguishing between levels 1 and 2, a significant function was generated $(\lambda=.58, \mathrm{~N}=36$, $\mathrm{p}<.01) \quad$ indicating that LaborSkillLevelAsAMajorConstraint, AverageNumberofTemporaryWorkers, and FirmsOfferingFormalTraining are able to accurately classify $68 \%$ of the countries in the cross-validated analysis. LaborSkillLevelAsAMajorConstraint and AverageNumberofTemporary Workers are both negatively associated $(r=-.31$ and $r=-.25$ respectively $)$ and FirmsOfferingFormalTraining is positively associated $(r=.18)$ with women in business leadership. In distinguishing between levels 2 and 3, a significant function was generated $(\lambda=.79, \mathrm{~N}=21, \mathrm{p}<.05)$ indicating that AverageNumberofTemporaryWorkers is able to accurately classify $64 \%$ of the countries in the cross-validated analysis, with a positive association $(r=.04)$. In distinguishing between levels 3 and 4 , a significant function was generated $\quad(\lambda=.88, \quad \mathrm{~N}=32, \quad \mathrm{p}<.05) \quad$ indicating $\quad$ that AverageNumberofUnskilledProductionWorkers is able to accurately classify $66 \%$ of the countries in the cross-validated analysis, with a negative association $(r=-.25)$. In 
distinguishing among all levels 1 through 4 , a significant function was generated $(\lambda=.78$, $\mathrm{N}=56, \mathrm{p}<.01$ ) indicating that YearsofExperienceoftheTopManagerWorking is able to accurately classify $40 \%$ of the countries in the cross-validated analysis, with a positive association $(r=.50)$.

Women's participation in business leadership is positively related to firms offering formal training and to the experience level of top managers but negatively related to firms thinking that labor skills are a major constraint. Mixed results are found for the relationship to temporary workers.

International trade: As can be seen in Table 8, obstacles to international trade are able to distinguish between all levels of women's participation in business leadership, except between levels 2 and 3. In distinguishing between levels 1 and 2, a significant function was generated $(\lambda=.89, \quad \mathrm{~N}=59, \quad \mathrm{p}<.01) \quad$ indicating that CustomsTradeRegsAsAMajorConstraint is able to accurately classify $66 \%$ of the countries in the cross-validated analysis, with a negative association $(r=-.25)$. In distinguishing between levels 3 and 4 , a significant function was generated $(\lambda=.89, N=33$, $\mathrm{p}<.10)$ indicating that CustomsTradeRegsAsAMajorConstraint again is able to accurately classify $66 \%$ of the countries in the cross-validated analysis, with a negative association $(r=-.29)$. In distinguishing among all levels 1 through 4 , a significant function was generated $(\lambda=.82, \mathrm{~N}=92, \mathrm{p}<.01)$ indicating that CustomsTradeRegsAsAMajorConstraint again is able to accurately classify $40 \%$ of the countries in the cross-validated analysis, with a negative association $(r=-.46)$. Women's participation in business leadership is negatively related to firms feeling that customs and trade regulations are a major constraint. 
Bureaucratic Procedures for Licenses and Permits: As can be seen in Table 8, bureaucratic procedures for licenses and permits are not able to distinguish between levels 1 and 2, 2 and 3, 3 and 4, or among all levels 1 through 4. Women's participation in business leadership is not related to bureaucratic procedures for licenses and permits.

Bureaucratic Procedures for Enforcing Contracts: As can be seen in Table 8, cumbersome bureaucratic procedures for enforcing contracts are able to distinguish between all levels of women's participation in business leadership, except between levels 2 and 3. In distinguishing between levels 1 and 2, a significant function was generated $(\lambda=.76, \mathrm{~N}=58, \mathrm{p}<.01)$ indicating that EnforcingContractsProcedures is able to accurately classify $73 \%$ of the countries in the cross-validated analysis, with a negative association $(r=-.46)$. In distinguishing between levels 3 and 4, a significant function was generated $(\lambda=.81, \mathrm{~N}=44, \mathrm{p}<.01)$ indicating that EnforcingContractsProcedures again is able to accurately classify $64 \%$ of the countries in the cross-validated analysis, with a negative association $(r=-.42)$. In distinguishing among all levels 1 through 4 , a significant function was generated $(\lambda=.70, \quad \mathrm{~N}=102, \quad \mathrm{p}<.001) \quad$ indicating that EnforcingContractsProcedures again is able to accurately classify $38 \%$ of the countries in the cross-validated analysis, with a negative association $(r=-.62)$. Cumbersome procedures to enforce contracts are negatively related to women's participation in business leadership.

Arduous Tax Systems: As can be seen in Table 8, arduous tax systems are able to distinguish between all levels of women's participation in business leadership, except among all levels 1 through 4 . In distinguishing between levels 1 and 2 , a significant function was generated $(\lambda=.92, \quad \mathrm{~N}=55, \quad \mathrm{p}<.05) \quad$ indicating that 
TypicalFirmReportsLessThanTotalSales is able to accurately classify $58 \%$ of the countries in the cross-validated analysis, with a positive association $(r=.23)$. In distinguishing between levels 2 and 3 , a significant function was generated $(\lambda=.88, \mathrm{~N}=42$, $\mathrm{p}<.05)$ indicating that TypicalFirmReportsLessThanTotalSales is able to accurately classify $67 \%$ of the countries in the cross-validated analysis, with a negative association $(r=-.35)$. In distinguishing between levels 3 and 4 , a significant function was generated $(\lambda=.89, \mathrm{~N}=34, \mathrm{p}=.05)$ indicating that TaxAdministrationAsAMajorConstraint is able to accurately classify $63 \%$ of the countries in the cross-validated analysis, with a negative association $(r=-.28)$. Women's participation in business leadership is positively related to firms reporting less that $100 \%$ of their sales in levels 1 and 2 , but negatively related to firms reporting less that $100 \%$ of their sales in the higher levels.

Bureaucratic Procedures for Starting a Business: As can be seen in Table 8, cumbersome bureaucratic procedures for starting a business are not able to distinguish between levels 1 and 2,2 and 3, 3 and 4, or among all levels 1 through 4. Women's participation in business leadership is not related to bureaucratic procedures for starting a business.

Tools to Finance a Business: As can be seen in Table 8, access to tools to finance a business is not able to distinguish between levels 1 and 2,2 and 3, 3 and 4, or among all levels 1 through 4 and is not related to women's participation in business leadership.

Global Business Competitiveness: As can be seen in Table 8, global business competitiveness is able to distinguish between all levels of women's participation in business leadership, except between levels 2 and 3. In distinguishing between levels 1 and 2, a significant function was generated $(\lambda=.86, N=58, \mathrm{p}<.01)$ indicating that 
GlobalCompetitivenessLaborMarketEfficiency is able to accurately classify $60 \%$ of the countries in the cross-validated analysis, with a positive association $(r=.37)$. In distinguishing between levels 3 and 4 , a significant function was generated $(\lambda=.87, \mathrm{~N}=42$, $\mathrm{p}<.05)$ indicating that GlobalCompetitivenessFinancialMarketEfficiency is able to accurately classify $64 \%$ of the countries in the cross-validated analysis, with a positive association $(r=.36)$. In distinguishing among all levels 1 through 4 , a significant function was generated $(\lambda=.85, \quad \mathrm{~N}=100, \quad \mathrm{p}<.01) \quad$ indicating that GlobalCompetitivenessIndex is able to accurately classify $32 \%$ of the countries in the cross-validated analysis, with a positive association $(r=.50)$. Global competitiveness overall, and global competitiveness of both labor market and financial market efficiencies in particular, are positively related to women's participation in business leadership.

Strong Entrepreneurial Environment: As can be seen in Table 8, a strong entrepreneurial environment is able to distinguish between all levels of women's participation in business leadership, except between levels 2 and 3. In distinguishing between levels 1 and 2, a significant function was generated $(\lambda=.29, \mathrm{~N}=12, \mathrm{p}<.05)$ indicating that StrongIntellectualPropertyRights, GoodMarketOpportunityandControls, and Accessible AffordableBusinessServicesSuppliers are able to accurately classify 67\% of the countries in the cross-validated analysis, all with a positive association $(r=.54, r=$ .52 , and $r=.52$ respectively). In distinguishing between levels 3 and 4 , a significant function was generated $(\lambda=.21, \quad \mathrm{~N}=14, \quad \mathrm{p}<.01) \quad$ indicating that PositiveImpressionOfGovtSupportEship, GoodMarketOpportunity andControls, and GoodAvailableEntrepreneurshipTraining are able to accurately classify $86 \%$ of the countries in the cross-validated analysis, all with a positive association $(r=.70, r=.32$, 
and $r=.60$ respectively). In distinguishing among all levels 1 through 4 , a significant function was generated $(\lambda=.61, \quad \mathrm{~N}=26, \quad \mathrm{p}<.05) \quad$ indicating that StrongIntellectualPropertyRights is able to accurately classify $42 \%$ of the countries in the cross-validated analysis, with a positive association $(r=.82)$. Strong intellectual property rights, good market opportunities and control, and access to affordable business services and suppliers, a positive impression of government support for entrepreneurship, and good available entrepreneurship training are all positively related to women's participation in business leadership. 


\begin{tabular}{|c|c|c|c|c|c|c|c|c|c|c|c|c|c|c|c|c|c|c|c|c|c|}
\hline \multirow{3}{*}{\begin{tabular}{|r|} 
Table 8 - Business \\
Sub-Category
\end{tabular}} & \multirow{3}{*}{\begin{tabular}{|c|} 
Enviornment H2 Discriminant Analysis Results Business Leadership \\
Variable \\
\end{tabular}} & \multicolumn{5}{|c|}{ Minim todorate Partieipan } & \multicolumn{5}{|c|}{ Moperatetostmating } & \multirow{2}{*}{\multicolumn{5}{|c|}{$\int_{\text {Par }}^{\text {Sucipatiop (Levels 3-4) }}$}} & \multirow{2}{*}{\multicolumn{5}{|c|}{ 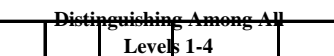 }} \\
\hline & & \multirow[b]{2}{*}{$\mathbf{N}$} & \multirow[b]{2}{*}{$?$} & \multirow[t]{2}{*}{ (Leve } & \multirow{3}{*}{$\begin{array}{l}\text { s- 2) } \\
\text { Correctly } \\
\text { Classified }\end{array}$} & \multirow[b]{2}{*}{$r$} & \multirow[b]{2}{*}{$\mathbf{N}$} & \multirow{2}{*}{\begin{tabular}{c|c|} 
Par \\
$?$ \\
\end{tabular}} & \multirow{2}{*}{ dicipatio } & (Levels 2-3) & & & & & & & & & & & \\
\hline & & & & & & & & & & \begin{tabular}{|l|l|} 
Correctly \\
Classified \\
\end{tabular} & $r$ & $\mathbf{N}$ & $?$ & $\mathbf{p}$ & Correctly & $r$ & $\mathbf{N}$ & ? & $\mathbf{p}$ & \begin{tabular}{|l|l|} 
Correctly \\
Chassified
\end{tabular} & $r$ \\
\hline & 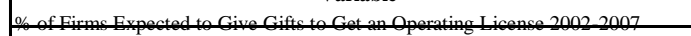 & & & & & & & & & & & & & & & & & & & & \\
\hline & \%of Firms Expected o Give Gifto Get an Import License $2002-2007$ & & & & & & & & & & & & & & & & - & & & & \\
\hline & 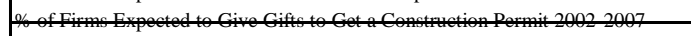 & & & & & & & & & & & & & & & & & & & & \\
\hline & 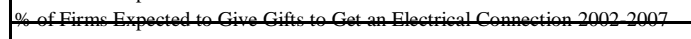 & & & & & & & & & & & & & & & & & & & & \\
\hline & 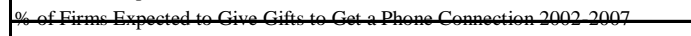 & & & & & & & & & & & & & & & & & & & & \\
\hline Gilt Giving & \%of Firms Expected Give Gifts o Get a Water Connection $2002-2007$ & & & & & & & & & & & & & & & & & & & & \\
\hline & 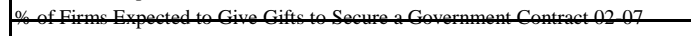 & & & & & & & & & & & & & & & & & & & & \\
\hline & 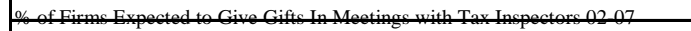 & & & & & & & & & & & & & & & & & & & & \\
\hline & \%of Firms Ex Ected o Pay Informal Payment (to Get Things Done) 02.07 & & & & & & & 0.87 & -0.023 & $63 \%$ & $0.35 *$ & & & & & & & & & & \\
\hline & Value of Gift Expected o Secure Government Contract 02.07 & & & & & & & & & & & & & & & & & & & & \\
\hline & 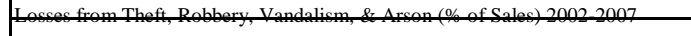 & & & & & & & & & & & & & & & & & & & & \\
\hline Crime \& & Tof Firms Identifying Crime, Theft and Disorder as Major Constraint $02-07$ & & & & & & & & & & & & & & & & & & & & \\
\hline Corruption & 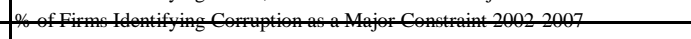 & & & & & & & & & & & & & & & & & & & & \\
\hline & Security costof $\quad$ Soles $2002-2007$ & & & & & & & & & & & & & & & & & & & & \\
\hline & Average Number of Temporary Workers $2002-2007$ & 36 & 0.58 & 0.001 & $68 \%$ & -.25 & 21 & 0.79 & 0.038 & $64 \%$ & 04 & & & & & & & & & & \\
\hline & Average Number fermanen, Full Time Workers 2002-2007 & & & & & & & & & & & & & & & & & & & & \\
\hline & 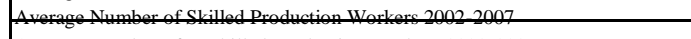 & & & & & & & & & & & & & & & & & & & & \\
\hline & \begin{tabular}{|l|l|l} 
&
\end{tabular} & & & & & & & & & & & & - 0.88 & +048- & $60 \%$ & 0.25 & & & & & \\
\hline & Average Number Production Workers $2002-2007$ & & & & & & & & & & & & & & & & _ & & & & \\
\hline Skill Level & 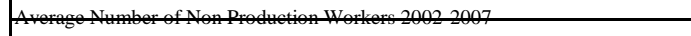 & & & & & & & & & & & & & & & & & & & & \\
\hline & 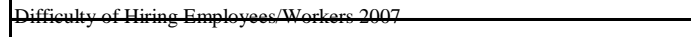 & & & & & & & & & & & & & & & & & & & & \\
\hline & Years of Experience of the Top Manager Working in the Firm's Sector $02-07$ & & & & & & & & & & & & & & & & 56 & 0.78 & 0.004 & $-40 \%$ & .50 : \\
\hline & 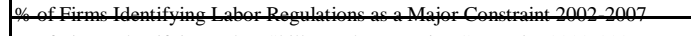 & & & & & & & & & & & & & & & & & & & & \\
\hline & 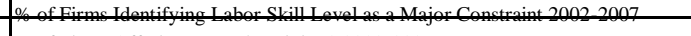 & & 0.58 & $-0,001$ & $-60 \%$ & $31 *$ & & & & & & & & & & & & & & & \\
\hline & \%o f Firms Offering Formal Training' 2002-2007 & $36-36$ & 0.58 & -0.001 & $68 \%$ & .18 & & & & & & & & & & & - & & & & \\
\hline & Average Time Clear Direct Exports Through Customs (days) 2002-2007 & & & & & & & & & & & & & & & & & & & & \\
\hline & A Time Clom & & & & & & & & & & & & & & & & & & & & \\
\hline Borders and & Frinding & & & & & & & & & & & & & & & & & & & & \\
\hline Customs & Frading Acros Borders Time for er (days) 2007 & & & & & & & & & & & & & & & & & & & & \\
\hline & 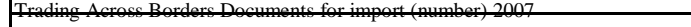 & & & & & & & & & & & & & & & & & & & & \\
\hline & 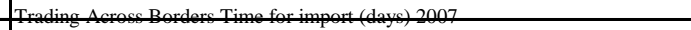 & & & & & & & & & & & & & & & & & & & & \\
\hline & \%o firms Identifying Customs/Trade Regulation as Major Constrain 02.07 & 59 & 0.89 & 0.009 & $-66 \%$ & -.25 & & & & & & 33. & 0.89 & 0.059 & $66 \%$ & -0.29 & 92 & 0.82 & 0.001 & $-40 \%$ & $-16 *$ \\
\hline & Dyy L L 2002-2007 & & & & & & & & & & & & & & & & 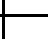 & & & & \\
\hline & P & & & & & & & & & & & & & & & & 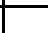 & & & & \\
\hline Licenses \& Permit & 8 P & & & & & & & & & & & & & & & & & & & & \\
\hline & 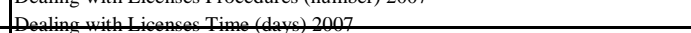 & & & & & & & & & & & & & & & & & & & & \\
\hline & \% of Firms Identifying Business Licening/Permits as Major Constraint 02.07 & & & & & & & & & & & & & & & & & & & & \\
\hline & Procedures tonfore antract (number) 2002-2007 & & & & & & & & & & & & & & & & & & & & \\
\hline Contracts & 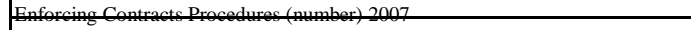 & 58 & 0.76 & 0.001 & $73 \%$ & -46** & & & & & & & 0.81 & -0.003 & $60 \%$ & $0.12:$ & 102 & 0.70 & +0.000 & $38 \%$ & $-62 *$ \\
\hline Contracts & Enforeing Contracts Time (days) 2007 & & & & & & & & & & & & & & & & & & & & \\
\hline & Time required to enforce a contrat (day) 2004 & & & & & & & & & & & & & & & & & & & & \\
\hline & 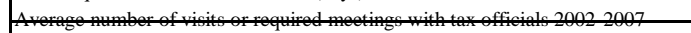 & & & & & & & & & & & & & & & & & & & & \\
\hline & Paying Tavec Paymente (number) 2007 & & & & & & & & & & & & & & & & & & & & \\
\hline Taxes & Paying Taxes Time (hows) 2007 & & & & & & & & & & & & & & & & & & & & \\
\hline & 6of Firm Identifying Tax Rates as Major Condrain $2002-2007$ & & & & & & & & & & & & & & & & & & & & \\
\hline & & & & & & & & & & & & & & & & & & & & & \\
\hline
\end{tabular}




\begin{tabular}{|c|c|c|c|c|c|c|c|c|c|c|c|c|c|c|c|c|c|c|c|c|c|}
\hline \multicolumn{2}{|c|}{ Table 8 Cont'd - Business Enviornment H2 Discriminant Analysis Business Leadership } & \multicolumn{5}{|c|}{$\begin{array}{l}\begin{array}{c}\text { Minimal to Moderate Participation } \\
\text { (Levels 1- 2) }\end{array} \\
\end{array}$} & \multicolumn{5}{|c|}{$\begin{array}{l}\text { Moderate to Substantial } \\
\text { Participation (Levels 2-3) }\end{array}$} & \multicolumn{5}{|c|}{$\begin{array}{l}\text { Substantial to Pronounced } \\
\text { Participation (Levels 3-4) }\end{array}$} & \multicolumn{5}{|c|}{$\begin{array}{c}\begin{array}{c}\text { Distinguishing Among All } \\
\text { Levels 1-4 }\end{array} \\
\end{array}$} \\
\hline Sub-Hypothessis & 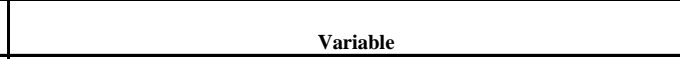 & $\mathbf{N}$ & $\lambda$ & $\mathbf{p}$ & \begin{tabular}{|l|} 
Correctly \\
Classified \\
\end{tabular} & $r$ & $\mathbf{N}$ & $\lambda$ & $\mathbf{p}$ & \begin{tabular}{l|} 
Correctly \\
Classified
\end{tabular} & $r$ & $\mathbf{N}$ & $\lambda$ & $\mathbf{p}$ & \begin{tabular}{l|} 
Correctly \\
Classified \\
\end{tabular} & $r$ & $\mathbf{N}$ & $\lambda$ & $\mathbf{p}$ & \begin{tabular}{|l|} 
Correctly \\
Classified \\
\end{tabular} & $r$ \\
\hline \multirow{10}{*}{ Start-up Procedure } & Procedures to register property (number) 2002-2007 & & & & & & & & & & & & & & & & & & & & \\
\hline & \begin{tabular}{|l|l|} 
Registering Property Procedures (number) 2007 \\
\end{tabular} & & & & & & & & & & & & & & & & & & & & \\
\hline & \begin{tabular}{|l|} 
Registering Property Time (days) 2007 \\
\end{tabular} & & & & & & & & & & & & & & & & & & & & \\
\hline & Time required to register property (days) 2004 & & & & & & & & & & & & & & & & & & & & \\
\hline & $\%$ of Senior MgmtTime Dealing w/ Requirements of Govt Regulation $02-07$ & & & & & & & & & & & & & & & & & & & & \\
\hline & Cost of business start-up procedures (\% of GNI per capita) 2002-2007 & & & & & & & & & & & & & & & & & & & & \\
\hline & Starting a Business Procedures (number) 2007 & & & & & & & & & & & & & & & & & & & & \\
\hline & Starting a Business Time (days) 2007 & & & & & & & & & & & & & & & & & & & & \\
\hline & Start-up procedures to register a business (number) 2004 & & & & & & & & & & & & & & & & & & & & \\
\hline & Time required to start a business (days) 2004 & & & & & & & & & & & & & & & & & & & & \\
\hline \multirow{4}{*}{ Financing } & $\%$ of Firms Using Banks to Finance Investments 2002-2007 & & & & & & & & & & & & & & & & & & & & \\
\hline & $\%$ of Firms Using Banks to Finance Expenses 2002-2007 & & & & & & & & & & & & & & & & & & & & \\
\hline & $\%$ of Firms Identifying Access/Cost of Finance as Major Constraint 2002-2007 & & & & & & & & & & & & & & & & & & & & \\
\hline & \begin{tabular}{|l|l} 
Value of Collateral Needed for a Loan (\% of the Loan Amount) 2002-2007 \\
\end{tabular} & & & & & & & & & & & & & & & & & & & & \\
\hline \multirow{8}{*}{$\begin{array}{c}\text { Global } \\
\text { Competitiveness }\end{array}$} & Global Competitiveness Index 2007 & & & & & & & & & & & & & & & & 100 & 0.85 & 0.001 & $32 \%$ & $.50^{*}$ \\
\hline & Global Competitiveness Institutions 2007 & & & & & & & & & & & & & & & & & & & & \\
\hline & Global Competitiveness Business Sophistication 2007 & & & & & & & & & & & & & & & & & & & & \\
\hline & Global Competitiveness Innovation 2007 & & & & & & & & & & & & & & & & & & & & \\
\hline & Global Competitiveness Labor Market Efficiency 2007 & 58 & 0.86 & 0.004 & $60 \%$ & $.37^{*}$ & & & & & & & & & & & & & & & \\
\hline & Global Competitiveness Financial Market Efficiency 2007 & & & & & & & & & & & & & & & & & & & & \\
\hline & Global Competitiveness Goods Market Efficiency 2007 & & & & & & & & & & & 42 & 0.87 & 0.021 & $64 \%$ & $36^{*}$ & & & & & \\
\hline & \begin{tabular}{|l|} 
Global Competitiveness Market Size 2007 \\
\end{tabular} & & & & & & & & & & & 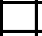 & & & & & & & & & \\
\hline \multirow{14}{*}{$\begin{array}{c}\text { Entrepreneurial } \\
\text { Framework } \\
\text { Conditions }\end{array}$} & Good Infrastructure and Communications 2003 & & & & & & & & & & & & & & & & & & & & \\
\hline & Respect for Individualistic and Innovative Entrepreneurs 2003 & & & & & & & & & & & & & & & & & & & & \\
\hline & Social Acceptance \& Respect for Entrepreneurs 2003 & & & & & & & & & & & & & & & & & & & & \\
\hline & Supportive Environment for Women 2003 & & & & & & & & & & & & & & & & & & & & \\
\hline & Business Opportunity Environment \& Entrepreneurial Ability 2003 & & & & & & & & & & & & & & & & & & & & \\
\hline & Positive Impression of Govt Support 2003 & & & & & & & & & & & 14 & 0.21 & 0.001 & $86 \%$ & $.70^{*}$ & & & & & \\
\hline & \begin{tabular}{|l|} 
Accessible \& Affordable Business Services \& Suppliers 2003 \\
\end{tabular} & 12 & 0.29 & 0.015 & $67 \%$ & .52 & & & & & & & & & & & & & & & \\
\hline & \begin{tabular}{|l|l|} 
Sufficient Funding 2003 \\
\end{tabular} & & & & & & & & & & & & & & & & & & & & \\
\hline & \begin{tabular}{|l|l|} 
Strong Intellectual Property Rights 2003 \\
\end{tabular} & 12 & 0.29 & 0.015 & $67 \%$ & .54 & & & & & & 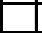 & & & & & 26 & 0.61 & 0.011 & $42 \%$ & $.82 *$ \\
\hline & Grade School Entrepreneurial Education Focus 2003 & & & & & & & & & & & & & & & & & & & & \\
\hline & \begin{tabular}{|l|} 
Good Market Opportunity and Controls 2003 \\
\end{tabular} & 12 & 0.29 & 0.015 & $67 \%$ & .52 & & & & & & 14 & 0.21 & 0.001 & $86 \%$ & .32 & & & & & \\
\hline & \begin{tabular}{|l|l|} 
Positive Research and Technology Environment 2003 \\
\end{tabular} & & & & & & & & & & & & & & & & & & & & \\
\hline & Timely access to utilities, communications, and permits/licenses 2003 & & & & & & & & & & & & & & & & & & & & \\
\hline & Good Available Entrepreneurship Training 2003 & & & & & & & & & & & 14 & 0.21 & 0.001 & $86 \%$ & $.60 *$ & & & & & \\
\hline
\end{tabular}




\begin{tabular}{|c|c|c|c|c|c|c|c|c|c|c|c|c|c|c|c|c|c|c|c|c|c|}
\hline \multicolumn{2}{|c|}{ Table 8 Cont'd - Business Enviornment H2 Discriminant Analysis Business Leadership } & \multicolumn{5}{|c|}{\begin{tabular}{|c|}
$\begin{array}{c}\text { Minimal to Moderate Participation } \\
\text { (Levels 1- 2) }\end{array}$ \\
\end{tabular}} & \multicolumn{5}{|c|}{$\begin{array}{c}\text { Moderate to Substantial } \\
\text { Participation (Levels 2-3) }\end{array}$} & \multicolumn{5}{|c|}{$\begin{array}{l}\text { Substantial to Pronounced } \\
\text { Participation (Levels 3-4) }\end{array}$} & \multicolumn{5}{|c|}{$\begin{array}{c}\text { Distinguishing Among All } \\
\text { Levels 1-4 }\end{array}$} \\
\hline Sub-Hypothessis & T & $\mathbf{N}$ & $\lambda$ & $\mathbf{p}$ & \begin{tabular}{|l|} 
Correctly \\
Classified \\
\end{tabular} & $r$ & $\mathbf{N}$ & $\lambda$ & $\mathbf{p}$ & \begin{tabular}{|l|} 
Correctly \\
Classified \\
\end{tabular} & $r$ & $\mathbf{N}$ & $\lambda$ & $\mathbf{p}$ & \begin{tabular}{|l|} 
Correctly \\
Classified \\
\end{tabular} & $r$ & $\mathbf{N}$ & $\lambda$ & $\mathbf{p}$ & \begin{tabular}{|l|} 
Correctly \\
Classified \\
\end{tabular} & $r$ \\
\hline \multirow{10}{*}{ Start-up Procedure } & \begin{tabular}{|l|} 
Procedures to register property (number) 2002-2007 \\
\end{tabular} & & & & & & & & & & & & & & & & & & & & \\
\hline & \begin{tabular}{|l|l|} 
Registering Property Procedures (number) 2007 \\
\end{tabular} & & & & & & & & & & & & & & & & & & & & \\
\hline & \begin{tabular}{|l|l} 
Registering Property Time (days) 2007 \\
\end{tabular} & & & & & & & & & & & & & & & & & & & & \\
\hline & \begin{tabular}{|l|l|} 
Time required to register property (days) 2004 \\
\end{tabular} & & & & & & & & & & & & & & & & & & & & \\
\hline & $\%$ of Senior MgmtTime Dealing w/ Requirements of Govt Regulation 02-07 & & & & & & & & & & & & & & & & & & & & \\
\hline & Cost of business start-up procedures (\% of GNI per capita) 2002-2007 & & & & & & & & & & & & & & & & & & & & \\
\hline & \begin{tabular}{|l|l|} 
Starting a Business Procedures (number) 2007 \\
\end{tabular} & & & & & & & & & & & & & & & & & & & & \\
\hline & \begin{tabular}{|l|l} 
Starting a Business Time (days) 2007 \\
\end{tabular} & & & & & & & & & & & & & & & & & & & & \\
\hline & Start-up procedures to register a business (number) 2004 & & & & & & & & & & & & & & & & & & & & \\
\hline & Time required to start a business (days) 2004 & & & & & & & & & & & & & & & & & & & & \\
\hline \multirow{4}{*}{ Financing } & $\%$ of Firms Using Banks to Finance Investments 2002-2007 & & & & & & & & & & & & & & & & & & & & \\
\hline & \% of Firms Using Banks to Finance Expenses 2002-2007 & & & & & & & & & & & & & & & & & & & & \\
\hline & $\%$ of Firms Identifying Access/Cost of Finance as Major Constraint 2002-2007 & & & & & & & & & & & & & & & & & & & & \\
\hline & Value of Collateral Needed for a Loan (\% of the Loan Amount) 2002-2007 & & & & & & & & & & & & & & & & & & & & \\
\hline \multirow{8}{*}{$\begin{array}{c}\text { Global } \\
\text { Competitiveness }\end{array}$} & Global Competitiveness Index 2007 & & & & & & & & & & & & & & & & 100 & 0.85 & 0.001 & $32 \%$ & $.50^{*}$ \\
\hline & \begin{tabular}{|l|l|} 
Global Competitiveness Institutions 2007 \\
\end{tabular} & & & & & & & & & & & & & & & & & & & & \\
\hline & \begin{tabular}{|l|} 
Global Competitiveness Business Sophistication 2007 \\
\end{tabular} & & & & & & & & & & & & & & & & & & & & \\
\hline & \begin{tabular}{|l|l} 
Global Competitiveness Innovation 2007 \\
\end{tabular} & & & & & & & & & & & & & & & & & & & & \\
\hline & \begin{tabular}{|l|l|} 
Global Competitiveness Labor Market Efficiency 2007 \\
\end{tabular} & 58 & 0.86 & 0.004 & $60 \%$ & $.37^{*}$ & & & & & & & & & & & & & & & \\
\hline & Global Competitiveness Financial Market Efficiency 2007 & & & & & & & & & & & & & & & & & & & & \\
\hline & Global Competitiveness Goods Market Efficiency 2007 & & & & & & & & & & & 42 & 0.87 & 0.021 & $64 \%$ & $.36^{*}$ & & & & & \\
\hline & Global Competitiveness Market Size 2007 & & & & & & & & & & & & & & & & & & & & \\
\hline \multirow{14}{*}{$\begin{array}{c}\text { Entrepreneurial } \\
\text { Framework } \\
\text { Conditions }\end{array}$} & Good Infrastructure and Communications 2003 & & & & & & & & & & & & & & & & & & & & \\
\hline & Respect for Individualistic and Innovative Entrepreneurs 2003 & & & & & & & & & & & & & & & & & & & & \\
\hline & \begin{tabular}{|l|l|} 
Social Acceptance \& Respect for Entrepreneurs 2003 \\
\end{tabular} & & & & & & & & & & & & & & & & & & & & \\
\hline & Supportive Environment for Women 2003 & & & & & & & & & & & & & & & & & & & & \\
\hline & Business Opportunity Environment \& Entrepreneurial Ability 2003 & & & & & & & & & & & & & & & & & & & & \\
\hline & Positive Impression of Govt Support 2003 & & & & & & & & & & & 14 & 0.21 & 0.001 & $86 \%$ & $.70^{*}$ & & & & & \\
\hline & Accessible \& Affordable Business Services \& Suppliers 2003 & 12 & 0.29 & 0.015 & $67 \%$ & .52 & & & & & & & & & & & & & & & \\
\hline & \begin{tabular}{|l|} 
Sufficient Funding 2003 \\
\end{tabular} & & & & & & & & & & & & & & & & & & & & \\
\hline & Strong Intellectual Property Rights 2003 & 12 & 0.29 & 0.015 & $67 \%$ & .54 & & & & & & & & & & & 26 & 0.61 & 0.011 & $42 \%$ & .82 \\
\hline & Grade School Entrepreneurial Education Focus 2003 & & & & & & & & & & & & & & & & & & & & \\
\hline & Good Market Opportunity and Controls 2003 & 12 & 0.29 & 0.015 & $67 \%$ & .52 & & & & & & 14 & 0.21 & 0.001 & $86 \%$ & .32 & & & & & \\
\hline & Positive Research and Technology Environment 2003 & & & & & & & & & & & & & & & & & & & & \\
\hline & Timely access to utilities, communications, and permits/licenses 2003 & & & & & & & & & & & & & & & & & & & & \\
\hline & Good Available Entrepreneurship Training 2003 & & & & & & & & & & & 14 & 0.21 & 0.001 & $86 \%$ & $.60^{*}$ & & & & & \\
\hline
\end{tabular}




\section{Hypothesis 3: Societal Development}

Hypothesis 3 stated that societal institutional variables can distinguish among qualitatively different levels of women's participation in positions of leadership. To test this hypothesis, a stepwise discriminant analysis was run on 5 sub-categories to determine which of the variables in each of these categories can distinguish between levels 1 and 2,2 and 3, 3 and 4, and among all levels 1 through 4 of women in business leadership. Correlations are provided to show the positive or negative relationship between each significant dependent and independent variable. Table 9 shows the results of these analyses. Hypothesis $3 a$ stated that societal development is positively related to the levels of women's participation in positions of leadership. As can be seen in the following review of the results, hypothesis 3a is supported.

Burgeoning employment: As can be seen in Table 9, burgeoning employment is able to distinguish between all levels of women's participation in business leadership. In distinguishing between levels 1 and 2, a significant function was generated $(\lambda=.41, \mathrm{~N}=25, \mathrm{p}<.001)$ indicating that EmployeeServicesFemale, UnemploymentFemale, and LaborforceParticipationMale, are able to accurately classify $75 \%$ of the countries in the cross-validated analysis. UnemploymentFemale and LaborforceParticipationMale are both negatively associated $(r=-.50$ and $r=-.19$ respectively) and EmployeeServicesFemale is positively associated $(r=.53)$ with women in business leadership. In distinguishing between levels 2 and 3, a significant function was generated $(\lambda=.75, \mathrm{~N}=30, \mathrm{p}<.01)$ indicating that UnemploymentFemale again is able to accurately classify $65 \%$ of the countries in the cross-validated analysis, but with a positive association $(r=.48)$. In distinguishing between levels 3 and 4 , a significant function was generated $(\lambda=.79, \mathrm{~N}=26, \mathrm{p}<.05)$ indicating that UnemploymentFemale again is able to accurately classify $67 \%$ of the 
countries in the cross-validated analysis, again with a negative association $(r=-.43)$. In distinguishing among all levels 1 through 4 , a significant function was generated $(\lambda=.49, \mathrm{~N}=51, \mathrm{p}<.001)$ with $40 \%$ of the countries correctly classified in the cross-validated analysis showing EmployeeServicesFemale again with a positive association $(r=.56)$ and UnemploymentFemale again with a negative association $(r=-.26)$. Women's participation in business leadership is positively related to the employment of women in the services sector. Mixed results are found for the relationship to the unemployment of women.

Gender Equality: As can be seen in Table 9, gender equality is able to distinguish between all levels of women's participation in business leadership, except between levels 2 and 3. In distinguishing between levels 1 and 2, a significant function was generated $(\lambda=.56, \mathrm{~N}=27, \mathrm{p}<.001)$ indicating that GenderRelatedDevelopmentIndexValue is able to accurately classify $78 \%$ of the countries in the cross-validated analysis, with a positive association $(r=.38)$. In distinguishing between levels 3 and 4 , a significant function was generated $(\lambda=.28, \mathrm{~N}=13, \mathrm{p}<.001)$ indicating that GenderEmpowermentMeasureValue is able to accurately classify $82 \%$ of the countries in the cross-validated analysis, with a positive association $(r=.17)$. In distinguishing among all levels 1 through 4, a significant function was generated $(\lambda=.28, \mathrm{~N}=24, \mathrm{p}<.001)$ indicating that GenderEmpowermentMeasureValue is able to accurately classify $78 \%$ of the countries in the cross-validated analysis, with a positive association $(r=.41)$. Gender empowerment and gender related development are positively related to women's participation in business leadership. 
Education and Literacy: As can be seen in Table 9, quality human capital is able to distinguish between all levels of women's participation in business leadership. In distinguishing between levels 1 and 2, a significant function was generated $(\lambda=.44, \mathrm{~N}=35, \mathrm{p}<.001)$ indicating that EducationCombinedPrimSecTerMales is able to accurately classify $75 \%$ of the countries in the cross-validated analysis, with a positive association $(r=.35)$. In distinguishing between levels 2 and 3 , a significant function was generated $(\lambda=.84, \mathrm{~N}=32, \mathrm{p}<.05)$ indicating that AdultLiteracyMalesAge15andOlder is able to accurately classify $68 \%$ of the countries in the cross-validated analysis, with a negative association $(r=-.02)$. In distinguishing between levels 3 and 4 , a significant function was generated $(\lambda=.76, \mathrm{~N}=27, \mathrm{p}<.01)$ indicating that GlobalCompetitivHigherEducationTraining is able to accurately classify $64 \%$ of the countries in the cross-validated analysis, with a positive association $(r=.30)$. In distinguishing among all levels 1 through 4, a significant function was generated $(\lambda=.48, \quad \mathrm{~N}=52, \quad \mathrm{p}<.001)$ indicating that AdultLiteracyFemalesAge15andOlder is able to accurately classify $40 \%$ of the countries in the cross-validated analysis, with a positive association $(r=.34)$. The education of males, higher education, and female literacy are positively related to women's participation in business leadership, male literacy is negatively related.

Population: is positively related to the levels of women's participation in positions of leadership. As can be seen in Table 9, age of the population is able to distinguish between levels 1 and 2 and among all levels 1 through 4 of women's participation in business leadership. In distinguishing between levels 1 and 2 , a significant function was generated $(\lambda=.75, \mathrm{~N}=67, \mathrm{p}<.001)$ indicating that Populationages65andaboveoftotal is able to accurately classify $76 \%$ of the countries in the cross-validated analysis, 
with a positive association $(r=.50)$. In distinguishing among all levels 1 through 4 , a significant function was generated $(\lambda=.82$, $\mathrm{N}=112, \mathrm{p}<.001$ ) indicating that Populationages65andaboveoftotal again is able to accurately classify $45 \%$ of the countries in the cross-validated analysis, with a positive association $(r=.31)$. Having adults over the age of 65 in a population is positively related to women's participation in business leadership.

Human Health and Environmental Development: As can be seen in Table 9, human health and environmental development is able to distinguish between all levels of women's participation in business leadership, except between levels 2 and 3 . In distinguishing between levels 1 and 2 , a significant function was generated $(\lambda=.76, \mathrm{~N}=19, \mathrm{p}<.05)$ indicating that PrevalenceOfUndernourishment is able to accurately classify $64 \%$ of the countries in the cross-validated analysis, with a negative association $(r=-.18)$. In distinguishing between levels 3 and 4 , a significant function was generated $(\lambda=.52, \mathrm{~N}=19, \mathrm{p}<.01)$ indicating that OutOfPocketHealthExpenditure and the HumanDevelopmentIndex are able to accurately classify $62 \%$ of the countries in the cross-validated analysis. OutOfPocketHealthExpenditure is negatively associated $(r=-.27)$ and the HumanDevelopmentIndex is positively associated $(r=.22)$ with women in business leadership. In distinguishing among all levels 1 through 4, a significant function was generated $(\lambda=.53, \mathrm{~N}=47, \mathrm{p}<.001)$ indicating that the HumanDevelopmentIndex and OutOfPocketHealthExpenditure are able to accurately classify $39 \%$ of the countries in the cross-validated analysis. The HumanDevelopmentIndex is positively associated $(r=.32)$ with women in business leadership. OutOfPocketHealthExpenditure is 
negatively associated $(r=-.29)$. Prevalence of undernourishment and out of pocket health expenditures are negatively related to women's participation in business leadership, and human development is positively related. 


\begin{tabular}{|c|c|c|c|c|c|c|c|c|c|c|c|c|c|c|c|c|c|c|c|c|c|}
\hline \multicolumn{2}{|c|}{ Table 9 - Societal Development H3 Discriminant Analysis Results Business Leadership } & \multicolumn{5}{|c|}{$\begin{array}{c}\text { Minimal to Moderate } \\
\text { Participation (Levels 1- 2) } \\
\end{array}$} & \multicolumn{5}{|c|}{$\begin{array}{c}\text { Moderate to Substantial } \\
\text { Participation (Levels 2-3) }\end{array}$} & \multicolumn{5}{|c|}{$\begin{array}{l}\text { Substantial to Pronounced } \\
\text { Participation (Levels 3-4) }\end{array}$} & \multicolumn{5}{|c|}{$\begin{array}{c}\text { Distinguishing Among All } \\
\text { Levels 1-4 }\end{array}$} \\
\hline Sub-Categories & $\begin{array}{c}\text { Variable } \\
\end{array}$ & $\mathbf{N}$ & $\lambda$ & $\mathbf{p}$ & \begin{tabular}{|l|} 
Correctly \\
Classified \\
\end{tabular} & $r$ & $\mathbf{N}$ & $\lambda$ & $\mathbf{p}$ & \begin{tabular}{|l|} 
Correctly \\
Classified \\
\end{tabular} & $r$ & $\mathbf{N}$ & $\lambda$ & $\mathbf{p}$ & \begin{tabular}{|l|} 
Correctly \\
Classified \\
\end{tabular} & $r$ & $\mathbf{N}$ & $\lambda$ & $\mathbf{p}$ & \begin{tabular}{|l|} 
Correctly \\
Classified \\
\end{tabular} & $r$ \\
\hline \multirow{22}{*}{ Employment } & Contributing Family Workers Females \% 2004 & & & & & & & & & & & & & & & & & & & & \\
\hline & Contributing Family Workers males \% 2004 & & & & & & & & & & & & & & & & & & & & \\
\hline & Employees, agriculture, female (\% of female employment) WDI 2004 & & & & & & & & & & & & & & & & & & & & \\
\hline & Employees, agriculture, male (\% of male employment) WDI 2004 & & & & & & & & & & & & & & & & & & & & \\
\hline & Employment in agriculture (\% of total employment) UN 2004 & & & & & & & & & & & & & & & & & & & & \\
\hline & Share of women in nonagriculture (\% of nonagricultural employment) 2004 & & & & & & & & & & & & & & & & & & & & \\
\hline & Employees, industry, female (\% of female employment) 2004 & & & & & & & & & & & & & & & & & & & & \\
\hline & Employees, industry, male (\% of male employment) 2004 & & & & & & & & & & & & & & & & & & & & \\
\hline & Employment in industry (\% of total employment) 2004 & & & & & & & & & & & & & & & & & & & & \\
\hline & Employees, services, female (\% of female employment) 2004 & & & & & & & & & & & & & & & & 51 & 0.49 & 0.0000 & $40 \%$ & $.56^{*}$ \\
\hline & Employees, services, male (\% of male employment) 2004 & 25 & 0.41 & 0.0002 & $75 \%$ & $.53 *$ & & & & & & & & & & & & & & & \\
\hline & Employment in services (\% of total employment) 2004 & & & & & & & & & & & & & & & & & & & & \\
\hline & Estimated earned income, female (PPP US\$) 2004 & & & & & & & & & & & & & & & & & & & & \\
\hline & Estimated earned income, male (PPP US\$) 2004 & & & & & & & & & & & & & & & & & & & & \\
\hline & Ratio of estimated female to male earned income 2003 & & & & & & & & & & & & & & & & & & & & \\
\hline & Labor force participation rate, female (\% of females ages 15-64) 2004 & & & & & & & & & & & & & & & & & & & & \\
\hline & Labor force participation rate, male (\% of males ages 15-64) 2004 & 25 & 0.41 & 0.0002 & $75 \%$ & -.19 & & & & & & & & & & & & & & & \\
\hline & Labor force participation rate, total (\% of total ages 15-64) 2004 & & & & & & & & & & & & & & & & & & & & \\
\hline & Labor force, female (\% of total labor force) $2004 *$ & & & & & & & & & & & & & & & & & & & & \\
\hline & Unemployment, female (\% of female labor force) 2004 & 25 & 0.41 & 0.0002 & $75 \%$ & $.50^{*}$ & 30 & 0.75 & 0.005 & $65 \%$ & $.48^{*}$ & 26 & 0.79 & 0.017 & $67 \%$ & $.43 *$ & 51 & 0.49 & 0.0000 & $40 \%$ & $-.26^{*}$ \\
\hline & Unemployment, male (\% of male labor force) 2004 & & & & & & & & & & & & & & & & & & & & \\
\hline & Unemployment, total (\% of total labor force) 2004 & & & & & & & & & & & & & & & & & & & & \\
\hline \multirow{12}{*}{\begin{tabular}{|l} 
Gender Equality \\
\\
\end{tabular}} & Proportion of Female Legislators, Senior Officials, \& Managers 2004 & & & & & & & & & & & & & & & & & & & & \\
\hline & Female professional and technical workers (\% of total) 2004 & & & & & & & & & & & & & & & & & & & & \\
\hline & \begin{tabular}{|l|l|} 
Female economic activity (ages 15+) Index 2004 \\
\end{tabular} & & & & & & & & & & & & & & & & & & & & \\
\hline & Female economic activity as \% of Male rate 2004 & & & & & & & & & & & & & & & & & & & & \\
\hline & $\%$ of Full Time Female Workers* 2002-2007 & & & & & & & & & & & & & & & & & & & & \\
\hline & \begin{tabular}{|l|l|} 
Gender Related Development Index Value 2004 \\
\end{tabular} & 27 & 0.56 & 0.000 & $78 \%$ & $.38 *$ & & & & & & & & & & & & & & & \\
\hline & Gender empowerment measure (GEM) Value 2004 & & & & & & & & & & & 13 & 0.28 & 0.0003 & $82 \%$ & .17 & 24 & 0.28 & 0.0000 & $32 \%$ & $.41^{*}$ \\
\hline & \begin{tabular}{|l|} 
Global Gender Gap Index 2007 \\
\end{tabular} & & & & & & & & & & & & & & & & & & & & \\
\hline & Gender Gap Economic Participation and Opportunity 2007 & & & & & & & & & & & & & & & & & & & & \\
\hline & \begin{tabular}{|l|} 
Gender Gap Educational Attainment 2007 \\
\end{tabular} & & & & & & & & & & & & & & & & & & & & \\
\hline & Gender Gap Health and Survival Subindex 2007 & & & & & & & & & & & & 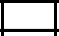 & & & & & & & & \\
\hline & Gender Gap Political Empowerment 2007 & & & & & & & & & & & & & & & & & & & & \\
\hline
\end{tabular}




\begin{tabular}{|c|c|c|c|c|c|c|c|c|c|c|c|c|c|c|c|c|c|c|c|c|c|}
\hline \multicolumn{2}{|c|}{ Table 9 Cont'd - Societal Development H3 Discriminant Analysis Business Leadership } & \multicolumn{5}{|c|}{$\begin{array}{c}\text { Minimal to Moderate } \\
\text { Participation (Levels 1- 2) }\end{array}$} & \multicolumn{5}{|c|}{$\begin{array}{l}\text { Moderate to Substantial } \\
\text { Participation (Levels 2-3) }\end{array}$} & \multicolumn{5}{|c|}{$\begin{array}{l}\text { Substantial to Pronounced } \\
\text { Participation (Levels 3-4) }\end{array}$} & \multicolumn{5}{|c|}{$\begin{array}{c}\text { Distinguishing Among All } \\
\text { Levels 1-4 }\end{array}$} \\
\hline Sub-Categories & Variable & $\mathbf{N}$ & $\lambda$ & $\mathbf{p}$ & \begin{tabular}{|l|} 
Correctly \\
Classified \\
\end{tabular} & $r$ & $\mathbf{N}$ & $\lambda$ & $\mathbf{p}$ & \begin{tabular}{|l|} 
Correctly \\
Classified \\
\end{tabular} & $r$ & $\mathbf{N}$ & $\lambda$ & $\mathbf{p}$ & \begin{tabular}{|l|} 
Correctly \\
Classified \\
\end{tabular} & $r$ & $\mathbf{N}$ & $\lambda$ & $\mathbf{p}$ & \begin{tabular}{|l|} 
Correctly \\
Classified \\
\end{tabular} & $r$ \\
\hline \multirow{15}{*}{ Education } & Adult literacy rate (\% ages 15 and older) 2004 & & & & & & & & & & & & & & & & & & & & \\
\hline & \begin{tabular}{|l|} 
Adult Literacy, females (\%) (age 15+) 2004* \\
\end{tabular} & & & & & & & & & & & & & & & & 52 & 0.48 & 0.0000 & $40 \%$ & $.34^{*}$ \\
\hline & Adult Literacy, males (\%) (age 15+) 2004* & & & & & & 32 & 0.84 & 0.024 & $68 \%$ & -.02 & & & & & & & & & & \\
\hline & Children out of school, primary, female 2004 & & & & & & & & & & & & & & & & & & & & \\
\hline & Children out of school, primary, male 204 & & & & & & & & & & & & & & & & & & & & \\
\hline & Combined gross enrolment ratio primary, secondary, tertiary schools (\%) 04 & & & & & & & & & & & & & & & & & & & & \\
\hline & Education Combined primary, secondary, tertiary schools, female (\%) 2004 & & & & & & & & & & & & & & & & & & & & \\
\hline & Education Combined primary, secondary, tertiary schools, male (\%) 2004 & 35 & 0.44 & 0.0000 & $75 \%$ & $.35^{*}$ & & & & & & & & & & & & & & & \\
\hline & Primary education, pupils 2004 & & & & & & & & & & & & & & & & & & & & \\
\hline & Primary education, pupils (\% female) 2004 & & & & & & & & & & & & & & & & & & & & \\
\hline & Public spending on education, total (\% of GDP) 2004 & & & & & & & & & & & & & & & & & & & & \\
\hline & Secondary education, pupils 2004 & & & & & & & & & & & & & & & & & & & & \\
\hline & \begin{tabular}{|l|} 
Secondary education, pupils (\% female) 2004 \\
\end{tabular} & & & & & & & & & & & & & & & & & & & & \\
\hline & Education index 2004 & & & & & & & & & & & & & & & & & & & & \\
\hline & Global Competitiveness Higher Education \& Training 2007 & & & & & & & & & & & 27 & 0.76 & 0.009 & $64 \%$ & $.30 *$ & & & & & \\
\hline \multirow{6}{*}{ Population } & Population ages 0-14 (\% of total) 2004 & & & & & & & & & & & & & & & & & & & & \\
\hline & Population ages 15-64 (\% of total) 2004 & & & & & & & & & & & & & & & & & & & & \\
\hline & Population ages 65 and above (\% of total) 2004 & 67 & 0.75 & 0.0000 & $76 \%$ & $.50 *$ & & & & & & & & & & & 112 & 0.82 & 0.0000 & $45 \%$ & $.31 *$ \\
\hline & Population, female (\% of total) 2004 & & & & & & & & & & & & & & & & & & & & \\
\hline & \begin{tabular}{|l|l|} 
Rural population (\% of total population) 2004 \\
\end{tabular} & & & & & & & & & & & & & & & & & & & & \\
\hline & \begin{tabular}{|l|} 
Urban population (\% of total) 2004 \\
\end{tabular} & & & & & & & & & & & & & & & & & & & & \\
\hline \multirow{14}{*}{$\begin{array}{c}\text { Health \& } \\
\text { Development }\end{array}$} & Birth rate, crude (per 1,000 people) 2004 & & & & & & & & & & & & & & & & & & & & \\
\hline & \begin{tabular}{|l|l} 
Death rate, crude (per 1,000 people) 2004 \\
\end{tabular} & & & & & & & & & & & & & & & & & & & & \\
\hline & Fertility rate, total (births per woman) 2004 & & & & & & & & & & & & & & & & & & & & \\
\hline & Human Development Index 2004 & & & & & & & & & & & 19 & 0.52 & 0.005 & $62 \%$ & .22 & 47 & 0.53 & 0.0001 & $39 \%$ & $.32 *$ \\
\hline & \begin{tabular}{|l|l|} 
Global Competitiveness Health \& Primary Education 2007 \\
\end{tabular} & & & & & & & & & & & & & & & & & & & & \\
\hline & Improved sanitation facilities (\% of population with access) 2004 & & & & & & & & & & & & & & & & & & & & \\
\hline & Improved water source (\% of population with access) 2004 & & & & & & & & & & & & & & & & & & & & \\
\hline & \begin{tabular}{|l|l} 
Life expectancy at birth (years) 2004 \\
\end{tabular} & & & & & & & & & & & & & & & & & & & & \\
\hline & \begin{tabular}{|l|} 
Life expectancy index 2004 \\
\end{tabular} & & & & & & & & & & & & & & & & & & & & \\
\hline & Life Expectancy at Birth, females 2004 & & & & & & & & & & & & & & & & & & & & \\
\hline & \begin{tabular}{|l|} 
Life Expectancy at Birth, males 2004 \\
\end{tabular} & & & & & & & & & & & & & & & & & & & & \\
\hline & Out-of-pocket health expenditure (\% of private expenditure on health) 2004 & & & & & & & & & & & 19 & 0.52 & 0.005 & $62 \%$ & -.27 & 47 & 0.53 & 0.0001 & $39 \%$ & -.29 \\
\hline & Physicians (per 1,000 people) 2004 & & & & & & & & & & & & & & & & & & & & \\
\hline & Prevalence of undernourishment (\% of population) 2004 & 19 & 0.76 & 0.032 & $64 \%$ & -.18 & & & & & & & & & & & & & & & \\
\hline
\end{tabular}




\section{$\underline{\text { Hypothesis 4: Economics Factors }}$}

Hypothesis 4 stated that economic institutional variables can distinguish between qualitatively different levels of women's participation in positions of leadership. To test this hypothesis, a stepwise discriminant analysis was run on 9 sub-categories to determine which of the variables in each of these categories can distinguish between levels 1 and 2, 2 and 3, 3 and 4, and among all levels 1 through 4 of women in business leadership. Correlations are provided to show the positive or negative relationship between each significant dependent and independent variable. Table 10 shows the results of these analyses. Hypothesis 4a stated that economic facilitating institutional forces are positively related to the levels of women's participation in positions of leadership. Hypothesis $4 \mathrm{~b}$ stated that economic inhibiting institutional forces are positively related to the levels of women's participation in positions of leadership. As can be seen in the following review of the results, both hypotheses $4 \mathrm{a}$ and $4 \mathrm{~b}$ are supported.

Economic Freedom: As can be seen in Table 10, economic freedom is able to distinguish between all levels of women's participation in business leadership, except between levels 2 and 3. In distinguishing between levels 1 and 2, 3 and 4, and among all levels 1 through 4 , a significant function was generated for each analysis $(\lambda=.85, N=62$, $\mathrm{p}<.01 ; \lambda=.90, \mathrm{~N}=44, \mathrm{p}<.05 ; \lambda=.79, \mathrm{~N}=101, \mathrm{p}<.001)$ respectively, indicating that the IndexofEconomicFreedom is able to accurately classify $76 \%, 68 \%$, and $36 \%$ of the countries in the cross-validated analysis respectively. The IndexofEconomicFreedom is positively associated with women in business leadership in all 3 cases $(r=.39, r=.32$, and $r=.41$, respectively). Economic freedom is positively related to women's participation in business leadership. 
Macroeconomic Stability: As can be seen in Table 10, the global competitiveness of macroeconomic stability is not able to distinguish between levels 1 and 2, 2 and 3, 3 and 4, or among all levels 1 through 4 and is not related to women's participation in business leadership.

Economic Development: As can be seen in Table 10, economic development is able to distinguish between levels 1 and 2 and among all levels 1 through 4 of women's participation in business leadership. In distinguishing between levels 1 and 2, a significant function was generated $(\lambda=.57, \mathrm{~N}=44, \mathrm{p}<.001)$ indicating that GDPperCapitaPPPUS\$ and GovtConsumptionExpenditureofGDP are able to accurately classify $73 \%$ of the countries in the cross-validated analysis, with a positive association $(r$ $=.45$ and $r=.16$ respectively). In distinguishing among all levels 1 through 4 , a significant function was generated $(\lambda=.71, \mathrm{~N}=73, \mathrm{p}<.001)$ indicating that GDPperCapitaPPPconstantInt $\$$ is able to accurately classify $41 \%$ of the countries in the cross-validated analysis, with a positive association $(r=.37)$. GDP and government expenditures are positively related to women's participation in business leadership.

Non-performing Bank Loans: As can be seen in Table 10, non-performing bank loans are able to distinguish between levels 1 and 2 only. A significant function was generated $(\lambda=.79, \mathrm{~N}=42, \mathrm{p}<.01)$ indicating that BankNonPerfomingLoans are able to accurately classify $74 \%$ of the countries in the cross-validated analysis, with a negative association $(r=-.45)$. Bank non-performing loans are negatively related to women's participation in business leadership.

Domestic Credit Provided to the Private Sector: As can be seen in Table 10, domestic credit provided to the private sector is able to distinguish between levels 3 and 4 
and among all levels 1 through 4 of women's participation in business leadership. In distinguishing between levels 3 and 4 , a significant function was generated $(\lambda=.89, N=45$, $\mathrm{p}<.05)$ indicating that DomesticCreditProvidedByBankingSector is able to accurately classify $67 \%$ of the countries in the cross-validated analysis, with a positive association ( $r$ $=.33$ ). In distinguishing among all levels 1 through 4 , a significant function was generated $(\lambda=.89, \mathrm{~N}=111, \mathrm{p}<.01)$ indicating that DomesticCreditToPrivateSector is able to accurately classify $34 \%$ of the countries in the cross-validated analysis, with a positive association $(r=.28)$. Domestic credit is positively related to women's participation in business leadership.

Taxes: As can be seen in Table 10, taxes are able to distinguish between levels 3 and 4 only. A significant function was generated $(\lambda=.85, \mathrm{~N}=25, \mathrm{p}<.10)$ indicating that HighestMarginalTaxRate is able to accurately classify $67 \%$ of the countries in the crossvalidated analysis, with a positively association $(r=.18)$. The highest marginal tax rate is positively related to women's participation in business leadership.

Inflation: As can be seen in Table 10, inflation is not able to distinguish between levels 1 and 2, 2 and 3, 3 and 4, or among all levels 1 through 4 and is not related to women's participation in business leadership.

Inflows and Outflows: As can be seen in Table 10, imports and exports signifying international trade are able to distinguish between levels 1 and 2 and between levels 3 and 4 of women's participation in business leadership. In distinguishing between levels 1 and 2, a significant function was generated $(\lambda=.87, \mathrm{~N}=60, \mathrm{p}<.01)$ indicating that ImportsOfGoodsAndServicesConstant2000US\$ are able to accurately classify $62 \%$ of the countries in the cross-validated analysis, with a positive association $(r=.36)$. In 
distinguishing between levels 3 and 4 , a significant function was generated $(\lambda=.87, N=41$, $\mathrm{p}<.05)$ indicating that ForeignDirectInvestmentInflows are able to accurately classify $64 \%$ of the countries in the cross-validated analysis, with a negative association $(r=-$ .35). Imports are positively related to women's participation in business leadership, but FDI inflows are negatively related.

Types of Goods and Services Produced and Sold: As can be seen in Table 10, the types of goods and services produced and sold are able to distinguish between all levels of women's participation in business leadership. In distinguishing between levels 1 and 2, a significant function was generated $(\lambda=.83, \mathrm{~N}=39, \mathrm{p}<.01)$ indicating that CommercialServiceExports is able to accurately classify $63 \%$ of the countries in the cross-validated analysis, with a positive association $(r=.32)$. In distinguishing between levels 2 and 3, a significant function was generated $(\lambda=.85, \mathrm{~N}=36, \mathrm{p}<.05)$ indicating that FoodExports is able to accurately classify $65 \%$ of the countries in the cross-validated analysis, with a positive association $(r=.23)$. In distinguishing between levels 3 and 4 , a significant function was generated $(\lambda=.85, \quad \mathrm{~N}=33, \mathrm{p}<.05)$ indicating that ComputerCommunicationsAnd OtherServicesExports is able to accurately classify $59 \%$ of the countries in the cross-validated analysis, with a positive association $(r=.32)$. Commercial services in general, food, and computer communications exports are all positively related to women's participation in business leadership. 


\begin{tabular}{|c|c|c|c|c|c|c|c|c|c|c|c|c|c|c|c|c|c|c|c|c|c|}
\hline \multicolumn{2}{|c|}{ Table 10- Economics H4 Discriminant Analysis Results Business Leadership } & \multicolumn{5}{|c|}{$\begin{array}{l}\text { Minimal to Moderate Participation } \\
\text { (Levels 1- 2) }\end{array}$} & \multicolumn{5}{|c|}{$\begin{array}{l}\text { Moderate to Substantial } \\
\text { Participation (Levels 2-3) }\end{array}$} & \multicolumn{5}{|c|}{$\begin{array}{l}\text { Substantial to Pronounced } \\
\text { Participation (Levels 3-4) }\end{array}$} & \multicolumn{5}{|c|}{\begin{tabular}{|c} 
Distinguishing Among All Levels \\
$1-4$
\end{tabular}} \\
\hline Sub-Category & Variable & $\mathbf{N}$ & $\lambda$ & $\mathbf{p}$ & $\begin{array}{l}\text { Correctly } \\
\text { Classified }\end{array}$ & $r$ & $\mathbf{N}$ & $\lambda$ & p & \begin{tabular}{l|l}
$\begin{array}{l}\text { Correctly } \\
\text { Classified }\end{array}$ \\
\end{tabular} & $r$ & $\mathbf{N}$ & $\lambda$ & $\mathbf{p}$ & \begin{tabular}{l|l}
$\begin{array}{l}\text { Correctly } \\
\text { Classified }\end{array}$ \\
\end{tabular} & $r$ & $\mathbf{N}$ & $\lambda$ & $\mathbf{p}$ & \begin{tabular}{l|l} 
Correctly \\
Classified
\end{tabular} & $r$ \\
\hline $\begin{array}{l}\text { Economic } \\
\text { Freedom } \\
\end{array}$ & Index of Economic Freedom 2005 & 62 & 0.85 & 0.002 & $60 \%$ & .39 & & & & & & 44 & 0.90 & 0.036 & $68 \%$ & $.32 *$ & 106 & 0.79 & 0.000 & $36 \%$ & $41 *$ \\
\hline $\begin{array}{c}\text { Macroeconomic } \\
\text { Stability }\end{array}$ & Global Competitiveness Macroeconomic Stability 2007 & & & & & & & & & & & & & & & & & & & & \\
\hline \multirow{10}{*}{$\begin{array}{l}\text { GDP Related } \\
\text { Factors }\end{array}$} & GDP per capita (constant 2000 US\$) 2004 & & & & & & & & & & & & & & & & & & & & \\
\hline & GDP per capita, PPP (constant 2000 international \$) 2004 & & & & & & & & & & & & & & & & 73 & 0.71 & 0.0000 & $41 \%$ & $37^{*}$ \\
\hline & GDP per capita (PPP US\$) 2004* & 44 & 0.57 & 0.0000 & $73 \%$ & $.45 *$ & & & & & & & & & & & & & & & \\
\hline & \begin{tabular}{|l|} 
GDP index 2004* \\
\end{tabular} & & & & & & & & & & & & & & & & & & & & \\
\hline & Final consumption expenditure (constant 2000 US\$) 2004 & & & & & & & & & & & & & & & & & & & & \\
\hline & Final consumption expenditure, etc. (\% of GDP) 2004* & & & & & & & & & & & & & & & & & & & & \\
\hline & \begin{tabular}{|l|} 
General government final consumption expenditure (\% of GDP)* \\
\end{tabular} & 44 & 0.57 & 0.0000 & $73 \%$ & .16 & & & & & & & & & & & & & & & \\
\hline & General government final consumption expenditure (constant2000US\$) 04 & & & & & & & & & & & & & & & & & & & & \\
\hline & Household final consumption expenditure (constant 2000 US\$) 2004 & & & & & & & & & & & & & & & & & & & & \\
\hline & Household final consumption expenditure, etc. (\% of GDP) 2004* & & & & & & & & & & & & & & & & & & & & \\
\hline Loans & Bank nonperforming loans to total gross loans (\%) 2004 & 42 & 0.79 & 0.003 & $74 \%$ & $-45^{*}$ & & & & & & & & & & & & & & & \\
\hline \multirow{2}{*}{ Domestic Credit } & Domestic credit provided by banking sector (\% of GDP) 2004 & & & & & & & & & & & 45 & 0.89 & 0.029 & $67 \%$ & $.33^{*}$ & 111 & 0.89 & 0.006 & $34 \%$ & $28^{*}$ \\
\hline & Domestic credit to private sector (\% of GDP) 2004 & & & & & & & & & & & & & & & & & & & & \\
\hline \multirow{2}{*}{ Taxes } & Highest marginal tax rate, individual rate (\%) 2004 & & & & & & & & & & & 25 & 0.85 & 0.055 & $67 \%$ & .18 & & & & & \\
\hline & Tax revenue (\% of GDP) 2004 & & & & & & & & & & & & & & & & & & & & \\
\hline \multirow{2}{*}{ Inflation } & Inflation, consumer prices (annual \%) 2004 & & & & & & & & & & & & & & & & & & & & \\
\hline & Inflation, GDP deflator (annual \%) 2004 & & & & & & & & & & & & & & & & & & & & \\
\hline \multirow{5}{*}{$\begin{array}{l}\text { Inflows \& } \\
\text { Outflows }\end{array}$} & Foreign direct investment, net inflows (\% of GDP) 2004 & & & & & & & & & & & 41 & 0.87 & 0.021 & $64 \%$ & $.35^{*}$ & & & & & \\
\hline & Imports of goods and services (\% of GDP) 2004 & & & & & & & & & & & & & & & & & & & & \\
\hline & Imports of goods and services (constant 2000 US\$) 2004 & 60 & 0.87 & 0.005 & $62 \%$ & $.36 *$ & & & & & & & & & & & & & & & \\
\hline & Exports of goods and services (\% of GDP) 2004 & & & & & & & & & & & & & & & & & & & & \\
\hline & Exports of goods and services (constant 2000 US\$) 2004 & & & & & & & & & & & & & & & & & & & & \\
\hline \multirow{11}{*}{$\begin{array}{c}\text { Types of Good } \\
\& \text { Services }\end{array}$} & International tourism, receipts (\% of total exports) 2004 & & & & & & & & & & & & & & & & & & & & \\
\hline & High-technology exports (\% of manufactured exports) 2004 & & & & & & & & & & & & & & & & & & & & \\
\hline & Commercial service exports (current US\$) 2004 & 39 & 0.83 & 0.008 & $63 \%$ & $32 *$ & & & & & & & & & & & & & & & \\
\hline & Computer, communications, other svcs (\% commercial svc exports) 2004 & & & & & & & & & & & 33 & 0.85 & 0.026 & $59 \%$ & $32 *$ & & & & & \\
\hline & Insurance and financial services (\% of commercial service exports) 2004 & & & & & & & & & & & & & & & & & & & & \\
\hline & \begin{tabular}{|l|} 
Manufactures exports (\% of merchandise exports) 2004 \\
\end{tabular} & & & & & & & & & & & & & & & & & & & & \\
\hline & Ores and metals exports (\% of merchandise exports) 2004 & & & & & & & & & & & & & & & & & & & & \\
\hline & \begin{tabular}{|l|l} 
ggricultural raw materials exports (\% of merchandise exports) 2004 \\
\end{tabular} & & & & & & & & & & & & & & & & & & & & \\
\hline & Food exports (\% of merchandise exports) 2004 & & & & & & 36 & 0.85 & 0.019 & $65 \%$ & .23 & & & & & & & & & & \\
\hline & \begin{tabular}{|l|l|} 
Fuel exports (\% of merchandise exports) 2004 \\
\end{tabular} & & & & & & & & & & & & & & & & & & & & \\
\hline & Arms imports (constant 1990 US\$) 2004 & & & & & & & & & & & & & & & & & & & & \\
\hline
\end{tabular}




\section{Hypothesis 5: Technology and Physical Infrastructure}

Hypothesis 5 stated that technology and physical infrastructure institutional variables can distinguish between qualitatively different levels of women's participation in positions of leadership. To test this hypothesis, a stepwise discriminant analysis was run on 2 sub-categories to determine which of the variables in each of these categories can distinguish between levels 1 and 2,2 and 3,3 and 4, and among all levels 1 through 4 of women in business leadership. Correlations are provided to show the positive or negative relationship between each significant dependent and independent variable. Table 11 shows the results of these analyses. Hypothesis 5a stated that technological advancements and physical infrastructure are positively related to the levels of women's participation in positions of leadership. As can be seen in the following review of the results, hypothesis 5a is supported.

Physical Infrastructure: As can be seen in Table 11, physical infrastructure is able to distinguish between all levels of women's participation in business leadership. In distinguishing between levels 1 and 2 , a significant function was generated $(\lambda=.63, N=27$, p<.01) indicating that ElectricPowerConsumption is able to accurately classify $64 \%$ of the countries in the cross-validated analysis, with a positive association $(r=.40)$. In distinguishing between levels 2 and 3 , a significant function was generated $(\lambda=.71, N=19$, $\mathrm{p}<.05)$ indicating that TelephoneMainlines is able to accurately classify $53 \%$ of the countries in the cross-validated analysis, with a negative association $(r=-.16)$. In distinguishing between levels 3 and 4 , a significant function was generated $(\lambda=.90, N=40$, $\mathrm{p}<.05)$ indicating that GlobalCompetitivenessBasicInfrastructure is able to accurately classify $60 \%$ of the countries in the cross-validated analysis, with a positive association ( $r$ 
$=.36$ ). In distinguishing among all levels 1 through 4 , a significant function was generated $(\lambda=.63, \mathrm{~N}=51, \mathrm{p}<.001)$ indicating that FixedLineAndMobilePhoneSubscribers are able to accurately classify $39 \%$ of the countries in the cross-validated analysis, with a positive association $(r=.31)$. Electric power, fixed line and mobile phone subscribers, and basic infrastructure are positively related to women's participation in business leadership, but telephone mainlines are negatively related. H5a is supported.

Technological Advancements: As can be seen in Table 11, technological advancements are able to distinguish only between levels 1 and 2 of women's participation in business leadership. A significant function was generated $(\lambda=.57, \mathrm{~N}=26$, $\mathrm{p}<.001$ ) indicating that MobilePhoneSubscribers are able to accurately classify $72 \%$ of the countries in the cross-validated analysis, with a positive association $(r=.44)$. In distinguishing among all levels 1 through 4 , a significant function was generated $(\lambda=.74$, $\mathrm{N}=47, \mathrm{p}<.01$ ) indicating that PersonalComputers are able to accurately classify $43 \%$ of the countries in the cross-validated analysis, with a positive association $(r=.38)$. Mobile phone subscribers and personal computers are positively related to women's participation in business leadership. H5b is supported. 


\begin{tabular}{|c|c|c|c|c|c|c|c|c|c|c|c|c|c|c|c|c|c|c|c|c|c|}
\hline \multicolumn{2}{|c|}{ Table 11- Infrastructure/Technology H5 Discriminant Analysis Business Leadership } & \multicolumn{5}{|c|}{$\begin{array}{c}\text { Minimal to Moderate } \\
\text { Participation (Levels 1- 2) }\end{array}$} & \multicolumn{5}{|c|}{$\begin{array}{l}\text { Moderate to Substantial } \\
\text { Participation (Levels 2-3) }\end{array}$} & \multicolumn{5}{|c|}{$\begin{array}{l}\text { Substantial to Pronounced } \\
\text { Participation (Levels 3-4) }\end{array}$} & \multicolumn{5}{|c|}{$\begin{array}{c}\text { Distinguishing Among All Levels } \\
1-4\end{array}$} \\
\hline $\begin{array}{c}\text { Sub- } \\
\text { Categories }\end{array}$ & $\begin{array}{c}\text { Variable } \\
\end{array}$ & $\mathbf{N}$ & $\lambda$ & $\mathbf{p}$ & \begin{tabular}{l|l} 
Correctly \\
Classified
\end{tabular} & $r$ & $\mathbf{N}$ & $\lambda$ & $\mathbf{p}$ & \begin{tabular}{|l|} 
Correctly \\
Classified \\
\end{tabular} & $r$ & $\mathbf{N}$ & $\lambda$ & p & \begin{tabular}{l|l} 
Correctly \\
Classified \\
\end{tabular} & $r$ & $\mathbf{N}$ & $\lambda$ & $\mathbf{p}$ & \begin{tabular}{|l|} 
Correctly \\
Classified \\
\end{tabular} & $r$ \\
\hline \multirow{7}{*}{$\begin{array}{c}\text { Physical } \\
\text { Infrastructure }\end{array}$} & Railways, goods transported (million ton-km) 2004 & & & & & & & & & & & & & & & & & & & & \\
\hline & Railways, passengers carried (million passenger-km) 2004 & & & & & & & & & & & & & & & & & & & & \\
\hline & Roads, paved (\% of total roads) 2004 & & & & & & & & & & & & & & & & & & & & \\
\hline & Electric power consumption (kWh per capita) 2004 & 27 & 0.63 & 0.001 & $64 \%$ & $.40^{*}$ & & & & & & & & & & & & & & & \\
\hline & Telephone mainlines (per 1,000 people) 2004 & & & & & & 19 & 0.71 & 0.017 & $53 \%$ & -.16 & & & & & & & & & & \\
\hline & Global Competitiveness Basic Infrastructure 2007 & & & & & & & & & & & 40 & 0.90 & 0.043 & $60 \%$ & $36 *$ & & & & & \\
\hline & Fixed line and mobile phone subscribers (per 1,000 people) 2004 & & & & & & & & & & & & & & & & 51 & 0.63 & 0.000 & $39 \%$ & $31 *$ \\
\hline \multirow{8}{*}{$\begin{array}{c}\text { Technology } \\
\text { Infrastructure }\end{array}$} & Mobile phone subscribers (per 1,000 people) 2004 & 26 & 0.57 & 0.0002 & $72 \%$ & $.44 *$ & & & & & & & & & & & & & & & \\
\hline & Broadband subscribers (per 1,000 people) 2004 & & & & & & & & & & & & & & & & & & & & \\
\hline & International Internet bandwidth (bits per person) 2004 & & & & & & & & & & & & & & & & & & & & \\
\hline & Internet users (per 1,000 people) 2004 & & & & & & & & & & & & & & & & & & & & \\
\hline & Information \& communication technology expenditure (\%ofGDP) 04 & & & & & & & & & & & & & & & & & & & & \\
\hline & Personal computers (per 1,000 people) 2004 & & & & & & & & & & & & & & & & 47 & 0.74 & 0.004 & $43 \%$ & $38 *$ \\
\hline & Households with television (\%) 2004 & & & & & & & & & & & & & & & & & & & & \\
\hline & Global Competitiveness Technological Readiness 2007 & & & & & & & & & & & & & & & & & & & & \\
\hline
\end{tabular}




\section{Hypothesis 6: Political Freedom}

Hypothesis 6 stated that political institutional variables can distinguish between qualitatively different levels of women's participation in positions of leadership. To test this hypothesis, a stepwise discriminant analysis was run on 2 sub-categories to determine which of the variables in each of these categories can distinguish between levels 1 and 2, 2 and 3, 3 and 4, and among all levels 1 through 4 of women in business leadership. Neither political rights or civil liberties are able to distinguish between levels 1 and 2, 2 and 3, 3 and 4, or among all levels 1 through 4 and are not related to women's participation in business leadership. Hypothesis 6a stated that political rights and civil liberties are positively related to the levels of women's participation in positions of leadership. Hypothesis 6a is not supported.

\section{Hypothesis 7: Culture}

Hypothesis 7 stated that cultural institutional variables can distinguish between qualitatively different levels of women's participation in positions of leadership. To test this hypothesis, a stepwise discriminant analysis was run on 3 sub-categories to determine which of the variables in each of these categories can distinguish between levels 1 and 2, 2 and 3, 3 and 4, and among all levels 1 through 4 of women in business leadership. This was done in 3 groupings of analyses: 1) cultural values and practices; 2) leadership practices; and 3) social axioms. Correlations are provided to show the positive or negative relationship between each significant dependent and independent variable. Table 12 shows the results of these analyses. In some cases, for cultural values and 
practices variables, correlations are provided between each practice and value variable to assist in interpreting whether the hypothesis is supported.

Hypothesis $7 \mathrm{a}$ stated that liberal and open cultural institutional forces are positively related to the levels of women's participation in positions of leadership. Hypothesis $7 \mathrm{~b}$ stated that constraining and restrictive cultural institutional forces are negatively related to the levels of women's participation in positions of leadership. Hypothesis $7 \mathrm{c}$ stated that transformational, participative, humane, and collaborative leadership skills and abilities are positively related to the levels of women's participation in positions of leadership. Hypothesis $7 \mathrm{~d}$ stated that self-serving leadership skills and abilities are negatively related to the levels of women's participation in positions of leadership. As can be seen in the following review of the results, hypotheses 7a, 7b, 7c and $7 \mathrm{~d}$ are supported.

Cultural Values and Practices: As can be seen in Table 12, performance orientation, assertiveness, power distance, and humane orientation are not able to distinguish between levels 1 and 2, 2 and 3, 3 and 4, or among all levels 1 through 4 and are not related to women's participation in business leadership.

Future orientation is able to distinguish between levels 1 and 2 only. A significant function was generated $(\lambda=.60, \quad \mathrm{~N}=20, \quad \mathrm{p}<.05)$ indicating that FutureOrientationSocietyPractice and FutureOrientationSocietyValues are able to accurately classify $75 \%$ of the countries in the cross-validated analysis. FutureOrientationSocietyPractice is negatively associated $(r=-.19)$ and FutureOrientationSocietyValues is positively associated $(r=.40)$ with women in business 
leadership. Future orientation practices are negatively related to women's participation in business leadership, but future orientation values are positively related.

Gender egalitarianism is able to distinguish between levels 2 and 3 and among all levels 1 through 4 of women's participation in business leadership. In distinguishing between levels 2 and 3, a significant function was generated $(\lambda=.83, \mathrm{~N}=21, \mathrm{p}<.10)$ indicating that GenderEgalitarianismSocietyPractice are able to accurately classify $71 \%$ of the countries in the cross-validated analysis, with a positive association $(r=.42)$. In distinguishing among all levels 1 through 4 , a significant function was generated $(\lambda=.83$, $\mathrm{N}=45, \mathrm{p}<.01$ ) indicating that GenderEgalitarianismSocietyValues are able to accurately classify $34 \%$ of the countries in the cross-validated analysis, with a positive association $(r$ $=.49$ ). Gender egalitarianism values and practices are positively related to women's participation in business leadership.

Collectivism is able to distinguish between levels 1 and 2 and among all levels 1 through 4 of women's participation in business leadership. In distinguishing between levels 1 and 2 , a significant function was generated $(\lambda=.70, \mathrm{~N}=20, \mathrm{p}<.05)$ indicating that InGroupCollectivismSocietyPractice is able to accurately classify $70 \%$ of the countries in the cross-validated analysis, with a negative association $(r=-.55) . \quad$ In distinguishing among all levels 1 through 4 , a significant function was generated $(\lambda=.78, N=45, p<.05)$ indicating that InGroupCollectivismSocietyPractice is able to accurately classify $40 \%$ of the countries in the cross-validated analysis, with a negative association $(r=-.41)$. Ingroup collectivism practices are negatively related to women's participation in business leadership. 
Uncertainty avoidance is able to distinguish between all levels of women's participation in business leadership, except between levels 2 and 3. In distinguishing between levels 1 and 2, 3 and 4, and among all levels 1 through 4, a significant function was generated in each case $(\lambda=.70, \mathrm{~N}=20, \mathrm{p}<.05 ; \lambda=.84, \mathrm{~N}=25, \mathrm{p}<.05 ; \lambda=.70, \mathrm{~N}=45$, p $<.01$ respectively) indicating that UncertaintyAvoidanceValues are able to accurately classify $60 \%, 72 \%$, and $88 \%$ respectively of the countries in the cross-validated analysis, with a negative association in each instance $(r=-.50, r=-.40$, and $r=-.50$ respectively). Uncertainty avoidance values are negatively related to women's participation in business leadership.

Culturally Endorsed Leadership Skills: As can be seen in Table 12, charismatic and visionary leadership and autonomous leadership are not able to distinguish between levels 1 and 2, 2 and 3,3 and 4, or among all levels 1 through 4 and are not related to women's participation in business leadership.

Team-oriented leadership is able to distinguish between only levels 2 and 3 of women's participation in business leadership. A significant function was generated $(\lambda=.80, \mathrm{~N}=21, \mathrm{p}<.05)$ indicating that TeamOrientedLeadership is able to accurately classify $71 \%$ of the countries in the cross-validated analysis, with a positive association $(r$ $=.45)$. Team-oriented leadership is positively related to women's participation in business leadership.

Participative leadership is able to distinguish between levels 3 and 4 only. A significant function was generated $(\lambda=.81, \quad \mathrm{~N}=25, \quad \mathrm{p}<.05)$ indicating that ParticipativeLeadership is able to accurately classify $60 \%$ of the countries in the cross- 
validated analysis, with a positive association $(r=.43)$. Participative leadership is positively related to women's participation in business leadership.

Humane-oriented leadership is able to distinguish between only levels 1 and 2 of women's participation in business leadership. A significant function was generated $(\lambda=.78, \mathrm{~N}=20, \mathrm{p}<.05)$ indicating that HumaneOrientedLeadership is able to accurately classify $70 \%$ of the countries in the cross-validated analysis, with a negative association $(r=-.47)$. Humane oriented leadership is negatively related to women's participation in business leadership.

Self-protective leadership is able to distinguish between levels 3 and 4, and among all levels 1 through 4 of women's participation in business leadership. In distinguishing between levels 3 and 4, a significant function was generated $(\lambda=.81, \mathrm{~N}=25$, $\mathrm{p}<.05$ ) indicating that SelfProtectiveLeadership is able to accurately classify $80 \%$ of the countries in the cross-validated analysis, with a negative association $(r=-.44)$. In distinguishing among all levels 1 through 4 , a significant function was generated $(\lambda=.70$, $\mathrm{N}=45, \mathrm{p}<.01$ ) indicating that SelfProtectiveLeadership is able to accurately classify $44 \%$ of the countries in the cross-validated analysis, with a negative association $(r=-.53)$. Self-protective leadership is negatively related to women's participation in business leadership.

Social Axioms: As can be seen in Table 12, complex social systems are not able to distinguish between levels 1 and 2, 2 and 3, 3 and 4, or among all levels 1 through 4 .

Cynicism is able to distinguish between only levels 3 and 4 of women's participation in business leadership. A significant function was generated $(\lambda=.53, \mathrm{~N}=12$, $\mathrm{p}<.05)$ indicating that SocialCynicism is able to accurately classify $75 \%$ of the countries 
in the cross-validated analysis, with a negative association $(r=-.69)$. Social cynicism is negatively related to women's participation in business leadership.

Rewards for application are able to distinguish between levels 1 and 2, and among all levels 1 through 4 of women's participation in business leadership. In distinguishing between levels 1 and 2, a significant function was generated $(\lambda=.51, N=20, p<.01)$ indicating that RewardforApplication is able to accurately classify $85 \%$ of the countries in the cross-validated analysis, with a negative association $(r=-.70)$. In distinguishing among all levels 1 through 4 , a significant function was generated $(\lambda=.39, N=15, p<.01)$ indicating that RewardforApplication is able to accurately classify $93 \%$ of the countries in the cross-validated analysis, with a negative association $(r=-.78)$. Reward for application is negatively related to women's participation in business leadership.

Flexible religion is able to distinguish between levels 1 and 2, and among all levels 1 through 4 of women's participation in business leadership. In distinguishing between levels 1 and 2, a significant function was generated $(\lambda=.40, N=20, p<.001)$ indicating that Religiosity is able to accurately classify $95 \%$ of the countries in the crossvalidated analysis, with a negative association $(r=-.77)$. In distinguishing among all levels 1 through 4 , a significant function was generated $(\lambda=.43, \mathrm{~N}=15, \mathrm{p}<.01)$ indicating that Religiosity is able to accurately classify $100 \%$ of the countries in the cross-validated analysis, with a negative association $(r=-.75)$. Religiosity is negatively related to women's participation in business leadership. 
Fate control is able to distinguish between levels 1 and 2 only. In distinguishing between levels 1 and 2 , a significant function was generated $(\lambda=.74, N=20, p<.05)$ indicating that FateControl is able to accurately classify $70 \%$ of the countries in the cross-validated analysis, with a negative association $(r=-.51)$. Fate control is positively related to women's participation in business leadership. 


\begin{tabular}{|c|c|c|c|c|c|c|c|c|c|c|c|c|c|c|c|c|c|c|c|c|c|}
\hline \multicolumn{2}{|c|}{ Table 12- Culture H7 Discriminant Analysis Results Business Leadership } & \multicolumn{5}{|c|}{$\begin{array}{c}\text { Minimal to Moderate } \\
\text { Participation (Levels 1- 2) }\end{array}$} & \multicolumn{5}{|c|}{$\begin{array}{l}\text { Moderate to Substantial } \\
\text { Participation (Levels 2-3) }\end{array}$} & \multicolumn{5}{|c|}{$\begin{array}{l}\text { Substantial to Pronounced } \\
\text { Participation (Levels 3-4) }\end{array}$} & \multicolumn{5}{|c|}{$\begin{array}{l}\text { Distinguishing Among All } \\
\text { Levels 1-4 } \\
\end{array}$} \\
\hline \begin{tabular}{c|} 
Sub- \\
Categories \\
\end{tabular} & \begin{tabular}{|c} 
Variable \\
\end{tabular} & $\mathbf{N}$ & $\lambda$ & $\mathbf{p}$ & \begin{tabular}{|l|} 
Correctly \\
Classified \\
\end{tabular} & $r$ & $\mathbf{N}$ & $\lambda$ & $\mathbf{p}$ & \begin{tabular}{|l|} 
Correctly \\
Classified \\
\end{tabular} & $r$ & $\mathbf{N}$ & $\lambda$ & $\mathbf{p}$ & \begin{tabular}{|l|} 
Correctly \\
Classified \\
\end{tabular} & $r$ & $\mathbf{N}$ & $\lambda$ & $\mathbf{p}$ & \begin{tabular}{|l|} 
Correctly \\
Classified \\
\end{tabular} & $r$ \\
\hline \multirow{18}{*}{$\begin{array}{c}\text { Cultural } \\
\text { Values and } \\
\text { Practices }\end{array}$} & Performance Orientation: Society Practices (As is) & & & & & & & & & & & & & & & & & & & & \\
\hline & Performance Orientation: Society Values (Should Be) & & & & & & & & & & & & & & & & & & & & \\
\hline & Future Orientation: Society Practices (As is) & 20 & 0.60 & 0.013 & $75 \%$ & -.19 & & & & & & & & & & & & & & & \\
\hline & Future Orientation: Society Values (Should Be) & 20 & 0.60 & 0.013 & $75 \%$ & $.40^{*}$ & & & & & & & & & & & & & & & \\
\hline & Gender Egalitarianism Society Practice (As Is) & & & & & & 21 & 0.83 & 0.061 & $71 \%$ & .42 & & & & & & & & & & \\
\hline & Gender Egalitarianism Society Values (Should Be) & & & & & & & & & & & & & & & & 45 & 0.73 & 0.005 & $34 \%$ & $.49 *$ \\
\hline & \begin{tabular}{|l|} 
Assertiveness Society Practices (As Is) \\
\end{tabular} & & & & & & & & & & & & & & & & & & & & \\
\hline & Assertiveness Society Values (Should Be) & & & & & & & & & & & & & & & & & & & & \\
\hline & Institutional Collectivism Society Practice (As Is) & & & & & & & & & & & & & & & & & & & & \\
\hline & In-Group Collectivism Society Practice (As Is) & 20 & 0.70 & 0.013 & 70 & $.55 *$ & & & & & & & & & & & 45 & 0.78 & 0.014 & $40 \%$ & $-.41 *$ \\
\hline & Institutional Collectivism Society Values (Should Be) & & & & & & & & & & & & & & & & & & & & \\
\hline & In-Group Collectivism Society Values (Should Be) & & & & & & & & & & & & & & & & & & & & \\
\hline & Power Distance Society Practices (As Is) & & & & & & & & & & & & & & & & & & & & \\
\hline & Power Distance Society Values Should Be) & & & & & & & & & & & & & & & & & & & & \\
\hline & Humane Orientation Society Practices (As Is) & & & & & & & & & & & & & & & & & & & & \\
\hline & Humane Orientation Society Values (Should Be) & & & & & & & & & & & & & & & & & & & & \\
\hline & Uncertainty Avoidance Practice (As Is) & & & & & & & & & & & & & & & & . & & & & \\
\hline & Uncertainty Avoidance Values (Should Be) & 20 & 0.70 & 0.025 & $60 \%$ & $-.50 *$ & & & & & & 25 & 0.84 & 0.048 & $72 \%$ & $-.40 *$ & 45 & 0.70 & 0.002 & $42 \%$ & $-.50 *$ \\
\hline \multirow{6}{*}{$\begin{array}{l}\text { Culturally } \\
\text { Endorsed } \\
\text { Leadership } \\
\text { Skills }\end{array}$} & Charismatic/Value-based leadership & & & & & & & & & & & & & & & & & & & & \\
\hline & Team-oriented leadership & & & & & & 21 & 0.80 & 0.042 & $71 \%$ & $.45^{*}$ & & & & & & & & & & \\
\hline & Participative leadership & & & & & & & & & & & 25 & 0.81 & 0.030 & $60 \%$ & $.43 *$ & & & & & \\
\hline & Humane-oriented leadership & 20 & 0.78 & 0.039 & $70 \%$ & $-.47 *$ & & & & & & & & & & & & & & & \\
\hline & \begin{tabular}{|l|} 
Autonomous leadership \\
\end{tabular} & & & & & & & & & & & 25 & 0.85 & 0.060 & $56 \%$ & -.38 & & & & & \\
\hline & Self-protective leadership & & & & & & & & & & & 25 & 0.81 & 0.029 & $80 \%$ & $-.44 *$ & 45 & 0.70 & 0.002 & $44 \%$ &. $.53 *$ \\
\hline \multirow{5}{*}{ Social Axioms } & Social Cynicism 2004 & & & & & & & & & & & 12 & 0.53 & 0.013 & $75 \%$ & $-.69 *$ & & & & & \\
\hline & Social Complexity 2004 & & & & & & & & & & & & & & & & & & & & \\
\hline & Reward for Application 2004 & 20 & 0.51 & 0.001 & $85 \%$ & $-.70 *$ & & & & & & & & & & & 32 & 0.530 & 0.0004 & $34 \%$ &. $.50 *$ \\
\hline & Religiosity 2004 & 20 & 0.40 & 0.000 & $85 \%$ & $-.77 *$ & & & & & & & & & & & 32 & $0.50 \mid \mathrm{c}$ & 0.0002 & $44 \%$ & $-.44 *$ \\
\hline & Fate Control 2004 & 20 & 0.74 & 0.021 & $85 \%$ & $-.51 *$ & & & & & & & & & & & & & & & \\
\hline
\end{tabular}




\section{$\underline{\text { Women in Political Leadership: Discriminant Analysis Results }}$}

In this section, results are presented for the women in political leadership dependent cluster variable only - women in business leadership are discussed in the prior section. This section follows the order of the hypotheses. As with the business leadership dependent variable, a discriminant analysis was run on the political leadership dependent variable separately for each category of variables in each hypothesis: the business environment (H2), societal development (H3), economics (H4), technology and infrastructure (H5), political freedom (H6), and culture (H7). Four analyses are run for each hypothesis section to uncover the variables that could discriminate among women in political leadership from: levels 1 and 2, levels 2 and 3, levels 3 and 4, and finally overall from levels 1 through 4 to reveal the factors that can distinguish among countries with low and high levels of participation of women in political leadership. Tables 13-18 show the discriminant analysis results for all hypotheses and sub-hypotheses for $\mathrm{H} 2$ through $\mathrm{H} 7$ for all combinations of levels - 1 and 2, 2 and 3, 3 and 4, and all levels 1 through 4.

Reported in this section are Lambda $(\lambda)$, sample size $(N)$, significance (p-value), and the percent of the countries correctly classified in the cross-validated analysis. When interpreting the significance of the percent correctly classified, it is important to note that when examining discriminating ability between two levels (1 and 2, 2 and 3, 3 and 4), by chance alone $50 \%$ of the countries can be correctly classified, and when distinguishing among all levels 1 through 4, by chance alone $25 \%$ of the countries can be correctly classified. Therefore, the higher the percent of the correctly classified countries beyond these two benchmarks, the more impact that variable has. Finally, to determine direction 
only, a Pearson's correlation is reported for each significant function variable found in the discriminant analysis (the significance of the correlation is not considered as important as the significant discriminant analysis results.)

Hypothesis 2: The Business Environment

Hypothesis 2 stated that business institutional variables can distinguish among qualitatively different levels of women's participation in positions of leadership. To test this hypothesis, a stepwise discriminant analysis was run on 11 sub-categories to determine which of the variables in each of these categories can distinguish between levels 1 and 2, 2 and 3,3 and 4, and among all levels 1 through 4 of women in political leadership. Correlations are provided to show the positive or negative relationship between each significant dependent and independent variable. Table 13 shows the results of these analyses. Hypothesis 2 a stated that business facilitating institutional forces are positively related to the levels of women's participation in positions of leadership. Hypothesis $2 \mathrm{~b}$ stated that business inhibiting institutional forces are negatively related to the levels of women's participation in positions of leadership. As can be seen in the following review of the results, both hypotheses $2 \mathrm{a}$ and $2 \mathrm{~b}$ are supported.

Gift Giving: As can be seen in Table 13, giving gifts to bureaucratic officials to facilitate business is able to distinguish between all levels, except levels 3 and 4 . In distinguishing between levels 1 and 2, a significant function was generated $(\lambda=.46, N=32$, $\mathrm{p}<.05)$ indicating that GiftGivingtoGetanElectricalConnection is able to accurately classify $75 \%$ of the countries in the cross-validated analysis, with a negative association $(r=-.37)$. In distinguishing between levels 2 and 3, a significant function was generated 
$(\lambda=.79, \mathrm{~N}=27, \mathrm{p}<.05)$ indicating that GiftGivingtoGetanOperatingLicense is able to accurately classify $65 \%$ of the countries in the cross-validated analysis, but with a weak positive association $(r=.15)$. In distinguishing among all levels 1 through 4 , a significant function was generated $(\lambda=.68, \quad \mathrm{~N}=44, \quad \mathrm{p}<.01)$ indicating that GiftGivingtoGetanElectricalConnection is able to accurately classify $43 \%$ of the countries in the cross-validated analysis, with a positive association $(r=-.36)$. Making informal payments to bureaucratic officials is in general negatively related to women's participation in political leadership.

Crime and Corruption: As can be seen in Table 13, costs associated with crime and corruption are able to distinguish between all levels of women's participation in political leadership, except between levels 3 and 4 . In distinguishing between levels 1 and 2, a significant function was generated $(\lambda=.91, N=68, \mathrm{p}<.05)$ indicating that SecurityCosts are able to accurately classify $59 \%$ of the countries in the cross-validated analysis, with a positive association $(r=.30)$. In distinguishing between levels 2 and 3 , a significant function was generated $(\lambda=.92, \mathrm{~N}=61, \mathrm{p}<.05)$ indicating that SecurityCosts again are able to accurately classify $57 \%$ of the countries in the cross-validated analysis, but with a negative association $(r=-.28)$. In distinguishing among all levels 1 through 4 , a significant function was generated $(\lambda=.88, \mathrm{~N}=95, \mathrm{p}<.01)$ indicating that SecurityCosts again are able to accurately classify only $22 \%$ of the countries in the cross-validated analysis, with a weak negative association $(r=-.02)$. Costs associated with crime and corruption are in general negatively related to women's participation in political leadership. 
Skill Level of Workers: As can be seen in Table 13, worker skills are able to distinguish between all levels of women's participation in political leadership, but not among all levels 1 through 4 together. In distinguishing between levels 1 and 2, a significant function was generated $(\lambda=.72, \quad \mathrm{~N}=41, \quad \mathrm{p}<.01)$ indicating that AverageNumberofUnskilledProductionWorkers, FirmsOfferingFormalTraining, and Average NumberofNonProductionWorkrs are able to accurately classify 59\% of the countries in the cross-validated analysis. FirmsOfferingFormalTraining and AverageNumberofNonProductionWorkrs are both positively associated $(r=.14$ and $r=$ .11 respectively) and Average NumberofUnskilledProductionWorkers is negatively associated $(r=-.12)$ with women in political leadership. In distinguishing between levels 2 and 3 , a significant function was generated $(\lambda=.88, N=32, \mathrm{p}<.05)$ indicating that YearsofExperienceoftheTopManagers are able to accurately classify $61 \%$ of the countries in the cross-validated analysis, with a negative association $(r=-.32)$. In distinguishing between levels 3 and 4 , a significant function was generated $(\lambda=.62, \mathrm{~N}=14, \mathrm{p}<.05)$ indicating that AverageNumberofSkilledProductionWorkers are able to accurately classify only $44 \%$ of the countries in the cross-validated analysis, with a weak negative association $(r=-.05)$. Women's participation in political leadership is positively related to firms offering formal training and non-production workers, but negatively related to unskilled production workers, top management experience, and skilled production workers, although the latter is extremely weak.

Obstacles to International Trade: As can be seen in Table 13, obstacles to international trade are able to distinguish between or among almost all levels of women's participation in political leadership. In distinguishing between levels 1 and 2 , a 
significant function was generated $(\lambda=.91, \mathrm{~N}=69, \mathrm{p}<.05)$ indicating that Customs TradeRegsAsAMajorConstraint is able to accurately classify $57 \%$ of the countries in the cross-validated analysis, with a negative association $(r=-.28)$. In distinguishing among all levels 1 through 4 , a significant function was generated $(\lambda=.86, N=95, p<.01)$ indicating that CustomsTradeRegsAsAMajorConstraint again is able to accurately classify $24 \%$ of the countries in the cross-validated analysis, with a negative association $(r=-.34)$. Women's participation in political leadership was negatively related to firms feeling that customs and trade regulations are a major constraint.

Bureaucratic Procedures for Licenses and Permits: As can be seen in Table 13, bureaucratic procedures for licenses and permits are able to distinguish between levels 1 and 2 only. A significant function was generated $(\lambda=.88, N=37, p<.05)$ indicating that DealingwithLicensesTime is able to accurately classify $51 \%$ of the countries in the crossvalidated analysis, with a negative association $(r=-.04)$. Women's participation in political leadership is weakly related to time needed for dealing with licenses.

Bureaucratic procedures for Enforcing Contracts: As can be seen in Table 13, cumbersome bureaucratic procedures for enforcing contracts are able to distinguish between all levels of women's participation in political leadership, except between levels 2 and 3. In distinguishing between levels 1 and 2, a significant function was generated $(\lambda=.91, \mathrm{~N}=100, \mathrm{p}<.01)$ indicating that EnforcingContractsProcedures is able to accurately classify $60 \%$ of the countries in the cross-validated analysis, with a negative association $(r=-.26)$. In distinguishing between levels 3 and 4, a significant function was generated $(\lambda=.73, \mathrm{~N}=38, \mathrm{p}<.001)$ indicating that EnforcingContractsProcedures again is able to accurately classify $79 \%$ of the countries in the cross-validated analysis, 
with a negative association $(r=-.54)$. In distinguishing among all levels 1 through 4 , a significant function was generated $(\lambda=.82, \quad \mathrm{~N}=138, \quad \mathrm{p}<.01)$ indicating that EnforcingContractsProcedures again is able to accurately classify $39 \%$ of the countries in the cross-validated analysis, with a negative association $(r=-.32)$. Cumbersome procedures to enforce contracts are negatively related to women's participation in political leadership.

Arduous tax systems: As can be seen in Table 13, arduous tax systems are able to distinguish between or among almost all levels of women's participation in political leadership. In distinguishing between levels 1 and 2, a significant function was generated $(\lambda=.91, \mathrm{~N}=66, \mathrm{p}<.05)$ indicating that TaxRateAsAMajorConstraint is able to accurately classify $61 \%$ of the countries in the cross-validated analysis, with a positive association $(r$ $=-.34)$. In distinguishing among all levels 1 through 4 , a significant function was generated $(\lambda=.86, \mathrm{~N}=89, \mathrm{p}=.01)$ indicating that TaxAdministrationAsAMajorConstraint is able to accurately classify $31 \%$ of the countries in the cross-validated analysis, with a negative association $(r=-.33)$. Women's participation in political leadership is negatively related to firms that feel that tax administration is a major constraint.

Bureaucratic Procedures for Starting a Business: As can be seen in Table 13, cumbersome bureaucratic procedures for starting a business are not able to distinguish between levels 1 and 2,2 and 3,3 and 4, or among all levels 1 through 4. Women's participation in political leadership is not related to bureaucratic procedures for starting a business. 
Tools to Finance a Business: As can be seen in Table 13, access to tools to finance a business is able to distinguish between levels 1 and 2 only. A significant function was generated $(\lambda=.94, \quad \mathrm{~N}=70, \quad \mathrm{p}<.05)$ indicating that AccessCost ofFinanceAsMajorConstraint is able to accurately classify $56 \%$ of the countries in the cross-validated analysis, with a negative association $(r=-.22)$. Access to financing, such as collateral, and costs of financing, such as interest rates, that are viewed as a major constraint are negatively related to women's participation in political leadership at the lower levels only.

Global Business Competitiveness: As can be seen in Table 13, global business competitiveness is not able to distinguish between levels 1 and 2,2 and 3, 3 and 4, or among all levels 1 through 4 . Global business competitiveness is not related to women's participation in political leadership.

Strong Entrepreneurial Environment: As can be seen in Table 13, a strong entrepreneurial environment is able to distinguish between all levels of women's participation in political leadership, except between levels 2 and 3. In distinguishing between levels 1 and 2, a significant function was generated $(\lambda=.18, \mathrm{~N}=11, \mathrm{p}<.01)$ indicating that AccessibleAffordableBusinessServicesSuppliers and RespectForIndividaulisticAndInnovative Entrepreneurs are able to accurately classify $82 \%$ of the countries in the cross-validated analysis. AccessibleAffordableBusinessServicesSuppliers is positively associated $(r=.74)$ and RespectForIndividaulisticAndInnovativeEntrepreneurs is negatively associated $(r=-.07)$ with women in political leadership. In distinguishing between levels 3 and 4 , a significant function was generated $(\lambda=.69, \quad \mathrm{~N}=18, \quad \mathrm{p}<.05)$ indicating that 
SocialAcceptanceRespectforEntrepreneurs is able to accurately classify $78 \%$ of the countries in the cross-validated analysis, all with a negative association $(r=-.56) . \quad$ In distinguishing among all levels 1 through 4 , a significant function was generated $(\lambda=.31$, $\mathrm{N}=29$, $\mathrm{p}<.001$ ) indicating that AccessibleAffordable BusinessServicesSuppliers and SocialAcceptanceRespectforEntrepreneurs are able to accurately classify $48 \%$ of the countries in the cross-validated analysis. AccessibleAffordableBusiness ServicesSuppliers are positively associated $(r=.12)$ and SocialAcceptanceRespectfor Entrepreneurs is negatively associated $(r=-.47)$ with women in political leadership. Access to affordable business services and suppliers is positively related to women's participation in political leadership, whereas respect for individualistic and entrepreneurial behavior and social acceptance and respect for entrepreneurs are negatively related. 


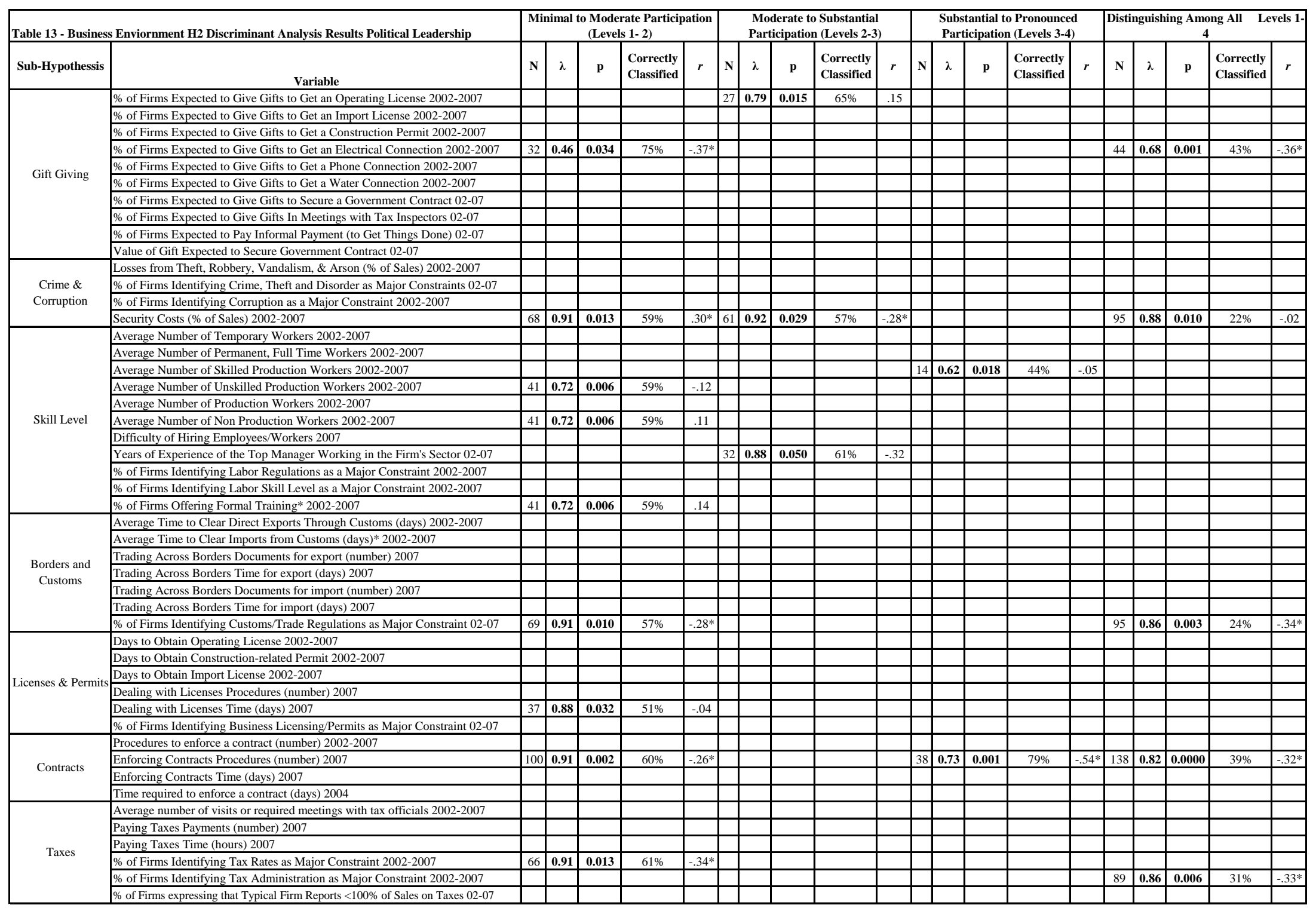




\begin{tabular}{|c|c|c|c|c|c|c|c|c|c|c|c|c|c|c|c|c|c|c|c|c|c|}
\hline \multicolumn{2}{|c|}{ Table 13 Cont'd - Business Enviornment H2 Discriminant Analysis Political Leadership } & \multicolumn{5}{|c|}{$\begin{array}{l}\text { Minimal to Moderate Participation } \\
\text { (Levels 1- 2) }\end{array}$} & \multicolumn{5}{|c|}{$\begin{array}{l}\text { Moderate to Substantial } \\
\text { Participation (Levels 2-3) }\end{array}$} & \multicolumn{5}{|c|}{$\begin{array}{l}\text { Substantial to Pronounced } \\
\text { Participation (Levels 3-4) }\end{array}$} & \multicolumn{5}{|c|}{$\begin{array}{c}\text { Distinguishing Among All Levels 1- } \\
4\end{array}$} \\
\hline Sub-Hypothessis & \begin{tabular}{|c} 
Variable \\
\end{tabular} & $\mathbf{N}$ & $\lambda$ & $\mathbf{p}$ & $\begin{array}{l}\text { Correctly } \\
\text { Classified }\end{array}$ & $r$ & $\mathbf{N}$ & $\lambda$ & $\mathbf{p}$ & $\begin{array}{l}\text { Correctly } \\
\text { Classified }\end{array}$ & $r$ & $\mathbf{N}$ & $\lambda$ & $\mathbf{p}$ & $\begin{array}{l}\text { Correctly } \\
\text { Classified }\end{array}$ & $r$ & $\mathbf{N}$ & $\lambda$ & $\mathbf{p}$ & $\begin{array}{l}\text { Correctly } \\
\text { Classified }\end{array}$ & $r$ \\
\hline \multirow{10}{*}{ Start-up Procedure } & Procedures to register property (number) 2002-2007 & & & & & & & & & & & & & & & & & & & & \\
\hline & Registering Property Procedures (number) 2007 & & & & & & & & & & & & & & & & & & & & \\
\hline & Registering Property Time (days) 2007 & & & & & & & & & & & & & & & & & & & & \\
\hline & \begin{tabular}{|l|l|} 
Time required to register property (days) 2004 \\
\end{tabular} & & & & & & & & & & & & & & & & & & & & \\
\hline & $\%$ of Senior MgmtTime Dealing w/ Requirements of Govt Regulation 02-07 & & & & & & & & & & & & & & & & & & & & \\
\hline & Cost of business start-up procedures (\% of GNI per capita) 2002-2007 & & & & & & & & & & & & & & & & & & & & \\
\hline & \begin{tabular}{|l|l|} 
Starting a Business Procedures (number) 2007 \\
\end{tabular} & & & & & & & & & & & & & & & & & & & & \\
\hline & \begin{tabular}{|l|} 
Starting a Business Time (days) 2007 \\
\end{tabular} & & & & & & & & & & & & & & & & & & & & \\
\hline & Start-up procedures to register a business (number) 2004 & & & & & & & & & & & & & & & & & & & & \\
\hline & Time required to start a business (days) 2004 & & & & & & & & & & & & & & & & & & & & \\
\hline \multirow{4}{*}{ Financing } & $\%$ of Firms Using Banks to Finance Investments 2002-2007 & & & & & & & & & & & & & & & & & & & & \\
\hline & \% of Firms Using Banks to Finance Expenses 2002-2007 & & & & & & & & & & & & & & & & & & & & \\
\hline & $\%$ of Firms Identifying Access/Cost of Finance as Major Constraint 2002-2007 & 70 & 0.94 & 0.038 & $56 \%$ & -.22 & & & & & & & & & & & & & & & \\
\hline & 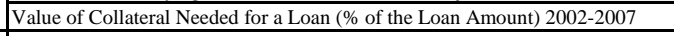 & & & & & & & & & & & & & & & & & & & & \\
\hline \multirow{8}{*}{$\begin{array}{c}\text { Global } \\
\text { Competitiveness }\end{array}$} & Global Competitiveness Index 2007 & & & & & & & & & & & & & & & & & & & & \\
\hline & Global Competitiveness Institutions 2007 & & & & & & & & & & & & & & & & & & & & \\
\hline & \begin{tabular}{|l|} 
Global Competitiveness Business Sophistication 2007 \\
\end{tabular} & & & & & & & & & & & & & & & & & & & & \\
\hline & \begin{tabular}{|l|l|} 
Global Competitiveness Innovation 2007 \\
\end{tabular} & & & & & & & & & & & & & & & & & & & & \\
\hline & Global Competitiveness Labor Market Efficiency 2007 & & & & & & & & & & & & & & & & & & & & \\
\hline & Global Competitiveness Financial Market Efficiency 2007 & & & & & & & & & & & & & & & & & & & & \\
\hline & \begin{tabular}{|l|l|} 
Global Competitiveness Goods Market Efficiency 2007 \\
\end{tabular} & & & & & & & & & & & & & & & & ( & & & & \\
\hline & \begin{tabular}{|l|} 
Global Competitiveness Market Size 2007 \\
\end{tabular} & & & & & & & & & & & & & & & & & & & & \\
\hline \multirow{14}{*}{$\begin{array}{c}\text { Entrepreneurial } \\
\text { Framework } \\
\text { Conditions }\end{array}$} & Good Infrastructure and Communications 2003 & & & & & & & & & & & & & & & & & & & & \\
\hline & Respect for Individualistic and Innovative Entrepreneurs 2003 & & & & & & & & & & & & & & & & & & & & \\
\hline & Social Acceptance \& Respect for Entrepreneurs 2003 & & & & & & & & & & & 18 & 0.69 & 0.016 & $78 \%$ &. $.56 *$ & 29 & 0.31 & 0.0005 & $48 \%$ & $-.47^{*}$ \\
\hline & Supportive Environment for Women 2003 & & & & & & & & & & & & & & & & & & & & \\
\hline & Business Opportunity Environment \& Entrepreneurial Ability 2003 & & & & & & & & & & & & & & & & & & & & \\
\hline & Positive Impression of Govt Support 2003 & & & & & & & & & & & & & & & & & & & & \\
\hline & \begin{tabular}{|l|l|} 
Accessible \& Affordable Business Services \& Suppliers 2003 \\
\end{tabular} & 11 & 0.18 & 0.001 & $82 \%$ & $.74 *$ & & & & & & & & & & & 29 & 0.31 & 0.0005 & $48 \%$ & .12 \\
\hline & Sufficient Funding 2003 & & & & & & & & & & & & & & & & & & & & \\
\hline & \begin{tabular}{|l|l|} 
Strong Intellectual Property Rights 2003 \\
\end{tabular} & & & & & & & & & & & & & & & & & & & & \\
\hline & Grade School Entrepreneurial Education Focus 2003 & & & & & & & & & & & & & & & & & & & & \\
\hline & Good Market Opportunity and Controls 2003 & & & & & & & & & & & & & & & & & & & & \\
\hline & \begin{tabular}{|l|l|} 
Positive Research and Technology Environment 2003 \\
\end{tabular} & & & & & & & & & & & & & & & & & & & & \\
\hline & Timely access to utilities, communications, and permits/licenses 2003 & & & & & & & & & & & & & & & & & & & & \\
\hline & Good Available Entrepreneurship Training 2003 & & & & & & & & & & & & & & & & & & & & \\
\hline
\end{tabular}




\begin{tabular}{|c|c|c|c|c|c|c|c|c|c|c|c|c|c|c|c|c|c|c|c|c|c|}
\hline \multicolumn{2}{|c|}{ Table 13 Cont'd - Business Enviornment H2 Discriminant Analysis Political Leadership } & \multicolumn{5}{|c|}{$\begin{array}{l}\text { Minimal to Moderate Participation } \\
\text { (Levels 1- 2) }\end{array}$} & \multicolumn{5}{|c|}{$\begin{array}{c}\text { Moderate to Substantial } \\
\text { Participation (Levels 2-3) }\end{array}$} & \multicolumn{5}{|c|}{$\begin{array}{l}\text { Substantial to Pronounced } \\
\text { Participation (Levels 3-4) }\end{array}$} & \multicolumn{5}{|c|}{\begin{tabular}{|cc} 
Distinguishing Among All Levels 1- \\
4
\end{tabular}} \\
\hline Sub-Hypothessis & Variable & $\mathbf{N}$ & $\lambda$ & $\mathbf{p}$ & $\begin{array}{l}\text { Correctly } \\
\text { Classified }\end{array}$ & $r$ & $\mathbf{N}$ & $\lambda$ & $\mathbf{p}$ & $\begin{array}{l}\text { Correctly } \\
\text { Classified }\end{array}$ & $r$ & $\mathbf{N}$ & $\lambda$ & $\mathbf{p}$ & \begin{tabular}{|l|} 
Correctly \\
Classified
\end{tabular} & $r$ & $\mathbf{N}$ & $\lambda$ & $\mathbf{p}$ & $\begin{array}{l}\text { Correctly } \\
\text { Classified }\end{array}$ & $r$ \\
\hline \multirow{10}{*}{ Start-up Procedure } & Procedures to register property (number) 2002-2007 & & & & & & & & & & & & & & & & & & & & \\
\hline & Registering Property Procedures (number) 2007 & & & & & & & & & & & & & & & & & & & & \\
\hline & \begin{tabular}{|l|} 
Registering Property Time (days) 2007 \\
\end{tabular} & & & & & & & & & & & & & & & & & & & & \\
\hline & Time required to register property (days) 2004 & & & & & & & & & & & & & & & & & & & & \\
\hline & $\%$ of Senior MgmtTime Dealing w/ Requirements of Govt Regulation 02-07 & & & & & & & & & & & & & & & & & & & & \\
\hline & Cost of business start-up procedures (\% of GNI per capita) 2002-2007 & & & & & & & & & & & & & & & & & & & & \\
\hline & Starting a Business Procedures (number) 2007 & & & & & & & & & & & & & & & & & & & & \\
\hline & Starting a Business Time (days) 2007 & & & & & & & & & & & & & & & & & & & & \\
\hline & Start-up procedures to register a business (number) 2004 & & & & & & & & & & & & & & & & & & & & \\
\hline & Time required to start a business (days) 2004 & & & & & & & & & & & & & & & & & & & & \\
\hline \multirow{4}{*}{ Financing } & $\%$ of Firms Using Banks to Finance Investments 2002-2007 & & & & & & & & & & & & & & & & & & & & \\
\hline & \% of Firms Using Banks to Finance Expenses 2002-2007 & & & & & & & & & & & & & & & & & & & & \\
\hline & $\%$ of Firms Identifying Access/Cost of Finance as Major Constraint 2002-2007 & 70 & 0.94 & 0.038 & $56 \%$ & -.22 & & & & & & & & & & & & & & & \\
\hline & Value of Collateral Needed for a Loan (\% of the Loan Amount) 2002-2007 & & & & & & & & & & & & & & & & & & & & \\
\hline \multirow{8}{*}{$\begin{array}{c}\text { Global } \\
\text { Competitiveness }\end{array}$} & Global Competitiveness Index 2007 & & & & & & & & & & & & & & & & & & & & \\
\hline & \begin{tabular}{|l|l|} 
Global Competitiveness Institutions 2007 \\
\end{tabular} & & & & & & & & & & & & & & & & & & & & \\
\hline & \begin{tabular}{|l|} 
Global Competitiveness Business Sophistication 2007 \\
\end{tabular} & & & & & & & & & & & & & & & & & & & & \\
\hline & \begin{tabular}{|l|} 
Global Competitiveness Innovation 2007 \\
\end{tabular} & & & & & & & & & & & & & & & & & & & & \\
\hline & Global Competitiveness Labor Market Efficiency 2007 & & & & & & & & & & & & & & & & & & & & \\
\hline & Global Competitiveness Financial Market Efficiency 2007 & & & & & & & & & & & & & & & & & & & & \\
\hline & Global Competitiveness Goods Market Efficiency 2007 & & & & & & & & & & & & & & & & & & & & \\
\hline & \begin{tabular}{|l|l|} 
Global Competitiveness Market Size 2007 \\
\end{tabular} & & & & & & & & & & & & & & & & & & & & \\
\hline \multirow{14}{*}{$\begin{array}{c}\text { Entrepreneurial } \\
\text { Framework } \\
\text { Conditions }\end{array}$} & Good Infrastructure and Communications 2003 & & & & & & & & & & & & & & & & & & & & \\
\hline & Respect for Individualistic and Innovative Entrepreneurs 2003 & & & & & & & & & & & & & & & & & & & & \\
\hline & Social Acceptance \& Respect for Entrepreneurs 2003 & & & & & & & & & & & 18 & 0.69 & 0.016 & $78 \%$ & $-.56^{*}$ & 29 & 0.31 & 0.0005 & $48 \%$ & $-.47 *$ \\
\hline & \begin{tabular}{|l|l|} 
Supportive Environment for Women 2003 \\
\end{tabular} & & & & & & & & & & & & & & & & & & & & \\
\hline & Business Opportunity Environment \& Entrepreneurial Ability 2003 & & & & & & & & & & & & & & & & & & & & \\
\hline & Positive Impression of Govt Support 2003 & & & & & & & & & & & & & & & & & & & & \\
\hline & Accessible \& Affordable Business Services \& Suppliers 2003 & 11 & 0.18 & 0.001 & $82 \%$ & $.74 *$ & & & & & & & & & & & 29 & 0.31 & 0.0005 & $48 \%$ & .12 \\
\hline & Sufficient Funding 2003 & & & & & & & & & & & & & & & & & & & & \\
\hline & Strong Intellectual Property Rights 2003 & & & & & & & & & & & & & & & & & & & & \\
\hline & Grade School Entrepreneurial Education Focus 2003 & & & & & & & & & & & & & & & & & & & & \\
\hline & Good Market Opportunity and Controls 2003 & & & & & & & & & & & & & & & & & & & & \\
\hline & \begin{tabular}{|l} 
Positive Research and Technology Environment 2003 \\
\end{tabular} & & & & & & & & & & & & & & & & & & & & \\
\hline & Timely access to utilities, communications, and permits/licenses 2003 & & & & & & & & & & & & & & & & & & & & \\
\hline & Good Available Entrepreneurship Training 2003 & & & & & & & & & & & & & & & & & & & & \\
\hline
\end{tabular}




\section{Hypothesis 3: Societal Development}

Hypothesis 3 stated that societal institutional variables can distinguish between qualitatively different levels of women's participation in positions of leadership. To test this hypothesis, a stepwise discriminant analysis was run on 5 sub-categories to determine which of the variables in each of these categories can distinguish between levels 1 and 2, 2 and 3, 3 and 4, and among all levels 1 through 4 of women in political leadership. Correlations are provided to show the positive or negative relationship between each significant dependent and independent variable. Table 14 shows the results of these analyses. Hypothesis 3 a stated that societal development is positively related to the levels of women's participation in positions of leadership. As can be seen in the following review of the results, hypothesis $3 \mathrm{a}$ is supported.

Burgeoning employment: As can be seen in Table 14, burgeoning employment is able to distinguish between all levels of women's participation in political leadership except between levels 2 and 3 . In distinguishing between levels 1 and 2 , a significant function was generated $(\lambda=.84, \mathrm{~N}=41, \mathrm{p}<.05)$ indicating that EmployeeServicesFemale are able to accurately classify $70 \%$ of the countries in the cross-validated analysis with a postitive association $(r=.39)$. In distinguishing between levels 3 and 4 , a significant function was generated $(\lambda=.75, \mathrm{~N}=24, \mathrm{p}<.05)$ indicating that EstimatedEearnedIncomeFemale was able to accurately classify $80 \%$ of the countries in the cross-validated analysis, again with a positive association $(r=.41)$. In distinguishing among all levels 1 through 4 , a significant function was generated $(\lambda=.71, \mathrm{~N}=52, \mathrm{p}<.01)$ with $43 \%$ of the countries correctly classified in 
the cross-validated analysis showing EstimatedEearnedIncomeFemale again with a positive association $(r=.46)$. Women's participation in political leadership is positively related to the employment and income level of women.

Gender Equality: As can be seen in Table 14, gender equality is able to distinguish between all levels of women's participation in political leadership. In distinguishing between levels 1 and 2 , a significant function was generated $(\lambda=.78, \mathrm{~N}=79$, $\mathrm{p}<.001$ ) indicating that the GenderGapIndex is able to accurately classify $66 \%$ of the countries in the cross-validated analysis, with a positive association $(r=.45)$. In distinguishing between levels 2 and 3 , a significant function was generated $(\lambda=.87, \mathrm{~N}=62$, $\mathrm{p}<.01)$ indicating that GenderGapPoliticalEmpowerment is able to accurately classify $73 \%$ of the countries in the cross-validated analysis, with a positive association $(r=.37)$. In distinguishing between levels 3 and 4 , a significant function was generated $(\lambda=.48, \mathrm{~N}=36, \mathrm{p}<.001)$ indicating that again GenderGapPoliticalEmpowerment is able to accurately classify $87 \%$ of the countries in the cross-validated analysis, with a positive association $(r=.71)$. In distinguishing among all levels 1 through 4 , a significant function was generated $(\lambda=.37, \mathrm{~N}=115, \mathrm{p}<.001)$ indicating that GenderGapPoliticalEmpowerment and the GenderGapIndex are able to accurately classify $56 \%$ of the countries in the cross-validated analysis, with a positive association $(r=.70$ and $r=.64$ respectively). Gender equality and the political empowerment of women are positively related to women's participation in political leadership.

Employment and Literacy: As can be seen in Table 14, quality human capital is able to distinguish between all levels of women's participation in political leadership. In distinguishing between levels 1 and 2, a significant function was generated 
$(\lambda=.81, \mathrm{~N}=45, \mathrm{p}<.001)$ indicating that AdultLiteracyFemalesAge15andOlder is able to accurately classify $62 \%$ of the countries in the cross-validated analysis, with a positive association $(r=.33)$. In distinguishing between levels 2 and 3 , a significant function was generated $(\lambda=.78, \mathrm{~N}=36, \mathrm{p}<.05)$ indicating that AdultLiteracyRateAges 15 andOlder and EducationCombinedPrimSecTerMales are able to accurately classify only $51 \%$ of the countries in the cross-validated analysis, with a weak positive association $(r=.02$ and $r=.04$ respectively). In distinguishing between levels 3 and 4 , a significant function was generated $(\lambda=.67, \mathrm{~N}=25, \mathrm{p}<.01)$ indicating that GlobalCompetitivHigherEducationTraining is able to accurately classify $75 \%$ of the countries in the cross-validated analysis, with a positive association $(r=.52)$. In distinguishing among all levels 1 through 4 , a significant function was generated $(\lambda=.77, \mathrm{~N}=59, \mathrm{p}<.01)$ indicating that PublicSpendingOnEducationTotal is able to accurately classify only $25 \%$ of the countries in the cross-validated analysis, with a positive association $(r=.28)$. Female literacy, the education and literacy of males, higher education, and public spending on education are positively related to women's participation in political leadership.

Population: As can be seen in Table 14, age and urban population are able to distinguish between all levels of women's participation in political leadership, except levels 2 and 3. In distinguishing between levels 1 and 2, a significant function was generated $(\lambda=.89, \mathrm{~N}=120, \mathrm{p}<.01)$ indicating that Populationfemaleoftotal and Rural populationoftotalpopulation are able to accurately classify $66 \%$ of the countries in the cross-validated analysis, with a positive association $(r=.27)$ and a negative association $(r=.15)$ respectively. In distinguishing between levels 3 and 4 , a significant function was generated $(\lambda=.85$, $\mathrm{N}=49$, $\mathrm{p}<.01)$ indicating that Ruralpopulationoftotalpopulation is able to accurately classify $62 \%$ of the countries in the cross-validated 
analysis, with a negative association $(r=-.36)$ In distinguishing among all levels 1 through 4 , a significant function was generated $(\lambda=.86, \mathrm{~N}=169, \mathrm{p}<.001)$ indicating that Populationages65andaboveoftotal again is able to accurately classify $39 \%$ of the countries in the cross-validated analysis, with a positive association $(r=.37)$. Having adults over the age of 65 in a population is positively related to women's participation in political leadership, whereas a rural population is negatively related.

Human Health and Environmental Development: As can be seen in Table 14, human health and environmental development is able to distinguish among all levels 1 through 4 only of women's participation in political leadership, but not between pairs of levels. A significant function was generated $(\lambda=.78, \mathrm{~N}=53, \mathrm{p}<.01)$ indicating that the HumanDevelopmentIndex is able to accurately classify $36 \%$ of the countries in the cross-validated analysis, with positive association $(r=.27)$. Overall human development is positively related to women's participation in political leadership. 


\begin{tabular}{|c|c|c|c|c|c|c|c|c|c|c|c|c|c|c|c|c|c|c|c|c|c|}
\hline \multicolumn{2}{|c|}{ Table 14 - Societal Development H3 Discriminant Analysis Results Political Leadership } & \multicolumn{5}{|c|}{$\begin{array}{c}\text { Minimal to Moderate Participation } \\
\text { (Levels 1- 2) }\end{array}$} & \multicolumn{5}{|c|}{$\begin{array}{l}\text { Moderate to Substantial } \\
\text { Participation (Levels 2-3) }\end{array}$} & \multicolumn{5}{|c|}{$\begin{array}{l}\text { Substantial to Pronounced } \\
\text { Participation (Levels 3-4) }\end{array}$} & \multicolumn{5}{|c|}{$\begin{array}{l}\text { Distinguishing Among All } \\
\text { Levels 1-4 }\end{array}$} \\
\hline $\begin{array}{c}\text { Sub- } \\
\text { Hypothessis }\end{array}$ & Variable & $\mathbf{N}$ & $\lambda$ & $\mathbf{p}$ & $\begin{array}{l}\text { Correctly } \\
\text { Classified } \\
\end{array}$ & $r$ & $\mathbf{N}$ & $\lambda$ & $\mathbf{p}$ & $\begin{array}{l}\text { Correctly } \\
\text { Classified }\end{array}$ & $r$ & $\mathbf{N}$ & $\lambda$ & $\mathbf{p}$ & \begin{tabular}{l|l} 
Correctly \\
Classified
\end{tabular} & $r$ & $\mathbf{N}$ & $\lambda$ & $\mathbf{p}$ & $\begin{array}{l}\text { Correctly } \\
\text { Classified } \\
\end{array}$ & $r$ \\
\hline \multirow{22}{*}{ Employment } & Contributing Family Workers Females \% 2004 & & & & & & & & & & & & & & & & & & & & \\
\hline & Contributing Family Workers males \% 2004 & & & & & & & & & & & & & & & 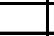 & & & & & \\
\hline & Employees, agriculture, female (\% of female employment) WDI 2004 & & & & & & & & & & & & & & & 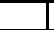 & & & & & \\
\hline & Employees, agriculture, male (\% of male employment) WDI 2004 & & & & & & & & & & & & & & & & & & & & \\
\hline & Employment in agriculture (\% of total employment) UN 2004 & & & & & & & & & & & & & & & 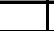 & & & & & \\
\hline & Share of women in nonagriculture (\% of nonagricultural employment) 2004 & & & & & & & & & & & & & & & & & & & & \\
\hline & Employees, industry, female (\% of female employment) 2004 & & & & & & & & & & & & & & & & & & & & \\
\hline & Employees, industry, male (\% of male employment) 2004 & & & & & & & & & & & & & & & & & & & & \\
\hline & Employment in industry (\% of total employment) 2004 & & & & & & & & & & & & & & & & & & & & \\
\hline & Employees, services, female (\% of female employment) 2004 & 41 & 0.84 & 0.010 & $70 \%$ & $.39 *$ & & & & & & & & & & & & & & & \\
\hline & Employees, services, male (\% of male employment) 2004 & & & & & & & & & & & & & & & & & & & & \\
\hline & Employment in services (\% of total employment) 2004 & & & & & & & & & & & & & & & & & & & & \\
\hline & Estimated earned income, female (PPP US\$) 2004 & & & & & & . & & & & & 24 & 0.75 & 0.013 & $80 \%$ & $.41 *$ & 52 & 0.71 & 0.001 & $43 \%$ & $.46^{*}$ \\
\hline & \begin{tabular}{|l|l|} 
Estimated earned income, male (PPP US\$) 2004 \\
\end{tabular} & & & & & & & & & & & & & & & & & & & & \\
\hline & Ratio of estimated female to male earned income 2003 & & & & & & & & & & & 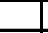 & & & & 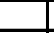 & & & & & \\
\hline & Labor force participation rate, female (\% of females ages 15-64) 2004 & & & & & & & & & & & & & & & & & & & & \\
\hline & Labor force participation rate, male (\% of males ages 15-64) 2004 & & & & & & & & & & & & & & & 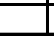 & & & & & \\
\hline & Labor force participation rate, total (\% of total ages 15-64) 2004 & & & & & & & & & & & & & & & & & & & & \\
\hline & Labor force, female (\% of total labor force) $2004 *$ & & & & & & & & & & & & & & & & & & & & \\
\hline & Unemployment, female (\% of female labor force) 2004 & & & & & & & & & & & & & & & & & & & & \\
\hline & Unemployment, male (\% of male labor force) 2004 & & & & & & & & & & & & & & & & & & & & \\
\hline & Unemployment, total (\% of total labor force) 2004 & & & & & & & & & & & & & & & & & & & & \\
\hline \multirow{11}{*}{ Gender Equality } & Proportion of Female Legislators, Senior Officials, \& Managers 2004 & & & & & & & & & & & & & & & & & & & & \\
\hline & Female professional and technical workers (\% of total) 2004 & & & & & & & & & & & & & & & & & & & & \\
\hline & Female economic activity (ages 15+) Index 2004 & & & & & & & & & & & & & & & & & & & & \\
\hline & Female economic activity as \% of Male rate 2004 & & & & & & & & & & & & & & & & & & & & \\
\hline & $\%$ of Full Time Female Workers* 2002-2007 & & & & & & & & & & & & & & & & & & & & \\
\hline & Gender Related Development Index Value 2004 & & & & & & & & & & & & & & & & & & & & \\
\hline & Global Gender Gap Index 2007 & 79 & 0.78 & 0.0000 & $66 \%$ & $.45 *$ & & & & & & & & & & & 115 & 0.37 & 0.0000 & $56 \%$ & $.64 *$ \\
\hline & Gender Gap Economic Participation and Opportunity 2007 & & & & & & & & & & & & & & & & & & & & \\
\hline & \begin{tabular}{|l|} 
Gender Gap Educational Attainment 2007 \\
\end{tabular} & & & & & & & & & & & & & & & & & & & & \\
\hline & \begin{tabular}{|l|} 
Gender Gap Health and Survival Subindex 2007 \\
\end{tabular} & & & & & & & & & & & & & & & & & & & & \\
\hline & Gender Gap Political Empowerment 2007 & & & & & & 62 & 0.87 & 0.003 & 73 & $.37 *$ & 36 & 0.48 & 0.0000 & $87 \%$ & $.71 *$ & 115 & 0.4 & 0.0000 & $56 \%$ & $.70^{*}$ \\
\hline
\end{tabular}




\begin{tabular}{|c|c|c|c|c|c|c|c|c|c|c|c|c|c|c|c|c|c|c|c|c|c|}
\hline \multicolumn{2}{|c|}{ Table 14 Cont'd - Societal Development H3 Discriminant Analysis Political Leadership } & \multicolumn{5}{|c|}{\begin{tabular}{|c|}
$\begin{array}{c}\text { Minimal to Moderate Participation } \\
\text { (Levels 1- 2) }\end{array}$ \\
\end{tabular}} & \multicolumn{5}{|c|}{$\begin{array}{l}\text { Moderate to Substantial } \\
\text { Participation (Levels 2-3) }\end{array}$} & \multicolumn{5}{|c|}{$\begin{array}{c}\text { Substantial to Pronounced } \\
\text { Participation (Levels 3-4) }\end{array}$} & \multicolumn{5}{|c|}{$\begin{array}{c}\text { Distinguishing Among All } \\
\text { Levels 1-4 }\end{array}$} \\
\hline $\begin{array}{c}\text { Sub- } \\
\text { Hypothessis }\end{array}$ & Variable & $\mathbf{N}$ & $\lambda$ & $\mathbf{p}$ & \begin{tabular}{|l|} 
Correctly \\
Classified \\
\end{tabular} & $r$ & $\mathbf{N}$ & $\lambda$ & $\mathbf{p}$ & \begin{tabular}{|l|} 
Correctly \\
Classified \\
\end{tabular} & $r$ & $\mathbf{N}$ & $\lambda$ & $\mathbf{p}$ & \begin{tabular}{|l|} 
Correctly \\
Classified \\
\end{tabular} & $r$ & $\mathbf{N}$ & $\lambda$ & $\mathbf{p}$ & \begin{tabular}{|l|} 
Correctly \\
Classified \\
\end{tabular} & $r$ \\
\hline \multirow{15}{*}{ Education } & Adult literacy rate (\% ages 15 and older) 2004 & & & & & & 36 & 0.78 & 0.015 & $51 \%$ & .02 & & & & & & & & & & \\
\hline & \begin{tabular}{|l|} 
Adult Literacy, females (\%) (age 15+) 2004* \\
\end{tabular} & 45 & 0.81 & 0.003 & $62 \%$ & $.33^{*}$ & & & & & & & & & & & & & & & \\
\hline & \begin{tabular}{|l|l|} 
Adult Literacy, males (\%) (age 15+) 2004* \\
\end{tabular} & & & & & & & & & & & & & & & - & & & & & \\
\hline & \begin{tabular}{|l|l} 
Children out of school, primary, female 2004 \\
\end{tabular} & & & & & & & & & & & & & & & & & & & & \\
\hline & \begin{tabular}{|l|} 
Children out of school, primary, male 204 \\
\end{tabular} & & & & & & & & & & & & & & & & & & & & \\
\hline & \begin{tabular}{|l|l} 
Combined gross enrolment ratio primary, secondary, tertiary schools (\%) 04 \\
\end{tabular} & & & & & & & & & & & & & & & & & & & & \\
\hline & Education Combined primary, secondary, tertiary schools, female (\%) 2004 & & & & & & & & & & & & & & & & & & & & \\
\hline & \begin{tabular}{|l} 
Education Combined primary, secondary, tertiary schools, male (\%) 2004 \\
\end{tabular} & & & & & & 36 & 0.78 & 0.015 & $51 \%$ & .04 & & & & & & & & & & \\
\hline & Primary education, pupils 2004 & & & & & & & & & & & & & & & & & & & & \\
\hline & \begin{tabular}{|l|l|} 
Primary education, pupils ( $\%$ female) 2004 \\
\end{tabular} & & & & & & & & & & & & & & & & & & & & \\
\hline & Public spending on education, total (\% of GDP) 2004 & & & & & & & & & & & . & & & & 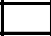 & 59 & 0.77 & 0.0020 & $25 \%$ & $.28 *$ \\
\hline & \begin{tabular}{|l|} 
Secondary education, pupils 2004 \\
\end{tabular} & & & & & & & & & & & & & & & & & & & & \\
\hline & \begin{tabular}{|l} 
Secondary education, pupils (\% female) 2004 \\
\end{tabular} & & & & & & & & & & & . & & & & 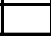 & & - & & & 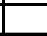 \\
\hline & Education index 2004 & & & & & & & & & & & & & & & & & & & & \\
\hline & Global Competitiveness Higher Education \& Training 2007 & & & & & & & & & & & 25 & 0.67 & 0.003 & $75 \%$ & $.52 *$ & & & & & \\
\hline \multirow{6}{*}{ Population } & Population ages 0-14 (\% of total) 2004 & & & & & & & & & & & & & & & & & & & & \\
\hline & Population ages 15-64 (\% of total) 2004 & & & & & & & & & & & & & & & & & & & & \\
\hline & \begin{tabular}{|l|l} 
Population ages 65 and above (\% of total) 2004 \\
\end{tabular} & & & & & & & & & & & & & & & & 169 & 0.86 & 0.0001 & $39 \%$ & $.37 *$ \\
\hline & \begin{tabular}{|l|} 
Population, female (\% of total) 2004 \\
\end{tabular} & 120 & 0.89 & 0.001 & $66 \%$ & $.27 *$ & & & & & & & & & & & & & & & \\
\hline & \begin{tabular}{|l|} 
Rural population (\% of total population) 2004 \\
\end{tabular} & 120 & 0.89 & 0.001 & $66 \%$ & -.15 & & & & & & 49 & 0.85 & 0.007 & $62 \%$ & $-.36^{*}$ & & & & & \\
\hline & \begin{tabular}{|l|} 
Urban population (\% of total) 2004 \\
\end{tabular} & & & & & & & & & & & & & & & & & & & & \\
\hline \multirow{14}{*}{$\begin{array}{c}\text { Health \& } \\
\text { Development }\end{array}$} & Birth rate, crude (per 1,000 people) 2004 & & & & & & & & & & & & & & & & & & & & \\
\hline & \begin{tabular}{|l|} 
Death rate, crude (per 1,000 people) 2004 \\
\end{tabular} & & & & & & & & & & & & & & & 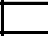 & & & & & \\
\hline & Fertility rate, total (births per woman) 2004 & & & & & & & & & & & & & & & & & & & & \\
\hline & Human Development Index 2004 & & & & & & & & & & & & & & & ב & 53 & 0.78 & 0.006 & $36 \%$ & $.27^{*}$ \\
\hline & Global Competitiveness Health \& Primary Education 2007 & & & & & & & & & & & & & & & & & & & & \\
\hline & Improved sanitation facilities (\% of population with access) 2004 & & & & & & & & & & & & & & & & & & & & \\
\hline & Improved water source (\% of population with access) 2004 & & & & & & & & & & & & & & & & & & & & \\
\hline & Life expectancy at birth (years) 2004 & & & & & & & & & & & & & & & & & & & & \\
\hline & Life expectancy index 2004 & & & & & & & & & & & & & & & & & & & & \\
\hline & Life Expectancy at Birth, females 2004 & & & & & & & & & & & & & & & & & & & & \\
\hline & Life Expectancy at Birth, males 2004 & & & & & & & & & & & & & & & & & & & & \\
\hline & Out-of-pocket health expenditure (\% of private expenditure on health) 2004 & & & & & & & & & & & & & & & & & & & & \\
\hline & Physicians (per 1,000 people) 2004 & & & & & & & & & & & & & & & & & & & & \\
\hline & Prevalence of undernourishment (\% of population) 2004 & & & & & & & & & & & & & & & & & & & & \\
\hline
\end{tabular}




\section{$\underline{\text { Hypothesis 4: Economics Factors }}$}

Hypothesis 4 stated that economic institutional variables can distinguish between qualitatively different levels of women's participation in positions of leadership. To test this hypothesis, a stepwise discriminant analysis was run on 9 sub-categories to determine which of the variables in each of these categories can distinguish between levels 1 and 2, 2 and 3, 3 and 4, and among all levels 1 through 4 of women in political leadership. Correlations are provided to show the positive or negative relationship between each significant dependent and independent variable. Table 15 shows the results of these analyses. Hypothesis 4a stated that economic facilitating institutional forces are positively related to the levels of women's participation in positions of leadership. Hypothesis $4 \mathrm{~b}$ stated that economic inhibiting institutional forces are positively related to the levels of women's participation in positions of leadership. As can be seen in the following review of the results, both hypotheses $4 \mathrm{a}$ and $4 \mathrm{~b}$ are supported.

Economic Freedom: As can be seen in Table 15, economic freedom is able to distinguish between almost all levels of women's participation in political leadership. In distinguishing between levels 1 and 2, and among all levels 1 through 4, a significant function was generated for each analysis $(\lambda=.96, \mathrm{~N}=103, \mathrm{p}<.05, \lambda=.90, \mathrm{~N}=148, \mathrm{p}<.01)$ respectively, indicating that the IndexofEconomicFreedom is able to accurately classify $57 \%$ and $33 \%$ of the countries in the cross-validated analysis respectively. The IndexofEconomicFreedom is positively associated with women in political leadership in all cases ( $r=.20$ and $r=.31$, respectively). Economic freedom is positively related to women's participation in political leadership. 
Macroeconomic Stability: As can be seen in Table 15, the global competitiveness of macroeconomic stability is not able to distinguish between levels 1 and 2, 2 and 3, 3 and 4, or among all levels 1 through 4. Macroeconomic stability is not related to women's participation in political leadership.

Economic Development: As can be seen in Table 15, GDP is able to distinguish between levels 3 and 4 and among all levels 1 through 4 of women's participation in political leadership. In distinguishing between levels 3 and 4, a significant function was generated $(\lambda=.87, \mathrm{~N}=33, \mathrm{p}<.05)$ indicating that GDPperCapitaConstantUS $\$ \$$ is able to accurately classify $77 \%$ of the countries in the cross-validated analysis, with a positive association $(r=.44)$. In distinguishing among all levels 1 through 4 , a significant function was generated $(\lambda=.81, \quad \mathrm{~N}=97, \quad \mathrm{p}<.001) \quad$ indicating that GDPperCapitaPPPconstantInt $\$$ is able to accurately classify $41 \%$ of the countries in the cross-validated analysis, with a positive association $(r=.39)$. GDP is positively related to women's participation in political leadership.

Non-Performing Bank Loans: As can be seen in Table 15, non-performing bank loans are able to distinguish between all levels, except between levels 3 and 4 . In distinguishing between levels 1 and 2, 2 and 3, and among all levels 1 through 4, a significant function was generated for each analysis $(\lambda=.94, N=64, p<.10 ; \lambda=.92, N=56$, $\mathrm{p}<.05 ; \lambda=.86, \mathrm{~N}=98, \mathrm{p}<.01$ respectively), indicating that BankNonPerfomingLoans are able to accurately classify $63 \%, 61 \%$, and $39 \%$ of the countries in the cross-validated analysis respectively. BankNonPerfomingLoans are negatively associated with women in political leadership in all 3 cases $(r=-.25, r=-.28$, and $r=-.34$, respectively). Non- 
performing bank loans are negatively related to women's participation in political leadership.

Domestic Credit Provided to the Private Sector: As can be seen in Table 15, domestic credit provided to the private sector is able to distinguish among all levels 1 through 4 only of women's participation in political leadership. A significant function was generated $(\lambda=.89, \mathrm{~N}=167, \mathrm{p}<.001)$ indicating that DomesticCreditToPrivateSector is able to accurately classify $38 \%$ of the countries in the cross-validated analysis, with a positive association $(r=.32)$. Domestic credit is positively related to women's participation in political leadership.

Taxes: As can be seen in Table 15, taxes are able to distinguish between almost all levels of women's participation in political leadership. In distinguishing between levels 1 and 2, a significant function was generated $(\lambda=.83, \mathrm{~N}=38, \mathrm{p}<.05)$ indicating that HighestMarginalTaxRate is able to accurately classify $58 \%$ of the countries in the crossvalidated analysis, with a positively association $(r=.31)$. In distinguishing among all levels 1 through 4 , a significant function was generated $(\lambda=.80, N=63, p<.01)$ indicating that HighestMarginalTaxRate is able to accurately classify $25 \%$ of the countries in the cross-validated analysis, with a positive association $(r=.31)$. The highest marginal tax rate is positively related to women's participation in political leadership.

Inflation: As can be seen in Table 15, inflation is not able to distinguish between levels 1 and 2, 2 and 3, 3 and 4, or among all levels 1 through 4 and is not related to women's participation in political leadership.

Inflows and Outflows: As can be seen in Table 15, imports and exports signifying international trade are able to distinguish between levels 1 and 2 only. A significant 
function was generated $(\lambda=.91, \quad \mathrm{~N}=70, \quad \mathrm{p}<.05) \quad$ indicating that ExportsOfGoodsAndServicesofGDP are able to accurately classify $55 \%$ of the countries in the cross-validated analysis, with a positive association $(r=.16)$. Exports are positively related to women's participation in political leadership.

Types of Goods and Services Produced and Sold: As can be seen in Table 15, the types of goods and services produced and sold are not able to distinguish between levels 1 and 2,2 and 3, 3 and 4, or among all levels 1 through 4 and are not related to women's participation in political leadership. 


\begin{tabular}{|c|c|c|c|c|c|c|c|c|c|c|c|c|c|c|c|c|c|c|c|c|c|}
\hline \multicolumn{2}{|c|}{ Table 15- Economics H4 Discriminant Analysis Results Political Leadership } & \multicolumn{5}{|c|}{$\begin{array}{c}\text { Minimal to Moderate } \\
\text { Participation (Levels 1- 2) }\end{array}$} & \multicolumn{5}{|c|}{$\begin{array}{l}\text { Moderate to Substantial } \\
\text { Participation (Levels 2-3) }\end{array}$} & \multicolumn{5}{|c|}{$\begin{array}{l}\text { Substantial to Pronounced } \\
\text { Participation (Levels 3-4) }\end{array}$} & \multicolumn{5}{|c|}{$\begin{array}{l}\text { Distinguishing Among All } \\
\text { Levels 1-4 }\end{array}$} \\
\hline Sub-Categories & Variable & $\mathbf{N}$ & $\lambda$ & $\mathbf{p}$ & $\begin{array}{l}\text { Correctly } \\
\text { Classified }\end{array}$ & $r$ & $\mathbf{N}$ & $\lambda$ & $\mathbf{p}$ & \begin{tabular}{|l|} 
Correctly \\
Classified \\
\end{tabular} & $r$ & $\mathbf{N}$ & $\lambda$ & $\mathbf{p}$ & \begin{tabular}{|l|} 
Correctly \\
Classified \\
\end{tabular} & $r$ & $\mathbf{N}$ & $\lambda$ & $\mathbf{p}$ & \begin{tabular}{l|} 
Correctly \\
Classified
\end{tabular} & $r$ \\
\hline $\begin{array}{c}\text { Economic } \\
\text { Freedom }\end{array}$ & Index of Economic Freedom 2005 & 103 & 0.96 & 0.040 & $57 \%$ & $.20 *$ & & & & & & & & & & & 148 & 0.90 & 0.001 & $33 \%$ & $.31 *$ \\
\hline $\begin{array}{c}\text { Macroeconomic } \\
\text { Stability }\end{array}$ & Global Competitiveness Macroeconomic Stability 2007 & & & & & & & & & & & & & & & & & & & & \\
\hline \multirow{10}{*}{$\begin{array}{l}\text { GDP Related } \\
\text { Factors }\end{array}$} & GDP per capita (constant 2000 US\$) 2004 & & & & & & & & & & & 33 & 0.87 & 0.042 & $77 \%$ & $.44 *$ & & & & & \\
\hline & GDP per capita, PPP (constant 2000 international \$) 2004 & & & & & & & & & & & & & & & & 97 & 0.81 & 0.0002 & $41 \%$ & $39 *$ \\
\hline & \begin{tabular}{|l|l} 
GDP per capita (PPP US\$) 2004* \\
\end{tabular} & & & & & & & & & & & & & & & & & & & & \\
\hline & \begin{tabular}{|l|} 
GDP index 2004* \\
\end{tabular} & & & & & & & & & & & & & & & & & & & & \\
\hline & \begin{tabular}{|l} 
Final consumption expenditure (constant 2000 US\$) 2004 \\
\end{tabular} & & & & & & & & & & & & & & & & & & & & \\
\hline & \begin{tabular}{|l|l|} 
Final consumption expenditure, etc. (\% of GDP) $2004^{*}$ \\
\end{tabular} & & & & & & & & & & & & & & & & & & & & \\
\hline & \begin{tabular}{|l|} 
General government final consumption expenditure (\% of GDP)* \\
\end{tabular} & & & & & & & & & & & & & & & & & & & & \\
\hline & \begin{tabular}{|l} 
General government final consumption expenditure (constant 2000 US\$) 2004 \\
\end{tabular} & & & & & & & & & & & & & & & & & & & & \\
\hline & Household final consumption expenditure (constant 2000 US\$) 2004 & & & & & & & & & & & & & & & & & & & & \\
\hline & Household final consumption expenditure, etc. (\% of GDP) 2004* & & & & & & & & & & & & & & & & & & & & \\
\hline Loans & Bank nonperforming loans to total gross loans (\%) 2004 & 64 & 0.94 & 0.051 & $63 \%$ & -.25 & 56 & 0.92 & 0.040 & $61 \%$ & $.28 *$ & & & & & & 98 & 0.86 & 0.003 & $39 \%$ & $.34 *$ \\
\hline \multirow{2}{*}{ Domestic Credit } & Domestic credit provided by banking sector (\% of GDP) 2004 & & & & & & & & & & & & & & & & & & & & \\
\hline & Domestic credit to private sector (\% of GDP) 2004 & & & & & & & & & & & & & & & & 167 & 0.89 & 0.0003 & $38 \%$ & $32 *$ \\
\hline \multirow{2}{*}{ Taxes } & Highest marginal tax rate, individual rate (\%) 2004 & 38 & 0.83 & 0.010 & $58 \%$ & $.31 *$ & & & & & & & & & & & 63 & 0.80 & 0.004 & $25 \%$ & $.39^{*}$ \\
\hline & Tax revenue (\% of GDP) 2004 & & & & & & & & & & & & & & & & & & & & \\
\hline \multirow{2}{*}{ Inflation } & Inflation, consumer prices (annual \%) 2004 & & & & & & & & & & & & & & & & & & & & \\
\hline & Inflation, GDP deflator (annual \%) 2004 & & & & & & & & & & & & & & & & & & & & \\
\hline \multirow{5}{*}{$\begin{array}{c}\text { Inflows \& } \\
\text { Outflows }\end{array}$} & Foreign direct investment, net inflows (\% of GDP) 2004 & & & & & & & & & & & & & & & & & & & & \\
\hline & Imports of goods and services (\% of GDP) 2004 & 70 & 0.91 & 0.013 & $55 \%$ & $.16 *$ & & & & & & & & & & & & & & & \\
\hline & Imports of goods and services (constant 2000 US\$) 2004 & & & & & & & & & & & & & & & & & & & & \\
\hline & Exports of goods and services (\% of GDP) 2004 & & & & & & & & & & & & & & & & & & & & \\
\hline & Exports of goods and services (constant 2000 US\$) 2004 & & & & & & & & & & & & & & & & & & & & \\
\hline \multirow{12}{*}{$\begin{array}{c} \\
\text { Types of Good } \\
\text { \& Services }\end{array}$} & International tourism, receipts (\% of total exports) 2004 & & & & & & & & & & & & & & & & & & & & \\
\hline & High-technology exports (\% of manufactured exports) 2004 & & & & & & & & & & & & & & & & & & & & \\
\hline & \begin{tabular}{|l|l|} 
Commercial service exports (current US\$) 2004 \\
\end{tabular} & & & & & & & & & & & & & & & & & & & & \\
\hline & Computer, communications, other svcs (\% commercial svc exports) 2004 & & & & & & & & & & & & & & & & & & & & \\
\hline & Insurance and financial services (\% of commercial service exports) 2004 & & & & & & & & & & & & & & & & & & & & \\
\hline & $\%$ of Exporter Firms 2002-2007 & & & & & & & & & & & & & & & & & & & & \\
\hline & \begin{tabular}{|l|} 
Manufactures exports (\% of merchandise exports) 2004 \\
\end{tabular} & & & & & & & & & & & & & & & & & & & & \\
\hline & Ores and metals exports (\% of merchandise exports) 2004 & & & & & & & & & & & & & & & & & & & & \\
\hline & \begin{tabular}{|l|} 
Agricultural raw materials exports (\% of merchandise exports) 2004 \\
\end{tabular} & & & & & & & & & & & & & & & & & & & & \\
\hline & Food exports (\% of merchandise exports) 2004 & & & & & & & & & & & & & & & & & & & & \\
\hline & Fuel exports (\% of merchandise exports) 2004 & & & & & & & & & & & & & & & & & & & & \\
\hline & Arms imports (constant 1990 US\$) 2004 & & & & & & & & & & & & & & & & & & & & \\
\hline
\end{tabular}




\section{Hypothesis 5: Technology and Physical Infrastructure}

Hypothesis 5 stated that technology and physical infrastructure institutional variables can distinguish between qualitatively different levels of women's participation in positions of leadership. To test this hypothesis, a stepwise discriminant analysis was run on 2 sub-categories to determine which of the variables in each of these categories can distinguish between levels 1 and 2, 2 and 3, 3 and 4, and among all levels 1 through 4 of women in political leadership. Correlations are provided to show the positive or negative relationship between each significant dependent and independent variable. Table 16 shows the results of these analyses. Hypothesis 5a stated that technological advancements and physical infrastructure are positively related to the levels of women's participation in positions of leadership. As can be seen in the following review of the results, hypothesis 5a is supported.

Physical Infrastructure: is positively related to the levels of women's participation in positions of leadership. As can be seen in Table 16, physical infrastructure is able to distinguish between all levels of women's participation in political leadership, except between levels 2 and 3. In distinguishing between levels 1 and 2, a significant function was generated $(\lambda=.38, \quad \mathrm{~N}=18, \quad \mathrm{p}<.001)$ indicating that FixedLineAndMobile PhoneSubscribers and TelephoneMainlines are able to accurately classify $61 \%$ of the countries in the cross-validated analysis, both with a positive association $(r=.33$ and $r=$ .29 respectively). In distinguishing between levels 3 and 4, a significant function was generated $(\lambda=.85, \mathrm{~N}=35, \mathrm{p}<.05)$ indicating that ElectricPowerConsumption is able to accurately classify $68 \%$ of the countries in the cross-validated analysis, with a positive association $(r=.37)$. In distinguishing among all levels 1 through 4 , a significant 
function was generated $(\lambda=.49, \mathrm{~N}=58, \mathrm{p}<.001)$ indicating that ElectricPowerConsumption and FixedLineAndMobilePhoneSubscribers are able to accurately classify $40 \%$ of the countries in the cross-validated analysis, both with a positive association $(r=.39$ and $r=$ .36 respectively). Electric power consumption, telephone mainlines, and fixed line and mobile phone subscribers are positively related to women's participation in political leadership.

Technological Advancements: As can be seen in Table 16, international internet bandwidth is able to distinguish between all levels of women's participation in political leadership, except levels 2 and 3. In distinguishing between levels 1 and 2, 3 and 4, and among all levels 1 through 4, a significant function was generated for each analysis $(\lambda=.92, \mathrm{~N}=53, \mathrm{p}<.05 ; \lambda=.78, \mathrm{~N}=30, \mathrm{p}<.01 ; \lambda=.69, \mathrm{~N}=75, \mathrm{p}<.001$ respectively), indicating that InternationalInternetBandwidth is able to accurately classify $63 \%, 78 \%$, and $43 \%$ of the countries in the cross-validated analysis respectively. InternationalInternetBandwidth is positively associated with women in political leadership in all 3 cases $(r=.34, r=.50$, and $r=.43$, respectively). International internet bandwidth is positively related to women's participation in political leadership. 


\begin{tabular}{|c|c|c|c|c|c|c|c|c|c|c|c|c|c|c|c|c|c|c|c|c|c|}
\hline \multicolumn{2}{|c|}{ Table 16- Infrastructure/Technology H5 Discriminant Analysis Political Leadership } & \multicolumn{5}{|c|}{$\begin{array}{c}\text { Minimal to Moderate } \\
\text { Participation (Levels 1- 2) }\end{array}$} & \multicolumn{5}{|c|}{$\begin{array}{l}\text { Moderate to Substantial } \\
\text { Participation (Levels 2-3) }\end{array}$} & \multicolumn{5}{|c|}{$\begin{array}{l}\text { Substantial to Pronounced } \\
\text { Participation (Levels 3-4) }\end{array}$} & \multicolumn{5}{|c|}{$\begin{array}{|cc|}\text { Distinguishing Among All } & \text { Levels } \\
1-4\end{array}$} \\
\hline $\begin{array}{c}\text { Sub- } \\
\text { Categories }\end{array}$ & Variable & $\mathbf{N}$ & $\lambda$ & $\mathbf{p}$ & $\begin{array}{l}\text { Correctly } \\
\text { Classified }\end{array}$ & $r$ & $\mathbf{N}$ & $\lambda$ & $\mathbf{p}$ & \begin{tabular}{l|} 
Correctly \\
Classified
\end{tabular} & $r$ & $\mathbf{N}$ & $\lambda$ & $\mathbf{p}$ & \begin{tabular}{|l|} 
Correctly \\
Classified
\end{tabular} & $r$ & $\mathbf{N}$ & $\lambda$ & $\mathbf{p}$ & \begin{tabular}{l|} 
Correctly \\
Classified
\end{tabular} & $r$ \\
\hline \multirow{7}{*}{$\begin{array}{c}\text { Physical } \\
\text { Infrastructure }\end{array}$} & Railways, goods transported (million ton-km) 2004 & & & & & & & & & & & & & & & & & & & & \\
\hline & Railways, passengers carried (million passenger-km) 2004 & & & & & & & & & & & & & & & & & & & & \\
\hline & Roads, paved (\% of total roads) 2004 & & & & & & & & & & & & & & & & & & & & \\
\hline & Electric power consumption (kWh per capita) 2004 & & & & & & & & & & & 35 & 0.85 & 0.019 & $68 \%$ & $.37 *$ & 58 & 0.49 & 0.0000 & $40 \%$ & $39 *$ \\
\hline & \begin{tabular}{|l|} 
Telephone mainlines (per 1,000 people) 2004 \\
\end{tabular} & 18 & 0.38 & 0.0006 & $61 \%$ & $.29 *$ & & & & & & & & & & & & & & & \\
\hline & Global Competitiveness Basic Infrastructure 2007 & & & & & & & & & & & & & & & & & & & & \\
\hline & \begin{tabular}{|l} 
Fixed line and mobile phone subscribers (per 1,000 people) 2004 \\
\end{tabular} & 18 & 0.38 & 0.0006 & $61 \%$ & $.33^{*}$ & & & & & & & & & & & 58 & 0.49 & 0.0000 & $40 \%$ & $.36^{*}$ \\
\hline \multirow{8}{*}{$\begin{array}{c}\text { Technology } \\
\text { Infrastructure }\end{array}$} & Mobile phone subscribers (per 1,000 people) 2004 & & & & & & & & & & & & & & & & & & & & \\
\hline & Broadband subscribers (per 1,000 people) 2004 & & & & & & & & & & & & & & & & & & & & \\
\hline & International Internet bandwidth (bits per person) 2004 & 53 & 0.92 & 0.034 & $63 \%$ & $.34 *$ & & & & & & 30 & 0.78 & 0.008 & $78 \%$ & $.50^{*}$ & 75 & 0.69 & 0.0000 & $43 \%$ & $.43 *$ \\
\hline & Internet users (per 1,000 people) 2004 & & & & & & & & & & & & & & & & & & & & \\
\hline & Information \& communication technology expenditure (\%ofGDP) 04 & & & & & & & & & & & & & & & & & & & & \\
\hline & Personal computers (per 1,000 people) 2004 & & & & & & & & & & & & & & & & & & & & \\
\hline & Households with television (\%) 2004 & & & & & & & & & & & & & & & & & & & & \\
\hline & \begin{tabular}{|l|l} 
Global Competitiveness Technological Readiness 2007 \\
\end{tabular} & & & & & & & & & & & & & & & & & & & & \\
\hline
\end{tabular}




\section{Hypothesis 6: Political Freedom}

Hypothesis 6 stated that political institutional variables can distinguish between qualitatively different levels of women's participation in positions of leadership. To test this hypothesis, a stepwise discriminant analysis was run on 2 sub-categories to determine which of the variables in each of these categories can distinguish between levels 1 and 2, 2 and 3, 3 and 4, and among all levels 1 through 4 of women in political leadership. Correlations are provided to show the positive or negative relationship between each significant dependent and independent variable. Table 17 shows the results of these analyses. Hypothesis 6a stated that political rights and civil liberties are positively related to the levels of women's participation in positions of leadership. Hypothesis 6a is partially supported.

As can be seen in Table 17, political rights are able to distinguish between 2 and 3 only. A significant function was generated $(\lambda=.95, \mathrm{~N}=88, \mathrm{p}<.05)$ indicating that PoliticalRights are able to accurately classify $61 \%$ of the countries in the cross-validated analysis, with a negative association $(r=-.23)$. Civil liberties are able to distinguish between 2 and 3 only. A significant function was generated $(\lambda=.94, N=88, p<.05)$ indicating that PoliticalRights are able to accurately classify $60 \%$ of the countries in the cross-validated analysis, with a negative association $(r=-.24)$. Political rights and civil liberties are negatively related to women's participation in political leadership. 


\begin{tabular}{|c|c|c|c|c|c|c|c|c|c|c|c|c|c|c|c|c|c|c|c|c|c|}
\hline \multicolumn{2}{|c|}{ Table 17 - Political H6 Discriminant Analysis Results Political Leadership } & \multicolumn{5}{|c|}{$\begin{array}{c}\text { Minimal to Moderate } \\
\text { Participation (Levels 1- 2) }\end{array}$} & \multicolumn{5}{|c|}{$\begin{array}{l}\text { Moderate to Substantial } \\
\text { Participation (Levels 2-3) } \\
\end{array}$} & \multicolumn{5}{|c|}{$\begin{array}{l}\text { Substantial to Pronounced } \\
\text { Participation (Levels 3-4) }\end{array}$} & \multicolumn{5}{|c|}{$\begin{array}{c}\text { Distinguishing Among All } \\
\text { Levels 1-4 }\end{array}$} \\
\hline Sub-Categories & Variable & $\mathbf{N}$ & $\lambda$ & $\mathbf{p}$ & $\begin{array}{l}\text { Correctly } \\
\text { Classified }\end{array}$ & $r$ & $\mathbf{N}$ & $\lambda$ & $\mathbf{p}$ & $\begin{array}{l}\text { Correctly } \\
\text { Classified }\end{array}$ & $r$ & $\mathbf{N}$ & $\lambda$ & $\mathbf{p}$ & $\begin{array}{l}\text { Correctly } \\
\text { Classified }\end{array}$ & $r$ & $\mathbf{N}$ & $\lambda$ & $\mathbf{p}$ & $\begin{array}{l}\text { Correctly } \\
\text { Classified }\end{array}$ & $r$ \\
\hline Political Rights & Political Rights 2005 & & & & & & 88 & 0.95 & 0.032 & $61 \%$ & $-.23 *$ & & & & & & & & & & \\
\hline Civil Liberties & Civil Liberties 2005 & & & & & & 88 & 0.94 & 0.024 & $60 \%$ & $-.24 *$ & & & & & & & & & & \\
\hline
\end{tabular}




\section{Hypothesis 7: Culture}

Hypothesis 7 stated that cultural variables can distinguish between qualitatively different levels of women's participation in positions of leadership. To test this hypothesis, a stepwise discriminant analysis was run on 3 sub-categories to determine which of the variables in each of these categories can distinguish between levels 1 and 2, 2 and 3, 3 and 4, and among all levels 1 through 4 of women in political leadership. This was done in 3 groupings of analyses: 1) cultural values and practices; 2) leadership practices; and 3) social axioms. Correlations are provided to show the positive or negative relationship between each significant dependent and independent variable. Table 18 shows the results of these analyses. In some cases, for the cultural values and practices variables, correlations are provided between each practice and value variable to assist in interpreting whether the hypothesis is supported.

Hypothesis 7a stated that liberal and open cultural institutional forces are positively related to the levels of women's participation in positions of leadership. Hypothesis $7 \mathrm{~b}$ stated that constraining and restrictive cultural institutional forces are negatively related to the levels of women's participation in positions of leadership. Hypothesis 7c stated that transformational, participative, humane, and collaborative leadership skills and abilities are positively related to the levels of women's participation in positions of leadership. Hypothesis $7 \mathrm{~d}$ stated that self-serving leadership skills and abilities are negatively related to the levels of women's participation in positions of leadership. As can be seen in the following review of the results, hypotheses $7 \mathrm{a}, 7 \mathrm{~b}, 7 \mathrm{c}$ and $7 \mathrm{~d}$ are supported. 
Cultural Values and Practices: Performance orientation is able to distinguish between levels 1 and 2 and among all levels 1 through 4 . In distinguishing between levels 1 and 2 , a significant function was generated $(\lambda=.74, \mathrm{~N}=36, \mathrm{p}<.001)$ indicating that PerformanceOrientationSocietyValues are able to accurately classify $67 \%$ of the countries in the cross-validated analysis, with a positive association $(r=.51)$. In distinguishing among all levels 1 through 4 , a significant function was generated $(\lambda=.78$, $\mathrm{N}=55, \mathrm{p}<.01)$ indicating that PerformanceOrientationSocietyValues are able to accurately classify $40 \%$ of the countries in the cross-validated analysis, with a positive association $(r$ $=.19$ ). Performance orientation is positively related to women's participation in political leadership.

Future orientation is able to distinguish among all levels 1 through 4 . A significant function was generated $(\lambda=.75, \quad \mathrm{~N}=55, \quad \mathrm{p}<.01)$ indicating that FutureOrientationSocietyValues are able to accurately classify $42 \%$ of the countries in the cross-validated analysis, with a negative association $(r=-.49)$. Future orientation values are negatively related to women's participation in political leadership.

Gender egalitarianism is able to distinguish between levels 1 and 2 and among all levels 1 through 4 of women's participation in political leadership. In distinguishing between levels 1 and 2, a significant function was generated $(\lambda=.69, \mathrm{~N}=36, \mathrm{p}<.001)$ indicating that GenderEgalitarianismSocietyValues are able to accurately classify $75 \%$ of the countries in the cross-validated analysis, with a positive association $(r=.56)$. In distinguishing among all levels 1 through 4 , a significant function was generated $(\lambda=.71$, $\mathrm{N}=55, \mathrm{p}<.001$ ) indicating that GenderEgalitarianismSocietyValues are able to accurately classify $36 \%$ of the countries in the cross-validated analysis, with a positive association ( $r$ 
$=.44)$. Gender egalitarianism values are positively related to women's participation in political leadership.

Assertiveness is able to distinguish between levels 3 and 4 only. A significant function was generated $(\lambda=.71, \mathrm{~N}=19, \mathrm{p}<.05)$ indicating that AssertivenessSocietyValues are able to accurately classify $79 \%$ of the countries in the cross-validated analysis, with a negative association $(r=-.54)$. Assertiveness values are negatively related to women's participation in political leadership. Collectivism is able to distinguish between levels 1 and 2 and among all levels 1 through 4 of women's participation in political leadership. In distinguishing between levels 1 and 2 , a significant function was generated $(\lambda=.56$, $\mathrm{N}=36, \quad \mathrm{p}<.001) \quad$ indicating that InGroupCollectivismSocietyValues and InGroupCollectivismSocietyPractice are able to accurately classify $81 \%$ of the countries in the cross-validated analysis, with a positive and negative association respectively ( $r=$ .47 and $r=-.33$ ). In distinguishing among all levels 1 through 4 , a significant function was generated $(\lambda=.62, \mathrm{~N}=55, \mathrm{p}<.001)$ indicating that InGroupCollectivismSocietyPractice is able to accurately classify $44 \%$ of the countries in the cross-validated analysis, with a negative association $(r=-.61)$. In-group collectivism practices are negatively related to women's participation in political leadership.

Power distance is able to distinguish among all levels 1 through 4 . A significant function was generated $(\lambda=.74, \quad \mathrm{~N}=55, \quad \mathrm{p}<.01) \quad$ indicating that PowerDistanceSocietyPractice are able to accurately classify $40 \%$ of the countries in the cross-validated analysis, with a negative association $(r=-.50)$. Power distance is negatively related to women's participation in political leadership. 
Humane orientation is able to distinguish between levels 3 and 4. A significant function was generated $(\lambda=.58, \quad \mathrm{~N}=19, \quad \mathrm{p}<.01) \quad$ indicating that HumaneOrientationSocietyPractice are able to accurately classify $68 \%$ of the countries in the cross-validated analysis, with a negative association $(r=-.65)$. Humane orientation is negatively related to women's participation in political leadership.

Uncertainty avoidance is able to distinguish between all levels of women's participation in political leadership, except between levels 2 and 3. In distinguishing between levels 1 and 2, 3 and 4, and among all levels 1 through 4, a significant function was generated in each case $(\lambda=.86, \mathrm{~N}=36, \mathrm{p}<.05 ; \lambda=.81, \mathrm{~N}=19, \mathrm{p}<.10, \lambda=.63, \mathrm{~N}=55$, p $<.001$ respectively) indicating that UncertaintyAvoidanceValues are able to accurately classify $58 \%, 68 \%$, and $40 \%$ respectively of the countries in the cross-validated analysis, with a negative association in each instance ( $r=-.37, r=-.44$, and $r=-.60$ respectively). Uncertainty avoidance values are negatively related to women's participation in political leadership.

Culturally Endorsed Leadership Skills: As can be seen in Table 18, charismatic and visionary leadership, team-oriented leadership, humane-oriented leadership, and autonomous leadership are not able to distinguish between levels 1 and 2, 2 and 3, 3 and 4, or among all levels 1 through 4 and is not related to women's participation in political leadership.

Participative leadership is able to distinguish between all levels of women's participation in political leadership, except between levels 2 and 3. In distinguishing between levels 1 and 2, 3 and 4, and among all levels 1 through 4, a significant function was generated in each case $(\lambda=.69, \mathrm{~N}=36, \mathrm{p}<.001 ; \lambda=.75, \mathrm{~N}=19, \mathrm{p}<.05 ; \lambda=.64, \mathrm{~N}=55$, 
p<.001 respectively) indicating that Uncertainty AvoidanceValues are able to accurately classify $81 \%, 79 \%$, and $42 \%$ respectively of the countries in the cross-validated analysis, with a positive association in each instance $(r=.55, r=.50$, and $r=.51$ respectively). Participative leadership is positively related to women's participation in political leadership.

Self-protective leadership is able to distinguish between levels 1 and 2, and among all levels 1 through 4 of women's participation in political leadership. In distinguishing between levels 1 and 2, a significant function was generated $(\lambda=.70, \mathrm{~N}=36$, $\mathrm{p}<.01$ ) indicating that Self ProtectiveLeadership is able to accurately classify $72 \%$ of the countries in the cross-validated analysis, with a negative association $(r=-.55)$. In distinguishing among all levels 1 through 4 , a significant function was generated $(\lambda=.59$, $\mathrm{N}=55, \mathrm{p}<.001$ ) indicating that Self ProtectiveLeadership is able to accurately classify $47 \%$ of the countries in the cross-validated analysis, with a negative association ( $r=-$ .61). Self-protective leadership is negatively related to women's participation in political leadership.

Social Axioms: As can be seen in Table 18, cynicism and flexible religion are not able to distinguish between levels 1 and 2,2 and 3,3 and 4, or among all levels 1 through 4 and is not related to women's participation in political leadership.

Complex social systems are able to distinguish between levels 3 and 4, and among all levels 1 through 4 of women's participation in political leadership. In distinguishing between levels 3 and 4 , a significant function was generated $(\lambda=.71, \mathrm{~N}=14, \mathrm{p}<.05)$ indicating that SocialComplexity is able to accurately classify $64 \%$ of the countries in the cross-validated analysis, with a positive association $(r=.54)$. In distinguishing among all 
levels 1 through 4 , a significant function was generated $(\lambda=.74, \mathrm{~N}=38, \mathrm{p}<.05)$ indicating that SocialComplexity is able to accurately classify $45 \%$ of the countries in the crossvalidated analysis, with a positive association $(r=.40)$. Social complexity is positively related to women's participation in political leadership.

Rewards for application are able to distinguish between levels 3 and 4 only. A significant function was generated $(\lambda=.71, \quad \mathrm{~N}=14, \mathrm{p}<.05)$ indicating that RewardforApplication is able to accurately classify $71 \%$ of the countries in the crossvalidated analysis, with a negative association $(r=-.54)$. Reward for application is negatively related to women's participation in political leadership.

External locus of control is able to distinguish between levels 1 and 2, and among all levels 1 through 4 of women's participation in political leadership. In distinguishing between levels 1 and 2, and among all levels 1 through 4, a significant function was generated in each case $(\lambda=.64, \mathrm{~N}=24, \mathrm{p}<.01 ; \lambda=.71, \mathrm{~N}=38, \mathrm{p}<.01$ respectively) indicating that FateControl are able to accurately classify $75 \%$ and $32 \%$ respectively of the countries in the cross-validated analysis, with a negative association in each instance $(r=$ -.60 and $r=-.42$ respectively). External locus of control is negatively related to women's participation in political leadership. 


\begin{tabular}{|c|c|c|c|c|c|c|c|c|c|c|c|c|c|c|c|c|c|c|c|c|c|}
\hline \multicolumn{2}{|c|}{ Table 18- Culture H7 Discriminant Analysis Results Political Leadership } & \multicolumn{5}{|c|}{$\begin{array}{c}\text { Minimal to Moderate } \\
\text { Participation (Levels 1- 2) }\end{array}$} & \multicolumn{5}{|c|}{$\begin{array}{l}\text { Moderate to Substantial } \\
\text { Participation (Levels 2-3) }\end{array}$} & \multicolumn{5}{|c|}{$\begin{array}{l}\text { Substantial to Pronounced } \\
\text { Participation (Levels 3-4) }\end{array}$} & \multicolumn{5}{|c|}{$\begin{array}{l}\text { Distinguishing Among All } \\
\text { Levels 1-4 }\end{array}$} \\
\hline $\begin{array}{c}\text { Sub- } \\
\text { Categories }\end{array}$ & Variable & $\mathbf{N}$ & $\lambda$ & $\mathbf{p}$ & \begin{tabular}{|l|} 
Correctly \\
Classified \\
\end{tabular} & $r$ & $\mathbf{N}$ & $\lambda$ & $\mathbf{p}$ & \begin{tabular}{|l|} 
Correctly \\
Classified \\
\end{tabular} & $r$ & $\mathbf{N}$ & $\lambda$ & $\mathbf{p}$ & \begin{tabular}{|l|} 
Correctly \\
Classified
\end{tabular} & $r$ & $\mathbf{N}$ & $\lambda$ & $\mathbf{p}$ & \begin{tabular}{|l|} 
Correctly \\
Classified
\end{tabular} & $r$ \\
\hline \multirow{18}{*}{$\begin{array}{c}\text { Cultural } \\
\text { Values and } \\
\text { Practices }\end{array}$} & Performance Orientation: Society Practices (As is) & & & & & & & & & & & & & & & & & & & & \\
\hline & Performance Orientation: Society Values (Should Be) & 36 & 0.74 & 0.001 & $67 \%$ & $.51^{*}$ & & & & & & & & & & & 55 & 0.78 & 0.005 & $40 \%$ & .19 \\
\hline & \begin{tabular}{|l|l} 
Future Orientation: Society Practices (As is) \\
\end{tabular} & & & & & & & & & & & & & & & & & & & & \\
\hline & Future Orientation: Society Values (Should Be) & & & & & & & & & & & & & & & & 55 & 0.75 & 0.002 & $42 \%$ & $-.49^{*}$ \\
\hline & \begin{tabular}{|l|} 
Gender Egalitarianism Society Practice (As Is) \\
\end{tabular} & & & & & & & & & & & & & & & & & & & & \\
\hline & \begin{tabular}{|l|l} 
Gender Egalitarianism Society Values (Should Be) \\
\end{tabular} & 36 & 0.69 & 0.0004 & $75 \%$ & $.56^{\mathrm{*}}$ & & & & & & & & & & & 55 & 0.71 & 0.0004 & $36 \%$ & $.44 *$ \\
\hline & \begin{tabular}{|l|} 
Assertiveness Society Practices (As Is) \\
\end{tabular} & & & & & & & & & & & & & & & & & & & & \\
\hline & \begin{tabular}{|l|} 
Assertiveness Society Values (Should Be) \\
\end{tabular} & & & & & & & & & & & 19 & 0.71 & 0.017 & $79 \%$ & $-.54 *$ & & & & & \\
\hline & Institutional Collectivism Society Practice (As Is) & & & & & & & & & & & & & & & & & & & & \\
\hline & In-Group Collectivism Society Practice (As Is) & 36 & 0.56 & 0.0001 & $81 \%$ & $.47 *$ & & & & & & & & & & & 55 & 0.62 & 0.0000 & $44 \%$ & $-.61^{*}$ \\
\hline & Institutional Collectivism Society Values (Should Be) & & & & & & & & & & & & & & & & & & & & \\
\hline & In-Group Collectivism Society Values (Should Be) & 36 & 0.56 & 0.0001 & $81 \%$ & $-.33^{*}$ & & & & & & & & & & & & & & & \\
\hline & Power Distance Society Practices (As Is) & & & & & & & & & & & & & & & & 55 & 0.74 & 0.001 & $40 \%$ & $-.50^{*}$ \\
\hline & \begin{tabular}{|l|} 
Power Distance Society Values Should Be) \\
\end{tabular} & & & & & & & & & & & & & & & & & & & & \\
\hline & \begin{tabular}{|l|} 
Humane Orientation Society Practices (As Is) \\
\end{tabular} & & & & & & & & & & & 19 & 0.58 & 0.003 & $68 \%$ & $-.65^{*}$ & & & & & \\
\hline & \begin{tabular}{|l} 
Humane Orientation Society Values (Should Be) \\
\end{tabular} & & & & & & & & & & & & & & & & & & & & \\
\hline & \begin{tabular}{|l|} 
Uncertainty Avoidance Practice (As Is) \\
\end{tabular} & & & & & & & & & & & & & & & & & & & & \\
\hline & Uncertainty Avoidance Values (Should Be) & 36 & 0.86 & 0.024 & $58 \%$ & $-.37 *$ & & & & & & 19 & 0.81 & 0.060 & $68 \%$ & -.44 & 55 & 0.63 & 0.0000 & $40 \%$ & $-.60^{*}$ \\
\hline \multirow{6}{*}{$\begin{array}{l}\text { Culturally } \\
\text { Endorsed } \\
\text { Leadership } \\
\text { Skills }\end{array}$} & Charismatic/Value-based leadership & & & & & & & & & & & & & & & & 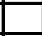 & & & & \\
\hline & Team-oriented leadership & & & & & & & & & & & & & & & & & & & & \\
\hline & \begin{tabular}{|l|} 
Participative leadership \\
\end{tabular} & 36 & 0.69 & 0.0005 & $81 \%$ & $.55^{\mathrm{*}}$ & & & & & & 19 & 0.75 & 0.028 & $79 \%$ & $.50^{*}$ & 55 & 0.64 & 0.0000 & $42 \%$ & $.51^{*}$ \\
\hline & Humane-oriented leadership & & & & & & & & & & & & & & & & & & & & \\
\hline & \begin{tabular}{|l|l} 
Autonomous leadership \\
\end{tabular} & & & & & & & & & & & & & & & & & & & & \\
\hline & \begin{tabular}{|l|} 
Self-protective leadership \\
\end{tabular} & 36 & 0.70 & 0.001 & $72 \%$ & $-.55^{*}$ & & & & & & & & & & & 55 & 0.59 & 0.0000 & $47 \%$ & $-.61^{*}$ \\
\hline \multirow{5}{*}{ Social Axioms } & \begin{tabular}{|l} 
Social Cynicism 2004 \\
\end{tabular} & & & & & & & & & & & & & & & & & & & & \\
\hline & \begin{tabular}{|l|} 
Social Complexity 2004 \\
\end{tabular} & & & & & & & & & & & 14 & 0.71 & 0.047 & $64 \%$ & $.54 *$ & 38 & 0.74 & 0.017 & $45 \%$ & $.40^{*}$ \\
\hline & Reward for Application 2004 & & & & & & & & & & & 14 & 0.71 & 0.047 & $71 \%$ & $-.54 *$ & & & & & \\
\hline & Religiosity 2004 & & & & & & & & & & & & & & & & & & & & \\
\hline & Fate Control 2004 & 24 & 0.64 & 0.002 & $75 \%$ & $-.60^{*}$ & & & & & & & & & & & 38 & 0.71 & 0.008 & $32 \%$ & $-.42 *$ \\
\hline
\end{tabular}




\section{CHAPTER 5: DISCUSSION}

Gender leadership research that compares women to men or argues that one gender is more disadvantaged than the other has been necessary but is no longer sufficient. Individual women and men, as well as the circumstances in which they operate, vary. Uncovering differences in style or characteristics between men and women has translated to some applicable action steps for training future leaders and provided various suggestions for leadership development, but since leadership development is a multifaceted and dynamic construct, research needs to broaden to examine more factors together. Since dichotomous-subject research continues to face the challenge of offering valuable male-female leadership theory useful for future leadership development, then perhaps research should move toward focusing on the skills, abilities, and contexts that promote and hinder leadership development. These may vary by gender, such that the challenges or obstacles that women face and the skills and abilities they possess may be different from those of men, but these can translate into actionable steps toward understanding how best to promote women leaders.

In addition, the challenges or obstacles that women face and the skills and abilities they possess may also differ depending on the context or society in which they operate. Regardless of prior institutions that have impeded women's advancement to leadership (gender stereotyping, role incongruity, and glass ceiling issues that affect women in leadership) women continue to ascend to positions of leadership and decisionmaking authority. Women as a whole, like many minority groups, either understand the 
obstacles confronting them and push into positions of influence anyway, or they don't acknowledge the obstacles, whether out of naïveté or obstinacy.

Institutional forces lead to a conforming of norms and increased legitimacy. Women function within institutions because of normative standards and social values that are inherent within the environment (March \& Olsen, 1984, 1989, 1996). However, women also respond to rules and incentives but consider their own priorities while interacting within the institution (Peters, 2000). As institutionalism increases and provides greater uniformity (Zucker, 1988), an infrastructure for women in leadership can prosper (Lucas, 2003).

In communities where women are not typically seen running their own businesses, for example, even one woman who operates a self-sustaining business that supports simply herself or her own household can be an unsuspecting indirect leader through her example to others. The same can be said about a woman who leads a small non-profit organization or networking/social group. It is argued here that such women who have broken the proverbial mold of traditional gender roles by independently leading their own organizations, are involved in their communities through their organizations, and may be particularly interested in promoting the advancement of other women. Herein lies the importance of women's participation in leadership and further study of the factors that positively or negatively affect it.

Women make up half of the population around the world. It is therefore a logical assumption that if the financially productive workforce in countries where women are less economically active is hypothetically doubled by the inclusion of this less operative other gender, the economy would prosper. While doubling the workforce is a grandiose 
and figurative proposition, and considering that most societies have low levels of involvement from women in leadership, if there is merely an incremental increase in participation from a less active economic sector, even a small percentage of growth in the economy can be expected. This is made possible through the additional goods produced and consumed and services offered and utilized and can then have exponential multiplicative effects as time goes on. This positive activity from women through smallscale enterprises as well as through larger and more prosperous organizations will also create jobs, boost the economy, and lead other women to follow suit and have subsequent similar effects. An increase in women's involvement in political positions can also set an example for other women who may become interested in leadership in any fashion.

However, the opposite can also result in more traditional cultures with maledominated societies and high gender inequality in that the acceptance of female coworkers can lead to feelings of stepping outside what is acceptable in the group. This leads to conflicts between traditional and modern business world cohabitation (Berry et al., 2002; Inglehart \& Baker, 2000), and between the recognized benefits of globalization at the societal level with consequent problems at the individual level. In other words, while accommodating global values has become recognized as important, these values may not have penetrated individual-level behaviors (Newburry et al., 2007). This dissertation aims to sort out exactly this point - some factors lead to an increase in women's participation in leadership, while others hinder women's advancement. 


\section{WOMEN IN BUSINESS LEADERSHIP DISCUSSION}

The following is a discussion of the results of this project, organized by each category of dependent variables and the effects of these on women's involvement in business leadership: business environment, societal development, economics, technology and infrastructure, political freedom, and culture. In particular, this discussion explores the variables that are effective in sorting out countries into the four global levels of women's participation in leadership: minimal participation level 1, moderate participation level 2, significant participation level 3, and pronounced participation level 4.

\section{The Business Environment}

This study reveals that business infrastructure variables do indeed distinguish among qualitatively different levels of women's participation in positions of business leadership. The factors that are found to make the most significant impact are gift giving to government officials, skill level of workers, obstacles to international trade, cumbersome bureaucratic procedures for enforcing contractual agreements, arduous tax systems, a globally competitive business environment, and a strong entrepreneurial environment.

Gift Giving, Corruption, and Crime: Giving gifts to bureaucratic officials to facilitate business is found to be negatively related to the levels of women's participation in positions of business leadership. Specifically, paying informal payments to get things done has a negative effect and is able to distinguish countries in level 2 from level 3 , moderate participation of women from more substantial involvement. While gift giving 
may depend on the context of the culture (Arunthanes, Tansuhaj, \& Lemak, 1994), this finding may indicate that at these middle levels of women's participation in leadership, giving gifts proves to be an inefficient business custom (Foellmi \& Oechslin, 2007; Shahabuddin, 2007). Interestingly, however, corruption and crime are not found to have any significant distinguishing effects on the levels of participation of women in leadership. Perhaps real corruption and crime don't affect women in business, whereas simply making informal payments is the way business is sometimes conducted (Hsing, 1997; Khanna \& Johnston, 2007; Rose-Ackerman, 1999; Zou \& Gao, 2007), but may be nonetheless inefficient.

Skill Level of Workers: Worker skills are found to be positively related to the levels of women's participation in positions of business leadership. In fact, the skill level of workers is able to distinguish among all levels. Skilled workers, formal training, and the years of experience of top management are positively associated with women's participation in business leadership, whereas unskilled labor shows a negative relationship, leading to fewer complaints that skill level is a major constraint as women's involvement grows.

Specifically, at the lower levels of women's participation in leadership, between levels 1 and 2, complaints about labor skill as a major constraint to business practices and the average number of temporary workers are able to distinguish between these 2 levels in a negative way, indicating that moderate proportions of women leaders at level 2 are less likely to have these characteristics than the lower minimal level 1 . However, firms that offered formal training to workers are another factor that is able to distinguish between levels 1 and 2 in a positive way. These findings indicate that countries with a 
moderate level of women business leaders are less likely to complain about skill level as a major constraint and more likely to offer their own job training than countries at the lowest minimal level of women's participation in business leadership.

The finding of a negative impact of temporary workers in distinguishing between countries at levels 1 and 2 is less clear. Perhaps job training indicates more opportunity for skill development and women to lead their own businesses rather than fill temporary positions for other employers in countries with more moderate involvement of women business leaders. This same variable is again able to distinguish between levels 2 and 3, but with a positive relationship, perhaps indicating that women business leaders are more likely to hire temporary workers themselves in countries with more substantial participation in business leadership.

In distinguishing between countries in levels 3 and 4, unskilled production workers are found to have a negative impact on women in business leadership. This echoes the importance of skill level and formal training that distinguished levels 1 from 2. These findings indicate that countries with more pronounced numbers of women business leaders have fewer unskilled laborers. In other words, the more unskilled laborers there are in society, the fewer women in business leadership. It may be assumed that high levels of unskilled labor indicate less education and formal training, for either

men or women. This same idea comes through again when examining the years of experience of top management, which has a positive impact when distinguishing among all levels 1 through 4 from the lowest to the highest levels of women's participation in business leadership. Overall, these analyses clearly indicate that skill level has a positive impact on women in leadership. 
Obstacles to International Trade: Obstacles to international trade are found to have a negative impact when distinguishing between the levels of women's participation in positions of leadership from the lowest through highest levels. In distinguishing betweens levels 1 and 2, 3 and 4, and among all levels 1 through 4, firms reported that customs and trade regulations are a major constraint to the operation and growth of businesses and this has a negative impact across the board on women in leadership. This finding indicates quite plainly that while customs may not be unavoidable when dealing in international trade, it is imperative that efficiency is a main focus. By applying a diffusion theory (Duval \& Biere, 2002; Littrell \& Miller, 2001; E. M. Rogers, 1962, 2003), this finding can be explained by the idea that international trade diffuses cultural values between countries. Obstacles to international trade are limiting outside ideas from coming into the country.

Cumbersome Bureaucratic Procedures: Bureaucratic procedures are examined in three areas: 1) obtaining licenses and permits, 2) enforcing contracts, and 3) for starting a business. The first and third are unable to distinguish between any levels of women's participation in business leadership. This is not to say that there are not obstacles in these business areas, but perhaps that they do not have a significant impact on women leaders. Enforcing contracts, however, is a significant factor in distinguishing between countries at all levels, except between levels 2 and 3. The number of procedures required to enforce a contract has a negative impact across the board on women in business leadership. This may be an issue of the importance of rule of law in that the government is needed. Institutional economics (Chang, 2002; Cheung, 1970; Commons, 1931; 
Hodgson, 2004) maintains that the minimum a government needs to provide for businesses to exist is rule of law and property rights.

Interestingly, women's participation in business leadership is not found to be affected by procedures for obtaining licenses and permits, or by procedures for starting a business. This lack of significant findings may indicate a positive perspective that women leaders at all levels may not find these areas burdensome. However, more investigation into this area is needed to know the validity of this conjecture.

Arduous Tax Systems: Burdensome tax systems are found to affect women's participation in business leadership and are able to distinguish between all levels. The belief that firms typically report less than $100 \%$ of sales on their taxes is able to distinguish between levels 1 and 2 with a positive relationship, but when distinguishing between levels 2 and 3 there is a negative relationship. The reason for this flip in direction is unclear; however, it may be noteworthy that the correlation is not significant between levels 1 and 2. In addition, firms noting that tax administration is a major constraint to business practices is a factor that is able to distinguish between levels 3 and 4, with a negative effect. As more tax systems are put in place, perhaps people report fewer sales on their taxes in countries with more moderate participation of women in business leadership than in countries with minimal participation of women in leadership. People are believed to then report more of their sales on their taxes in countries with substantial participation of women in business leadership perhaps as more income is taxed and tax systems become more efficient. In order to explicate the basis for this finding, more empirical research is needed, possibly on this relationship with economic and tax system development. 
Global Business Competitiveness: Global business competitiveness is a significant factor in distinguishing among countries at almost all levels in a positive direction. In particular, being globally competitive in labor market efficiency is found to have a positive effect in distinguishing between countries in levels 1 and 2, and global competitiveness in financial market efficiency is found to have a positive effect in distinguishing between countries in levels 3 and 4 . This suggests the importance of labor market efficiency in countries with lower levels of women's participation in business leadership and the importance of financial market efficiency at the higher levels. In other words, countries with moderate numbers of women leading businesses in level 2 are distinguishable from countries with minimal numbers in level 1 as the focus on labor markets became more efficient. Then, countries in level 4 with a pronounced numbers of women in business leadership are distinguished from level 3 as the focus on financial markets became more sophisticated. If countries want to increase the levels of women in leadership, at the lower levels, the focus needs to be on the labor market. The focus then changes to the financial market at higher levels. Overall global competitiveness is able to positively distinguish between the lowest level 1 through the highest level 4 . This confirms that global business competitiveness is positively related to women's participation in business leadership. Applying the isomorphism component of institutional theory (DiMaggio \& Powell, 1983) and diffusion theory as it relates to competition (Jovanovic \& MacDonald, 1994), one of the mechanisms through which countries become more similar is competition. This then relates to the idea that as institutions imitate each other, globalized values that are accepting of women in leadership also spread. 
Entrepreneurial Environment: A strong entrepreneurial environment is found to be positively related to the levels of women's participation in positions of business leadership and is able to classify countries into all levels. In distinguishing between levels 1 and 2, strong intellectual property rights, good market opportunity and controls, and accessible and affordable business services and suppliers are able to accurately classify countries, all with a positive association. By examining the components of these variables, as described in the methods section, this finding implies that countries in level 2 with moderate participation of women in business leadership are more likely to have strong intellectual property rights, opportunities for new businesses and new products to come to market, and access to affordable suppliers, contractors, and professional, legal, and banking services than countries with the least participation of women in business leadership. In distinguishing between the higher levels 3 and 4, a positive impression of government support for entrepreneurship, good market opportunity and controls, and good available entrepreneurship training are able to accurately classify countries, all with a positive association. Finally, again, strong intellectual property rights are able to distinguish among all levels 1 through 4, from the minimal to the pronounced participation.

Even though these data are unavoidably limited by sample size, these findings suggest that more sophisticated entrepreneurial environments with strong intellectual property rights, good market opportunities and business services, and the involvement of government support and training are conducive to increasing women in business leadership (Acs \& Szerb, 2007; Coeurderoy \& Murray, 2008; Nystrom, 2008). 
In summary to this business environment section of the women in business leadership analysis: 1) Giving gifts proves to be an inefficient business custom particularly at the middle levels of women's participation in leadership, but real crime and corruption didn't seem to have an effect on women in business. 2) Labor skill level has a positive impact on women in leadership. In countries with a moderate level of women in business leadership, firms are less likely to complain about skill level as a major constraint and more likely to offer their own job training than countries with minimal participation. In addition, job training and skill development may lead women to run their own businesses, rather than fill temporary positions for other employers, and to hire their own temporary workers in countries with more substantial participation from women in business leadership. 3) Findings indicate that women may be discriminated against when enforcing business-related contracts or when dealing in cross-border commerce. Women may also be shying away from such activities because of dealing in a male-dominated profession. However, findings indicate that women business leaders may not find procedures for obtaining licenses and permits or procedures for starting a business to be burdensome. 4) Burdensome tax systems are found to affect women's participation in business leadership and are able to distinguish among all levels. 5) The focal point then must change to the financial market in countries with more pronounced proportions of women in business leadership. Global business competitiveness has a positive effect on women's participation in business leadership across the board. 6) More sophisticated entrepreneurial environments with strong intellectual property rights, good market opportunities, accessible business services, and the involvement of government support and training are conducive to increasing women in business leadership. 


\section{$\underline{\text { Societal Development }}$}

Factors related to societal develop are found to distinguish among qualitatively different levels of women's participation in positions of business leadership. The factors that are found to make the most significant impact are burgeoning employment, gender equality, human capital, the age of the population, and human health and environmental development.

Employment: Burgeoning employment is able to distinguish among all levels of women's participation in business leadership. The employment of women in services and the unemployment of women in general are both consistently important variables for distinguishing between levels of women's participation in business leadership. The negative impact of males in the labor force is able to distinguish countries with minimal participation of women in business leadership from countries with more moderate participation, indicating that in the countries with the lowest levels of women in business leadership, with more women in the workforce, men dominate the labor force less.

Employment of Women in Services: In distinguishing between levels 1 and 2 and among all levels 1 through 4, females working in the services sector are able to accurately classify countries. This consistent positive association implies that as opportunities for women grow in the services sector, women business leaders emerge. This also echoes the consistency of women predominately working in the services sector (Hossein, Redfern, \& Carothers, 2006; Jones et al., 2006; H. Mandel \& Semyonov, 2005), which has been argued by Boserup (Boserup, 1986) to be an intermediate step in economic evolution from women's work in agriculture to work in more modern occupations. 
Unemployment of Women: The unemployment of women is also able to distinguish between all levels but with a strange positive effect between levels 2 and 3 . In other words, as women in business leadership goes up, between levels 2 and 3, the unemployment of women in general goes up. In distinguishing between levels 1 and 2, 3 and 4, and among all levels 1 through 4, the unemployment of women has a consistent negative effect - as women in business leadership goes up, the unemployment of women goes down (the employment of women in general goes up). The reason for this S-shaped relationship is unclear and needs further empirical investigation beyond the current analysis. An explanation may be that unemployment goes down from level 1 to 2 as small numbers of women business leaders set the example for more women to enter the workforce. Unemployment goes up from levels 2 to 3 as more women leave the formal labor market to start their own micro-businesses employing mostly only themselves in level 3 and are counted in national surveys as unemployed, and then unemployment begins to decrease again from levels 3 to 4 as more women join the labor force in level 4 either as workers or business leaders. Another explanation of the positive relationship between levels 2 and 3 may be offered by Boserup's (1986) assertion that as modernization happens and villagers move away from their homes because of lack of local village employment or lack of land to cultivate, the stream of migrants to more urban settings is too much to be accommodated by limited urban employment opportunities.

Gender Equality: Gender equality is found to be positively related to the levels of women's participation in positions of leadership and is able to distinguish among almost all levels. In distinguishing between minimal representation of women in business 
leadership in level 1 and more moderate representation in level 2, the Gender Related Development Index (UNDP, 2006) is able to accurately classify countries with a positive association. This index considers life expectancy, literacy, education, and income as these specifically are related to the equality of women and men. Higher levels of the Gender Related Development Index indicate equality of genders on human development factors. While seemingly obvious, this finding confirms that countries with moderate participation of women in business leadership have more gender equality than countries with minimal participation from women.

Moving from the basic equality measure of human development to the empowerment of women, in distinguishing between countries with substantial numbers of women in business leadership in level 3 and more pronounced participation in level 4 , as well as among all levels from the lowest to the highest levels of participation, the Gender Empowerment Measure (UNDP, 2006) is able to accurately classify countries with a positive association. This measure is a composite of women in parliament, female professional and technical workers, female senior legislatures and officials, and income. This means that higher gender empowerment translates to more women in business leadership. Not surprisingly, whereas gender equality in basic human development is able to distinguish between the lowest levels of women in leadership, gender empowerment in business and politics is able to distinguish between the highest levels.

Human Capital: Quality human capital is found to be positively related to the levels of women's participation in positions of leadership. In distinguishing between countries with minimal and moderate proportions of women in business leadership, the total combined education of males from primary through tertiary school has a positive 
association with women's participation in business leadership. It may be that the complete formal education of males, as well as the education of females, has a positive impact on the economy and development of $\operatorname{society}^{26}$ (see Appendix 3 correlation table), and this positive societal development is beneficial to women advancing into positions of leadership. ${ }^{27}$ The education of men is significant rather than education of women probably because at lower levels of development, men are educated before women, especially in poor societies where families can only afford an education for some and not all of their children. Similarly, male literacy is able to classify countries into level 2 with moderate numbers of women in business leadership or into level 3 with more substantial participation, but with a negative association. The reason for this relationship is unclear.

In distinguishing between substantial numbers of women in business leadership in level 3 and more pronounced proportions in level 4, higher education has a positive association. In distinguishing among all levels 1 through 4 from lowest to highest, female literacy has a positive association. These two findings clearly indicate that female literacy, across the board, and a formal education, including a higher education particularly at the highest level play an important role in the advancement of women to business leadership.

These findings regarding human capital and education reveal that the government in any given country must allocate resources to the education of both women and men. In countries with lower representations of women in business leadership, concentration

\footnotetext{
${ }^{26}$ EducationCombinedPrimSecTerFemales correlation with EducationCombinedPrimSecTerMales $(\mathrm{r}=$ $.959, \mathrm{p}<.01)$; CombinedGrossEnrolmentRatioForPrimSecTer correlation with HumanDevelopmentIndex ( $\mathrm{r}$ $=.887, \mathrm{p}<.01)$.

${ }^{27}$ WomenInBusinessLeadershipClusters correlation with HumanDevelopmentIndex $(r=.322, \mathrm{p}<.01)$.
} 
should be on literacy and basic education. In countries with greater proportions of women in business leadership, higher education should the be focus when basic educational needs have been already met.

Population Make-up: It could be argued that because younger individuals are expected to have more access to education and an attraction to modern societal and business practices that would lead to higher levels of women in leadership, in an urban population that is more cosmopolitan and more culturally understanding about women in leadership (Christy, 1987). However, this is not supported. On the contrary, population with ages 65 and over is found to distinguish among almost all levels, from the lowest to the highest levels of participation of women in leadership. The reason for this may be that an aging population is a sign of development as people live longer ${ }^{28}$ and economic development and women in business leadership have already been found to be significantly and positively related. ${ }^{29}$ In addition, this echoes the effects of human development on women in political leadership, as shown in the next discussion section; and increase in human development is found to be associated with an increase in women's participation in business leadership.

Health and Environmental Development: Human health and environmental development are found to distinguish between all levels of women's participation in business leadership, except the two middle levels. It is prudent to interpret these results along with the examination of the strong and significant correlations between women in

\footnotetext{
28 Populationages65andabove correlation with GDPperCapitaPPPUS\$ $(\mathrm{r}=.685, \mathrm{p}<.01)$; Populationages65andabove correlation with HumanDevelopmentIndex $(r=.739, p<.01)$

${ }^{29}$ WomenInBusinessLeadershipClusters correlation with GDPperCapitaPPPUS $\$(r=.365, \mathrm{p}<.01)$.
} 
business leadership and development. ${ }^{30}$ Specifically, the prevalence of undernourishment is able to distinguish minimal women's participation in level 1 and more moderate participation in level 2 with a negative effect, pointing to the reality that a societal preoccupation with basic survival needs stunts the movement of women into positions of business leadership and productive activities.

In distinguishing among all levels, out-of-pocket health expenditures and the Human Development Index are able to accurately classify countries. Whereas basic nourishment is a health concern at the lowest level, the negative relationship of out-ofpocket health expenditures with women's participation in leadership signifies that women are spending time and money stressing about health concerns in expensive health care systems and less attention to running businesses. The Human Development Index (UNDP, 2007) is a composite measure of life expectancy, literacy, education, and GDP per capita, and measures the overall human development of a country. The positive relationship between the Human Development Index and women in business leadership indicates that human development is related to the advancement of women and that countries at level 4 have higher levels of human development than countries in level 3. This supports the conjecture that healthier infants at birth, vast reading ability, complete education, and economic growth all signify a prospering social system, which affords women the opportunity to lead businesses.

In summary to this societal development section of the women in business leadership analysis: 1) In countries with the lowest levels of women in business leadership, as more women join the workforce, men have less command over the labor

\footnotetext{
${ }^{30}$ WomenInBusinessLeadershipClusters correlation with HumanDevelopmentIndex $(r=.322, \mathrm{p}<.01)$.
} 
force. As opportunities for women grow in the services sector, more women business leaders emerge. In addition, a curious S-shaped relationship exists between women in business leadership and unemployment. A decrease in unemployment from minimal to more moderate participation from women may be a result of women business leaders plowing the way for more women to enter the workforce. An increase in unemployment from moderate to more substantial participation may be a result of women leaving the formal labor market to start their own micro-businesses employing only themselves and counted in national surveys as unemployed. Unemployment then begins to decrease again as women's participation moves from substantial to more pronounced participation when more women join the labor force either as workers or business leaders. 2) Gender equality and higher gender empowerment translate to more women in business leadership. 3) The complete formal education of males and females has a positive impact on society which has a positive influence on women advancing into positions of leadership. Government in any given country must allocate resources to the education of both women and men. The focus needs to be on literacy and basic education in countries with fewer women in business leadership. When basic education is widely available, the focus needs to be on higher education in countries with greater representations of women in business leadership. 4) An aging population can be viewed as a sign of human development as people live longer, and as human development increases, more women seek out positions as business leaders. 5) In countries with problems related to malnutrition, women are preoccupied with the basic health and survival needs of their families, allowing them fewer opportunities for education and running their own businesses. For countries that have successfully afforded basic nourishment to their 
citizens, women are still spending time and money stressing about health concerns in more expensive health care systems, and paying less attention to leading businesses. Overall, an increase in human development frees women to lead businesses; an increase in women in leadership contributes to economic development.

\section{$\underline{\text { Economics Factors }}$}

Factors related to the economy are found to distinguish among qualitatively different levels of women's participation in positions of business leadership. The factors that are found to make the most significant impact are economic freedom, economic development, credit to the private sector, taxes, and international trade.

Economic Freedom: Economic freedom is able to distinguish between almost all levels of women's participation in business leadership, with a positive relationship in every case. Countries with the highest levels of economic development have the liberal property rights, business, trade, monetary, fiscal, investment, financial, and labor freedoms and freedom from corruption. Economic freedom is strongly related to good economic performance and important for pursuing sustainable prosperity (Holmes, Feulner, \& O’Grady, 2008).

Economic Development: Economic development is able to distinguish among all levels of women's participation in business leadership, with a positive association in all cases. More specifically, GDP per capita is able to distinguish among all levels 1 through 4, and GDP per capita and government expenditures are able to distinguish between levels 1 and 2. The positive relationship between GDP per capita and women in business leadership simply signifies that as women become more involved in business, the 
economy grows. Conversely, as the economy develops along with the rest of society in terms of equality, education, and health, as women become more involved in business leadership. The significant finding of government expenditures points out that countries with moderate participation of women in business leadership in level 2 are making more of an investment in goods and services and boosting economic activity than in countries with more minimal participation from women in level 1, which is beneficial to women becoming more involved in leading businesses. Furthermore, in support of this contention, Rosenbluth, Salmond, and Thies (2006) propose that as government spending provides for the wellbeing of its citizens, women are motivated to defend and expand the welfare state, and are more drawn to political activity.

Credit to the Private Sector: Non-performing bank loans are able to classify countries only into minimal or moderate levels of participation of women in business leadership and with a negative association. Domestic credit provided to the private sector is able to distinguish between levels 3 and 4 and among all levels 1 through 4 from the lowest to the highest levels of women's participation in business leadership with a positive association. These findings signify that in order for women to lead businesses, they need to be extended credit by lending institutions, but non-performing bank loans have a negative impact on women being able to get those loans, especially at the lowest levels of women in leadership where women are not recognized as savvy business leaders.

Taxes: A high marginal tax rate is able to distinguish between substantial participation level 3 and pronounced participation in level 4 with a positive relationship. The highest marginal tax rate is the highest rate shown on the schedule of tax rates 
applied to the taxable income of individuals (World Bank, 2007e). GDP, the human development index, and the highest marginal tax rate are all significantly positively correlated (see Appendix 3 correlation table) and GDP, the human development index, and the women in business leadership are all significantly positively correlated. Therefore, as the economy grows and society develops, more women run businesses, and individuals pay higher taxes.

International Trade: Inflows and outflows signifying international trade are able to distinguish between levels 1 and 2 and between levels 3 and 4 of women's participation in business leadership. While classifying countries into minimal amounts of participation from women in business leadership or more moderate proportions of women's participation, imports of goods and services showed a positive association. When classifying countries into substantial amounts of participation from women in business leadership or more pronounced representation of women's participation, foreign direct investment inflows showed a negative association. In distinguishing among all levels 1 through 4 from the lowest to the highest, exports of goods and services showed a positive association. These factors signify that international trade, in a basic interpretation, is positively related to women in business leadership. International trade diffuses cultural values between countries (Duval \& Biere, 2002; Littrell \& Miller, 2001; E. M. Rogers, 1962, 2003)s. This type of diffusion theory supports the idea of institutional isomorphism, that institutions imitate one another for best practices and competition and the spread of global cultural norms. The negative relationship between women in business leadership and FDI inflows may be explained by the idea that in 
countries will less direct investment from abroad, women are more involved in business to support the domestic market.

In turns out that not only are inflows and outflows of international trade significant, but particular types of goods and services are also able to significantly distinguish between levels of women's participation in business leadership at all levels. Commercial service exports in general are able to distinguish between level 1 with minimal participation from women and level 2 with more moderate participation; food exports are able to distinguish between level 2 and level 3 with more substantial participation; and computer communications and other services exports are able to distinguish between level 3 and level 4 with the most pronounced participation of women in business leadership. All relationships are positive. These findings indicate that exports of almost any kind are positively related to the levels of women in business leadership, and at the higher levels, exports in technology that require advanced education are particularly associated. Boserup's (Boserup, 1986) earlier propositions of economic growth that women's work in agriculture, moves to services, and then to more commercial and modern employment support these findings. In addition, the export of commercial services, including computer, communications, financial, and insurance support services most likely becomes a specialty as the local labor force fulfills outsourced services from developed countries (Ackermann, 2008; Miller, 2005; Wagley, 2008).

In summary to this economic environment section of the women in business leadership analysis: 1) Economic freedom is important for development and for women in business leadership. 2) As women become more involved in business, the economy 
grows. 3) As the economy develops along with the rest of society in terms of equality, education, and health, women become more involved in business leadership. 4) Extending credit to women enables them to lead businesses; however, non-performing bank loans have a negative effect on the ability of women to get the loans they need, especially in countries with the lowest proportions of women business leaders where women are less recognized as proficient business leaders. 5) Imports and exports of goods and services denote international trade and international learning through diffusion of culture, which has a positive effect on women business leaders. In particular, practically any kind of import or export is positively related to countries with fewer women in business leadership, but for countries with more women in business, technology exports and services that require advanced education are particularly important.

\section{Technology and Physical Infrastructure}

Factors related to the technological environment and physical infrastructure are also found to distinguish among qualitatively different levels of women's participation in positions of business leadership. The factors that are found to make the most significant impact are electric power, telephone mainlines, the global competitiveness of basic infrastructure, mobile phone subscribers and personal computers. Electric power and mobile phones are able to distinguish between levels 1 and 2 with a positive relationship; telephone mainlines are able to distinguish between levels 2 and 3 with a negative relationship; basic infrastructure in general is able to distinguish between levels 3 and 4; and fixed lines and mobile phone subscribers and personal computers are able to 
distinguish among all levels 1 through 4 with a positive relationship. These findings indicate that as the physical infrastructure and technological advancements make society more efficient, there is a growth in women in business leadership. This conjecture may even be extended to represent modernity and, as countries modernize, women become more involved in leadership (Fagerberg, 1994; Inglehart \& Baker, 2000). This is supported by a prior study of the positive effects of personal computers on entrepreneurship (Fairlie, 2006; Postman, 1993). The negative finding for the relationship between women in leadership and telephone mainlines mirrors the positive relationship between women in leadership and mobile phone subscribers, indicating that countries at lower levels of modernity are leapfrogging over the unnecessary expense of telephone line installation and moving right to mobile technology (Fink \& Kenny, 2003; Lee et al., 2006; Mrad, 2006).

\section{$\underline{\text { Political Freedom }}$}

Surprisingly, political freedoms, examined by both individual civil liberties and political rights (F. House, 2008) are not found to significantly impact women in business leadership at any level. This is a conundrum and the reasons for this finding are quite unclear. It would seem that an independent media, open political competition, a strong rule of law, respect for civil liberties, a lack of ethnic and religious strife, and lower levels of political corruption would provide an environment with ample opportunity for women in business leadership. However, no significant relationships are found, positive or even negative. 


\section{$\underline{\text { Culture }}$}

Factors related to culture are found to distinguish among qualitatively different levels of women's participation in positions of business leadership. The factors that are found to make the most significant impact are future orientation, gender egalitarianism, in-group collectivism, uncertainty avoidance, team-oriented leadership, participative leadership, humane-oriented leadership, self-protective leadership, social cynicism, reward for application, religiosity, and fate control. The performance orientation, assertiveness, power distance, and humane orientation cultural dimensions are not found to be significant factors that affect women in business leadership, nor are the charismatic/value-based leadership or autonomous leadership dimensions.

Cultural Values and Practices: The GLOBE research team collected two sets of cultural variables by asking two different samples of respondents to answer questions regarding how society really is (real societal practices) or questions regarding how society should be (societal values) (R. J. House \& Javidan, 2004). In order to uncover these seemingly subtle facets of societal culture and since before Project GLOBE values and practices have never been gathered for comparison purposes, both sets of data are included in the present study. In several of the cases, the practices and values scores for a variable are negatively related to one another, which is true for future orientation, humane orientation, performance orientation, power distance, and uncertainty avoidance. Only gender egalitarianism and in-group collectivism have positively related values and practices scores (Hanges, 2004). When discussing any significant results for these dimensions, this negative relationship between practices and values will be explicated. 
Future Orientation: Future orientation is able to distinguish between levels 1 and 2 only of women's participation in business leadership with an impressive number of countries correctly classified and a strong correlation. Future oriented practices are negatively associated with women's participation in business leadership, and future oriented values are positively associated, meaning that culture dictates that individuals should think ahead and plan for the future. Given that future orientation practices are negatively related to future orientation values (Ashkanasy et al., 2004; Hanges, 2004), it might mean that societies with weaker future orientation practices tend to value a future orientation style more, and vice versa. In other words, people in these societies recognize the importance of planning ahead and investing in the future but don't necessarily behave in accordance with those values (Ashkanasy et al., 2004). Ashkanasy et al. propose that societies lacking future orientation practices value such behaviors because they experience unfavorable uncertainty and volatility by planning for future events and have stronger aspirations for future orientation.

Therefore, it is feasible that the negative relationship found between women in business leadership and future orientation practices and the positive relationship with future orientation values suggests that while countries value future-oriented behavior, the society has not yet adopted those practices and remains reactive with regard to life occurrences rather than proactive. The implication for countries interested in including more women into business leadership is to adopt such practices. The implication for women who want to be business leaders is the same - future oriented practices should assist with intrinsic motivation and strategic planning skills that aid in achieving economic success (Ashkanasy et al., 2004). 
Gender Egalitarianism: Gender egalitarianism practices are able to distinguish between levels 2 and 3 with a positive relationship and gender egalitarianism values are able to distinguish among all levels 1 through 4 of women's participation in business leadership with a positive relationship. Gender egalitarianism is also able to correctly classify an impressive number of countries and with a strong correlation. Since gender egalitarianism values and practices are positively correlated with one another, these findings indicate that all levels of women's participation in business leadership are positively related to cultures that have more women in the labor force and in authoritative positions, bestow women a high position in society and respect their roles in decision making, have less gender segregation in the workplace, and have more literate and educated women.

Collectivism: As hypothesized, collectivistic societal practices are found to be negatively related to the levels of women's participation in positions of leadership, and therefore individualism is positively related. Because individualistic societies view individuals as autonomous and independent beings, value individual goals over group goals, believe in the nuclear family unit rather than a tight allegiance to the extended family, and have higher divorce rates as women have the freedom to break away from unhappy marriages (Gelfand et al., 2004), such customs are found to lend to the freedom of women to break away from somewhat limiting home and family responsibilities and into positions of leadership.

The GLOBE in-group collectivism dimension, which deals specifically with the extent to which individuals are proud of, loyal to, and dependent on families, is able to distinguish among all levels of women's participation in business leadership with an 
impressive number of countries correctly classified and a strong correlation. In-group collectivist societal practices are able to distinguish among countries with a negative association, suggesting that countries with higher levels of women in business leadership tend to be more individualistic than countries with fewer women in leadership.

Institutional collectivism, practices or values are not found to affect women in business leadership. Therefore, the extent to which an economic system favors individual or groups interests, or whether individualism or group cohesion is valued more in society (Gelfand et al., 2004), do not have any bearing on women becoming business leaders. As it turns out, societal collectivism is not as important as family-oriented collectivism in determining women's participation in business leadership. This means that women are not as affected by societal pressure to stay close to home or to seek personal advancement as they are by family pressure and obligation. A family that gives a woman negative feedback to the idea that she might run her own business is more influential than societal pressure. On the other hand, a family that shows support and encourages a woman to be a business leader will have more of a shaping effect than societal acceptance or hype. This influence may be extended to a close family friend or a like-family member who carries clout with the family, and may equally persuade a woman toward or away from business leadership.

Leadership of cultural change is extremely difficult because it requires changing basic assumptions and getting at the deeper levels of culture and dealing with the anxiety associated with those assumptions (Schein, 1992). In order for women leaders to inspire or coach new women in leadership, not only is the opinion of the woman who may be contemplating starting her own business important, but the feelings of her family may 
carry even more weight. This means that social acceptance of women leading businesses needs to penetrate family-deep, in order for more women to have the support to embark on such experiences. Having a few visible powerful women or a female prime minister may initiate societal acceptance, but if individuals view these women as exceptions to the rule, it may be harder to get family support for their own wives and daughters to act more individualistic. While education has been found to be important for women to advance into leadership positions, it has not proven to be enough to change family perceptions of women targeting their attentions outside the home (Read \& Oselin, 2008).

Uncertainty Avoidance: Results indicate that uncertainty avoidance values are able to distinguish between levels 1 and 2, levels 3 and 4, and among all levels 1 through 4, all with a strong negative relationship and an impressive number of countries correctly classified. As mentioned at the start of this section on cultural values and practices, uncertainty avoidance is one of the GLOBE dimensions where practices and values are negatively related to one another (Hanges, 2004; SullydeLuque \& Javidan, 2004). It was hypothesized that uncertainty avoidance societal practices would be negatively related to the levels of women's participation in positions of leadership because societies that score high on uncertainty avoidance tend to resist change, prefer established rules that allow for predictability, and be intolerant of rule breaking, making it harder for women to move out of the home and family responsibilities to take on more leadership roles in the business world. However, in order for women as a minority in the business world to become more involved in leadership they would need to take risks with uncertain outcomes, be less resistant to change, and be willing to debunk established rules and regulations that govern behavior. Since uncertainty avoidance practices and values are negatively related, while 
practices in society may be more in accordance with high uncertainty making it difficult for women to break the traditional gender role expectations, societies with high proportions of women business leaders tend to value change and low uncertainty avoidance, debunk rules and regulations, and take risks in the interest of making improvements.

Leadership Practices: Team-oriented leadership is able to distinguish between levels 2 and 3 of women's participation in business leadership with a positive association. Participative leadership is able to distinguish between levels 3 and 4 with a positive association. Autonomous leadership is able to distinguish between levels 3 and 4 with a negative association. Self-protective leadership is able to distinguish between levels 3 and 4 and among all levels 1 through 4 of women's participation in business leadership with a negative association. All 3 leadership dimensions are also able to accurately classify an impressive number of countries and with a strong correlation. These findings indicate that countries with higher levels of women in business leadership are inclined to value collaborative, diplomatic, and participative leadership styles, as opposed to selfcentered leadership styles.

These findings are very interesting and echo much of the earlier women in leadership research which argued that women are nurturing and collaborative (Alice $\mathrm{H}$ Eagly \& Linda L Carli, 2003; Eagly \& Johnson, 1990; Eagly \& Mitchell, 2004; Helgesen, 1990; Vinnicombe \& Singh, 2002; G. Yukl, 2002). This is contrary, however to much of that research that argued women have been held back from moving into leadership because of incongruities with attributions of what constitutes effective leadership. Role congruity theory (Eagly \& Karau, 2002) positioned women as discriminated against 
because of their feminine nature because leaders are typically seen as male, and men are considered to be by nature dominating and authoritative. The findings here in the current study argue exactly the opposite - that because of the context of the culture, women are advancing into leadership positions precisely because these nurturing, collaborative, participative leadership styles are value by society - and supported by prior literature (Foels et al., 2000; Hansen \& Otero, 2006; Sargent, 1981; Vecchio, 2002; Vinnicombe \& Singh, 2002).

Humane-oriented leadership is negatively associated with women in business leadership but is able to distinguish between only levels 1 and 2 . The reason for this negative relationship is unclear and counterintuitive. It would be expected that if women are participative and focus on collaborative leaders who work closely with team members, they would also be compassionate and supportive, as are characteristic of humane-oriented leadership. However, it may be that women in more humane-oriented societies don't need to get involved in political leadership to change things. Therefore, in less humane-oriented societies women get involved in humane-oriented political leadership in order to change how society treats others. In less humane-oriented societies, women political leaders who value humane-oriented leadership are needed.

Social Axioms: Leung et al.'s (K. Leung \& Bond, 2004; K. Leung et al., 2002) social axioms represent higher level general beliefs that relate to social behaviors. Four of their social axioms are significant in classifying countries into levels of women's participation in business leadership. Cynicism is able to distinguish between levels 3 and 4 of women's participation in business leadership with a negative association; religiosity is able to distinguish between levels 1 and 2 and among all levels 1 through 4 
with a negative association; fate control is able to distinguish between levels 1 and 2 with a negative association. High levels of social cynicism represent a prejudiced opinion or stereotypes of people from other groups, high levels of religiosity represent mystical or spiritual forces and less logic and reason, and high levels of fate control represent the belief that outcomes are left to fate rather than to individual control. This supports arguments made by Norris and Inglehart (2004) that Islam is negatively related women's participation leadership. Therefore, as hypothesized, these findings indicate that women in business leadership is positively associated with open-mindedness for the advancement of minorities, a lower preoccupation with religion and fate, and a strong affinity toward self-efficacy and control over life circumstances.

It is hypothesized that rewards for application would be positively related to the advancement of women in leadership. This is because rewards for application represents a general expectancy that hard work, experience, and a sensible strategy will lead to positive outcomes and therefore that if women work hard in their aspirations toward positions of leadership, they will be more inclined to achieve those goals. Rewards for application are able to distinguish between levels 1 and 2 and among all levels 1 through 4 with a negative association in both cases.

Building on Leung and Bond's (2004) earlier speculations, this negative association may indicate that difficult socioeconomic conditions, like leadership positions that have been typically held by men and where women are a minority, are related to an intense belief in reward for application as a strategy to cope with hardships, and that hard work and determination leave little attention paid to more frivolous activities. In other words, women in countries with fewer women in leadership will have a stronger belief in 
rewards for application than women in higher level countries who may not need to fight as hard to achieve positions of leadership since it is more common to find women in such positions. This is consistent with Leung and Bond's finding that reward for application is negatively related to gender equality. This mirrors Minnit and Nardone's (2007) application of expectancy theory in their finding that when women believe they have the ability and experience to start and lead businesses, and are confident that their efforts will lead to success, they are more likely to engage in such activities.

In summary to this culture section of the women in business leadership analysis: 1) Future-oriented behaviors, like planning ahead and saving for the future, are found to be important for countries that are interested in bringing more women into business leadership, or would be important practices for women who want to be business leaders to adopt. 2) Countries with more women in business leadership have more women in the labor force and in authoritative positions, bestow women a high position in society and respect their roles in decision making, have less gender segregation in the workplace, and have more literate and educated women. 3) Because individualistic societies view individuals as autonomous and independent beings, value individual over group goals, and afford women and men the right to divorce, women are more able to lead businesses without sole responsibility of caring for the home and family. Societal pressure toward collectivistic versus individualistic values does not affect women like family demands. A family, or a family friend who carries clout, can strongly influence a women to remain in the home and care for love ones, or to partake in leadership activities. Social acceptance of women leading businesses needs to go beyond a few visible powerful women or a female prime minister and penetrate family deep in order for more women to be 
motivated to embark on careers of leadership. 4) Societies with visible numbers of women in business tend to value change, debunk rules and regulations, and take risks in the interest of making improvements. 5) Countries with higher levels of women in business leadership tend to appreciate collaborative, diplomatic, and participative leadership styles, as opposed to self-interested leadership styles. 6) Women in business leadership is positively associated with welcoming the advancement of minorities, less attention paid to religion and fate, and a strong sense of self-efficacy and personal control over life circumstances. 7) Countries that have fewer women in leadership have a stronger belief in rewards for application because women recognize the need to persevere and work hard in order to achieve status positions.

\section{Conclusion to the Women in Business Leadership Findings}

Much the same way that Acs and Szerb (2007) propose that promoting enterprise development in middle-income countries should follow different strategies than in developed economies, the results of the present study show that a similar approach is true for promoting women in business leadership. Acs and Szerb suggest that middle-income countries need to concentrate on building human capital and improving technology, while developed countries should concentrate on reforming the labor market and financial market deregulation. Like in the current project, Minniti and Nardone (2007) argue socio-economic and contextual factors affect gender differences in entrepreneurial activity. However, the valuable Minniti and Nardone paper explores only age, education, household income, work status, GDP, GDP growth, and economic freedom and argues that other contextual factors may be at play. The present paper includes the missing 
contextual factors not covered by Minniti and Nardone. Illuminated in this concluding section are the areas on which countries with minimal (level 1), moderate (level 2), substantial (level 3), or pronounced (level 4) proportions of participation of women in business leadership should focus.

Level 1 - Minimal Participation of Women in Business Leadership: In level 1 with minimal representation of women in business leadership, the focus needs to be on labor skill and formal job training to increase the talent pool of the labor and make workers and the labor market more productive and efficient. Customs and trade regulations are a major constraint and bureaucratic procedures, like enforcing contracts for example, are inefficient obstacles. Entrepreneurial capacities like intellectual property rights, opportunities for new businesses and new products, and access to affordable suppliers, contactors, and professional, legal, and banking services are important to further the advancement of women into business leadership. At this level, unemployment is an issue and where jobs are available, they tend to go the men, causing women to dominate the services sector. Fundamental human development and equality of genders in life prosperity are challenges and undernourishment is a societal concern. Economic freedoms are strong. Individuals need access to bank loans and the provisions and support to make payments on those loans in order for the business environment to prosper. In level 1, imports of any kind bring in needed supplies and know-how, and the export of commercial services, including computer, communications, financial, and insurance support services, becomes a specialty as the local labor force works for outsourced services from developed countries. Electric power is of fundamental infrastructural importance, and as societies progress mobile phones allow them to 
leapfrog over the need to lay traditional telephone lines and equipment. Finally, in level 1, women work very hard to provide for themselves and their families, but are constrained by family and household responsibilities, a fear of the unknown and change, feelings of a lack of control over their own lives, and by cultures that lack practice in planning for the future and are limited by religious tradition.

Level 2 - Moderate Participation of Women in Business Leadership: In level 2 with moderate representation of women in business leadership, many of the similar characteristics as in level 1 persist with some progress made. Bureaucratic procedures like paying officials with gifts to get things done in the customs sector and enforcing contracts make for inefficient business customs, and firms report less than $100 \%$ of their sales most likely because they do not trust the government financial system. While skill level of workers remains a major constraint, more firms offer formal training and have a positive impact on women leading businesses. Labor market efficiency is critical for global competitiveness. Intellectual property rights, opportunities for new businesses and new products, and access to affordable suppliers, contactors, and professional, legal, and banking services are improved over countries in level 1 and help women advance into business leadership with a significant impact. Unemployment is an issue, and where jobs are available that is combated by women thriving in the services sector. Education is available, but more so for men, and literacy of women, gender equality, and the empowerment of women are paramount across the board for the advancement of women into leadership, although to a lesser extent than in level 1. Fundamental human development, basic nourishment, and health expenditures remain a societal concern, but again, to a lesser extent than in level 1. Economic freedoms are vital to the advancement 
of women into business leadership. Domestic credit provided from banks for business loans and a focus on building expertise in commercial services are still important for international trade and creating more opportunities for women. While basic infrastructure remains an important institutional focus, electric power and traditional telephone lines are less of a concern and society moves toward mobile phone technology and more use of personal computers. Finally, in level 2, across-the-board gender egalitarian values and practices, a comfort with the unknown and making changes, more individualistic, less dominance from religious values, more belief in personal selfefficacy and internal locus of control, and team-oriented leadership practices characterize culture and the business environment that is conducive to women becoming more involved in leading businesses.

Level 3 - Substantial Participation of Women in Business Leadership: In level 3 with more substantial representation of women in business leadership, making informal payments to officials to get things done, customs and trade regulations, contract enforcement, and tax administration are all constraints to business efficiency. The skill level of workers is still a concern, and higher education becomes more important than in prior levels, while basic female literacy and education remain an important focal point as well. While labor market efficiency remains important, the focus becomes expanded to financial market efficiency in order to achieve global competitiveness. Gender empowerment, reducing out-of-pocket health expenditures, and overall growth in human development are all powerful forces in the advance of women to participate more in business leadership. Economic freedoms are even more significant. Business loans, basic infrastructure, and technology are all persistently important forces for women to 
become business leaders. Foreign direct investment is more characteristic in level 3 than in the prior two levels and computer and communication oriented service exports remain critical to opportunities for women to lead businesses. Culturally, society still supports gender egalitarianism, risk-taking propensities, individualism, fewer expectations to adhere to traditional religious values, an affiliation toward hard work in the face of challenges that women face to ascending to leadership positions, and participative leadership styles versus individualistic and autonomous or self-centered leadership.

Level 4 - Pronounced Participation of Women in Business Leadership: In level 4 with more pronounced representation of women in business leadership, payments and gifts for government officials are less of an issue, although customs and trade regulations and enforcing contracts are still major constraints. Level 4 countries have more financial sophistication, stronger intellectual property rights, good market opportunities and controls, good available entrepreneurship training, and a positive impression of government support and services. Employment of women in the services sectors, in communication-oriented service exports in particular, is still an important factor reducing unemployment of women and helping women lead businesses. Literacy of females is less of an issue as in earlier levels and gender empowerment is strong and higher education is essential. Economic freedoms are still assign of more sophisticated economy. Business loans, basic infrastructure, and technology remain vital forces for women to become business leaders. Foreign direct investment has a negative impact perhaps as foreign companies open operations and women become employees instead of starting their own businesses. Culture revolves around gender equality, lower uncertainty avoidance values, support for individual accomplishments and growth, less pressure to follow traditional 
religious values, hard work and determination for women to lead businesses, participative and democratic leadership styles as opposed to those more autonomous or self-protective in nature.

\section{WOMEN IN POLITICAL LEADERSHIP DISCUSSION}

The following is a discussion of the results of this project, organized by each category of dependent variables and the positive or negative effects of these on women's involvement in political leadership: business environment, societal development, economics, technology and infrastructure, political freedom, and culture. In particular, this discussion explores the variables that are effective in sorting out countries into the four global levels of women's participation in leadership: minimal participation level 1, moderate participation level 2, significant participation level 3, and pronounced participation level 4.

\section{$\underline{\text { The Business Environment }}$}

This study revealed that factors related to the business environment can distinguish among qualitatively different levels of women's participation in positions of political leadership. The most significant factors to impact the involvement of women in political leadership are paying gifts to government officials, costs for security, skill level of workers, obstacles to international trade, cumbersome bureaucratic procedures for licenses, permits, enforcing contracts, arduous tax systems, financing the business, and a strong entrepreneurial environment. 
Gift-Giving to Facilitate Business: Giving gifts to bureaucratic officials to facilitate business is mostly found to be negatively related to the levels of women's participation in positions of political leadership. Specifically, being expected to give gifts to get an electrical connection has a negative impact on women in political leadership and is able to strongly distinguish countries in level 1 from countries in level 2, minimal participation of women from more moderate involvement, and distinguish countries in level 3 from countries in level 4, substantial participation of women from more pronounced levels of women's involvement in political leadership. In addition, a significant number of countries are able to be accurately classified with this specific variable, indicating its importance. This finding may indicate that having to give gifts to bureaucratic officials for basic electricity proves to be an inefficient business custom (Foellmi \& Oechslin, 2007; Shahabuddin, 2007).

Conversely, firms expecting to give gifts for obtaining an operating license are able to distinguish between levels 2 and 3 with a positive affect, distinguishing moderate levels from more substantial participation of women. It may be that the low insignificant correlation simply shows that there is a slight positive relationship, meaning that at these middle levels of women's participation in political leadership, giving gifts to bureaucratic officials for operating licenses is simply the way business is done (Hsing, 1997; Khanna \& Johnston, 2007; Rose-Ackerman, 1999; Zou \& Gao, 2007). However, it is important to note that this particular variable is not able to classify a terribly impressive percentage of countries, so its importance may be in question.

Corruption and Crime: Costs associated with crime and security are able to distinguish between all levels of women's participation in political leadership with both 
positive and negative effects. Security costs as a percent of annual sales (World Bank, 2007d) are positively related to women in political leadership when classifying countries into level 1 or level 2. This perhaps indicates that in order for women to move from quite minimal participation in political leadership to a more moderate level of involvement, it is necessary to pay for security and protection. On the other hand, in classifying countries into level 2 or 3, or when distinguishing among all four levels, these security costs have a significant negative impact, indicating that as more women become visible in political leadership, these security costs are less necessary. As with the prior discussion regarding paying gifts for operating licenses, security costs also are able to classify a less impressive percentage of countries, so its importance may too be in question. This is supported by the argument that an established rule of law provided by government is needed. Institutional economics (Chang, 2002; Cheung, 1970; Commons, 1931; Hodgson, 2004) maintains that for businesses to exist a government needs to provide at a minimum a rule of law and property rights.

Skill Level of Workers: Women's participation in political leadership is found to be positively related to non-production workers and to firms offering formal training (World Bank, 2008a), but negatively related to unskilled production workers, top management experience, and skilled production workers, although the latter is extremely weak. In classifying countries into level 1 or level 2, unskilled production workers are associated with minimal representation of women in political leadership, whereas nonproduction workers and firms offering formal training are associated with moderate involvement of women. This indicates that as these lower levels of women in political leadership, training and work outside of the production/manufacturing sector are 
associated with more moderate involvement of women in political leadership. This is echoed by finding that the employment of women in the services sector is able to positively classify countries into the moderate level 2 of women's participation in political leadership over the more minimal level 1.

Years of top management experience is able to classify countries into levels 2 or 3, with a negative effect. In other words, upper echelon management experience in the private business sector is negatively related to substantial levels of women's participation in political leadership. The reverse result is found with regard to top management experience and women in business leadership - a positive relationship. These opposing findings lead to the conclusion that women with high levels of industry experience are more likely to participate in business leadership, rather than political leadership and to remain in the private sector.

A similar finding leading to this conclusion is with regard to the negative effect of skilled production workers on distinguishing between levels 3 and 4 of women's participation in political leadership. Even though the percent of countries classified correctly with this variable is low, skilled production workers are more associated with level 3 than the more visible and pronounced participation of women in level 4 . In other words, the more skilled laborers in society, the fewer women in political leadership. It may be assumed that high levels of skilled labor indicate more involvement in the private sector and less in the public sector, for either men or women.

Bureaucratic Systems: Obstacles to international trade are found to have a negative impact when distinguishing among any of the levels of women's participation in political leadership from the lowest through highest levels. Firms reporting that customs 
and trade regulations are a major constraint to business practices have a negative impact across the board on women in leadership. This finding is the same with regard to the negative impact on women in business leadership and indicates again that efficiency is imperative concerning customs and trade regulations. However, the reason for the negative impact of customs and trade regulations on women in getting involved in political leadership is less clear. It may be that this indicates an overall inefficiency with regard to government activities, making political leadership less attractive to women. This is seen again in the next two sections regarding bureaucratic procedures for permits, licenses, and contracts. This finding can be explained by applying a diffusion theory (Duval \& Biere, 2002; Littrell \& Miller, 2001; E. M. Rogers, 1962, 2003), the idea that international trade diffuses, or spreads, cultural values between countries. Obstacles to international trade are preventing globalized ideas from entering the country.

Bureaucratic procedures are examined in three areas: 1) obtaining licenses and permits, 2) enforcing contracts, and 3) for starting a business. The number of procedures required to enforce a contract is a significant factor in classifying countries into most levels and has a negative impact across the board on women in political leadership. The same negative impact on women in political leadership in found for time spent dealing with licenses, although to a lesser extent. Again, the reasons for this are unclear, but also may signify that bureaucratic inefficiency causes women to evade political leadership government needs to provide a rule of law and property rights (Chang, 2002; Cheung, 1970; Commons, 1931; Hodgson, 2004).

Arduous tax systems are found to be negatively related to women's participation in political leadership. Specifically, the factor that is most important for classifying 
countries into the lowest two, minimal or moderate, levels of women in political leadership is tax rates being viewed as a major business constraint by firms. Slightly different, but along the same lines, the factor that is most important for classifying countries into the highest two, substantial or pronounced, levels of women in political leadership is tax administration being viewed as a major business obstacle by firms. The means at the lowest levels of women's involvement, basic tax rates are constraining, while at the highest levels of women's involvement, over all tax administration is burdensome. The reason for this negative relationship with political leadership is again unclear; however, the common thread throughout this discussion on bureaucratic systems shows that inefficiency of government in multiple ways has a negative impact on women becoming more involved in political leadership.

Financing and Entrepreneurial Environment: Access to financing (e.g., collateral) and the costs associated with financing (e.g., interest rates) that are viewed as a major constraint are negatively related to women's participation in political leadership at the lower levels only. The more firms feel these are obstacles, the less likely women are to seek out positions of political leadership. The reason for this relationship is unclear, but perhaps the ease of getting financing for business development signifies a sophisticated business environment and therefore a progressive society, and one that might welcome more room for women to be involved in leadership, whether in the public or private sector.

A strong entrepreneurial environment is found to be positively related to the levels of women's participation in positions of leadership; however, the impact on political leadership is mixed. Across almost all levels, accessible and affordable business 
suppliers and services have a positive relationship and are able to classify a respectable proportion of countries across all four levels. As explained in the methods sections when this variable is described, it includes the cost, accessibility, and quality of subcontractors, suppliers, legal, banking, and accounting services. As with the prior discussion on financing a business, accessible and affordable business suppliers and services may signify a sophisticated business environment with a modern society (Inglehart \& Baker, 2000) that may encourage more women to be involved in public or private leadership.

Similarly, the finding of the negative relationship between women in political leadership and social acceptance and respect for entrepreneurs supports this same idea - a sophisticated business environment and progressive society - but draws women away from political leadership and into leading their own businesses. In addition, this indicates that beyond a sophisticated and modern business-oriented society, a strong entrepreneurial environment will bring women into business leadership in the private sector more than into political leadership in the public sector.

In summary to this business infrastructure section of the women in political leadership analysis: 1) having to give gifts to bureaucratic officials for basic electricity appears to be an inefficient business custom, but giving gifts to bureaucratic officials for operating licenses is simply the way business is done. 2) In countries with the lowest proportions of women in political leadership, it is necessary to pay for security and protection, but as more women become visible in political leadership, these security costs are less necessary. 3) Training and work in the services sector, outside of the production/manufacturing sector, are associated with a moderate involvement of women in political leadership. However, women with high levels of managerial experience in 
the private sector are more likely to participate in business leadership, rather than political leadership, and to remain in the private sector. 4) Governmental bureaucratic inefficiency can cause women to eschew political leadership. A sophisticated business environment and progressive society welcome women into leadership, whether in the

public or private sector. 5) A strong entrepreneurial environment will bring women into business leadership in the private sector more than into political leadership in the public sector.

\section{$\underline{\text { Societal Development }}$}

Factors related to societal development are found to distinguish among qualitatively different levels of women's participation in positions of political leadership. The factors that are found to make the most significant impact are burgeoning employment, gender equality, human capital, the make-up of the population, and human health and environmental development.

Employment: Burgeoning employment is able to distinguish among all levels of women's participation in political leadership. The employment of women in services is useful for classifying countries into either minimal or moderate levels of participation of women in political leadership with a strong positive relationship, indicating that with more women in the labor force, particularly in the services sector where women dominate (Hossein et al., 2006; Jones et al., 2006; H. Mandel \& Semyonov, 2005), more women than men aspire to political leadership. Boserup's (1986) propositions that service work is used as an intermediate step between agriculture and modern occupations support these findings. The strong impact of estimated earned income of women in classifying 
countries into all 4 levels of women's participation in political leadership similarly indicates that as women's incomes rise, more women advance into parliamentary positions. This female income variable is a more intriguing measure of economic development considering the dependent variables examined in this study. An increase of women's incomes indicates a reflection of a growing private sector and education levels, and concludes with an increase in participation of women in leadership.

Gender Equality: Gender equality is found to be positively related to the women's participation in political leadership and is able to distinguish among all levels. In distinguishing among all levels, and between countries with the lowest levels in particular, the Gender Related Development Index (UNDP, 2006) is able to accurately classify countries with a positive association. This index considers the equality of women and men on life expectancy, literacy, education, and income. Higher levels of Gender Related Development indicate equality of genders on human development factors. While this relationship may already be assumed, this finding confirms that countries with more gender equality have higher levels of women's participation in political leadership.

A more specific variable to accurately classify countries into low to high levels of women's participation in political leadership is the Political Empowerment component of the Gender Gap Index (Forum, 2008). This too is an equality measure: high levels of political empowerment in the Gender Gap Index indicate equality. In distinguishing among all levels, and between the highest levels in particular, Gender Gap Political Empowerment is able to accurately classify countries with a positive association. This means that the higher the equality between men and women in terms of political 
empowerment, the more who will advance to parliamentary positions ${ }^{31}$ (see Appendix 3 correlation table).

Human Capital: Quality human capital is found to be positively related to the levels of women's participation in positions of leadership. In distinguishing between levels 1 and 2 the literacy of adult females has a positive association with women's participation in political leadership, confirming that countries with moderate participation of women in political leadership are more likely to have women who are educated at least with basic literacy skills than countries with minimal participation of women. At the next two levels, distinguishing countries with moderate participation from countries with substantial participation of women in political leadership, literacy of adults in general, males and females, has a significant positive impact.

In distinguishing between moderate participation level 2 and substantial participation level 3, the total combined education of males from primary through tertiary school has a positive association with women's participation in political leadership. The complete formal education of males signifies positive societal development, ${ }^{32}$ which is beneficial to women advancing into positions of leadership. ${ }^{33}$

In distinguishing between substantial participation level 3 and pronounced participation level 4, higher education has a positive association. In other words,

\footnotetext{
${ }^{31}$ The United Nations Gender Empowerment Measure used in the analysis of the women in business leadership DV was not used in the analysis of the political leadership DV because one of the components for the measure is female seats in parliament, which was used in the cluster analysis of the same DV.

${ }^{32}$ EducationCombinedPrimSecTerFemales correlation with EducationCombinedPrimSecTerMales $\quad(\mathrm{r}=$ $.959, \mathrm{p}<.01)$; CombinedGrossEnrolmentRatioForPrimSecTer correlation with HumanDevelopmentIndex ( $\mathrm{r}$ $=.887, \mathrm{p}<.01)$.

${ }^{33}$ KmeansClusterPoliticalLeadership correlation with HumanDevelopmentIndex $(r=.227, \mathrm{p}<.01)$.
} 
countries with pronounced participation of women in political leadership are more associated with higher education than countries with fewer women in political leadership. In distinguishing among all levels 1 through 4 , public spending on education has a positive association. This finding clearly indicates that public spending on education, across the board, plays an important role in the advancement of women to political leadership.

All of these findings related to education and human capital reveal that public institutions need to allocate resources to education of both women and men. In countries with fewer women in political leadership, the educational focus needs to be primarily on literacy and basic education. In countries with higher proportions of women in parliamentary positions, the human capital focus should be on higher education. The same is suggested for the advancement of women into business leadership positions.

Population Make-up: The hypothesis regarding the composition of the population is that a young and urban population is positively related to the levels of women's participation in positions of leadership. The reason for this is that it is expected that younger individuals who have more access to education and an affinity for globalized and modern (Inglehart \& Baker, 2000) societal and business practices would contribute to higher levels of women in leadership. In addition, an urban population would also be more cosmopolitan and more culturally accepting of women in leadership (Christy, 1987). This is partially supported for the countries with the lowest levels of women's participation in political leadership. Contrary to what is expected, populations with ages 65 and over are found to distinguish among all levels 1 through 4 , with positive relationship. The reason for this is not clear, but it may be that an aging population is a 
sign of development as people live longer. ${ }^{34}$ Economic development and women in political leadership are significantly and positively related. ${ }^{35}$ In addition, this echoes the results of human development on women in political leadership, as shown the next discussion section; human development is found to be significantly and positively related to women's participation in political leadership.

However, in line with what is hypothesized, a rural population is found to be negatively related to women in political leadership across almost all levels. This supports the assertion that a more urban population would most likely be more sophisticated and more culturally welcoming of women into parliamentary positions. In addition, female population is also significantly related to women in political leadership, most likely for the fundamental reason that the more women who exist in society, the more women who could participate in political leadership - any implication beyond that would be unsupported.

Health and Environmental Development: Human health and environmental development are found to distinguish among all levels of women's participation in political leadership. Specifically, the Human Development Index is able to accurately classify countries into all 4 levels from low to high. The Human Development Index (UNDP, 2007) is an aggregate measure of the overall human development of a country, and includes life expectancy, literacy, education, and GDP per capita. The positive relationship between the Human Development Index and women in political leadership indicates that human development is related to the advancement of women. This

34 Populationages65andabove correlation with GDPperCapitaPPPUS\$ $(\mathrm{r}=.685, \mathrm{p}<.01)$; Populationages65andabove correlation with HumanDevelopmentIndex $(r=.739, p<.01)$.

${ }^{35}$ KmeansClusterPoliticalLeadership correlation with GDPperCapitaPPPUS $(r=.372, p<.01)$. 
supports the conjecture that life expectancy at birth, literacy, education, and economic growth all allude to a prosperous society, which positively affects women's advancement to political leadership.

In summary to this societal development section of the women in political leadership analysis: 1) More women in the labor force, and in the services sector specifically, should lead more women to seek out positions of political leadership as countries progress from minimal levels of women in leadership to more moderate participation. Furthermore, as women's incomes rise, more women may advance into parliamentary positions, even more so in countries with more pronounced participation of women in political leadership then countries with substantial levels. 2) Countries with more gender equality have higher levels of women's participation in political leadership. Higher equality between men and women in terms of political empowerment should encourage women to advance into parliamentary positions. 3) Public spending on education universally contributes to the advancement of women to political leadership. Countries with moderate participation of women in political leadership are more likely to have women who are educated at least with basic literacy skills than countries with minimal participation of women. Government and public institutions need to allocate resources toward the education of both women and men - focus on literacy and basic education for countries with fewer women in political leadership and focus on higher education for countries with higher levels of women in parliamentary positions. 4) A more urban population most likely results in a more cultivated and cultured society that is hospitable to the movement of women into parliamentary positions. An aging population 
may be a sign of development as people live longer. 5) Overall human development positively affects women's advancement to political leadership

\section{$\underline{\text { Economics Factors }}$}

Factors related to the economy are found to distinguish among qualitatively different levels of women's participation in positions of political leadership. The factors that are found to make the most significant impact are economic freedom, economic development, credit to the private sector, taxes, and international trade.

Economic Freedom: Economic freedom is able to distinguish among all levels of women's participation in political leadership, with a positive relationship in every case. Countries with the highest levels of economic development have the liberal property rights, business, trade, monetary, fiscal, investment, financial, and labor freedoms and freedom from corruption. Economic freedom is strongly related to good economic performance and important for pursuing sustainable prosperity (Holmes et al., 2008).

Economic Development: Economic development is able to distinguish among all levels of women's participation in political leadership with a strong positive association in all cases. The positive relationship between GDP per capita and women in political leadership simply denotes that as women become more involved in politics, the economy prospers; and the other way around, that as women become more involved in political leadership, the economy prospers. GDP is often used as an overall measure of economic development, and by examining the other factors that are positively related to GDP (Appendix 3) it becomes clear that education, health, employment, and gender equality in 
addition to economic growth all create a setting for women to prosper and engage in leadership activity.

Credit to the Private Sector: Non-performing bank loans are able to classify countries into all levels of participation of women in political leadership and with a negative association. Domestic credit provided to the private sector is able to distinguish between countries in all levels as well, but with a positive association. As is shown in the business environment section, access to credit signifies a burgeoning and productive business environment; this societal and governmental efficiency may attract women to parliamentary leadership. Non-performing bank loans stunt or hurt the economy, causing women and men to divert attention to basic economic provisions to support their livelihoods and away from political leadership.

Taxes: A high marginal tax rate is able to distinguish among all levels of women's participation in political leadership with a positive relationship. The highest marginal tax rate is the highest rate shown on the schedule of tax rates applied to the taxable income of individuals (World Bank, 2007e). Women in political leadership, GDP, the human development index, and the highest marginal tax rate are all significantly positively correlated (see Appendix 3 correlation table). As the economy grows and society develops, women get more involved in politics, and individuals pay higher taxes. However, it should be noted that the percent of countries able to be accurately classified is unimpressive and the correlations are weak, so this finding should be considered suspect.

International Trade: Inflows and outflows signifying international trade are less capable of distinguishing between levels of women's participation in political leadership. 
While imports of good and services are a significant discriminating factor, the percent of countries classified correctly is unexceptional and the correlation is weak, therefore this finding should be considered lightly. The types of goods and services are also unable to significantly distinguish between levels of women's participation of business leadership.

In summary of the most important findings from this economic environment section of the women in political leadership analysis: 1) Women in political leadership are positively related to economic development, and countries with the highest levels of economic development have the most liberal economic freedoms. 2) As women become more involved in politics, the economy prospers along with education, health, employment, and gender equality, which all creates a setting for women to prosper and engage in leadership activity. 3) Access to credit signifies an efficient and productive business environment, which may attract women to leadership. A stunted or hurting economy may cause women and men to divert their attention away from political leadership to focus on basic economic provisions to support their livelihoods. If there is a correlation between women holding public office and the economic competitiveness of the nation, as found by (Hunt, 2007), then as the economy hurts, women's advancement into politics also suffers, whereas when women become more involved in politics, the economy prospers.

\section{Technology and Physical Infrastructure}

Factors related to the technological environment and physical infrastructure are also found to distinguish among qualitatively different levels of women's participation in positions of political leadership. The factors that are found to make the most significant 
impact are electric power, telephone mainlines, mobile phone subscribers, and international internet bandwidth. All of these variables have strong correlations and a compelling ability to classify countries. Physical infrastructure and technological advancements make society more efficient, which mirrors economic development, as can be seen in the correlations with these variables to GDP and the Human Development Index in the Appendix 3 table. These societal advances represent modernity (Fagerberg, 1994; Fink \& Kenny, 2003; Lee et al., 2006; Mrad, 2006) and have a positive impact on women becoming more involved in leadership.

\section{$\underline{\text { Political Freedom }}$}

Unexpectedly, political freedoms, examined with both individual civil liberties and political rights (F. House, 2008) are found to significantly impact women in political leadership only when classifying countries into moderate or substantial representation of participation. In addition, the relationships are negative. It would seem that an independent media, open political competition, a strong rule of law, respect for civil liberties, a lack of ethnic and religious strife, and lower levels of political corruption would provide an environment with ample opportunity for women to engage in politics. However, it may be that the more politically oppressive a country, the more women will strive for political leadership in an effort to create change in the political system toward more political freedom. 


\section{$\underline{\text { Culture }}$}

Factors related to culture are found to distinguish among qualitatively different levels of women's participation in positions of political leadership. Those that are found to make the most significant impact are performance orientation, future orientation, gender egalitarianism, assertiveness, in-group collectivism, power distance, humane orientation, uncertainty avoidance, participative leadership, self-protective leadership, social complexity, reward for application, and fate control. The social cynicism and religiosity social axioms are not found to be significant factors that affect women in political leadership, nor are the charismatic/value-based leadership, humane-oriented leadership, autonomous leadership, and team-oriented leadership dimensions.

Cultural Values and Practices: The GLOBE research team collected sets of cultural variables, asking different samples of respondents to answer questions regarding how society really is (real societal practices) or questions regarding how society should be (societal values) (R. J. House \& Javidan, 2004). Before Project GLOBE, values and practices have never been gathered together for comparison. Therefore, both sets of data are examined in the present study in an effort to better understand the effects of these phenomena on women in leadership. In several of the cases, the practices and values scores for any given variable are negatively related to each other, as is the case with future orientation, humane orientation, performance orientation, power distance, and uncertainty avoidance (Hanges, 2004). The only two dimensions with positively related values and practices scores are gender egalitarianism and in-group collectivism. When discussing the results for these dimensions, this negative relationship between practices and values will be explored. 
Performance Orientation: Performance orientation values are able to distinguish among all levels of women's participation in political leadership with a strong positive relationship and with an impressive number of countries correctly classified. Since performance orientation values and practices are positively related to one another (Hanges, 2004; Javidan, 2004), these findings suggest that across-the-board women's participation in political leadership is positively related to cultures that: value training and development, concentrate on results, reward performance and individual achievement, respect competitive behavior and assertiveness, are motivated by success, and have a sense of urgency (Javidan, 2004). All of these characteristics create an environment for women to advance into political leadership because judgments are made on performance and merit, rather than gender.

Future Orientation: Future-orientation is able to distinguish among all levels of women's participation in political leadership with an impressive number of countries correctly classified and a strong correlation. Future oriented values are negatively associated with women's participation in political leadership. This does not necessarily mean that culture dictates that people should not think ahead and plan for the future. Because future orientation practices are found to be negatively related to future orientation values (Ashkanasy et al., 2004; Hanges, 2004), then societies with weaker future orientation practices may tend to value a future orientation style more, and vice versa. In other words, the lower the practices score, the higher the value of future orientation (Ashkanasy et al., 2004). Conversely, the lower the values score, the higher the actual future orientation practice in a society. Askanasy et al. proposed that societies that place a lower value on future orientation are likely to have stronger future-oriented 
behavior. Therefore, it is probable that this finding of the negative relationship between future orientation values and women in political leadership is that in societies with higher levels of women in parliament, future orientation is practiced more than in societies with fewer women in political leadership.

Gender Egalitarianism: Gender egalitarianism values are able to distinguish among all levels of women's participation in political leadership with a strong positive relationship and with an impressive number of countries correctly classified. Since gender egalitarianism values and practices are positively related to each other, these findings suggest that across-the-board women's participation in political leadership is positively related to cultures that: have higher representation of women in the workforce and in positions of authority, recognize women's roles in making decisions and afford them a respectful position in society, have more gender integration, and have higher educated women.

Assertiveness: Assertiveness is able to distinguish between levels 3 and 4 only of women's participation in political leadership with an impressive number of countries correctly classified and a strong correlation. Assertiveness values are negatively associated with women's participation in political leadership. This does not necessarily mean that culture dictates that women should not be assertive, aggressive, or tough. On the contrary, because assertiveness practices are found to be negatively related to assertiveness values (Deanne N. Den Hartog, 2004; Hanges, 2004), then societies with weaker assertiveness values may tend to be more assertive in practice, and vice versa (societies with weaker assertiveness values may tend to value more assertive behaviors). In other words, the lower the values score, the higher the actual assertiveness practices 
score (Deanne N. Den Hartog, 2004). Den Hartog et al. found a pattern in that the majority of countries that have high levels of assertiveness practices and lower values, actually wanted less assertive behavior perhaps out of desire for a less threatening, nonaggressive society. Therefore, it is probable that this finding of the negative relationship between assertiveness values and women in political leadership is that in societies with pronounced levels of women in parliament, assertive and tough characteristics are what got the women to their leadership positions, but perhaps such behaviors are no longer necessary and society seeks more modest or peaceful practices.

Collectivism: The GLOBE in-group collectivism dimension represents the extent to which individuals are proud of, loyal to, and dependent on families. Mixed results are found for in-group collectivism, but all results are able to correctly classify an impressive percentage of countries and have strong correlations. On one hand, as hypothesized, in discriminating among all 4 levels of women's participation in political leadership, collectivistic societal practices are found to be negatively related to the levels of women's participation in positions of political leadership, and therefore individualism is positively related. This suggests that countries with higher proportions of women in political leadership tend to be more individualistic than countries with fewer women in parliament. Because individualistic societies view individuals as autonomous and independent beings, value individual goals over group goals, believe in the nuclear family unit rather than a tight allegiance to the extended family, and have higher divorce rates as women have the freedom to break away from unhappy marriages (Gelfand et al., 2004), it is hypothesized that such customs would lend to the freedom of women to break away 
from somewhat limiting home and family responsibilities and into positions of leadership. This is true across all 4 levels in general.

However, on the one hand, in distinguishing countries in level 1 with minimal participation of women in political leadership from countries in level 2 with more moderate participation, there is a negative effect for in-group collectivism values, but a positive effect for in-group collectivism practices. Specifically at these lowest levels of women's participation, it may be that in countries with the fewest women in parliament, women rely on the support of their family to seek political leadership but value more individualistic behaviors that relieve women of some of the allegiance to remain solely caring for the family.

Institutional collectivism is not found to impact women in political leadership. The institutional collectivism dimension is described as involving economic systems that favor individual or group interests, being included as a member of a group, and the extent to which individualism or group cohesion is more valued in society (Gelfand et al., 2004). These factors are not found to affect women becoming political leaders. Societal collectivism is not as important as family-oriented collectivism in predicting women's participation in political leadership. This means that women are not as affected by societal pressure to either pay allegiance to the family or to work toward individualistic goals as they are by family demands and responsibilities. A family that discourages a woman away from the idea that she might pursue a political career is more influential than any societal forces. A family that supports or even encourages a woman to strive for political leadership will have more powerful influence than societal approval or 
propaganda. Similarly, an acquaintance who carries the respect of the family members and is revered may equally sway a woman toward or away from political leadership.

Even though education has been found to be important for women to advance into leadership positions, it is not necessarily enough to transform family beliefs regarding women who direct their efforts toward activities other than related to the family unit (Read \& Oselin, 2008). In order for women politicians to arouse or mentor new women into political leadership, not only do they need to motivate women, but they need to consider family impressions as well. This means that social acceptance of women in politics needs to permeate society at the individual family level in order for more women to embark on such journeys. A handful of prominent influential women or the occasional woman prime minister may instigate societal acceptance, but if these women are viewed as extraordinary or remarkable, the challenge for family support of their wives and daughters to act more individualistic is real.

Power Distance: As hypothesized, power distance is able to distinguish among all levels of women's participation in political leadership and is able to correctly classify an impressive percentage of countries with a strong negative association. This means that countries with high representation of women in political leadership are more likely to welcome upward mobility of people into higher positions, treat all groups as equal, openly share information, and afford citizens civil liberties (Carl et al., 2004). Women in such societies are able to move up the ranks into influential political positions because of low power distance practices that allow superiors to converse with subordinates and welcome individuals to work hard and achieve higher levels of respect and authority. 
Humane Orientation: Humane orientation reflects the extent to which individuals in a society promote and compensate fairness, altruism, friendliness, benevolence, caregiving, and helpfulness expressed both in individual treatment of others and in societal institutions (Kabasakal \& Bodur, 2004). It is hypothesized that such behaviors would be positively related to women in leadership. Humane orientation practices are able to accurately classify countries into all levels, but with a negative relationship. This does not necessarily mean that women leaders are not humane-oriented. Because humane orientation practices are found to be negatively related to humane orientation values (Hanges, 2004; Kabasakal \& Bodur, 2004), then societies with weaker humaneorientation practices may tend to value a humane style more, and vice versa. In other words, the lower the practices score, the higher the value of humane-orientation (Kabasakal \& Bodur, 2004). Conversely, the lower the values score, the higher the actual humane-orientation practice in a society. Kabasakal and Bodur proposed that societies that have lower humane-oriented practices are likely to want more humane-oriented behavior. In addition, Kabasakal and Bodur also propose that the higher the value on humane-orientation and the lower the practices, the more likely that societies would like to reduce power distances and behavior more assertively and that humane-oriented, teamoriented, charismatic/values-based, and participative leadership styles will be favored.

Uncertainty Avoidance: Results indicate that uncertainty avoidance values are able to distinguish among all levels with a strong negative relationship and an impressive number of countries correctly classified. Uncertainty avoidance is another of the GLOBE dimensions where practices and values are negatively related to one another (Hanges, 2004; SullydeLuque \& Javidan, 2004). It is hypothesized that uncertainty avoidance 
societal practices would be negatively related to the levels of women's participation in positions of leadership because societies that score high on uncertainty avoidance tend to avoid change, desire conventional and predictable rules, and scorn rule-breakers, making it difficult for women to take on fewer home and family responsibilities and move toward more leadership roles in politics. Concomitantly, however, in order for women to participate in political leadership they would need to take more risks, be comfortable with change, show less affinity for rules and regulations, and be willing to debunk traditional gender role expectations. The negative relationship between uncertainty avoidance practices and values indicates therefore that while societal practices may dictate established rules and expectations and resist change, societies with high proportions of women in parliament tend to value change, debunk rules and regulations, and take risks in the interest of making improvements.

Leadership Practices: Participative leadership is able to distinguish among all levels 1 through 4 of women's participation in political leadership with a strong positive association. Self-protective leadership is able to distinguish among all levels of women's participation in political leadership with a strong negative association. Both factors are able to classify an impressive number of countries into all levels. Consistent with the women in business leadership results, these findings indicate that countries with higher representation of women in parliament are inclined to value collaborative, diplomatic, and participative leadership styles, as opposed to self-centered leadership styles.

These findings mirror a lot of the earlier women in leadership literature that argued that women are nurturing and collaborative (Alice H Eagly \& Linda L Carli, 2003; Eagly \& Johnson, 1990; Eagly \& Mitchell, 2004; Helgesen, 1990; Vinnicombe \& 
Singh, 2002; G. Yukl, 2002). This opposes, however, a lot of prior articles that argued that women have been discriminated against and unable to move into leadership because of contrasting attributions of what represents effective leadership. Role congruity theory (Eagly \& Karau, 2002) positioned women as discriminated against because they are feminine, leaders are typically perceived as male, and men are considered to be more dominating and authoritative. Supported by prior research (Foels et al., 2000; Hansen \& Otero, 2006; Sargent, 1981; Vecchio, 2002; Vinnicombe \& Singh, 2002), the findings in the current study argue an opposing view: the cultural context within which women advance into leadership positions values these nurturing, collaborative, and participative leadership styles.

Social Axioms: Leung et al.'s (K. Leung \& Bond, 2004; K. Leung et al., 2002) social axioms represent higher level general beliefs that relate to social behaviors. Three of their social axioms are significant in classifying countries into levels of women's participation in political leadership with a correlation and with an impressive number of countries correctly classified. Complex social systems are able to distinguish among all levels of women's participation in political leadership. Social complexity is the notion that human behavior can be complex and unpredictable and therefore numerous approaches can be employed to achieve an outcome with few criteria to follow. Outcomes are difficult to predict and individuals deal with circumstances on a situational basis because the underlying phenomena can be unclear. In such an environment women can have the freedom to be creative and calculating in order to select the best conduit or tools to achieve positions of parliamentary leadership. 
It is hypothesized that rewards for application would be positively related to the progression of women into leadership positions. The rewards for application social axiom dimension represents a general expectancy that hard work, experience, and a sensible strategy lead to favorable results, hence if women persevere toward positions of political leadership, they will be more inclined to reach their goals. Rewards for application are able to discriminate between countries with substantial participation of women in parliament and countries with more pronounced involvement from women in such positions, but with a negative association.

Following Leung and Bond's (2004) logic, this negative association might suggest that strenuous socioeconomic conditions - such as men dominating leadership positions and women being a minority - are related to a belief in reward for application as a tactic to handle adversity. In other words, women in countries with fewer women in political leadership have a stronger belief in rewards for application than women in countries with more pronounced and visible women leaders who because of strength in numbers may not need to fight as hard to achieve such positions because female leaders are more common. This is consistent with Leung and Bond's finding that reward for application is negatively related to gender equality. This finding is supported by a finding by Minnit and Nardone (2007) through their application of expectancy theory. They found that if women believe in their abilities and experiences to start and lead businesses, and are confident that the efforts they put forth will make them successful, then they are more likely to partake in such activities.

Fate control is able to discriminate among all levels of women's participation in political leadership with a negative association. High levels of fate control represent the 
belief that outcomes are left to fate rather than to individual control. Therefore, as hypothesized, these findings indicate that women in political leadership are positively associated with a strong affinity toward self-efficacy and control over life circumstances.

In summary to this culture section of the women in business leadership analysis: 1) Countries that reward performance and individual achievement create an environment for women to advance into political leadership because judgments are made on performance and merit, rather than gender. 2) In societies with higher levels of women in parliament, future-oriented behaviors, such as planning for the future, are practiced more than in societies with fewer women in political leadership. 3) Countries with high proportions of women political leaders have higher representation of women in the workforce and in positions of authority, recognize women's roles in making decisions and show them respect in society, have more gender integration, and have higher educated women. 4) Assertive and tough characteristics assist women in their pursuit of leadership positions, but it may be that such behaviors are no longer necessary and society would prefer more modest or peaceful approaches. 5) Countries with higher proportions of women in political leadership tend to be more individualistic because such societies view people as individuals, value individual goals over group goals, and allow women the freedom to separate from somewhat restrictive home and family responsibilities and into positions of leadership. In countries with the fewest women in parliament, women rely on the support of their families to seek political leadership but still value more individualistic behaviors that relieve women of some of the responsibility of caring for the family. Women are less affected by societal pressure than by family demands and responsibilities. A family, or strongly revered family friend, can discourage 
or encourage a woman to pursue a political career and is more influential than societal forces. Social acceptance of women in politics needs to permeate society at the individual family level in order for more women to embark on such journeys. 6) Women in low power distance societies are able to aspire to political leadership because of practices that allow superiors to converse with subordinates and welcome individuals to work hard and achieve higher levels of respect and authority. 7) Societies that have lower humane-oriented practices are likely to want less power distance and more assertiveness, and humane-oriented behavior and value humane-oriented, team-oriented, charismatic/values-based, and participative leadership styles. 8) Societies with high representation of women in parliament tend to be more comfortable with uncertainty, value change, debunk rules and regulations, and take risks in the interest of making improvements. 9) Countries with higher proportions of women in parliament are inclined to value collaborative, diplomatic, and participative leadership styles, as opposed to selfinterested leadership styles. 10) In circumstances where there are fewer women in political leadership, women have a stronger belief in rewards for application because of the belief that they need to work extremely hard to overcome challenges and achieve leadership positions. 11) Women in political leadership have a strong sense of selfefficacy and personal control over life circumstances. 


\section{Conclusion to the Women in Political Leadership Findings}

Described in this concluding section are the areas on which countries with minimal (level 1), moderate (level 2), substantial (level 3), or pronounced (level 4) proportions of participation of women in political leadership should focus.

Level 1 - Minimal Participation of Women in Political Leadership: In level 1 with minimal representation of women in political leadership, the focus needs to be on labor skill, non-production work, and formal job training to increase the labor talent pool of productive, employable, and efficient works. Customs and trade regulations are a major constraint, and bureaucratic procedures like enforcing contracts and giving gifts to get an electrical connection, time dealing with licenses, access to financing and costs associated with financing, and tax administration are inefficiencies. Security costs may be necessary for women to engage in politics or gain independence. Entrepreneurial capacities offer women the opportunity to gain independence in a progressive business environment, such as access to affordable suppliers, contractors, professional, legal, and banking services, and respect for individualistic and innovative entrepreneurs, and are important to further the advancement of women into political leadership, but also may encourage women to become entrepreneurs. At this level, income levels for women are a challenge and women predominantly work in the services sector. Public spending on education is vital and female literacy is imperative for women to become involved in political leadership. Fundamental human development and equality between and men and women in access to resources and opportunities are a challenge. Economic freedoms are strong Individuals need access to bank loans in order to start a business and introduce 
new goods and services to the market and advance the economy. Provisions and support to ensure payments on those loans are imperative in order for business institutions to become more effective and dependable. In level 1, exports of any kind stimulate international trade and also boost GDP. Electric power, telephone lines, mobile phones, and the internet are of fundamental infrastructural and technological importance. Finally, in level 1, women work very hard to provide for themselves and their families, but are constrained by family and household responsibilities and gender inequality. Society has less structured policies and procedures and perpetuates internal locus of control tendencies, but needs to focus on rewarding individuals for excellence and participative rather than self-protective leadership styles.

Level 2 - Moderate Participation of Women in Political Leadership: In level 2 with moderate representation of women in political leadership, many of the similar characteristics as in level 1 persist with some improvements. Bureaucratic procedures like giving gifts to get an electrical connection or an operating license, and enforcing contracts, time dealing with licenses, access to financing and costs associated with financing, and tax administration all make for inefficient business customs but to a lesser extent than in level 1. Security costs may also be necessary for women to participate in politics or gain independence. While skill level of workers remains a major constraint, more firms offer formal training, and the number of years of experience of top managers becomes a focus. Inefficiencies remain, like customs and trade regulations, enforcing contracts, giving gifts to get an electrical connection, time dealing with licenses, access to financing and costs associated with financing, and tax administration, but to a lesser extent than in level 1. Security costs may also be less necessary for women to engage in 
politics or gain independence. A strong entrepreneurial environment is still important to the advancement of women into political leadership, but still may attract women to become entrepreneurs. At level 2, women still predominantly work in the services sector, but income levels are higher than in level 1. Fundamental human development and equality between and men and women in access to resources and opportunities are a challenge, and equality of political empowerment becomes particularly important. Public spending on education is vital for both men and women, and female literacy is still of utmost importance for women to become involved in political leadership. Fundamental human development remains a societal concern, but again, to a lesser extent than in level 1. Economic freedoms are remain strong, while economic growth, domestic credit provided for business loans, and systems in place to ensure repayment of bank loans are vital for a successful economy. In level 2, as in level 1, exports of any kind fuel international trade and also raise GDP. Electric power, telephone lines, mobile phones, and the internet are more available than in level 1 and are critical for societies to modernize and for women to envision running for parliamentary seats. Finally, in level 2, and even more so than in level 1, culture respects hard work in response to challenges, individualistic behaviors, gender inequality, taking more calculated risks to avoid uncertainty, external locus of control tendencies, and rewards individuals for excellence and participative rather than self-protect leadership styles.

Level 3 - Substantial Participation of Women in Political Leadership: In level 3 with more substantial representation of women in political leadership, giving gifts to get an electrical connection remains a problem, but giving gifts to officials for an operating license seems to be a more efficient means of business. Customs and trade regulations, 
contract enforcement, and tax administration are still constraints to business efficiency. The skill level of workers is still a concern, but skilled workers are associated with level 3 and higher education becomes more important than in prior levels, while basic female literacy and education remain an important focal point for public investment. A stronger entrepreneurial environment is still important to the advancement of women into political leadership, but may attract women to become entrepreneurs. Gender empowerment in politics is particularly important, and level 3 is characterized by a more urban and older population with higher human development. Economic freedoms are further strengthend. Economic development, domestic credit provided for business development, and higher repayment rates of bank loans are signs of a successful economy. In level 3, as in level 2, exports of any kind fuel international trade and also raise GDP. Electric power, telephone lines, mobile phones, and the internet are more available than in level 2 and remain essential for societies to modernize and for women to envisage running for parliament. Finally, in level 3, and even more so than in prior levels, society establishes regulations and procedures to combat uncertainties, culture values fairness, altruism, and generosity, supports individualistic behaviors, gender egalitarianism, belief in control over one's life circumstances, hard work in response to adversity and the idea that there is more than one way to achieve outcomes. Society encourages individual improvement and excellence, supports movement and association between hierarchical levels, and rewards participative rather than self-protective leadership styles.

Level 4 - Pronounced Participation of Women in Political Leadership: In level 4 with more pronounced representation of women in political leadership, paying officials or giving gifts to get things done is less of a concern. Customs and trade regulations, 
contract enforcement, and tax administration are still constraints but to a lesser extent than in prior levels. There are fewer production workers as higher education becomes more widely available than in prior levels. A strong entrepreneurial environment is still important, but still may attract women to become entrepreneurs. Gender equality is more widespread and gender empowerment in politics is particularly important. Level 4 countries have more prosperous urban sectors and a healthier population that lives longer. Economic freedoms are still strong and economic development, domestic credit provided for business development, and higher repayment rates of bank loans are signs of an even more successful economy than in level 3. In level 4, as in level 3, exports promote international trade and positively affect GDP. Electric power, telephone lines, mobile phones, and the internet are universally available and lend to a modernized society that supports women in parliament. Finally, level 4 is characterized by a culture that promotes well-being and the fair treatment of others, values individual goals over group goals, attaches importance to gender equality, takes more calculated risks and establishes rules and procedures to avoid risks, believes individuals have control over their life circumstances, has faith that minorities can achieve success with hard work, and believes that there is more than one method to achieve goals. Society rewards individual advancement, power distances are opaque and social mobility is possible, and participative rather than self-protective leadership styles are respected. 


\section{CHAPTER 6: CONCLUSIONS}

This is an understudied area, so there is no one stream of logic that will explain everything. The most important findings presented in this dissertation are: First, The diffusion of ideas through the isomorphism of institutions made possible by globalization, international trade, and technology spreads a supportive environment where the acceptance of women in leadership becomes institutionalized. Second, human and economic development are vital for the advancement of women. Specifically, basic health and survival needs, literacy, and the fundamentals of education are most important in countries with lower levels of women's participation in leadership, while health expenditures and higher education are essential in countries with more women in leadership positions. Third, economic and political freedoms and gender empowerment are significant forces across the board for women's participation in leadership. Forth, a rule of law and provisions for property rights provided by government are necessary for facilitating safe business practices. In societies where there is this government support, women will gravitate toward business leadership. In societies where a rule of law is lacking, women may be motivated to become engaged in politics. Fifth, a strong entrepreneurial environment and available credit are important for countries in all levels

of women's participation in leadership. Sixth, cultural norms that support a belief in hard work, a belief in personal ability, individualism, risk taking behaviors, and participative leadership are indicative of women's participation in leadership.

While the intention of this study was not to make a modernization argument, a modernization tenet nonetheless runs through these findings. Economic development, 
societal development, economic and political freedom, and gender empowerment are all signs of globalizing and modernizing forces, and are shown in the results of this analysis to be positive factors in the support of women in leadership.

We may expand the concept of the global levels of women in leadership and suggest that these levels might in fact be stages that countries move through as the proportion of women in leadership grows. It might be suggested that a country could gradually progress to the next stage when it acquires certain characteristics or capabilities. At some point the combined impact of these acquisitions may result in qualitative changes. The following is a description of what each proposed stage might look like.

In countries with higher participation of women in leadership, gender equality in the work force is visible. Women have been increasingly moving into higher levels in existing organizations and into leadership positions over the past half century and particularly over approximately the last 10 years. This is not to say that women in the developed world don't face discrimination. They do, but to an increasingly lesser extent, as the idea of women in leadership is not such a foreign concept and societies become institutionalized to the idea (Lucas, 2003). This levels theory could be transformed to a stage theory that proposes that women's increasing movement into leadership is a process and as societal acceptance grows and socio-economic conditions transform, more room is made for more women in influential positions, and so on.

In societies with lower participation of women in leadership, women are at the earlier stages of this process. With fewer women in positions of leadership, general societal acceptance remains lower because of confusion from the comingling of long- 
standing cultural norms and modern movements (Inglehart \& Baker, 2000), and there are fewer role models to mentor women and fewer practices that encourage women to attempt to hold positions of influence.

In level/stage 1 with minimal representation of women in business leadership, women's roles in society are more traditional and women are found solely in supportive and submissive roles of family care-giving and household responsibilities. Any women in these societies who have broken this subservient mold and made strides toward independence have done so under the radar and in many cases in secret. Stereotypes and gender biases are extremely high, and the proverbial glass ceiling is virtually made of steel. An extreme example is Afghanistan during the Taliban rule when women were placed in positions of complete control by their male family members. Women who dared to grasp any small bit of independence did so in extreme privacy out of fear of sever reproof. Women had no rights whatsoever and had little to no protection from the brutality of men if such an unfortunate event occurred (S. Groves, 2001; Hosseini, 2007). Fortunately, changes in education and in attitude in Afghanistan are making leadership or small business development more possible for women (Mujtaba, 2005). Countries can theoretically move from stage 1 to stage 2 when they acquire the qualities associated with stage 2 as outlined in the previous conclusion sections on either women in business leadership or political leadership.

A society has achieved level/stage 2 with moderate representation of women in business leadership. Visible movement of women can be seen in those who have gained independence, although in small numbers with only little cultural acceptance. This move toward independence or even influence stems from a motivation based on either need or 
emergency, or based on a perceived opportunity to make a difference for themselves, their family, or the community. There is a slow-moving acceptance of women in these situations because of an understanding of the circumstances that have facilitated such activities, which is usually accompanied by a simultaneous backlash from traditional segments of society who do not agree with such changes. At level/stage 2 there is still mostly a steel ceiling with regard to women in leadership positions, and stereotypes and biases persist. Countries can theoretically move from stage 2 to stage 3 when they acquire the qualities associated with stage 3 as outlined in the previous conclusion sections on both women in business leadership or political leadership.

In level/stage 3 with more substantial representation of women in business leadership, other women who have witnessed the efforts and successes made by the influential women who came before them, begin to make their strides toward independence and even leadership. This can be done in small ways, for example through teaching, engaging in small informal business or money-making activities, or getting involved in non-profit efforts or in local politics. As more women set an example by partaking in these activities, other women around them, and from the next generation behind them, develop a sense of self-efficacy that they themselves can do something similar. Often the second generation learns from the hardships that their predecessors faced and start to find more efficient and effective ways to improve the systems in which they operate or lead. Level/Stage 3 reveals the beginnings of the glass ceiling in that women can see the upper hierarchical levels and even aspire to them, but still face strong stereotypes and biases in many cases. Countries can theoretically move from stage 3 to 
stage 4 when they acquire the qualities associated with stage 4 as outlined in the previous conclusion sections on either women in business leadership or political leadership.

Level/stage 4 with more pronounced representation of women in business leadership is reached in a society when gender equality is evident at almost all levels of society, and in situations or locales where inequality remains present it is possible and regularly supported by the greater societal composition. At this level/stage, women and men equally make up the active, paid workforce, even though certain industries or job sectors are dominated by one gender or the other. However, at higher levels of political and big business leadership, women are still a strong minority, representing in some cases mere percentages. While there is widespread acceptance of women in leadership positions and the glass ceiling becomes more of a mesh screen that can easily be broken, women still grapple for access to an "old boy's network." Despite the fact that women still may find ribbons of traditional gender-role expectations and stereotypes, albeit to a lesser degree than in the earlier three stages, biases against women are less prevalent. The women who do achieve higher leadership positions do so with mixed leadership qualities, exhibiting both male and female traits (nurturing and inclusive combined with authoritative and decisive), sometimes in an androgynous fashion (Hansen \& Otero, 2006; Vinnicombe \& Singh, 2002). In stage 4 women are taking advantage of the flexible benefits of owning their own businesses (Jennings \& McDougald, 2007; Martins et al., 2002; Rothbard, 2001; Walker \& Webster, 2007) which allow them to set their own hours and control the size of their organizations.

Compelling to note is that at level/stage 4 the reverse perspective of an acceptance of men to be more "feminine" also happens. Male leaders begin to learn the benefits of 
the before-mentioned "feminine advantage" and adopt the sensitive and power-sharing styles of leadership. It also becomes increasingly acceptable for men to share family-care and household responsibilities in support of the working women and women leaders in their lives.

Level/stage 5 represents complete gender equality at all levels. In this stage, women and men are found representing equal halves of almost all job sectors and in almost all industries. There are few to no male- or female-dominated sectors of society and either gender is equally welcomed to participate in any activity - gender becomes functionally invisible. Women are also equally present among all hierarchical stages and can be found equally through all levels of politics and at the helms of large businesses alongside their male counterparts in equally large organizations. At this level, the equality of position is also accompanied by equality of responsibility and expectation. Women, no more than men, have to make familial sacrifices for the sake of their careers, and men share in all responsibilities - gender-based role expectations are obsolete. Political and economic freedoms not only exist for all members of society, but race and gender are not topics of the economic or political processes. Stage 5 breeds a social acceptance at all levels, leaving members of society unoccupied with such matters and therefore better able to focus on more sophisticated and efficient welfare systems.

There are no known true cases of any societies at level 5, although the closest societal-level examples would be the Scandinavian countries. These countries have most of the characteristics just described, but the proportions of women in business or political leadership still do not represent full equality. It is conceivable that stage 5 has not been 
reached, not because women are marginalized, but because of a large percentage of women who chose to focus on children and their families.

Two important considerations need to be expelled here. One, the factors proposed here that affect women's participation in leadership roles, and the individual variables that constitute these factors, may not affect each level to the same degree and some variables may have a different level of significance at different level. In addition, even a substantial change in one of these factors at one level may be necessary, but not sufficient for moving a country to the next level. A change in all significant factors would be required for a country to progress to the next level in the model. Rostow referred to this as "a decisive interval in the history of a society when growth becomes its normal tradition ... and the slow-moving changes of the pre-conditions period - when the forces of modernization contend against habits and institutions, the values and vested interests of the traditional society, make a decisive break-through" (p. 36). Often the beginning of this movement can be traced to a particular stimulus. In other words, a substantial change in one factor may not be enough to move a country to the next level, but it may ignite a series of events which would begin a growth period required for progression.

Two, these proposed levels are in no way expected to be equidistant, nor the time for movement among stages the same for each country (Klein \& Kozlowski, 2000). Demand changes may also affect stages and stage movement (Rostow, 1960, 1990). Progression may not be a smooth process from one stage to another and it is likely that major events, like war (Goldstein, 2001; Silber, 2007), may set a country forward or back in terms of women in leadership. A few examples of progress in women's involvement in participation in leadership roles include: 1) during World War II in the United States 
when large numbers of women worked outside the home for the first time because men were serving in the armed forces abroad (E. Mandel \& Sinclair, 2002), 2) women's movements and the fight for suffrage and equal rights (Allen, 2002), 3) during the first Gulf War, American troops brought a Western influence to Saudi Arabia and women drove cars for the first time (Abdelkarim, 1999), and 4) the AIDS and war epidemics in some parts of Africa have left grandmothers to raise the families, and hence women are in charge of their own land (Bindura-Mutangadura, 2001; Wane \& Kavuma, 2001).

This movement among levels can also happen in the reverse during times of religious revolution or cultural conservatism, as in, for example: 1) Iran in the 1970s when women were required to veil after years of Western influence on modernity had been commonplace (Rahimi, 2007), 2) after the overthrow of the warlords in Afghanistan when the Taliban came into power and required educated women who had worked as doctors to wear burkas and stay home under the control of their male family members (Dorronsoro, 2005), and 3) after the troops left Saudi Arabia at the end of the first Gulf War, women returned home and most driving privileges were again reserved for men (Abdelkarim, 1999). Other factors, such as economics and technology, can also have slow or rapid effects and can be significant at different stages, for example: the need for a two-income American household in order to maintain societal norms and purchase consumer goods (Daily, 1993; Harcar, Spillan, \& Kucukemiroglu, 2005) and the subsequent decrease in family size and birthrates (Papagni, 2006). 


\section{Directions for Future Research}

Kirkman, Lowe, and Gibson (2006) argue that there has been a lack of multi-level research and encourage researchers to formulate cultural theory across levels. They also suggest that prior research has essentially failed to study separate cultural effects across countries, i.e., when certain cultural values affect one country differently than another. What is needed is sufficient theory to explain how national cultural effects based on country differences affect individuals. This is the nucleus of this thesis.

Ecological and socio-political changes cause culture to constantly acclimate, and individual characteristics can evolve within the context in which they operate (Berry et al., 2002). In response to changing environments, individual psychological characteristics will evolve with a flexibility that goes seemingly unnoticed together with a concerted effort to assimilate old psychological tendencies with new cultural practices and public meanings (Kitayama, 2002). Although culture has been treated as a very stable characteristic of a society, it is constantly evolving. Modern values of individual achievement and competition can co-exist with strong traditional values (Kwok Leung et al., 2005).

With the coexistence of mass cultural change and persistent traditional values, Inglehart and Baker (2000) propose that economic development instigated by industrialization and modernization is accompanied by cultural shifts away from absolute norms and values toward those that are more rational, tolerant, trusting, participatory, and cross-national. In tandem, a lasting imprint is left by the broad cultural heritage of a society and endures despite any rising education and income levels, the influence of mass 
media, and occupational specialization. These modern movements bring about changes in gender roles, attitudes toward authority, broader political participation, and a more sophisticated public body. Because it seems like cultures in a globalized world are becoming more similar, it is less apparent, although very real, that there are very strong, persistent values and norms still in place.

Persistent and changing culture can also be reflected in particular artifacts that show fundamental cultural differences and similarities throughout time, such as iPods, the internet, cellular phones, and chopsticks versus forks. Including artifacts in a cultural analysis allows researchers to capture a real assessment of what is actually valued in society (Earley, 2006). The blending of traditional with modern values may be uncovered by observing the merging of new and old in certain cultures. For example, traditional values can be witnessed in the wearing of the long flowing black gown, the abaya, and the shela covering the head, by women in the Muslim United Arab Emirates, and the long white cloak, the kundura or dishdash, by the men. In recent years, this traditional national dress has been combined with the extensive use of cellular and wireless technological capabilities, the internet, and a high-quality university system.

Earley (2006) proposes that often researchers focus too much on values in a culture and then misinterpret the culture as being defined by those values, instead of by meaning. More important than values, which vary from person to person, is the awareness of a shared understanding of the meaning of a particular circumstance. Twisting the previous example to make another point, Muslim men and women in the UAE value a national dress, but with differing degrees of preference for maintaining a traditional look or adding a modern touch. For example, some women wear a more 
simple abaya, while other women adorn the same traditional cloak with ornate embroidery and beading. These traditional types of values combined with modern flairs and advanced education and access to technology show that the people in this society understand the impact of both systems intertwined for the future growth of their country, although personal value judgments related to this may differ. Earley suggests that researchers move beyond grand surveys of values and toward research that focuses on the linkages between culture, perception, action, and practice, with the goal of developing theories and frameworks applicable to these linkages. In other words, for example, how do culture and context affect practice?

In instances where culture does not explain a large amount of variance in outcomes, other variables must be considered as important predictors alongside culture mediators and moderators (Kirkman et al., 2006; Kwok Leung et al., 2005). The need to use mediation to support theoretical arguments is critical in order to avoid threats to internal consistency. Without tests for mediation, it is difficult to conclude that country differences are due to culture (Kirkman et al., 2006). In addition, the stronger the impact of moderating conditions on culture, the less predictive culture will be of individual outcomes. Leung et al. also recommend searching for situational characteristics that serve to moderate the impact of national culture on individual perceptions, beliefs, and behaviors. For example, it may also be fruitful to examine this the other way and look at moderating conditions that affect the impact of culture on women's participation in the economy - moderators like economics, education, and technological factors, for example. The lack of other forces besides culture being included in cultural studies often results in 
low effect sizes and a low amount of explained variance of cultural effects (Kirkman et al., 2006).

Interesting future research would be to determine how and when culture makes a difference (Kirkman et al., 2006; Kwok Leung et al., 2005). It is more than plausible that culture has less of an impact when other factors are considered. Here are some examples: 1) Maybe the cultural slant that women should not be competing in business with men is moderated by the times when men are working in other countries as migrant workers. Culture has less of an impact on women's roles in business when men are away, and limits women in the traditional sense when men are present and participating in the same local workforce. 2) Perhaps the impact of culture on women in business is moderated by women's computer experience, in that when women have more internet skills and sell goods online, men are less threatened in their more traditional male-centric jobs. 3) It is plausible that culture's impact on the perceptions of women in leadership is moderated by age in society; as society's youth become more connected to the outside world and exposed to Western business practices, women in leadership seem less radical. 4) Maybe the impact of culture on women in business is moderated by the types of goods and services they offer, particularly if these are of a traditionally feminine nature, like handbags, cakes, and massages. 5) The impact of culture on women in leadership can also be moderated by the amount of income they can make (if they make less than their husband, the husband is not as threatened) and the fact that women still need men to approve their business decisions and help connect them to others with status. 6) Locus of control may also moderate the relationship between culture and women in leadership - 
women with a belief that their own actions can lead them to independence or positions of leadership rather than relying on fate or external happenings.

Moderator variables, setting or context, and how the criterion measure is operationalized, can have differential impacts on outcome results. For example, the operationalization of the criterion variable can emerge as a moderator and the type of criterion chosen can moderate relationships (K. B. Lowe, Kroeck, \& Sivasubramaniam, 1996). The advancement of women in leadership is growing at both the political and at the general labor force levels (Newburry et al., 2007).

This review of culture and cross-cultural studies points to multi-layered, multifaceted, contextual, and dynamic views of culture. This suggests that the philosophy of cultural research entails much more than cultural dimensions, and that culture is manifested through many levels and domains. Some cultural elements are dynamic and changing, while others are stable. A major challenge for the field is to develop dynamic frameworks of culture that portray the sensitivities of cultural nuances in different contexts (Kwok Leung et al., 2005). Culture can be an antecedent (a moderator or a mediator) and a consequence, and its effects may be domain-specific and are subjected to boundary conditions. Cultural change is intertwined with socioeconomic-political variables, and these contextual variables may also add to, moderate, and/or mediate the effects of culture on particular outcomes - in this case, women's participation in leadership. 


\section{$\underline{\text { Limitations }}$}

A few main limitations restrict this study. First, there are minority subcultures in any country that do not subscribe to the norms and systems of the greater majority. These subcultures are unfortunately not able to be detected and covered in a country-level analysis and these exceptions should be remembered when interpreting empirical findings. For example, there is a very small subculture of the United States that involves an exclusive polygamous society with a private religious element followed only by members of that society. In this culture women are married at very young ages and men can have multiple wives. Due to the civil liberties provided by the American Constitution, these communities skirt much of the great societal expectations and practices. These systems are interrupted only when a federal or state law is broken and therefore can be prosecuted. However, the practices of such a subculture are misunderstood by the greater societal majority and even condemned by the disapproving masses (Turley, 2004). This subculture will not be captured in the greater country-level analysis and therefore should be considered to be an "exception to the rule" when empirical findings are discussed.

The second limitation has to do with the sample and missing data. The related challenges are: 1) Since this country-level data for all secondary sources except for the Global Entrepreneurship Monitor, GLOBE, and the Social Axioms survey research data, the sample size will always be an issue. From any given data source, there are only slightly more than 200 countries that exist in the world for data collection, meaning the sample size will never be in the thousands. While the Global Entrepreneurship Monitor 
and GLOBE survey data provide the benefit of having thousands of individuals represented in the samples, the data are nonetheless aggregated to the country level, and country means for 32,56 , and 29 countries respectively are available for analysis in this study. 2) There is no one source that provides data for business environment, societal development, economics, infrastructure and technology, political freedom, and culture together, this study required gathering data from numerous secondary sources. Since the data in this study come from 10 secondary sources, a major limitation is that not all data collection sources collect data on the same countries across the world. 3) Not only do different data sources collect data on slightly different countries, but the data available are missing from year to year for any given countries for any given variable, which is particularly the case with the World Bank Group and United Nations Development Program data sets. When all these data are combined into one dataset, data are missing completely at random. In other words, data are missing by year or by country, or both. With a sample size between 100 and 200, assigning values by any method for missing values would grossly manipulate the data.

The third limitation to this study is related to the lack of comparison potential for the factors that affect men in business or political leadership. It is not possible to empirically say that the factors in this study that are found to significantly impact women in leadership positively or negatively are different from the factors that affect men in leadership. In order to duplicate this study for the analysis of male leaders, the two dependent variables that comprised data from the World Bank Group and the United Nations Development Program would need to be collected for males by these two institutions. 
Based on these limitations, this study specifically calls for more widespread data collection from the World Bank World Development Indicators, the World Bank Enterprises Survey, the World Bank Doing Business Survey, and the United Nations Development Program. These two organizations provide some of the most important and rich data available at the country level; however, the limitations outlined here are severe. Of particular importance are the data provided on the business environment in the Enterprise Survey, which is only collected on approximately 80 developing countries, rendering impossible any potential learning from valuable comparisons between developing and developed countries. 


\section{REFERENCES}

12Manage. (2008). The executive fast track: Pest analysis.

Abdelkarim, A. (Ed.). (1999). Change and development in the gulf. London: Palgrave Macmillan

Ackermann, M. (2008). Fidelity unit seeks growth via self-clearing market. American Banker, 173(68), 12.

Acs, Z. J., \& Szerb, L. (2007). Entrepreneurship, economic growth and public policy. Small Business Economics, 28(2-3), 109-123.

Adler, N. J. (1999). Global leaders: Women of influence. In G. N. Powell (Ed.), Handbook of gender \& work (pp. 239-261). Thousand Oaks, CA: Sage.

Afrin, S. (1999). Women in a micro-enterprise development program in bangladesh. Asian Journal of Women's Studies, 5(4), 100.

Aguilar, F. (2006). Scanning the business environment. New York: Macmillan.

Aldrich, H. E., \& Cliff, J. E. (2003). The pervasive effects of family on entrepreneurship: Toward a family embeddedness perspective. Journal of Business Venturing, 18(5), 573-596.

Allen, A. T. (2002). Feminist modernism and national tradition: Britain, the united states, hungary, india. Journal of Women's History, 14(2), 172-183.

Andaleeb, S. S., \& Wolford, G. V. (2004). Participation in the workplace: Gender perspectives from bangladesh. Women in Management Review, 19(1/2), 53.

Anthony, D. (2005). Cooperation in microcredit borrowing groups: Identity, sanctions, and reciprocity in the production of collective goods American Sociological Review, 70(3), 496-516.

Ardichvili, A. (2001). Leadership styles and work-related values of managers and employees of manufacturing enterprises in post-communist countries. Human Resource Development Quarterly, 12(4), 363-383.

Arnott, J. (2003). A description of cluster analysis. Retrieved May 20, 2008, from http://www.eng.auburn.edu/ gilbert/Comp7120/ClusterAnalysisDescription.pdf

Arunthanes, W., Tansuhaj, P., \& Lemak, D. J. (1994). Cross-cultural business gift giving. International Marketing Review, 11(4), 44-56. 
Ashkanasy, N., Gupta, V., Mayfield, M. S., \& Trevor-Roberts, E. (2004). Future orientation. In R. J. House, P. J. Hanges, M. Javidan, P. W. Dorfman \& V. Gupta (Eds.), Culture, leadership and organizations: The globe study of 62 societies (pp. p. 239-281). Thousand Oaks, CA: Sage Publications.

Bajdo, L. M., \& Dickson, M. W. (2001). Perceptions of organizational culture and women's advancement in organizations: A cross-cultural examination. Sex Roles, 45(5/6), 399.

Bandura, A. (1977). Social learning theory. Englewood Cliffs, NJ: Prentice-Hall.

Barnett, J. M. (1995). Women's entrepreneurship a global priority. Women's Business Exclusive, 3(6), 1.

Bartol, K. M., Martin, D. C., \& Kromkowski, J. A. (2003). Leadership and the glass ceiling: Gender and ethnic group influences on leader behaviors at middle and executive managerial levels. Journal of Leadership \& Organizational Studies, $9(3), 8$.

Bass, B. M., Burger, P. C., Doktor, R., \& Barrett, G. V. (1979). Assessment of managers: An international comparison. New York: Free Press.

Bates, T. (2002). Restricted access to markets characterizes women-owned businesses. Journal of Business Venturing, 17, 313-324.

Beach, W. W., \& Kane, T. (2008). Chapter 4: Methodology: Measuring the 10 economic freedoms. Washington D.C.: The Heritage Foundation.

Beck, D. E. (2000). Stages of social development: The cultural dynamics that spark violence, spread prosperity, and shape globalization, State of the World Forum. New York: Integral World, http://www.integralworld.net/index.html?beck2.html.

Berger, J., Ridgeway, C. L., Fisek, M. H., \& Norman., R. Z. (1998). The legitimation and delegitimation of power and prestige orders. American Sociological Review, 63(3), 379-416.

Berry, J. W., Poortinga, Y. H., Segall, M. H., \& Dasen, P. R. (2002). Cross-cultural psychology: Research and application (2nd ed.). New York: Cambridge University Press.

Bertrand, M., Djankov, S., Hanna, R., \& Mullainathan, S. (2007). Obtaining a driving license in India: An experimental approach to studying corruption? Quarterly Journal of Economics.

Bindura-Mutangadura, G. (2001). HIV/AIDS, poverty, and elderly women in urban Zimbabwe. Southern African Feminist Review, 4(2/V.5), 93. 
Booysen, L. A. E., \& vanWyk, M. W. (2007). Culture and leadership in South Africa. In J. S. Chhokar, F. C. Brodbeck \& R. J. House (Eds.), Culture and leadership across the world: The globe book of in-depth studies of 25 societies (pp. 440). Mahwah, New Jersey: Lawrence Erlbaum Associates.

Boserup, E. (1970). Woman's role in economic development. New York, NY: St. Martin's.

Boserup, E. (1986). Woman's role in economic development. Vermont, USA: Gower.

Brodbeck, F. C., \& Frese, M. (2007). Societal culture and leadership in Germany. In J. S. Chhokar, F. C. Brodbeck \& R. J. House (Eds.), Culture and leadership across the world: The globe book of in-depth studies of 25 societies. Mahwah, New Jersey: Lawrence Erlbaum Associates.

Brodbeck, F. C., Frese, M., Akerblom, S., Audia, G., Bakacsi, G., Bendova, H., et al. (2000). Cultural variation of leadership prototypes across 22 european countries. Journal of Occupational and Organizational Psychology, 73(1), 1-29.

Brown, A. M. (2006). WID and GAD in Dar es Salaam, Tanzania: Reappraising gender planning approaches in theory and practice. Journal of Women, Politics \& Policy, $28(2), 57$.

Bryman, A. S. (1996). The importance of context: Qualitative research and the study of leadership. Leadership Quarterly, 7(3), 353-370.

Burke, S., \& Collins, K. M. (2001). Gender differences in leadership styles and management skills. Women in Management Review, 16(5/6), 244.

Burrell, B. (1996). A woman's place is in the house: Campaigning for congress in the feminist era. Ann Arbor, Michigan University of Michigan Press.

Butler, D., \& Geis, F. L. (1990). Nonverbal affect responses to male and female leaders: Implications for leadership evaluations. Journal of Personality and Social Psychology, 58, 48-59.

Caiazza, A. (2004). Does women's representation in elected office lead to womenfriendly policy? Analysis of state-level data. Women \& Politics, 26(1), 35.

Caputo, R. K., \& Dolinsky, A. (1998). Women's choice to pursue self-employment: The role of financial and human capital of household members. Journal of Small Business Management, 36(3), 8.

Carl, D., Gupta, V., \& Javidan, M. (2004). Power distance. In R. J. House, P. J. Hanges, M. Javidan, P. W. Dorfman \& V. Gupta (Eds.), Culture, leadership and organizations: The globe study of 62 societies (pp. p. 513-563). Thousand Oaks, CA: Sage Publications. 
Carli, L. L. (1991). Gender, status, and influence. In E. Lawler (Ed.), Advances in group processes (Vol. 8, pp. 89-113).

Chan, S., \& Qingyang, G. (2006). Investment in China migrates inland. Far Eastern Economic Review(May), 52-57.

Chang, H.-J. (2002). Globalization, economic development and the role of the state. London Zed Books.

Chen, D., Newburry, W., \& Park, S. H. (Forthcoming). Improving sustainability: An international evolutionary framework. Journal of International Management.

Chen, M., Vanek, J., Lund, F., Heintz, J., Jhabvala, R., \& Bonner, C. (2005). Progress of the world's women 2005: Women, work, \& poverty. New York: United Nations Development Fund for Women.

Chen, X.-P., \& Li, S. (2005). Cross-national differences in cooperative decision-making in mixed-motive business contexts: The mediating effect of vertical and horizontal individualism. Journal of International Business Studies 36, 622-636.

Cheung, S. N. S. (1970). The structure of a contract $\&$ the theory of a non-exclusive resource. Journal of Law and Economics, 13, 49-70.

Chhokar, J. S., Brodbeck, F. C., \& House, R. J. (2007). Culture and leadership across the world: The globe book of in-depth studies of 25 societies. Mahwah, New Jersey: Lawrence Erlbaum Associates.

Chiang, F. F. T., \& Birtch, T. A. (2006). An empirical examination of reward preferences within and across national settings. Management International Review, 46(5), 573.

Chow, I. H.-S. (2005). Gender differences in perceived leadership effectiveness in Hong Kong Women in Management Review, 20(3/4), 216-233.

Chowdhry, G. (Ed.). (1995). Engendering development? Women in development (WID) in international development regimes. New York, NY: Routledge.

Christy, C. (1987). Sex differences in political participation: Processes of change in fourteen nations. Westport CT Praeger Publishers

Cingranelli, D. L., \& Richards, D. L. (2004). Cingranelli and Richards human rights dataset, from http://www.humanrightsdata.com

Cliff, J. E. (1998). Does one size fit all? Exploring the relationship between attitudes towards growth, gender and business size. Journal of Business Venturing, 13, $523-542$. 
Coeurderoy, R., \& Murray, G. (2008). Regulatory environments and the location decision: Evidence from the early foreign market entries of new-technology-based firms. Journal of International Business Studies, 39(4), 670-688.

Coleman, I. (2004). The payoff from women's rights. Foreign Affairs, 83(3), 80.

Coleman, S. (2004). Access to debt capital for women- and minority-owned small firms: Does educational attainment have an impact? Journal of Developmental Entrepreneurship, 9(2), 127.

Collinson, D. (2006). Rethinking followership: A post-structuralist analysis of follower identities. Leadership Quarterly, 17(2), 179.

Commons, J. (1931). Institutional economics. American Economic Review, 21, 648-657.

Currie, D. H. (1999). Gender analysis from the standpoint of women: The radical potential of women's studies in development". Asian Journal of Women's Studies, $5,9-44$

Dahan, N., Doh, J., \& Guay, T. (2006). The role of multinational corporations in transnational institution building: A policy network perspective. Human Relations, 59, 1571-1600.

Daily, C. M. (1993). The (r)evolution of the American woman. Business Horizons, 36(2), $1-6$.

Dana, L. P. (2000). Creating entrepreneurs in India. Journal of Small Business Management, 38(1), 86.

Darcy, R., Welch, S., \& Clark, J. (1994). Women, elections, and representation, $2 n d$ ed. Lincoln, Nebraska: University of Nebraska Press.

De Hoogh, A. H. B., Den Hartog, D. N., Koopman, P. L., Thierry, H., Van den Berg, P. T., Van der Weide, J. G., et al. (2005). Leader motives, charismatic leadership, and subordinates' work attitude in the profit and voluntary sector. The Leadership Quarterly, 16(1), 17-38.

de Bruin, A., Brush, C. G., \& Welter, F. (2007). Advancing a framework for coherent research on women's entrepreneurship. Entrepreneurship Theory and Practice, 31(3), 323-339.

Demirgüç-Kunt, A., López-Córdova, J. E., Pería, M. S. M., \& Woodruff, C. (2007). Remittances and banking services: Evidence from mexico new. The World Bank.

Den Hartog, D. N. (2004). Assertiveness. In R. J. House, P. J. Hanges, M. Javidan, P. W. Dorfman \& V. Gupta (Eds.), Culture, leadership and organizations: The globe study of 62 societies (pp. p. 395-436). Thousand Oaks, CA: Sage Publications. 
Den Hartog, D. N., House, R. J., Hanges, P. J., Quintanilla, S. A. R., Dorfman, P. W., \& Associates. (1999). Culture specific and cross-culturally generalizable implicit leadership theories: Are attributes of charismatic/transformational leadership universally endorsed? Leadership Quarterly, 10(2), 219-256.

Dickson, M. W., Hanges, P. J., \& Lord, R. M. (2001). Trends, developments, and gaps in cross-cultural research on leadership. In W. Mobley \& M. McCall (Eds.), Advances in global leadership (Vol. 2, pp. 75-100). Stamford, CT: JAI Press.

Dickson, M. W., Hartog, D. N. D., \& Mitchelson, J. K. (2003). Research on leadership in a cross-cultural context: Making progress, and raising new questions. The Leadership Quarterly, 14, 729-768.

DiMaggio, P. J., \& Powell, W. W. (1983). The iron cage revisited: Institutional isomorphism and collective rationality in organizational fields. American Sociological Review, 48(2), 147-160.

DiMaggio, P. J., \& Powell, W. W. (1991). Introduction. In W. W. Powell \& P. J. DiMaggio (Eds.), The new institutionalism in organizational analysis (pp. 1-38). Chicago: University of Chicago Press.

Dorfman, P. W., Hanges, P. J., \& Brodbeck, F. C. (2004). Leadership and cultural variation: Identification of culturally endorsed leadership profiles. In R. J. House, P. J. Hanges, M. Javidan, P. W. Dorfman \& V. Gupta (Eds.), Culture, leadership and organizations: The globe study of 62 societies (pp. p. 669-719). Thousand Oaks, CA: Sage Publications.

Dorronsoro, G. (Ed.). (2005). Revolution unending: Afghanistan, 1979 to the present New York: Columbia University Press

Dumas, C. (2001). Evaluating the outcomes of microenterprise training for low income women: A case study. Journal of Developmental Entrepreneurship, 6(2), 97.

Duval, Y., \& Biere, A. (2002). Product diffusion and demand for new food products Agribusiness, 18(1), 23.

Eagly, A. H., \& Carli, L. L. (2003). The female leadership advantage: An evaluation of the evidence. Leadership Quarterly, 14(6), 807.

Eagly, A. H., \& Carli, L. L. (2003). Finding gender advantage and disadvantage: Systematic research integration is the solution. Leadership Quarterly, 14(6), 851.

Eagly, A. H., \& Carli, L. L. (2004). Women and men as leaders. In J. Antonakis, A. Cianciolo \& R. Sternberg (Eds.), The nature of leadership. Thousand Oaks: Sage Publications. 
Eagly, A. H., \& Johnson, B. T. (1990). Gender and leadership style: A meta-analysis. Psychological Bulletin, 108(2), 233.

Eagly, A. H., \& Karau, S. J. (2002). Role congruity theory of prejudice toward female leaders. Psychological Review, 109(3), 573-598.

Eagly, A. H., Karau, S. J., \& Makhijani, M. G. (1995). Gender and the effectiveness of leaders: A meta-analysis. Psychological Bulletin, 117(1), 125.

Eagly, A. H., Makhijani, M. G., \& Klonsky, B. G. (1992). Gender and the evaluation of leaders: A meta-analysis. Psychological Bulletin, 111(1), 3.

Eagly, A. H., \& Mitchell, A. (2004). Social role theory of sex differences and similarities: Implications for the sociopolitical attitudes of women and men. In M. A. Paludi (Ed.), Praeger guide to the psychology of gender. Westport, Conn: Praeger.

Eagly, A. H., \& Steffen, V. J. (1984). Gender stereotypes stem from the distribution of women and men into social roles. Journal of Personality and Social Psychology(46), 735-754.

Earley, P. C. (2006). Commentary: Leading cultural research in the future: A matter of paradigms and taste. Journal of International Business Studies, 37, 922-931.

Elder, L. (2004). Why women don't run: Explaining women's under-representation in america's political institutions. Women \& Politics 26(2), 27-56.

Ellyson, S. L., Dovidio, J. F., \& Brown, C. E. (1992). The look of power: Gender differences and similarities. In C. Ridgeway (Ed.), Gender, interaction, and inequality (pp. 50-80). New York: Springer-Verlag.

Emrich, C. G., Denmark, F. L., \& Den Hartog, D. N. (2004). Cross-cultural differences in gender egalitarianism. In R. J. House, P. J. Hanges, M. Javidan, P. W. Dorfman \& V. Gupta (Eds.), Culture, leadership and organizations: The globe study of 62 societies (pp. p. 343-394). Thousand Oaks, CA: Sage Publications.

Erez, M., \& Gati, E. (2004). A dynamic, multi-level model of culture: From the micro level of the individual to the macro level of a global culture. Applied Psychology: An International Review, 53(4), 583-598.

Erikson, E. (1964). Childhood and society, 2nd ed. New York: Norton.

Eweje, G. (2006). The role of MNEs in community development initiatives in developing countries: Corporate social responsibility at work in Nigeria and South Africa. Business and Society, 45(2), 93-130. 
Fabowale, L., Orser, B., \& A., R. (1995). Gender, structural factors, and credit terms between Canadian small businesses and financial institutions. Entrepreneurship Theory and Practice, 19(4), 41-66.

Fagerberg, J. (1994). Technology and international differences in growth rates. Journal of Economic Literature, 32, 1147-1175.

Fairlie, R. W. (2006). The personal computer and entrepreneurship. Management Science, 52(2), 187.

Farid, M. (2007). Entrepreneurship in Egypt and the us compared: Directions for further research suggested. The Journal of Management Development, 26(5), 428.

Fink, C., \& Kenny, C. J. (2003). W(h)ither the digital divide? The Journal of Policy, Regulation and Strategy for Telecommunications, Information and Media, 5(6), 15-25.

Foellmi, R., \& Oechslin, M. (2007). Who gains from non-collusive corruption? Journal of Development Economics, 82(1), 95.

Foels, R., Driskell, J. E., Mullen, B., \& Salas, E. (2000). The effects of democratic leadership on group member satisfaction. Small Group Research, 31(676-701).

Forum, W. E. (2007). Global competitiveness report 2007-2008. Retrieved May 12, 2008, from http://www.weforum.org/en/initiatives/gcp/index.htm

Forum, W. E. (2008). Global gender gap index. Retrieved May 12, 2008, from http://www.weforum.org/en/Communities/Women\%20Leaders\%20and\%20Gend er\%20Parity/index.htm

Foundation, T. H. (2008). Index of economic freedom. Retrieved May 7, 2008, from http://www.heritage.org/research/features/index/downloads.cfm

Freedom house. (2008). from www.freedomhouse.org

Friedman, R., Chi, S.-C., \& Liu, L. A. (2006). An expectancy model of ChineseAmerican differences in conflict-avoiding. Journal of International Business Studies, 37, 76-91.

Friedman, T. (2005). The world is flat. New York: Farrar, Straus, and Giroux.

Fu, P. P., Kennedy, J., Tata, J., Yukl, G., Bond, M. H., Peng, T.-K., et al. (2004). The impact of societal cultural values and individual social beliefs on the perceived effectiveness of managerial influence strategies: A meso approach. Journal of International Business Studies, 35, 284-305. 
Gelfand, M. J., Bhawuk, D. P. S., Nishi, L. H., \& Bechtold, D. J. (2004). Individualism and collectivism. In R. J. House, P. J. Hanges, M. Javidan, P. W. Dorfman \& V. Gupta (Eds.), Culture, leadership and organizations: The globe study of 62 societies (pp. p. 437 - 512). Thousand Oaks, CA: Sage Publications.

Ghemawat, P. (2001). Distance still matters: The hard reality of global expansion. Harvard Business Review, 79(8), 137-147.

Ghemawat, P. (2007). Redefining global strategy: Crossing borders in a world where differences still matter. Harvard Business School Press, 1st Ed(September 27).

Ghodsee, K. (2003). And if the shoe doesn't fit? (wear it anyway): Economic transformation and western paradigms of women in development programs in post-communist central and eastern Europe. Women's Studies Quarterly, 31(3/4), 19.

Goldstein, J. S. (2001). War and gender. Cambridge: Cambridge University Press.

Goode, W. J. (1960). A theory of role strain. American Sociological Review, 25, 483-496.

Graen, G. B., Hui, C., Wakabayashi, M., \& Wang, Z.-M. (1997). Cross-cultural research alliances in organizational research. In P. C. Earley \& M. Erez (Eds.), New perspectives on international industrial/organizational psychology (pp. 160-189). San Francisco, CA: Jossey-Bass.

Green, S. B., \& Salkind, N. J. (2005). Discriminant analysis. In Using SPSS for windows or Macintosh: Analyzing and understanding data, fourth edition. New Jersey: Pearson Prentice Hall.

Groves, K. S. (2005). Gender differences in social and emotional skills and charismatic leadership. Journal of Leadership \& Organizational Studies, 11(3), 30.

Groves, S. (2001). Afghan women speak out. Feminist Studies, 27(3), 753-760.

Haire, M., Ghiselli, E. E., \& Porter, L. W. (1966). Managerial thinking: An international study. New York: Wiley.

Hamilton, G. G. (Ed.). (1994). Civilizations and organization of economies. Princeton, NJ: Princeton University Press.

Hanges, P. J. (2004). Appendix a: Societal-level correlations among globe societal cultural scales. In R. J. House, P. J. Hanges, M. Javidan, P. W. Dorfman \& V. Gupta (Eds.), Culture, leadership and organizations: The globe study of 62 societies (pp. p. 733-736). Thousand Oaks, CA: Sage Publications. 
Hansen, S. B., \& Otero, L. W. (2006). A woman for U.S. President? Gender and leadership traits before and after 9/11. Journal of Women, Politics \& Policy 28(1), 35.

Harcar, T., Spillan, J. E., \& Kucukemiroglu, O. (2005). A multi-national study of family decision-making. Multinational Business Review. , 13(2), 3-22.

Hausmann, R., Tyson, L. D., \& Zahidi, S. (2007). The global gender gap index 2007: Measuring the global gender gap. Retrieved May 12, 2008, from http://www.weforum.org/pdf/gendergap/index2007.pdf

Havergal, M., \& Edmonstone, J. (1999). The facilitator's toolkit. Gower publishing ltd. Uk. .

Helgesen, S. (1990). The female advantage: Women's ways of leadership. New York: Doubleday.

Hill, C. W. L. (2008a). Chapter 8: Regional economic integration. In Global business today, 5e. New York: McGraw-Hill/Irwin.

Hill, C. W. L. (2008b). Global business today, 5e. New York: McGraw-Hill/Irwin.

Hillman, A. J., Shropshire, C., \& Cannella, A. A. (2007). Organizational predictors of women on corporate boards. Academy of Management Journal, 50(4), 941-952.

Hodgson, G. M. (2004). The evolution of institutional economics: Agency, structure and Darwinism in American institutionalism. London and New York: Routledge.

Hofstede, G. (1980). Culture's consequences: International differences in work-related values. Beverly Hills, CA: Sage.

Hofstede, G. (1983). The cultural relativity of organizational practices. Journal of International Business Studies, 75-89.

Hofstede, G. (1997). Culture and organizations: Software of the mind. New York: McGraw-Hill.

Hofstede, G. (1998). Masculinity and feminity: The taboo dimension of national cultures. Thousand Oaks, CA: Sage.

Hofstede, G. (2001). Culture's consequences: Comparing values, behaviors, institutions, and organizations across nations. Thousand Oaks, CA: Sage.

Holmes, K. R., Feulner, E. J., \& O’Grady, M. A. (2008). Index of economic freedom: Washington, D.C.: The Heritage Foundation and Dow Jones \& Company, Inc., 2008. 
Hoskisson, R. E., Eden, L., Lau, C. M., \& Wright, M. (2000). Strategy in emerging economies. Academy of Management Journal, 43(249-67).

Hossein, C., Redfern, J., \& Carothers, R. (2006). An Egyptian case study: Financial services for young people who work. International Journal of Emerging Markets, 1(4), 329.

Hosseini, K. (2007). A thousand splendid suns. New York: Riverhead Books

House, F. (2008). Political freedom index, from www.freedomhouse.org

House, R. J., Hanges, P. J., Javidan, M., Dorfman, P. W., \& Gupta, V. (Eds.). (2004).

Culture, leadership and organizations: The globe study of 62 societies. Thousand Oaks, CA: Sage Publications.

House, R. J., \& Javidan, M. (2004). Overview of globe. In R. J. House, P. J. Hanges, M. Javidan, P. W. Dorfman \& V. Gupta (Eds.), Culture, leadership and organizations: The globe study of 62 societies. Thousand Oaks, CA: Sage Publications.

Hoyt, C. L. (2005). The role of leadership efficacy and stereotype activation in women's identification with leadership. Journal of Leadership \& Organizational Studies, $11(4), 2$.

Hsing, Y.-T. (1997). Building Guanxi across the straits: Taiwanese capital and local Chinese bureaucrats NewYork and London: Routledge.

Huang, Y. H., Hammer, L. B., Neal, M. B., \& Perrin, N. A. (2004). The relationship between work-to-family conflict and family-to-work conflict: A longitudinal study Journal of Family and Economic Issues, 25, 79-100.

Hui, M. K., Au, K., \& Fock, H. (2004). Empowerment effects across cultures. Journal of International Business Studies, 35, 46-60.

The hunger project. (2005). Retrieved August 19, 2005, from http://www.thp.org/index.html

Hunt, S. (2007). Let women rule. Foreign Affairs, 86(3), 109.

Huntington, S. P. (1965). Political development and political decay. World Politics, 17.

Huntington, S. P. (1968). Political order in changing societies. New Haven: Yale University Press.

Husted, B. W. (2005). Culture and ecology: A cross-national study of the determinants of environmental sustainability. Management International Review, 45(3), 349. 
ILO. (2005a). International labor organization bureau for gender equality. Retrieved Feb 12, from http://www.ilo.org/public/english/gender.htm

ILO. (2005b). International labor organization gender audit report. Retrieved Feb 12, from http://www.ilo.org/public/english/gender.htm

Inglehart, R., \& Baker, W. E. (2000). Modernization, cultural change, and the persistence of traditional values. American Sociological Review, 61(1), 19-51.

Ingram, P., \& Clay, K. (2000). The choice-within-constraints new institutionalism and implications for sociology. Annual Review of Sociology, 26, 525-546.

Isserles, R. G. (2003). Microcredit: The rhetoric of empowerment, the reality of "Development as usual". Women's Studies Quarterly, 31(3/4), 38.

Jackson, R., \& Sorensen, G. (2003). Introduction to international relations: Theories and approaches, second edition. New York: Oxford University Press.

Jalalzai, F. (2004). Women political leaders: Past and present. Women \& Politics 26(3/4), $85-108$.

Javidan, M. (2004). Performance orientation. In R. J. House, P. J. Hanges, M. Javidan, P. W. Dorfman \& V. Gupta (Eds.), Culture, leadership and organizations: The globe study of 62 societies (pp. p. 239-281). Thousand Oaks, CA: Sage Publications.

Javidan, M., \& Carl, D. E. (2004). East meets west: Searching for the etic in leadership. Journal of Management Studies.

Javidan, M., \& Carl, D. E. (2005). Leadership across cultures: A study of Canadian and taiwanese executives. Management International Review, 45(1), 23.

Javidan, M., \& House, R. J. (2001). Cultural acumen for the global manager: Lessons from project globe. Organizational Dynamics, 29(4), 289-305.

Javidan, M., House, R. J., Dorfman, P. W., Hanges, P. J., \& deLuque, M. S. (2006). Conceptualizing and measuring cultures and their consequences: A comparative review of globe's and Hofstede's approaches. Journal of International Business Studies, 37, 897-914.

Jennings, J. E., \& McDougald, M. S. (2007). Note: Work-family interface experiences and coping strategies: Implications for entrepreneurship research and practice. Academy of Management Review, 32(3), 747-760.

Jones, L., Snelgrove, A., \& Muckosy, P. (2006). The double-x factor: Harnessing female human capital for economic growth. International Journal of Emerging Markets, l(4), 291. 
Jurik, N. C. (1998). Getting away and getting by: The experiences of self-employed homeworkers. Work and Occupations, 25, 7-35.

Kabasakal, H., \& Bodur, M. (2004). Humane orientation in societies, organizations, and leader attributes. In R. J. House, P. J. Hanges, M. Javidan, P. W. Dorfman \& V. Gupta (Eds.), Culture, leadership and organizations: The globe study of 62 societies (pp. p. 564-601). Thousand Oaks, CA: Sage Publications.

Kantor, P. (2002). Gender, microenterprise success and cultural context: The case of south asia. Entrepreneurship Theory and Practice, 26(4), 131.

Khandker, S. R. (2005). Microfinance and poverty: Evidence using panel data from bangladesh. The World Bank Economic Review, 19(2), 263-287.

Khanna, J., \& Johnston, M. (2007). India's middlemen: Connecting by corrupting? Crime, Law and Social Change, 48(3-5), 151-169.

Kim, J. L. S., \& Ling, C. S. (2001). Work-family conflict of women entrepreneurs in singapore. Women in Management Review, 16, 204-221.

Kirkman, B. L., Lowe, K. B., \& Gibson, C. B. (2006). A quarter century of culture's consequences: A review of empirical research incorporating Hofstede's cultural values framework Journal of International Business Studies, 37(3), 285.

Kitayama, S. (Ed.). (2002). Cultural psychology of the self: A renewed look at independence and interdependence. Florence, KY: Taylor \& Francis/Routledge.

Klein, K., \& Kozlowski, S. W. (2000). Multilevel theory, research and methods in organizations. San Francisco, CA: Jossey-Bass.

Koh, W. T. H. (2006). Singapore's transition to innovation-based economic growth: Infrastructure, institutions and government's role. $R \&$ D Management, 36(2), 143.

Kohlberg, L. (1973). The claim to moral adequacy of a highest stage of moral judgment. Journal of Philosophy, 70, 630-646.

Kostova, T., \& Zaheer, S. (1999). Organizational legitimacy under conditions of uncertainty: The case of the multinational enterprise. Academy of Management Review, 24(64-81).

Kulich, C., Ryan, M. K., \& Haslam, S. A. (2007). Where is the romance for women leaders? The effects of gender on leadership attributions and performance-based pay. Applied Psychology, 56(4), 582.

Labor, U. S. D. o. (1991). A report on the glass ceiling initiative. Washington, DC. 
Lattin, J., Carroll, D. J., \& Green, P. E. (2003a). Cluster analysis. In Analyzing multivariate data (pp. 264-306). Pacific Grove, CA: Brooks/Cole - Thomas Learning.

Lattin, J., Carroll, D. J., \& Green, P. E. (2003b). Discriminant analysis. In Analyzing multivariate data (pp. 426-470). Pacific Grove, CA: Brooks/Cole - Thomas Learning.

Lee, K.-h., Yang, G., \& Graham, J. L. (2006). Tension and trust in international business negotiations: American executives negotiating with chinese executives. Journal of International Business Studies 37(5), 623.

Leung, K., Bhagat, R. S., Buchan, N. R., Erez, M., \& Gibson, C. B. (2005). Culture and international business: Recent advances and their implications for future research. Journal of International Business Studies, 36, 357-378.

Leung, K., \& Bond, M. H. (2004). Social axioms: A model for social beliefs in multicultural perspective. In M. P. Zanna (Ed.), Advances in experimental social psychology (Vol. 36, pp. 119-197). San Diego, CA: Elsevier Academic Press.

Leung, K., Bond, M. H., Reimel de Carrasquel, S., Muñoz, C., Herna'ndez, M., Murakami, F., et al. (2002). Social axioms: The search for universal dimensions of general beliefs about how the world functions. Journal of Cross-Cultural Psychology, 33(3), 286-302.

Lieb, H., \& Thistle, S. (2005). Marriage, work, poverty, and children: The changing impact of marriage, motherhood and work on women's poverty. Journal of Women, Politics \& Policy 27(3/4), 5.

Lincove, J. A. (2008). Growth, girls' education, and female labor: A longitudinal analysis. The Journal of Developing Areas, 41(2), 45-66.

Littrell, M. A., \& Miller, N. J. (2001). Marketing across cultures: Consumers' perceptions of product complexity, familiarity and compatibility. Journal of Global Marketing, 15(1), 67.

Lord, R. G., \& Maher, K. J. (1990). Alternative information-processing models and their implications for theory, research, and practice. The Academy of Management Review, 15(1), 9-18.

Lord, R. G., \& Maher, K. J. (1991). Leadership and information processing: Linking perceptions and performance. Cambridge, MA: Unwin Hyman.

Loscocco, K. A., \& Leicht, K. T. (1993). Gender, work-family linkages, and economic success among small business owners. Journal of Marriage and the Family, 55, 875-887. 
Lowe, K. B., \& Gardner, W. L. (2000). Ten years of the leadership quarterly: Contributions and challenges for the future. Leadership Quarterly, 11(4), 459.

Lowe, K. B., Kroeck, K. G., \& Sivasubramaniam, N. (1996). Effectiveness correlates of transformational and transactional leadership: A meta analytic review of the MLQ literature. Leadership Quarterly, 7(3), 385425.

Lucas, J. W. (2003). Status processes and the institutionalization of women as leaders. American Sociological Review, 68(3), 464.

Mandel, E., \& Sinclair, B. (2002). Pioneers of production: Women industrial workers in world war ii. Journal of Women's History, 14(1), 158-182.

Mandel, H., \& Semyonov, M. (2005). Family policies, wage structures, and gender gaps: Sources of earnings inequality in 20 countries. American Sociological Review, 70(6), 949-968.

March, J. G., \& Olsen, J. P. (1984). The new institutionalism: Organizational factors in political life. American Political Science Review, 78, 738-749.

March, J. G., \& Olsen, J. P. (1989). Rediscovering institutions. New York: Free Press.

March, J. G., \& Olsen, J. P. (1996). Democratic governance. New York: Free Press.

Marks, S. R. (1977). Multiple roles and role strain: Some notes on human energy, time and commitment. American Sociological Review, 42, 921-936.

Marsella, A. J., \& Choi, S. C. (1993). Psychological aspects of modernization and economic development in East Asian nations. Psychologia, 36, 201-213.

Marshall, R. S., \& Boush, D. M. (2001). Dynamic decision-making: A cross-cultural comparison of U.S. And Peruvian export managers. Journal of International Business Studies, 32, 873.

Martins, L. L., Eddleston, K. A., \& Veiga, J. F. (2002). Moderators of the relationship between work-family conflict and career satisfaction. Academy of Management Journal, 45. 399-409.

McGregor, D. M. (1960). The human side of enterprise. New York: McGraw-Hill.

Mehta, R., Larsen, T., Rosenbloom, B., Mazur, J., \& Polsa, P. (2001). Leadership and cooperation in marketing channels: A comparative empirical analysis of the USA, finland and poland. International Marketing Review, 18(6), 633-667.

Mertler, C. A., \& Vannatta, R. A. (2002). Discriminant analysis. In Advanced and multivariate statistical methods, second edition. Los Angeles, CA: Pyrczak Publishing. 
Milkie, M. A., \& Peltola, P. (1999). Playing all the roles: Gender and the work-family balancing act. Journal of Marriage and the Family, 61, 476-490.

Miller, J. P. (2005, Apr 19). R.R. Donnelley to buy British business services firm for $\$ 990$ million. Knight Ridder Tribune Business News, 1.

Minniti, M., Arenius, P., \& Langowitz, N. (2004). Global entrepreneurship monitor: 2004 report on women and entrepreneurship. Babson Park, MA and London: Center for Women's Leadership at Babson College and London Business School.

Minniti, M., \& Nardone, C. (2007). Being in someone else's shoes: The role of gender in nascent entrepreneurship. Small Business Economics, 28(2-3), 109-123.

Mirus, R., \& Rylska, N. (2001). Economic integration: Free trade areas vs. Customs unions. School of Business and the Department of Economics, University of Alberta, Edmonton, AB: Western Centre for Economic Research.

Mitra, R. (2002). The growth pattern of women-run enterprises: An empirical study in india. Journal of Developmental Entrepreneurship, 7(2), 217.

Moen, P., \& Yu, Y. (2000). Effective work/life strategies: Working couples, work conditions, gender and life quality. Social Problems, 47, 291-326.

Montgomery, K., \& Oliver, A. L. (1996). Responses by professional organizations to multiple and ambiguous institutional environments: The case of aids. Organization Studies, 17, 649-671.

Morrison, A. M., White, R. P., \& Van Velsor, E. (1987). Breaking the glass ceiling: Can women reach the top of America's largest corporations? Reading, MA: AddisonWesley The Center for Creative Leadership.

Morrison, M. (2008). Scanning the business environment. Rapidbi.

Moulettes, A. (2007). The absence of women's voices in Hofstede's cultural consequences: A postcolonial reading. Women In Management Review, 22(6), 443-455.

Mrad, F. (2006). Meeting Arab socio-economic development needs through information and communications technologies. Journal of Transnational Management, 11(3), 3.

Mujtaba, B. G. (2005). Management and leadership developments in Afghanistan: An interview with Sayed Tayeb Jawad, Afghanistan's ambassador to the united states. Journal of Applied Management and Entrepreneurship, 10(4), 90-101.

Navari, C. (1989). The great illusion revisited: The international theory of Norman Angell. Review of International Studies, 15, 341-358. 
Neubert, M. J., \& Taggar, S. (2004). Pathways to informal leadership: The moderating role of gender on the relationship of individual differences and team member network centrality to informal leadership emergence. The Leadership Quarterly, $15,175-194$.

Neumayer, E., \& deSoysa, I. (2007). Globalisation, women's economic rights and forced labour. World Economy, 30(10), 1510-1535.

Newburry, W., Belkin, L. Y., \& Ansari, P. (2007). Perceived career opportunities from globalization: Globalization capabilities and attitudes towards women in iran and the us. Journal of International Business Studies, November 22 Online.

Newburry, W., \& Yakova, N. (2006). Standardization preferences: A function of national culture, work interdependence and local embeddedness. Journal of International Business Studies, 37, 44-60.

Niederman, F., Kundu, S., \& Salas, S. (2006). It software development offshoring: A multi-level theoretical framework and research agenda. Journal of Global Information Management, 14(2), 52-75.

Norris, P., \& Inglehart, R. (2004). Sacred and secular: Religion and politics worldwide. New York: Cambridge University Press.

North, D. C. (1990). Institutions, institutional change, and economic performance. Cambridge: Cambridge University Press.

Nystrom, K. (2008). The institutions of economic freedom and entrepreneurship: Evidence from panel data. Public Choice, 136(3-4), 269-283.

OECD. (2008). Organization for economic cooperation and development statistics. Retrieved February 4, 2008, from stats.oecd.org through Florida International University Library Database

Ogden, S. M., McTavish, D., \& McKean, L. (2006). Clearing the way for gender balance in the management of the UK financial services industry: Enablers and barriers. Women in Management Review, 21(1), 40.

Oliver, C. (1991). Strategic responses to institutional processes. Academy of Management Review, 16, 145-179.

Oppedisano, J. (2004). Giving back: Women's entrepreneurial philanthropy. Women in Management Review, 19(3), 174.

Osborn, R. N., \& Vicars, W. M. (1976). Sex stereotypes: An artifact in leader behavior and subordinate satisfaction analysis? Academy of Management Journal, 19, 439449. 
Papagni, E. (2006). Household borrowing constraints, fertility dynamics, and economic growth. Journal of Economic Dynamics \& Control, 30(1), 27.

Papamarcos, S. D., \& Watson, G. W. (2006). Culture's consequences for economic development: An empirical examination of culture, freedom, and national market performance Journal of Global Business and Technology, 2(1), 48-58.

Parboteeah, K. P., Cullen, J. B., Victor, B., \& Sakano, T. (2005). National culture and ethical climates: A comparison of U.S. and Japanese accounting firms. Management International Review, 45(4), 459.

Pellegrini, E. K., \& Scandura, T. A. (2006). Leader-member exchange (LMX), paternalism, and delegation in the Turkish business culture: An empirical investigation. Journal of International Business Studies, 37, 264-279.

Peng, M. W. (2003). Institutional transitions and strategic choices. Academy of Management Review, 28(2), 275-296.

Pereira, A., Hsu, C.-C., \& Kundu, S. (2002). A cross-cultural analysis of ethnocentrism in China, India, and Taiwan. Journal of International Consumer Marketing, 15(1), 77-91.

Peters, G. (2000). Institutional theory: Problems and prospects (No. 69). Vienna: Institute for Advanced Studies.

Piaget, J. (1954). The construction of reality in the child. New York: Basic Books.

Porter, M. E. (1980). Competitive strategy: Techniques for analyzing industries and competitors. New York: Free Press.

Porter, M. E. (1990). The competitive advantage of nations. New York: Free Press.

Porter, N., Geis, F. L., Cooper, E., \& Newman, E. (1985). Androgyny and leadership in mixed-sex groups. Journal of Personality and Social Psychology, 39(3), 808-823.

Postman, N. (1993). Technopoly: The surrender of culture to technology. New York: Vintage Books.

Powell, G. N., \& Butterfield, D. A. (1994). Investigating the "'glass ceiling", phenomenon: An empirical study of actual promotions to top management. Academy of Management Journal, 37(1), 68-86.

Powell, G. N., Butterfield, D. A., \& Parent, J. D. (2002). Gender and managerial stereotypes: Have the times changed? . Journal of Management, 28(2), 177-193.

Puddington, A. (2008). Freedom in retreat: Is the tide turning? Findings of freedom in the world 2008 Washington D.C.: Freedom House. 
Rahimi, B. (2007). Reading legitimation crisis in Tehran: Iran and the future of liberalism. Middle East Policy, 14(3), 153-157.

Rahman, A. (1999). Micro-credit initiatives for equitable and sustainable development: Who pays? World Development 27, 6782.

Read, J. n. G., \& Oselin, S. (2008). Gender and the education-employment paradox in ethnic and religious contexts: The case of Arab Americans. American Sociological Review, 73(2), 296-314.

Reynolds, P., Bono, N. D., \& Autio, E. (2003). Gem 2003 expert questionnaire procedural document: Arthur Blank Centre for Entrepreneurial Studies, Babson College, Wellesley, MA, USA. Foundation for Entrepreneurial Management, London Business School, London, UK.

Reynolds, P., Bosma, N., Autio, E., Hunt, S., Bono, N. D., Servais, I., et al. (2005). Global entrepreneurship monitor: Data collection design and implementation: 1998-2003. Small Business Economics, 24, 205-231.

Reynolds, P. D., \& Hechavarria, D. M. (2007). Consolidated global entrepreneurship monitor [gem] adult population survey data set: 1988-2003: ICPSR Study 20320.

Ricart, J. E., Enright, M. J., Ghemawat, P., Hart, S. L., \& Khanna., T. (2004). New frontiers in international strategy Journal of International Business Studies, 35(3), 175 .

Ridgeway, C. L., Johnson, C., \& Diekema, D. (1994). External status, legitimacy, and compliance in male and female groups. Social Forces 72, 1051-1077.

Robbins, K. (2007). Bridging worlds by 'doing it all': Vietnamese adolescent girls and expanded gender roles in the u.S. . Asian Journal of Women's Studies, 13(2), 83100.

Roberts, K. H., Hulin, C. L., \& Rousseau, D. M. (1978). Aggregation problems in organizational science. In Developing an interdisciplinary science of organizations (pp. 81-109). San Fransisco, CA: Josey-Bass, Inc.

Robie, C., Johnson, K. M., Nilsen, D., \& Hazucha, J. F. (2001). The right stuff: Understanding cultural differences in leadership performance. Journal of Management Development, 20(7), 639-650.

Rogers, E. M. (1962). Diffusion of innovations. Glencoe: Free Press.

Rogers, E. M. (2003). Diffusion of innovations (5 ed.). New York, NY: Free Press.

Rogers, J. (1999). Facilitating groups London: Management Futures Ltd. . 
Rosa, P., Carter, S., \& Hamilton, D. (1996). Gender as a determinant of small business performance: Insights from a British study. Small Business Economics, 8, 463478.

Rose-Ackerman, S. (1999). Corruption and government: Causes, consequences and reform. Cambridge: Cambridge University Press.

Rosenbluth, F., Salmond, R., \& Thies, M. F. (2006). Welfare works: Explaining female legislative representation. Politics \& Gender, 2(2), 165-183.

Rosette, A. S., Leonardelli, G. J., Tost, L. P., \& Phillips, K. W. (2006). Leadership subtype activation: Favorable evaluations of women leaders in chief positions, Academy of Management Best Conference Paper. Atlanta, GA.

Rostow, W. W. (1960). The stages of economic growth: A non-communist manifesto. New York: Cambridge University Press.

Rostow, W. W. (1990). The stages of economic growth: A non-communist manifesto, third edition. New York: Cambridge University Press.

Rothbard, N. P. (2001). Enriching or depleting? The dynamics of engagement in work and family roles. Administrative Science Quarterly, 46, 655-684.

Rotter, J. B. (1966). Generalized expectancies for internal versus external control of reinforcement. Psychological Monographs, 80(1).

Ruderman, M. N., Ohlott, P. J., Panzer, K., \& King, S. N. (2002). Benefits of multiple roles for managerial women. Academy of Management Journal, 45(2), 369-386.

Sachs, J. (1997). Nature, nurture, and growth. The Economist, 19-22.

Sachs, J. (2005). The end of poverty. New York: Penguin Books.

Sala-i-Martin, X. (2007). Global competitiveness index. New York: World Economic Forum

Sala-i-Martin, X., Blanke, J., Hanouz, M. D., Geiger, T., Mia, I., \& Paua, F. (2007). Chapter 1.1 the global competitiveness index: Measuring the productive potential of nations. New York: World Economic Forum.

Sampson, G. P., \& Woolcock, S. (Eds.). (2003). Regionalism, multilateralism and economic integration, the recent experience. Honk Kong: The United Nations University.

Sargent, A. G. (1981). The androgynous manager. New York: AMACOM. 
Scandura, T., \& Dorfman, P. (2004). Leadership research in an international and crosscultural context. The Leadership Quarterly, 15(2), 277-307.

Schein, E. H. (1992). Organizational culture and leadership. San Francisco: Jossey-Bass.

Schmitz, H. (1995). Collective efficiency: Growth path for small scale industry. Journal of Development Studies, 31(4), 529-566.

Schumpeter, J. (1934). The theory of economic development. Oxford: Oxford University Press.

Schwartz, S. H., \& Bilsky, W. (1990). Toward a theory of universal content and structure of values: Extensions and cross-cultural replications. Journal of Personality and Social Psychology, 58(5), 878-891.

Schyns, B., \& Sanders, K. (2005). Exploring gender differences in leaders' occupational self-efficacy. Women in Management Review, 20(7/8), 513.

Sclove, S. L. (2001). Notes on cluster analysis Retrieved May 28, 2008

Scott, W. R. (1987). The adolescence of institutional theory. Administrative Science Quarterly, 32, 493-511.

Sczesny, S. (2003). A closer look beneath the surface: Various facets of the think-leaderthink-male stereotype. Sex Roles, 49, 353-363.

Seltzer, R., Newman, J., \& Leighton, M. (1997). Sex as a political variable: Women as candidates and voters in U.S. Elections. Boulder, CO Lynne Rienner.

Sen, G. (1996). Gender, markets and states: A selective review and research agenda. World Development, 24, 821-829.

Shabbir, A., \& Di Gregorio, S. (1996). An examination of the relationship between women's personal goals and structural factors influencing their decision to start a business: The case of Pakistan. Journal of Business Venturing, 11(6), 507.

Shahabuddin, S. (2007). Corruption and its economic and business implications. The Business Review, Cambridge, 8(1), 305-306.

Sharma, S. (2007). Financial development and innovation in small firms The World Bank.

Sieber, S. D. (1974). Toward a theory of role accumulation. American Sociological Review, 39, 567-578.

Silber, I. C. (2007). Local capacity building in "Dysfunctional" Times: Internationals, revolutionaries, and activism in postwar El Salvador Women's Studies Quarterly, 35(3/4), 167-183. 
Simon, R. W. (1995). Gender, multiple roles, role meaning and mental health. Journal of Health and Social Behavior, 36, 182-194.

Skarmeas, D., Katsikeas, C. S., \& Schlegelmilch, B. B. (2002). Drivers of commitment and its impact on performance in cross-cultural buyer-seller relationships: The importer's perspective. Journal of International Business Studies, 33(4), 757.

Smith, E., \& Fox, R. L. (2001). The electoral fortunes of women candidates for congress. Political Research Quarterly, 54, 205-221.

Smith, P. B. (2002). Culture's consequences: Something old and something new. Human Relations, 55(1), 119-135.

Smock, A. C. (1981). Women's education in developing countries: Opportunities and outcomes. New York: Praeger Publishers.

StatSoft. (2008). Cluster analysis.

Stelter, N. Z. (2002). Gender differences in leadership: Current social issues and future organizational implications. Journal of Leadership \& Organizational Studies, $8(4), 88$.

SullydeLuque, M., \& Javidan, M. (2004). Uncertainty avoidance. In R. J. House, P. J. Hanges, M. Javidan, P. W. Dorfman \& V. Gupta (Eds.), Culture, leadership and organizations: The globe study of 62 societies (pp. p. 602-653). Thousand Oaks, CA: Sage Publications.

Szabo, E., Brodbeck, F. C., Hartog, D. N. D., Reber, G., Weibler, J., \& Wunderer, R. (2002). The Germanic Europe cluster: Where employees have a voice. Journal of World Business, 37, 55-68.

Tanimoto, M. (Ed.). (2006). The role of tradition in japan's industrialization: Another path to industrialization. New York: Oxford University Press.

Temtime, Z. T., Chinyoka, S. V., \& Shunda, J. P. W. (2004). A decision tree approach for integrating small business assistance schemes. The Journal of Management Development, 23(5/6), 563.

Toye, J. (1987). Dilemmas of development: Reflections in the counterrevolution in development theory. Oxford: Blackwell.

Turley, J. (2004, October 3). Polygamy laws expose our own hypocrisy. USA Today News.

UN. (2003, September 8). Millennium development goals. Retrieved August 19, 2005, from http://www.un.org/millenniumgoals/ 
UN. (2004). Millennium indicators database. Retrieved March 2004, from http://millenniumindicators.un.org

UN. (2005a). Division for the advancement of women. Retrieved August 19, 2005, from http://www.un.org/womenwatch/daw/daw/

UN. (2005b). Investment in development: A practical plan to achieve the millennium development goals. New York: United Nations Development Programme.

UNDP. (2003). Millennium development goals: A compact among nations to end human poverty. New York: United Nations Development Programme.

UNDP. (2004). Cultural liberty in today's diverse world. New York: United Nations Development Programme.

UNDP. (2005). International cooperation at a crossroads: Aid, trade and security in an unequal world. New York: United Nations Development Programme.

UNDP. (2006). Beyond scarcity: Power, poverty and the global water crisis. New York: United Nations Development Programme.

UNDP. (2007). Making globalization work for all: United nations development programme annual report 2007. New York: United Nations Development Programme.

UNESCO. (2001). Correspondence on combined gross enrolment ratio. Paris.

UNIFEM. (2008). United nations development fund for women, from www.unifem.org

Van de Vliert, E. (2003). Thermoclimate, culture, and poverty as country-level roots of workers' wages. Journal of International Business Studies, 34(1), 40.

Vavrus, F., \& Richey, L. A. (2003). Women and development: Rethinking policy and reconceptualizing practice. Women's Studies Quarterly, 31(3/4), 6.

Vecchio, R. P. (2002). Leadership and gender advantage. The Leadership Quarterly, 13(6), 643-671.

Vinnicombe, S., \& Singh, V. (2002). Sex role stereotyping and requisites of successful top managers. Women in Management Review, 17(3/4), 120.

Wagley, J. (2008). Internet threat management. Security Management, 52(3), 51.

Waldstrøm, C., \& Madsen, H. (2007). Social relations among managers: Old boys and young women's networks Women in Management Review, 22(2), 136-147. 
Walker, E. A., \& Webster, B. J. (2007). Gender, age and self-employment: Some things change, some stay the same. Women in Management Review, 22(2), 122-135.

Wane, N. N., \& Kavuma, E. (2001). Grandmothers called out of retirement: The challenges for African women facing aids today. Canadian Woman Studies, $21(2), 10$.

Wang, C. L., Lin, X., Chan, A. K. K., \& Shi, Y. (2005). Conflict handling styles in international joint ventures: A cross-cultural and cross-national comparison. Management International Review, 45(1), 3-21.

Watson, J., \& Robinson, S. (2003). Adjusting for risk in comparing the performances of male- and female-controlled SME's. Journal of Business Venturing, 18, 773-788.

Weibler, J., \& Wunderer, R. (2007). Leadership and culture in Switzerland - theoretical and empirical findings. In J. S. Chhokar, F. C. Brodbeck \& R. J. House (Eds.), Culture and leadership across the world: The globe book of in-depth studies of 25 societies (pp. 251). Mahwah, New Jersey: Lawrence Erlbaum Associates.

Weikart, L. A., Chen, G., Williams, D. W., \& Hromic, H. (2006). The democratic sex: Gender differences and the exercise of power. Journal of Women, Politics \& Policy, 28(1), 119.

Weiss, J. (1988). Industry in developing countries: Theory, practice, and evidence. London: Croom Helm.

White, G. (1984). Development states and socialist industrialisation in the third world. Journal of Development Studies, 21(1), 97-120.

Wishart, D. (1998). Clustan - a class act Retrieved May 20, 2008, from http://www.clustan.com/what_is_cluster_analysis.html

Wolfram, H.-J., Mohr, G., \& Schyns, B. (2007). Professional respect for female and male leaders: Influential gender-relevant factors Women in Management Review, 22 (1), $19-32$

World Bank. (2004). World Bank International Comparison Programme (ICP). Washington, DC.

World Bank. (2007a). Doing business project. Retrieved January/February 2008, from www.doingbusiness.org

World Bank. (2007b). Doing business report 2008: Comparing regulations in 178 economies. Washington, D.C.

World Bank. (2007c). Table 5.1 private sector in the economy. In World Bank World Development Indicators. Washington D.C.: World Bank Publications. 
World Bank. (2007d). The World Bank Enterprise Survey core module. Unpublished manuscript, Washington D.C.

World Bank. (2007e). World bank world development indicators. Retrieved February 5, 2008, from http://www.worldbank.org/data/wdi2004/ accessed through the Florida International University Library

World Bank. (2008a). Enterprise Survey. Retrieved January/February 2008, from www.enterprisesurveys.org

World Bank. (2008b). Paying taxes 2008: The global picture. Washington, D.C.: The World Bank / Price Waterhouse Coopers.

Youssef, N. H. (1974). Women and work in developing societies. Berkeley, CA: Greenwood Press.

Yukl, G. (1998). Leadership in organizations. Upper Saddle River, NJ: Prentice-Hall.

Yukl, G. (2002). Leadership in organizations. Upper Saddle River, NJ: Prentice-Hall.

Yukl, G., \& Howell, J. M. (1999). Organizational and contextual influences on the emergence and effectiveness of charismatic leadership. Leadership Quarterly, $10(2), 257-283$.

Zárate, R. O. d. (2008). Women world leaders 1945-2007 Retrieved August 2008, from http://www.terra.es/personal2/monolith/00women.htm

Zou, F., \& Gao, Y. (2007). Guanxi with government as a source of competitive advantage in mainland china. Journal of American Academy of Business, 10(2), 158-163.

Zucker, L. G. (1988). Where do institutional patterns come from? Organizations as actors in social systems. In L. G. Zucker (Ed.), Institutional patterns and organizations: Culture and environment (pp. 23-49). Cambridge, MA: Ballinger. 
APPENDICES

\begin{tabular}{|c|c|c|c|c|}
\hline \multicolumn{5}{|c|}{ Appendix 1: Variable List } \\
\hline Hypothesis & Sub-Category & Variable & Source & $\mathrm{N}$ \\
\hline \multirow{5}{*}{$\begin{array}{c}\text { Women in } \\
\text { Leadership DV's }\end{array}$} & \multirow{3}{*}{ Business Leadership } & Proportion of Firms with Female Employers \& Own Account Works OECD 2004 & OECD & 29 \\
\hline & & Proportion of Firms With Females in Ownership Developing Countries 02-07 & WB Enterprises Survey & 76 \\
\hline & & Proportion of Women in Serior Positions Developing Countries 2002-2007 & WB Enterprises Survey & 66 \\
\hline & \multirow{2}{*}{ Political Leadership } & Proportion of seats held by women in national parliament (\%) 2004 WDI & UNDP & 176 \\
\hline & & Proportion Seats in parliament held by women (\% of total) 2004 UNDP & UNDP & 171 \\
\hline \multirow{70}{*}{$\begin{array}{c}\text { Business } \\
\text { Environment }\end{array}$} & \multirow{10}{*}{ H2a: Gift Giving } & $\%$ of Firms Expected to Give Gifts to Get an Operating License 2002-2007 & WB Enterprises Survey & 58 \\
\hline & & $\%$ of Firms Expected to Give Gifts to Get an Import License 2002-2007 & WB Enterprises Survey & 61 \\
\hline & & $\%$ of Firms Expected to Give Gifts to Get a Construction Permit 2002-2007 & WB Enterprises Survey & 60 \\
\hline & & $\%$ of Firms Expected to Give Gifts to Get an Electrical Connection 2002-2007 & WB Enterprises Survey & 67 \\
\hline & & $\%$ of Firms Expected to Give Gifts to Get a Phone Connection 2002-2007 & WB Enterprises Survey & 65 \\
\hline & & $\%$ of Firms Expected to Give Gifts to Get a Water Connection 2002-2007 & WB Enterprises Survey & 56 \\
\hline & & $\%$ of Firms Expected to Give Gifts to Secure a Govemment Contract 2002-2007 & WB Enterprises Survey & 95 \\
\hline & & $\%$ of Firms Expected to Give Gifts In Meetings With Tax Inspectors 2002-200? & WB Enterprises Survey & 95 \\
\hline & & $\%$ of Firms Expected to Pay Informal Payment (to Get Things Done) 2002-2007 & WB Enterprises Survey & 93 \\
\hline & & Value of Gift Expected to Secure Government Contract (\% of Contract) 2002-2007 & WB Enterprises Survey & 95 \\
\hline & \multirow{4}{*}{$\mathrm{H} 2 \mathrm{~b}$ : Crime \& Comuption } & Losses fromTheft, Robbery, Vandalism, \& Arson (\% of Sales) 2002-2007 & WB Enterprises Survey & 101 \\
\hline & & $\%$ of Firms Identifying Crime, Theft and Disorder as Major Constraints 2002-200? & WB Enterprises Survey & 101 \\
\hline & & $\%$ of Firms Identifying Comuption as a Major Constraint 2002-2007 & WB Enterprises Survey & 104 \\
\hline & & Security Costs (\% of Sales) 2002-200? & WB Enterprises Survey & 100 \\
\hline & \multirow{11}{*}{ H2c: Skill Level } & Average Number of Temporary Workers 2002-200? & WB Enterprises Survey & 102 \\
\hline & & Average Number of Permanent, Full Time Workers 2002-2007 & WB Enterprises Survey & 104 \\
\hline & & Average Number of Skilled Production Workers 2002-2007 & WB Enterprises Survey & 101 \\
\hline & & Average Number of Unskilled Production Workers 2002-2007 & WB Enterprises Survey & 101 \\
\hline & & Average Number of Production Workers 2002-2007 & WB Enterprises Survey & 97 \\
\hline & & Average Number of Non Production Workers 2002-2007 & WB Enterprises Survey & 98 \\
\hline & & Difficulty of Hiring Employees/Workers 2007 & WB Doing Business & 172 \\
\hline & & Years of Experience of the Top Manager Working in the Firm's Sector 2002-2007 & WB Enterprises Survey & 61 \\
\hline & & $\%$ of Firms Identifying Labor Regulations as a Major Constraint 2002-2007 & WB Enterprises Survey & 104 \\
\hline & & $\%$ of Firms Identifying Labor Skill Level as a Major Constraint 2002-200? & WB Enterprises Survey & 104 \\
\hline & & $\%$ of Firms Offering Formal Training* 2002-2007 & WB Enterprises Survey & 104 \\
\hline & & Average Time to Clear Direct Exports Through Customs (days) 2002-2007 & WB Enterprises Survey & 100 \\
\hline & & Average Time to Clear Imports from Customs (days)* 2002-2007 & WB Enterprises Survey & 100 \\
\hline & & Trading Across Borders Documents for export (number) 2007 & WB Doing Business & 172 \\
\hline & H2d: Borders and Customs & Trading Across Borders Time for export (days) 2007 & WB Doing Business & 172 \\
\hline & & Trading Across Borders Documents for import (number) 2007 & WB Doing Business & 172 \\
\hline & & Trading Across Borders Time for import (days) 2007 & WB Doing Business & 172 \\
\hline & & $\%$ of Firms Identifying Custorns \& Trade Regulations as a Major Constraint 2002-2007 & WB Enterprises Survey & 104 \\
\hline & & Days to Obtain Operating License 2002-2007 & WB Enterprises Survey & 57 \\
\hline & & Days to Obtain Construction-related Permit 2002-2007 & WB Enterprises Survey & 61 \\
\hline & H2e. Iicenses \& Permits & Days to Obtain Import License 2002-2007 & WB Enterprises Survey & 59 \\
\hline & H2e: Lucenses \& Permuts & Dealing with Licenses Procedures (number) 2007 & WB Doing Business & 171 \\
\hline & & Dealing with Licenses Time (days) 2007 & WB Doing Business & 171 \\
\hline & & $\%$ of Firms Identifying Business Licensing \& Permits as Major Constraint 2002-2007 & WB Enterprises Survey & 104 \\
\hline & & Procedures to enforce a contract (number) 2002-2007 & WB WDI & 141 \\
\hline & แาค. $\mathrm{C}$ - & Enforcing Contracts Procedures (number) $200 ?$ & WB Doing Business & 172 \\
\hline & H2f:Contracts & Enforcing Contracts Time (days) 2007 & WB Doing Business & 172 \\
\hline & & Time required to enforce a contract (days) 2004 & WB WDI & 141 \\
\hline & & Average number of visits or required meetings with tax officials 2002-200? & WB Enterprises Survey & 102 \\
\hline & & Paying Taxes Payments (number) 2007 & WB Doing Business & 172 \\
\hline & H2a. Taxes & Paying Taxes Time (hours) 2007 & WB Doing Business & 171 \\
\hline & & $\%$ of Firms Identifying Tax Rates as Major Constraint 2002-2007 & WB Enterprises Survey & 104 \\
\hline & & $\%$ of Firms Identifying Tax Administration as Major Constraint 2002-200? & WB Enterprises Survey & 104 \\
\hline & & $\%$ of Firms expressing that a Typical Firm Reports $<100 \%$ of Sales for Taxes $2002-2007$ & WB Enterprises Survey & 97 \\
\hline & & Procedures to register property (number) 2002-2007 & WB WDI & 138 \\
\hline & & Registering Property Procedures (number) 2007 & WB Doing Business & 168 \\
\hline & & Registering Property Time (days) 2007 & WB Doing Business & 168 \\
\hline & & Time required to register property (days) 2004 & WB WDI & 138 \\
\hline & H2h. Start-un Pmocedures & $\%$ of Serior Management Time Dealing w/ Requirements of Govt Regulation 2002-2007 & WB Enterprises Survey & 100 \\
\hline & & Cost of business start-up procedures (\% of GNI per capita) 2002-2007 & WB WDI & 141 \\
\hline & & Starting a Business Procedures (number) 2007 & WB Doing Business & 172 \\
\hline & & Starting a Business Time (days) 2007 & WB Doing Business & 172 \\
\hline & & Start-up procedures to register a business (number) 2004 & WB WDI & 140 \\
\hline & & Time required to start a business (days) 2004 & WB WDI & 141 \\
\hline & & $\%$ of Firms Using Banks to Finance Investments 2002-2007 & WB Enterprises Survey & 104 \\
\hline & HOi. Financing & $\%$ of Firms Using Banks to Finance Expenses 2002-2007 & WB Enterprises Survey & 104 \\
\hline & & $\%$ of Firms Identifying Access/cost of Finance as a Major Constraint 2002-2007 & WB Enterprises Survey & 104 \\
\hline & & Value of Collateral Needed for a Loan ( $\%$ of the Loan Amount) 2002-2007 & WB Enterprises Survey & 101 \\
\hline & & Global Competitiveness Index 2007 & World Economic Fonum & 128 \\
\hline & & Global Competitiveness Institutions 2007 & World Economic Fonum & 128 \\
\hline & & Global Competitiveness Business Sophistication 2007 & World Economic Fonum & 128 \\
\hline & H2j: Global & Global Competitiveness Innovation 2007 & World Economic Fonum & 128 \\
\hline & Competitiveness & Global Competitiveness Labor Market Efficiency 2007 & World Economic Fonum & 128 \\
\hline & & Global Competitiveness Financial Market Sophistication $200 ?$ & World Economic Fonum & 128 \\
\hline & & Global Competitiveness Goods Market Efficiency 2007 & World Economic Fonum & 128 \\
\hline & & Global Competitiveness Market Size 2007 & World Economic Fonum & 128 \\
\hline
\end{tabular}




\begin{tabular}{|c|c|c|c|c|}
\hline \multicolumn{5}{|c|}{ Appendix l: Variable List Cont'd } \\
\hline Hypothesis & Sub-Category & \begin{tabular}{|r|} 
Variable \\
\end{tabular} & \begin{tabular}{|c|} 
Source \\
\end{tabular} & $\mathrm{N}$ \\
\hline \multirow{14}{*}{$\begin{array}{c}\text { Business } \\
\text { Ervironment, } \\
\text { Cont'd }\end{array}$} & \multirow{14}{*}{$\begin{array}{l}\text { H2k: Entrepreneurial } \\
\text { Framework Conditions }\end{array}$} & Good Infrastructure and Cormunurications 2003 & Global E'ship Monitor & 32 \\
\hline & & Respect for Individaulistic and Innovative Entrepreneurs 2003 & Global E'ship Monitor & 32 \\
\hline & & Social Acceptance \& Respect for Entrepreneurs 2003 & Global E'ship Monitor & 32 \\
\hline & & Supportive Ervironment for Women 2003 & Global E'ship Monitor & 32 \\
\hline & & Business Opporturity Ervironment \& Entrepreneurial Ability 2003 & Global E'ship Monitor & 32 \\
\hline & & Positive Impression of Govt Support 2003 & Global E'ship Moritor & 32 \\
\hline & & Accessible \& Affordable Business Services \& Suppliers 2003 & Global E'ship Monitor & 32 \\
\hline & & Sufficient Funding 2003 & Global E'ship Monitor & 32 \\
\hline & & Strong Intellectual Property Rights 2003 & Global E'ship Monitor & 32 \\
\hline & & Grade School Entrepreneurial Education Focus 2003 & Global E'ship Monitor & 32 \\
\hline & & Good Market Opporturity and Controls 2003 & Global E'ship Monitor & 32 \\
\hline & & Positive Research and Technology Environment 2003 & Global E'ship Monitor & 32 \\
\hline & & Timely access to utilities, communications, and permitslicenses 2003 & Global E'ship Monitor & 32 \\
\hline & & Good Available Entrepreneurship Training 2003 & Global E'ship Monitor & 32 \\
\hline \multirow{44}{*}{$\begin{array}{c}\text { Societal } \\
\text { Development }\end{array}$} & \multirow{29}{*}{ H3a: Employment } & Contributing Farnily Workers Females $\% 2004$ & UNDP & 90 \\
\hline & & Contrbuting Family Workers males $\% 2004$ & UNDP & 90 \\
\hline & & Employees, agriculture, female (\% of female employment) WDI 2004 & WB WDI & 71 \\
\hline & & Employees, agriculture, male (\% of male employment) WDI 2004 & WB WDI & 71 \\
\hline & & Employment Agriculture Females \% UN 2003* & UNDP & 82 \\
\hline & & Employment Agriculture Males \% UN 2003 & UNDP & 84 \\
\hline & & Employment in agriculture (\% of total employment) UN 2004 & WB WDI & 75 \\
\hline & & Share of women in nonagriculture ( $\%$ of total nonagricultural employment) 2004 & WB WDI & 129 \\
\hline & & Employees, industry, female (\% of female employment) 2004 & WB WDI & 71 \\
\hline & & Employees, industry, male (\% of male employment) 2004 & WB WDI & 71 \\
\hline & & Employment Industry Females \% 2003* & UNDP & 86 \\
\hline & & Employment Industry Males \% 2003 & UNDP & 86 \\
\hline & & Employment in industry ( $\%$ of total employment) 2004 & WB WDI & 75 \\
\hline & & Employees, services, female (\% of female employment) 2004 & WB WDI & 71 \\
\hline & & Employees, services, male (\% of male employment) 2004 & WB WDI & 71 \\
\hline & & Employment Services Females \% 2003* & UNDP & 86 \\
\hline & & Employment Services Males \% 2003 & UNDP & 86 \\
\hline & & Employment in services (\% of total employment) 2004 & WB WDI & 75 \\
\hline & & Estimated eamed income, female (PPP US\$) 2004 & UNDP & 160 \\
\hline & & Estimated eamed income, male (PPP US\$) 2004 & UNDP & 160 \\
\hline & & Ratio of estimated fermale to male eamed income 2003 & UNDP & 160 \\
\hline & & Labor force participation rate, female (\% of female population ages $15-64) 2004^{*}$ & WB WDI & 172 \\
\hline & & Labor force participation rate, male (\% of male population ages $15-64) 2004$ & WB WDI & 172 \\
\hline & & Labor force participation rate, total (\% of total population ages 15-64) 2004 & WB WDI & 172 \\
\hline & & Labor force, female ( $\%$ of total labor force) $2004^{*}$ & WB WDI & 172 \\
\hline & & Labor force, total 2004 & WB WDI & 172 \\
\hline & & Unemployment, female ( $\%$ of female labor force) 2004 & WB WDI & 74 \\
\hline & & Unemployment, male (\% of male labor force) 2004 & WB WDI & 74 \\
\hline & & Unemployment, total (\% of total labor force) 2004 & WB WDI & 77 \\
\hline & \multirow{15}{*}{ H3b: Gender Equality } & Proportion of Fermale Legislators, Serior Officials, \& Managers 2004 & UNDP & 80 \\
\hline & & Female professional and technical workers (\% of total) 2004 & UNDP & 80 \\
\hline & & Female economic activity (ages 15+) Rate 2004 & UNDP & 168 \\
\hline & & Female economic activity (ages 15+) Index 2004 & UNDP & 168 \\
\hline & & Female economic activity as \% of Male rate 2004 & UNDP & 168 \\
\hline & & $\%$ of Full Time Fermale Workers* 2002-2007 & WB Enterprises Survey & 75 \\
\hline & & Gender Related Development Index Rank 2004 & UNDP & 136 \\
\hline & & Gender Related Development Index Value 2004 & UNDP & 136 \\
\hline & & Gender empowerment measure (GEM) rark 2004 & UNDP & 75 \\
\hline & & Gender empowement measure (GEM) Value 2004 & UNDP & 75 \\
\hline & & Global Gender Gap Index 2007 & World Economic Fonum & 127 \\
\hline & & Gender Gap Econornic Participation and Opportunity 2007 & World Economic Forum & 127 \\
\hline & & Gender Gap Educational Attainment 2007 & World Economic Fonum & 127 \\
\hline & & Gender Gap Health and Survival Subindex 2007 & World Economic Fonum & 127 \\
\hline & & Gender Gap Political Empowerment 2007 & World Economic Fonum & 127 \\
\hline
\end{tabular}




\begin{tabular}{|c|c|c|c|c|}
\hline \multicolumn{2}{|c|}{ Appendix l: Variable List Cont'd } & \multirow[b]{2}{*}{ Variable } & \multirow[b]{2}{*}{ Source } & \multirow[b]{2}{*}{$\mathrm{N}$} \\
\hline Hypothesis & Sub-Category & & & \\
\hline \multirow{35}{*}{$\begin{array}{c}\text { Societal } \\
\text { Development } \\
\text { Cont'd }\end{array}$} & \multirow{15}{*}{ H3c: Education } & Adult literacy rate (\% ages 15 and older) 2004 & UNDP & 173 \\
\hline & & Adult Literacy, females (\%) (age 15+) 2004* & UNDP & 146 \\
\hline & & Adult Literacy, males (\%) (age 15+) 2004* & UNDP & 132 \\
\hline & & Children out of school, primary, female 2004 & WB WDI & 136 \\
\hline & & Children out of school, primary, male 204 & WB WDI & 136 \\
\hline & & Combined gross enrolment ratio for primary, secondary and tertiary schools (\%) 2004 & UNDP & 173 \\
\hline & & Education Combined primary, secondary and tertiary schools, fermale (\%) 2004 & UNDP & 164 \\
\hline & & Education Combined primary, secondary and tertiary schools, male (\%) 2004 & UNDP & 164 \\
\hline & & Primary education, pupils 2004 & WB WDI & 168 \\
\hline & & Primary education, pupils (\% female) 2004 & WB WDI & 164 \\
\hline & & Public spending on education, total ( $\%$ of GDP) 2004 & WB WDI & 107 \\
\hline & & Secondary education, pupils 2004 & WB WDI & 161 \\
\hline & & Secondary education, pupils (\% female) 2004 & WB WDI & 159 \\
\hline & & Education index 2004 & UNDP & 173 \\
\hline & & Global Competitiveness Higher Education \& Training 2007 & World Economic Forum & 128 \\
\hline & \multirow{6}{*}{ H3d: Population } & Population ages $0-14(\%$ of total) 2004 & WB WDI & 173 \\
\hline & & Population ages $15-64(\%$ of total) 2004 & WB WDI & 173 \\
\hline & & Population ages 65 and above (\% of total) 2004 & WB WDI & 173 \\
\hline & & Population, fermale (\% of total) 2004 & WB WDI & 173 \\
\hline & & Rural population ( $\%$ of total population) 2004 & WB WDI & 187 \\
\hline & & Urban population (\% of total) 2004 & WB WDI & 187 \\
\hline & \multirow{14}{*}{$\begin{array}{l}\mathrm{H} 3 \mathrm{e}: \text { Health \& } \\
\text { Development }\end{array}$} & Birth rate, crude (per 1,000 people) 2004 & WB WDI & 79 \\
\hline & & Death rate, crude (per 1,000 people) 2004 & WB WDI & 77 \\
\hline & & Fertility rate, total (births per woman) 2004 & WB WDI & 90 \\
\hline & & Hurnan Development Index 2004 & UNDP & 173 \\
\hline & & Global Competitiveness Health \& Primary Education 2007 & World Economic Forum & 128 \\
\hline & & Improved saritation facilities (\% of population with access) 2004 & WB WDI & 155 \\
\hline & & Improved water source (\% of population with access) 2004 & WB WDI & 165 \\
\hline & & Life expectancy at birth (years) 2004 & UNDP & 173 \\
\hline & & Life expectancy index 2004 & UNDP & 173 \\
\hline & & Life Expectancy at Birth, fermales 2004 & UNDP & 168 \\
\hline & & Life Expectancy at Birth, males 2004 & UNDP & 168 \\
\hline & & Out-of-pocket health expenditure ( $\%$ of private expenditure on health) 2004 & WB WDI & 179 \\
\hline & & Physicians (per 1,000 people) 2004 & WB WDI & 64 \\
\hline & & Prevalence of undemourishment (\% of population) 2004 & WB WDI & 167 \\
\hline \multirow{36}{*}{ Economics } & H4a: Econormic Freedom & Index of Economic Freedom 2005 & Heritage Foundation & 150 \\
\hline & $\begin{array}{c}\mathrm{H} 4 \mathrm{~b}: \text { Macroeconomic } \\
\text { Stability }\end{array}$ & Global Competitiveness Macroeconomic Stability 2007 & World Economic Fonum & 128 \\
\hline & \multirow{10}{*}{ H4c: GDP Related Factors } & GDP per capita (constant 2000 US\$) 2004 & WB WDI & 176 \\
\hline & & GDP per capita, PPP (constant 2000 international \$) 2004 & WB WDI & 166 \\
\hline & & GDP per capita (PPP US\$) 2004* & UNDP & 173 \\
\hline & & GDP index 2004* & UNDP & 173 \\
\hline & & Final consurmption expenditure (constant 2000 US\$) 2004 & WB WDI & 103 \\
\hline & & Final consumption expenditure, etc. (\% of GDP) $2004^{*}$ & WB WDI & 162 \\
\hline & & General government final consumption expenditure (\% of GDP)* & WB WDI & 161 \\
\hline & & General govemument final consumption expenditure (constant 2000 US\$) 2004 & WB WDI & 130 \\
\hline & & Household final consumption expenditure (constant 2000 US\$) 2004 & WB WDI & 130 \\
\hline & & Household final consumption expenditure, etc. (\% of GDP) $2004^{*}$ & WB WDI & 160 \\
\hline & H4d: Loans & Bank nomperfoming loans to total gross loans (\%) 2004 & WB WDI & 100 \\
\hline & $\mathrm{H} 4 \mathrm{e}$ :Domestic Credit & Domestic credit provided by banking sector (\% of GDP) 2004 & WB WDI & 172 \\
\hline & H4e: Domestic Credit & Domestic credit to private sector ( $\%$ of GDP) 2004 & WB WDI & 172 \\
\hline & H4f: Taxes & Highest marginal tax rate, individual rate (\%) 2004 & WB WDI & 95 \\
\hline & H4r. 1axes & Tax revenue (\% of GDP) 2004 & WB WDI & 94 \\
\hline & H4r. Inflation & Inflation, consumer prices (annual \%) 2004 & WB WDI & 156 \\
\hline & H4g: Intlation & Inflation, GDP deflator (anrual \%) 2004 & WB WDI & 179 \\
\hline & & Foreign direct irvestment, net inflows (\% of GDP) 2004 & WB WDI & 164 \\
\hline & & Imports of goods and services (\% of GDP) 2004 & WB WDI & 166 \\
\hline & H4h: Inflows \& Outflows & Imports of goods and services (constant 2000 US\$) 2004 & WB WDI & 138 \\
\hline & & Exports of goods and services (\% of GDP) 2004 & WB WDI & 165 \\
\hline & & Exports of goods and services (constant 2000 US\$) 2004 & WB WDI & 140 \\
\hline & & Intemational tourism, receipts (\% of total exports) 2004 & WB WDI & 119 \\
\hline & & High-technology exports (\% of manufactured exports) 2004 & WB WDI & 121 \\
\hline & & Commercial service exports (current US\$) 2004 & WB WDI & 146 \\
\hline & & Computer, communications and other services (\% of commercial service exports) 2004 & WB WDI & 144 \\
\hline & & Insurance and financial services (\% of commercial service exports) 2004 & WB WDI & 142 \\
\hline & H4i: Types of Good \& & \% of Exporter Firms 2002-2007 & WB WDI & 104 \\
\hline & Services & Manufactures exports (\% of merchandise exports) 2004 & WB WDI & 128 \\
\hline & & Ores and metals exports (\% of merchandise exports) 2004 & WB WDI & 128 \\
\hline & & Agricultural raw materials exports (\% of merchandise exports) 2004 & WB WDI & 127 \\
\hline & & Food exports (\% of merchandise exports) 2004 & WB WDI & 128 \\
\hline & & Fuel exports (\% of merchandise exports) 2004 & WB WDI & 126 \\
\hline & & Arms imports (constant 1990 US\$) 2004 & WB WDI & 169 \\
\hline
\end{tabular}




\begin{tabular}{|c|c|c|c|c|}
\hline \multicolumn{2}{|c|}{ Appendix 1: Variable List Cont'd } & \multirow[b]{2}{*}{ Variable } & \multirow[b]{2}{*}{\begin{tabular}{|c|} 
Source \\
\end{tabular}} & \multirow[b]{2}{*}{$\mathrm{N}$} \\
\hline Hypothesis & Sub-Category & & & \\
\hline \multirow{17}{*}{$\begin{array}{l}\text { Technology and } \\
\text { Physical } \\
\text { Infrastructure }\end{array}$} & \multirow{9}{*}{$\begin{array}{l}\text { H5a: Physical } \\
\text { Infrastructure }\end{array}$} & Global Competitiveness Basic Infrastructure 2007 & World Econormic Fonum & 128 \\
\hline & & Rail lines (total route-km) 2004 & WB WDI & 70 \\
\hline & & Railways, goods transported (million ton-km) 2004 & WB WDI & 69 \\
\hline & & Railways, passengers caried (million passenger-km) 2004 & WB WDI & 67 \\
\hline & & Roads, paved ( $\%$ of total roads) 2004 & WB WDI & 65 \\
\hline & & Roads, total network (km) 2004 & WB WDI & 76 \\
\hline & & Electric power consurmption ( $\mathrm{kWh}$ per capita) 2004 & WB WDI & 127 \\
\hline & & Telephone mainlines (per 1,000 people) 2004 & WB WDI & 168 \\
\hline & & Fixed line and mobile phone subscribers (per 1,000 people) 2004 & WB WDI & 168 \\
\hline & \multirow{8}{*}{$\begin{array}{l}\text { HSb: Technology } \\
\text { Infrastructure }\end{array}$} & Mobile phone subscribers (per 1,000 people) 2004 & WB WDI & 183 \\
\hline & & Broadband subscribers (per 1,000 people) 2004 & WB WDI & 127 \\
\hline & & Intemational Intemet bandwidth (bits per person) 2004 & WB WDI & 126 \\
\hline & & Intemet users (per 1,000 people) 2004 & WB WDI & 180 \\
\hline & & Information and communication technology expenditure (\% of GDP) 2004 & WB WDI & 74 \\
\hline & & Personal computers (per 1,000 people) 2004 & WB WDI & 152 \\
\hline & & Households with television $(\%) 2004$ & WB WDI & 39 \\
\hline & & Global Competitiveness Technological Readiness 2007 & World Economic Fonum & 128 \\
\hline \multirow{2}{*}{ Political Freedom } & H6a: Political Rights & Political Rights 2005 & Freedom House & 170 \\
\hline & H6b: Civil Liberties & Civil Liberties 2005 & Freedom House & 170 \\
\hline \multirow{29}{*}{ Culture } & \multirow{2}{*}{$\begin{array}{c}\text { H7 a: Performance } \\
\text { Orientation }\end{array}$} & Performance Orientation: Society Practices ( $\mathrm{As}$ is) & Project GLOBE & 56 \\
\hline & & Performance Orientation: Society Values (Should Be) & Project GLOBE & 56 \\
\hline & \multirow{2}{*}{$\mathrm{H} 7 \mathrm{~b}$ : Future Orientation } & Future Orientation: Society Practices ( $\mathrm{As}$ is) & Project GLOBE & 56 \\
\hline & & Future Orientation: Society Values (Should Be) & Project GLOBE & 56 \\
\hline & \multirow{2}{*}{ H7c: Gender Egalitarianism } & Gender Egalitarianism Society Practice (As Is) & Project GLOBE & 56 \\
\hline & & Gender Egalitarianism Society Values (Should Be) & Project GLOBE & 56 \\
\hline & \multirow{2}{*}{ H7d: Assertiveness } & Assertiveness Society Practices (As Is) & Project GLOBE & 56 \\
\hline & & Assertiveness Society Values (Should Be) & Project GLOBE & 56 \\
\hline & \multirow{4}{*}{ H7e: Collectivism } & Institutional Collectivism Society Practice (As Is) & Project GLOBE & 56 \\
\hline & & In-Group Collectivism Society Practice (As Is) & Project GLOBE & 56 \\
\hline & & Institutional Collectivism Society Values (Should Be) & Project GLOBE & 56 \\
\hline & & In-Group Collectivism Society Values (Should Be) & Project GLOBE & 56 \\
\hline & \multirow{2}{*}{ H7f: Power Distance } & Power Distance Society Practices (As Is) & Project GLOBE & 56 \\
\hline & & Power Distance Society Values Should Be) & Project GLOBE & 56 \\
\hline & \multirow{2}{*}{ H7g: Humane Orientation } & Humane Orientation Society Practices (As Is) & Project GLOBE & 56 \\
\hline & & Hurmane Orientation Society Values (Should Be) & Project GLOBE & 56 \\
\hline & \multirow{2}{*}{$\begin{array}{l}\text { H7h: Uncertainty } \\
\text { Avoidance }\end{array}$} & Uncertainty Avoidance Practice (As Is) & Project GLOBE & 56 \\
\hline & & Uncertainty Avoidance Values (Should Be) & Project GLOBE & 56 \\
\hline & $\mathrm{H} 7 \mathrm{i}$ & Charismatic/Value-based leadership & Project GLOBE & 56 \\
\hline & $\mathrm{H} 7 \mathrm{j}$ & Tearn-oriented leadership & Project GLOBE & 56 \\
\hline & $\mathrm{H} 7 \mathrm{k}$ & Participative leadership & Project GLOBE & 56 \\
\hline & $\mathrm{H} 7 \mathrm{l}$ & Humane-oriented leadership & Project GLOBE & 56 \\
\hline & $\mathrm{H} 7 \mathrm{~m}$ & Autonomous leadership & Project GLOBE & 56 \\
\hline & $\mathrm{H} 7 \mathrm{n}$ & Self-protective leadership & Project GLOBE & 56 \\
\hline & $\mathrm{H} 70$ & Social Cynism 2004 & Leunge \& Associates & 39 \\
\hline & $\mathrm{H} 7 \mathrm{p}$ & Social Complexity 2004 & Leunge \& Associates & 39 \\
\hline & $\mathrm{H} 7 \mathrm{q}$ & Reward for Application 2004 & Leunge \& Associates & 39 \\
\hline & $\mathrm{H} 7 \mathrm{r}$ & Religiosity 2004 & Leunge \& Associates & 39 \\
\hline & $\mathrm{H} 7 \mathrm{~s}$ & Fate Control 2004 & Leunge \& Associates & 39 \\
\hline
\end{tabular}




\begin{tabular}{|c|c|c|c|c|c|c|c|c|c|c|c|c|c|}
\hline \multicolumn{14}{|c|}{ Appendix 2 - Final Cluster Analysis for Women in Leadership Dependent Variables } \\
\hline \multirow[b]{2}{*}{ Country } & \multicolumn{8}{|c|}{\begin{tabular}{|c|} 
Women in Business Leadership \\
\end{tabular}} & \multicolumn{3}{|c|}{ Women in Political Leadership } & \multirow[b]{2}{*}{$\begin{array}{c}\text { GDP per } \\
\text { capita (PPP } \\
\text { US\$) 2004* }\end{array}$} & \multirow[b]{2}{*}{$\begin{array}{c}\text { Global } \\
\text { Gender } \\
\text { Gap } \\
\text { Index } \\
2007\end{array}$} \\
\hline & $\begin{array}{c}\text { Firms with } \\
\text { Female } \\
\text { Employers \& } \\
\text { Own Account } \\
\text { Workers } \\
\text { Developed N } \\
=29\end{array}$ & \begin{tabular}{|c|} 
Firms With \\
Females in \\
Ownership \\
Developing N \\
$=76$
\end{tabular} & $\begin{array}{c}\text { Women in } \\
\text { Senior } \\
\text { Positions } \\
\text { Developing } \\
\mathrm{N}=66\end{array}$ & \begin{tabular}{|c|} 
K-Mean \\
Cluster \\
Firms With \\
Women \\
Owners \\
Developed \& \\
Developing \\
$\mathrm{N}=95$
\end{tabular} & \begin{tabular}{|c|} 
Distance of \\
Country from \\
Cluster Center \\
K-Mean Cluster \\
Firms With \\
Women \\
Owners \\
Developed \& \\
Developing
\end{tabular} & \begin{tabular}{|c|} 
\\
K-Means \\
Firms with \\
Women \\
Owners and \\
Senior \\
Positions \\
$\mathrm{N}=97$ \\
\end{tabular} & \begin{tabular}{|c|} 
Distance of \\
Country from \\
Cluster Center \\
K-Means \\
Firms with \\
Women \\
Owners and \\
Senior \\
Positions \\
\end{tabular} & \begin{tabular}{|c|} 
\\
Women in \\
Business \\
Leadership 4- \\
cluster \\
variable \\
$\mathrm{N}=115$
\end{tabular} & $\begin{array}{c}\text { Proportion of } \\
\text { seats held by } \\
\text { women in } \\
\text { national } \\
\text { parliament } \\
\text { WDI }\end{array}$ & $\begin{array}{c}\text { Proportion of } \\
\text { seats in } \\
\text { parliament } \\
\text { held by } \\
\text { women } \\
\text { UNDP }\end{array}$ & $\begin{array}{c}\text { K-Means } \\
\text { Cluster } \\
\text { Political } \\
\text { Leadership N } \\
=181\end{array}$ & & \\
\hline Afghanistan & & \begin{tabular}{|l|l|l}
0.141 &
\end{tabular} & 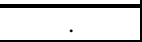 & \begin{tabular}{l|l|l}
1 &
\end{tabular} & \begin{tabular}{|l|l|l}
0.004 & \\
\end{tabular} & 1 & 0.018 & 1 & 0.06 & \begin{tabular}{l|l}
0.071 & \\
\end{tabular} & \begin{tabular}{|l|l|}
1 &
\end{tabular} & & \\
\hline Albania & . &. &. & . &. & . & . & . & 0.06 & 0.053 & 1 & 4,978 & 0.67 \\
\hline Algeria & . & . & 0.036 & . & . & 1 & 0.009 & 1 & 0.14 & . & 2 & 6,603 & 0.61 \\
\hline Andorra & . & . & . & . & . & . & . & . & 0.16 & 0.15 & 2 & . & . \\
\hline Angola & & 0.234 & 0.084 & 2 & 0.011 & 2 & 0.025 & 2 & 0.05 & 0.139 & 1 & 2,180 & 0.60 \\
\hline Antigua and Barbuda & & & . & . & . & . & & . & 0.31 & 0.365 & 4 & 12,586 & \\
\hline Argentina & & 0.303 & 0.114 & 3 & 0.042 & 3 & 0.041 & 3 & 0.05 & 0.053 & 1 & 13,298 & 0.70 \\
\hline Armenia & & 0.125 &. & 1 & 0.020 & 1 & 0.034 & 1 & 0.25 & 0.283 & 3 & 4,101 & 0.67 \\
\hline Australia & 0.325 & 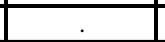 & . & 4 & 0.028 & . &. & 4 & 0.34 & 0.322 & 4 & 30,331 & 0.72 \\
\hline Austria & 0.335 & & . & 4 & 0.018 & . & & 4 & 0.11 & 0.123 & 2 & 32,276 & 0.71 \\
\hline Azerbaijan & & 0.144 & . & 1 & 0.001 & 1 & 0.015 & 1 & 0.2 & 0.268 & 3 & 4,153 & 0.68 \\
\hline Bahamas, The & . &. & . & . & . & . & . & . & 0 & 0.075 & 1 & 17,843 & \\
\hline Bahrain & . & . &. & . & . & . & . & . & 0.02 & 0.148 & 1 & 20,758 & 0.59 \\
\hline Bangladesh & . & 0.161 & 0.01 & 1 & 0.016 & 1 & 0.035 & 1 & 0.13 & 0.176 & 2 & 1,870 & 0.63 \\
\hline Barbados & & & . & . & & . & & & 0.1 & 0.298 & 3 & 15,720 & \\
\hline $\begin{array}{l}\text { Belarus } \\
\end{array}$ & & 0.238 & . & 2 & 0.007 & 2 & 0.022 & 2 & 0.35 & 0.357 & 4 & 6,970 & 0.71 \\
\hline Belgium & 0.281 & . & . & 2 & 0.003 & . & . & 2 & 0.03 & 0.119 & 1 & 31,096 & 0.72 \\
\hline Belize & . & . & . & . & . & . & . & . & 0.07 & 0.072 & 1 & 6,747 & 0.64 \\
\hline Benin & - & . & 0.042 & . & . & 1 & 0.003 & 1 & 0.09 & 0.093 & 1 & 1,091 & 0.57 \\
\hline Bhutan & & & & . & & . & & & 0.19 & 0.146 & 2 & 1,969 & \\
\hline Bolivia & & 0.411 & 0.146 & 4 & 0.007 & 4 & 0.030 & 4 & 0.17 & 0.123 & 2 & 2,720 & 0.66 \\
\hline Bosnia/Herzegovina & . & 0.252 & . & 2 & 0.007 & 2 & 0.007 & 2 & 0.17 & 0.111 & 2 & 7,032 & . \\
\hline Botswana & . & 0.409 & 0.112 & 4 & 0.009 & 4 & 0.016 & 4 & 0.09 & 0.091 & 1 & 9,945 & 0.68 \\
\hline Brazil & & & 0.032 & . & 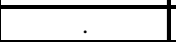 & 1 & 0.014 & 1 & 0.26 & 0.221 & 3 & 8,195 & 0.66 \\
\hline Bulgaria & & 0.365 & . & 3 & 0.021 & 3 & 0.021 & 3 & 0.12 & 0.117 & 2 & 8,078 & 0.71 \\
\hline Burkina Faso & & 0.233 & 0.103 & 2 & 0.011 & 2 & 0.034 & 2 & 0.18 & 0.317 & 3 & 1,169 & 0.59 \\
\hline Burundi & . & 0.348 & 0.166 & 3 & 0.004 & 3 & 0.054 & 3 & 0.1 & 0.114 & 2 & 677 &. \\
\hline Cambodia & . &. & 0.14 & . & . & 4 & 0.021 & 1 & 0.09 & 0.089 & 1 & 2,423 & 0.64 \\
\hline Cameroon & . & 0.353 & 0.079 & 3 & 0.009 & 3 & 0.035 & 3 & 0.21 & 0.243 & 3 & 2,174 & 0.59 \\
\hline
\end{tabular}




\begin{tabular}{|c|c|c|c|c|c|c|c|c|c|c|c|c|c|}
\hline \multicolumn{14}{|c|}{ Appendix 2 Cont'd - Final Cluster Analysis for Women in Leadership Dependent Variables } \\
\hline \multirow[b]{2}{*}{ Country } & \multicolumn{8}{|c|}{\begin{tabular}{|c|} 
Women in Business Leadership \\
\end{tabular}} & \multicolumn{3}{|c|}{ Women in Political Leadership } & \multirow[b]{2}{*}{\begin{tabular}{|c} 
GDP per \\
capita (PPP \\
US\$) 2004*
\end{tabular}} & \multirow[b]{2}{*}{$\begin{array}{c}\text { Global } \\
\text { Gender } \\
\text { Gap } \\
\text { Index } \\
2007 \\
\end{array}$} \\
\hline & $\begin{array}{c}\text { Firms with } \\
\text { Female } \\
\text { Employers \& } \\
\text { Own Account } \\
\text { Workers } \\
\text { Developed N } \\
=29\end{array}$ & $\begin{array}{c}\text { Firms With } \\
\text { Females in } \\
\text { Ownership } \\
\text { Developing N } \\
=76\end{array}$ & $\begin{array}{l}\text { Women in } \\
\text { Senior } \\
\text { Positions } \\
\text { Developing } \\
\mathrm{N}=66\end{array}$ & \begin{tabular}{|c|} 
K-Mean \\
Cluster \\
Firms With \\
Women \\
Owners \\
Developed \& \\
Developing \\
$\mathrm{N}=95$
\end{tabular} & \begin{tabular}{|c|} 
Distance of \\
Country from \\
Cluster Center \\
K-Mean Cluster \\
Firms With \\
Women \\
Owners \\
Developed \& \\
Developing
\end{tabular} & \begin{tabular}{|c|} 
\\
K-Means \\
Firms with \\
Women \\
Owners and \\
Senior \\
Positions \\
$\mathrm{N}=97$ \\
\end{tabular} & \begin{tabular}{|c|} 
Distance of \\
Country from \\
Cluster Center \\
K-Means \\
Firms with \\
Women \\
Owners and \\
Senior \\
Positions \\
\end{tabular} & \begin{tabular}{|} 
Women in \\
Business \\
Leadership 4- \\
cluster \\
variable \\
$\mathrm{N}=115$
\end{tabular} & $\begin{array}{c}\text { Proportion of } \\
\text { seats held by } \\
\text { women in } \\
\text { national } \\
\text { parliament } \\
\text { WDI }\end{array}$ & $\begin{array}{c}\text { Proportion of } \\
\text { seats in } \\
\text { parliament } \\
\text { held by } \\
\text { women } \\
\text { UNDP } \\
\end{array}$ & $\begin{array}{c}\text { K-Means } \\
\text { Cluster } \\
\text { Political } \\
\text { Leadership N } \\
=181\end{array}$ & & \\
\hline Canada & 0.388 &. & . & \begin{tabular}{|l|l|l}
4 &
\end{tabular} & 0.035 & . &. & 4 & 0.11 & 0.153 & 2 & 31,263 & 0.72 \\
\hline Cape Verde & . & 0.427 & 0.117 & 4 & 0.009 & 4 & 0.004 & 4 & . & 0.105 & 1 & 5,727 & . \\
\hline Cayman Islands & . & & & . & . & . & . & . & 0.06 & 0.065 & 1 & 1,094 & . \\
\hline Chad & . & & & . & & & . & . & 0.13 & 0.127 & 2 & 2,090 & 0.54 \\
\hline Chile & . & 0.278 & 0.098 & 2 & 0.034 & 2 & 0.025 & 2 & 0.2 & 0.203 & 3 & 10,874 & 0.65 \\
\hline \begin{tabular}{|l|} 
China \\
\end{tabular} &. &. & . &. & . & . &. & . & 0.12 & 0.108 & 2 & 5,896 & 0.66 \\
\hline Colombia & . & 0.43 & 0.189 & 4 & 0.013 & 4 & 0.071 & 4 &. & 0.03 & 1 & 7,256 & 0.71 \\
\hline Comoros & . & & & . & . & & . & . & 0.08 & 0.101 & 1 & 1,943 &. \\
\hline Congo, Dem. Rep. & . & 0.212 & 0.063 & 2 & 0.032 & 2 & 0.051 & 2 & 0.09 & 0.102 & 1 & 978 & . \\
\hline Congo, Rep. & . &. &. & . &. & . &. & . & 0.35 & 0.386 & 4 & 705 & . \\
\hline Costa Rica & . & 0.347 & 0.064 & 3 & 0.003 & 3 & 0.049 & 3 & 0.09 & 0.085 & 1 & 9,481 & 0.70 \\
\hline Cote d'Ivoire & . & & & . & & &. & . & 0.18 & 0.217 & 3 & 1,551 &. \\
\hline Croatia & . & 0.2 & & 2 & 0.044 & 1 & 0.041 & 1 & 0.36 & 0.36 & 4 & 12,191 & 0.72 \\
\hline Cuba &. &. &. &. &. & . &. & . & 0.11 & 0.143 & 2 & 5,700 & 0.72 \\
\hline Cyprus &. & &. & . &. &. &. &. & 0.17 & 0.157 & 2 & 22,805 & 0.65 \\
\hline Czech Republic & 0.263 & 0.218 & & 2 & 0.031 & 2 & 0.041 & 2 & 0.38 & 0.369 & 4 & 19,408 & 0.67 \\
\hline Denmark & 0.221 & & & 3 & 0.008 & &. & 3 & 0.11 & 0.108 & 2 & 31,914 & 0.75 \\
\hline Djibouti & . &. &. & . &. & . & . & . & 0.19 & 0.129 & 2 & 1,993 &. \\
\hline Dominica & . & . & . & . & . & . & . & . & 0.17 & 0.154 & 2 & 5,643 & . \\
\hline Dominican Republic & . & . & . & . & . & . & . & . & 0.16 & 0.16 & 2 & 7,449 & 0.67 \\
\hline Ecuador & . & 0.327 & 0.134 & 3 & 0.017 & 3 & 0.027 & 3 & 0.02 & 0.038 & 1 & 3,963 & 0.69 \\
\hline Egypt, Arab Rep. & . & & 0.019 & . & . & 1 & 0.027 & 1 & 0.11 & 0.167 & 2 & 4,211 & 0.58 \\
\hline El Salvador &. & 0.396 & 0.112 & 4 & 0.022 & 4 & 0.028 & 4 & 0.05 & 0.18 & 2 & 5,041 & 0.69 \\
\hline Equatorial Guinea &. &. &. & . &. & . &. & . & 0.22 & 0.22 & 3 & 20,510 &. \\
\hline Eritrea & . & & & . &. & &. & . & 0.19 & 0.188 & 3 & 977 &. \\
\hline Estonia & . & 0.341 & & 3 & 0.004 & 3 & 0.003 & 3 & 0.08 & 0.214 & 2 & 14,555 & 0.70 \\
\hline Ethiopia &. & 0.309 & 0.031 & 3 & 0.035 & 2 & 0.071 & 3 & 0.06 & 0.117 & 1 & 756 & 0.60 \\
\hline Fiji &. &. & . & . & . & . &. & . & 0.38 & 0.375 & 4 & 6,066 &. \\
\hline Finland & 0.32 & & & 4 & 0.033 & . & . & 4 & 0.12 & 0.139 & 2 & 29,951 & 0.80 \\
\hline
\end{tabular}




\begin{tabular}{|c|c|c|c|c|c|c|c|c|c|c|c|c|c|}
\hline \multicolumn{14}{|c|}{ Appendix 2 Cont'd - Final Cluster Analysis for Women in Leadership Dependent Variables } \\
\hline \multirow[t]{2}{*}{ 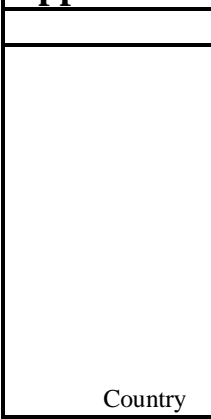 } & \multicolumn{8}{|c|}{ Women in Business Leadership } & \multicolumn{3}{|c|}{ Women in Political Leadership } & \multirow[b]{2}{*}{\begin{tabular}{|c} 
GDP per \\
capita (PPP \\
US\$) 2004*
\end{tabular}} & \multirow[b]{2}{*}{$\begin{array}{c}\text { Global } \\
\text { Gender } \\
\text { Gap } \\
\text { Index } \\
2007\end{array}$} \\
\hline & $\begin{array}{c}\text { Firms with } \\
\text { Female } \\
\text { Employers \& } \\
\text { Own Account } \\
\text { Workers } \\
\text { Developed N } \\
=29\end{array}$ & \begin{tabular}{|c|} 
Firms With \\
Females in \\
Ownership \\
Developing N \\
$=76$
\end{tabular} & $\begin{array}{c}\text { Women in } \\
\text { Senior } \\
\text { Positions } \\
\text { Developing } \\
\mathrm{N}=66\end{array}$ & \begin{tabular}{|c|} 
K-Mean \\
Cluster \\
Firms With \\
Women \\
Owners \\
Developed \& \\
Developing \\
$\mathrm{N}=95$
\end{tabular} & \begin{tabular}{|c|} 
Distance of \\
Country from \\
Cluster Center \\
K-Mean Cluster \\
Firms With \\
Women \\
Owners \\
Developed \& \\
Developing
\end{tabular} & \begin{tabular}{|c|} 
\\
K-Means \\
Firms with \\
Women \\
Owners and \\
Senior \\
Positions \\
$\mathrm{N}=97$
\end{tabular} & \begin{tabular}{|c|} 
Distance of \\
Country from \\
Cluster Center \\
K-Means \\
Firms with \\
Women \\
Owners and \\
Senior \\
Positions
\end{tabular} & \begin{tabular}{|c|} 
\\
Women in \\
Business \\
Leadership 4- \\
cluster \\
variable \\
$\mathrm{N}=115$
\end{tabular} & $\begin{array}{c}\text { Proportion of } \\
\text { seats held by } \\
\text { women in } \\
\text { national } \\
\text { parliament } \\
\text { WDI }\end{array}$ & $\begin{array}{c}\text { Proportion of } \\
\text { seats in } \\
\text { parliament } \\
\text { held by } \\
\text { women } \\
\text { UNDP }\end{array}$ & $\begin{array}{c}\text { K-Means } \\
\text { Cluster } \\
\text { Political } \\
\text { Leadership N } \\
=181\end{array}$ & & \\
\hline France & 0.356 & \begin{tabular}{|l|l|l}
. &
\end{tabular} & . & \begin{tabular}{|l|l|}
4 &
\end{tabular} & \begin{tabular}{|l|l|}
0.004 & \\
\end{tabular} & . & & 4 & \begin{tabular}{l|l|l}
0.09 & \\
\end{tabular} & \begin{tabular}{|l|l|}
0.119 &
\end{tabular} & \begin{tabular}{|l|l|}
2 &
\end{tabular} & 29,300 & 0.68 \\
\hline Gabon & . &. & . & . & . & . & . & & 0.13 & 0.132 & 2 & 6,623 & \\
\hline Gambia, The & . & 0.213 & 0.051 & 2 & 0.031 & 1 & 0.054 & 2 & 0.07 & 0.094 & 1 & 1,991 & 0.64 \\
\hline Georgia &. & 0.369 & . & 3 & 0.025 & 3 & 0.025 & 3 & 0.32 & 0.305 & 4 & 2,844 & 0.67 \\
\hline Germany & 0.284 & 0.203 &. & 2 & 0.042 & 1 & 0.044 & 2 & 0.09 & 0.109 & 1 & 28,303 & 0.76 \\
\hline Ghana & & 0.44 & 0.048 & 4 & 0.022 & 4 & 0.072 & 4 & 0.09 & 0.13 & 2 & 2,240 & 0.67 \\
\hline Greece & 0.26 & 0.244 & . & 2 & 0.018 & 2 & 0.015 & 2 & 0.27 & 0.286 & 3 & 22,205 & 0.67 \\
\hline Grenada & . & . & . & . & . & . & . & . & 0.08 & 0.082 & 1 & 8,021 &. \\
\hline Guatemala & & 0.284 & 0.104 & 2 & 0.040 & 2 & 0.034 & 2 & & 0.14 & 2 & 4,313 & 0.61 \\
\hline Guinea-Bissau & & 0.199 & 0.064 & 2 & 0.045 & 1 & 0.044 & 1 & 0.19 & 0.193 & 3 & 722 &. \\
\hline Guinea & & 0.254 & 0.029 & 2 & 0.010 & 2 & 0.053 & 2 & 0.2 & 0.308 & 3 & 2,180 & . \\
\hline Guyana & . &. & 0.05 & . & . & 1 & 0.004 & 1 & 0.04 & 0.062 & 1 & 4,439 & . \\
\hline Haiti & . & . & . & . & & . & & . & 0.06 & 0.234 & 2 & 1,892 &. \\
\hline Honduras & . & 0.399 & 0.081 & 4 & 0.019 & 4 & 0.044 & 4 &. & & . & 2,876 & 0.67 \\
\hline Hong Kong, China & & & . & & & . & & & 0.1 & 0.104 & 1 & 30,822 & \\
\hline Hungary & 0.314 & 0.401 & . & 4 & 0.042 & 4 & 0.022 & 4 & 0.3 & 0.333 & 4 & 16,814 & 0.67 \\
\hline Iceland & 0.279 & . & . & 2 & 0.001 & . & & 2 & 0.09 & 0.092 & 1 & 33,051 & 0.78 \\
\hline India & . & 0.091 & 0.088 & 1 & 0.054 & 1 & 0.081 & 1 & 0.08 & 0.113 & 1 & 3,139 & 0.59 \\
\hline Indonesia & & . & 0.016 & . & & 1 & 0.029 & 1 & 0.04 & 0.041 & 1 & 3,609 & 0.66 \\
\hline Iran, Islamic Rep. & & & . & - & & . & & & 0.13 & 0.142 & 2 & 7,525 & 0.59 \\
\hline Ireland & 0.168 & 0.416 & . & 3 & 0.094 & 4 & 0.007 & 4 & & & & 38,827 & 0.75 \\
\hline Isle of Man & 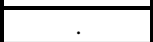 & . & . & . & . & . & . & . & 0.15 & 0.142 & 2 & . & . \\
\hline Israel & &. & . &. & . & . & $i^{2}$ & . & 0.12 & 0.161 & 2 & 24,382 & 0.70 \\
\hline Italy & 0.284 & . & . & 2 & 0.006 & . & & 2 & 0.12 & 0.136 & 2 & 28,180 & 0.65 \\
\hline Jamaica & & 0.322 & . & 3 & 0.022 & 3 & 0.022 & 3 & 0.07 & 0.107 & 1 & 4,163 & 0.69 \\
\hline Japan & 0.258 & 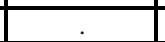 & . & 2 & 0.020 & . & & 2 & 0.06 & 0.079 & 1 & 29,251 & 0.65 \\
\hline Jordan & & 0.131 & 0.049 & 1 & 0.014 & 1 & 0.028 & 1 & 0.1 & 0.086 & 1 & 4,688 & 0.62 \\
\hline Kazakhstan & . & 0.361 & . & 3 & 0.017 & 3 & 0.017 & 3 & 0.07 & 0.073 & 1 & 7,440 & 0.70 \\
\hline Kenya & . &. & 0.031 & . & . & 1 & 0.014 & 1 & 0.05 &. & 1 & 1140 & 0.65 \\
\hline
\end{tabular}




\begin{tabular}{|c|c|c|c|c|c|c|c|c|c|c|c|c|c|}
\hline \multicolumn{14}{|c|}{ Appendix 2 Cont'd - Final Cluster Analysis for Women in Leadership Dependent Variables } \\
\hline \multirow[b]{2}{*}{ Country } & \multicolumn{8}{|c|}{ Women in Business Leadership } & \multicolumn{3}{|c|}{ Women in Political Leadership } & \multirow[b]{2}{*}{$\begin{array}{c}\text { GDP per } \\
\text { capita (PPP } \\
\text { US\$) 2004* }\end{array}$} & \multirow[b]{2}{*}{$\begin{array}{c}\text { Global } \\
\text { Gender } \\
\text { Gap } \\
\text { Index } \\
2007\end{array}$} \\
\hline & $\begin{array}{c}\text { Firms with } \\
\text { Female } \\
\text { Employers \& } \\
\text { Own Account } \\
\text { Workers } \\
\text { Developed N } \\
=29\end{array}$ & $\begin{array}{c}\text { Firms With } \\
\text { Females in } \\
\text { Ownership } \\
\text { Developing N } \\
=76\end{array}$ & $\begin{array}{l}\text { Women in } \\
\text { Senior } \\
\text { Positions } \\
\text { Developing } \\
\mathrm{N}=66\end{array}$ & \begin{tabular}{|c} 
K-Mean \\
Cluster \\
Firms With \\
Women \\
Owners \\
Developed \& \\
Developing \\
$\mathrm{N}=95$
\end{tabular} & \begin{tabular}{|c|} 
Distance of \\
Country from \\
Cluster Center \\
K-Mean Cluster \\
Firms With \\
Women \\
Owners \\
Developed \& \\
Developing
\end{tabular} & $\begin{array}{l} \\
\text { K-Means } \\
\text { Firms with } \\
\text { Women } \\
\text { Owners and } \\
\text { Senior } \\
\text { Positions } \\
\mathrm{N}=97\end{array}$ & \begin{tabular}{|c|} 
Distance of \\
Country from \\
Cluster Center \\
K-Means \\
Firms with \\
Women \\
Owners and \\
Senior \\
Positions \\
\end{tabular} & \begin{tabular}{|} 
Women in \\
Business \\
Leadership 4- \\
cluster \\
variable \\
$\mathrm{N}=115$
\end{tabular} & $\begin{array}{c}\text { Proportion of } \\
\text { seats held by } \\
\text { women in } \\
\text { national } \\
\text { parliament } \\
\text { WDI }\end{array}$ & $\begin{array}{c}\text { Proportion of } \\
\text { seats in } \\
\text { parliament } \\
\text { held by } \\
\text { women } \\
\text { UNDP }\end{array}$ & \begin{tabular}{|c|} 
K-Means \\
Cluster \\
Political \\
Leadership N \\
$=181$
\end{tabular} & & \\
\hline Kiribati & . &. & . &. & . & . &. &. & 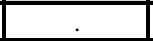 & . & \begin{tabular}{|l|l|}
. &
\end{tabular} &. & . \\
\hline Korea, Dem. Rep. &. & 0.191 & . & 1 & 0.046 & 1 & 0.032 & 1 & 0.06 & 0.134 & 1 &. & . \\
\hline Korea, Rep. & 0.285 & . & . & 2 & 0.007 & . & . & 2 & 0 & 0.015 & 1 & 20,499 & 0.64 \\
\hline Kuwait & . & & & . & . & . & . & . & 0.1 & 0 & 1 & 19,384 & 0.64 \\
\hline Kyrgyz Republic & . & 0.273 & 0.099 & 2 & 0.028 & 2 & 0.022 & 2 & 0.23 & 0.229 & 3 & 1,935 & 0.67 \\
\hline Lao PDR & . & & . & . & . & . & . & . & 0.21 & 0.21 & 3 & 1,954 & . \\
\hline Latvia & . & 0.423 & . & 4 & 0.005 & 4 & 0.000 & 4 & 0.02 & 0.047 & 1 & 11,653 & 0.73 \\
\hline Lebanon & . & 0.279 &. & 2 & 0.034 & 2 & 0.020 & 2 & 0.12 & 0.17 & 2 & 5,837 &. \\
\hline Lesotho & . & & . & . & . & . & . & . & 0.08 &. & 1 & 2,619 & 0.71 \\
\hline Liberia & . &. &. &. &. & . & . &. & . & 0.047 & 1 & . & . \\
\hline Libya & . & . & . & . & . & . & . & . & 0.12 & . & 2 & 7,570 & . \\
\hline Liechtenstein & . & . & . & . & . & . & . & . & 0.11 & 0.22 & 2 &. & . \\
\hline Lithuania & . & 0.255 & 0.08 & 2 & 0.011 & 2 & 0.004 & 2 & 0.17 & 0.233 & 3 & 13,107 & 0.72 \\
\hline Luxembourg & . & & & . & . & . & . & . &. & . & . & 69,961 & 0.68 \\
\hline Macao, China & . & & & . & . & . & . & . & 0.18 & 0.192 & 2 &. & 0.70 \\
\hline Macedonia, FYR & . & 0.175 & & 1 & 0.030 & 1 & 0.016 & 1 & 0.04 & 0.084 & 1 & 6,610 & . \\
\hline Madagascar & . & & 0.042 & . & . & 1 & 0.004 & 1 & 0.09 & 0.136 & 2 & 857 & 0.65 \\
\hline Malawi & . & 0.158 & 0.159 & 1 & 0.013 & 1 & 0.114 & 1 & 0.11 & 0.131 & 2 & 646 & 0.65 \\
\hline Malaysia & . & 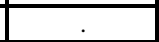 & 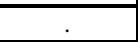 & . & . & . & . & . & 0.06 & 0.12 & 1 & 10,276 & 0.64 \\
\hline Maldives & . & & & . & . & . & . & . & 0.1 & 0.102 & 1 & 4,798 & 0.64 \\
\hline Mali & . & & 0.061 & . & . & 1 & 0.016 & 1 & 0.09 & 0.092 & 1 & 998 & 0.60 \\
\hline Malta & . & . &. & . & . & . &. & . & 0.03 & . & 1 & 18,879 & 0.66 \\
\hline Marshall Islands & . & . &. & . & . & . & . & . & 0.04 & . & 1 &. &. \\
\hline Mauritania & . & 0.173 & 0.14 & 1 & 0.028 & 1 & 0.096 & 1 & 0.06 & 0.171 & 2 & 1,940 & 0.60 \\
\hline Mauritius & . & & 0.033 & . & . & 1 & 0.012 & 1 & 0.23 & 0.25 & 3 & 12,027 & 0.65 \\
\hline Mexico & 0.316 & 0.248 & 0.124 & 2 & 0.038 & 2 & 0.044 & 2 & 0 & . & 1 & 9,803 & 0.64 \\
\hline Micronesia, Fed. Sts. & . & & & . & . & . & . & . & 0.13 & 0.218 & 2 & . & . \\
\hline Moldova & . & 0.275 & 0.107 & 2 & 0.031 & 2 & 0.031 & 2 & 0.21 & . & 3 & 1,729 & 0.72 \\
\hline Monaco & . & & & . & . & & . & . & 0.11 & 0.066 & 1 &. & . \\
\hline
\end{tabular}




\begin{tabular}{|c|c|c|c|c|c|c|c|c|c|c|c|c|c|}
\hline Appendix 2 & t'd - Final & l Cluster $A$ & Analysis & for Wom & en in Lead & lership D & Dependent & Variable & & & & & \\
\hline & & & & Women in Bus & siness Leadership & & & & Women & n in Political Lea & eadership & & \\
\hline Country & $\begin{array}{c}\text { Firms with } \\
\text { Female } \\
\text { Employers \& } \\
\text { Own Account } \\
\text { Workers } \\
\text { Developed N } \\
=29\end{array}$ & \begin{tabular}{|c|} 
Firms With \\
Females in \\
Ownership \\
Developing N \\
$=76$
\end{tabular} & $\begin{array}{c}\text { Women in } \\
\text { Senior } \\
\text { Positions } \\
\text { Developing } \\
\mathrm{N}=66\end{array}$ & \begin{tabular}{|c|} 
K-Mean \\
Cluster \\
Firms With \\
Women \\
Owners \\
Developed \& \\
Developing \\
$\mathrm{N}=95$ \\
\end{tabular} & \begin{tabular}{|c|} 
Distance of \\
Country from \\
Cluster Center \\
K-Mean Cluster \\
Firms With \\
Women \\
Owners \\
Developed \& \\
Developing \\
\end{tabular} & \begin{tabular}{|c|} 
\\
K-Means \\
Firms with \\
Women \\
Owners and \\
Senior \\
Positions \\
$\mathrm{N}=97$ \\
\end{tabular} & \begin{tabular}{|c|} 
Distance of \\
Country from \\
Cluster Center \\
K-Means \\
Firms with \\
Women \\
Owners and \\
Senior \\
Positions \\
\end{tabular} & \begin{tabular}{|c|} 
\\
Women in \\
Business \\
Leadership 4- \\
cluster \\
variable \\
$\mathrm{N}=115$ \\
\end{tabular} & $\begin{array}{c}\text { Proportion of } \\
\text { seats held by } \\
\text { women in } \\
\text { national } \\
\text { parliament } \\
\text { WDI }\end{array}$ & $\begin{array}{c}\text { Proportion of } \\
\text { seats in } \\
\text { parliament } \\
\text { held by } \\
\text { women } \\
\text { UNDP }\end{array}$ & $\begin{array}{c}\text { K-Means } \\
\text { Cluster } \\
\text { Political } \\
\text { Leadership N } \\
=181\end{array}$ & \begin{tabular}{|c|} 
\\
GDP per \\
capita (PPP \\
US\$) 2004*
\end{tabular} & $\begin{array}{c}\text { Global } \\
\text { Gender } \\
\text { Gap } \\
\text { Index } \\
2007\end{array}$ \\
\hline Mongolia & & \begin{tabular}{|c|}
. \\
\end{tabular} & . & . & & . & & & $\begin{array}{ll} \\
\end{array}$ & & & \begin{tabular}{|l|}
2,056 \\
\end{tabular} & 0.67 \\
\hline Montenegro & . & 0.232 & 0.083 & 2 & 0.012 & 2 & 0.027 & 2 & 0.11 & 0.064 & 1 &. &. \\
\hline Morocco & . &. & 0.019 & . &. & 1 & 0.026 & 1 & 0.3 & 0.348 & 4 & 4,309 & 0.57 \\
\hline Mozambique & . &. &. & . &. & . & . & . & 0.26 & 0.269 & 3 & 1,237 & 0.69 \\
\hline Namibia & . & 0.334 & 0.127 & 3 & 0.010 & 3 & 0.017 & 3 & 0.06 & 0.067 & 1 & 7,418 & 0.70 \\
\hline Nepal & & . & . & & & . & & & 0.37 & 0.342 & 4 & 1,490 & 0.56 \\
\hline Netherlands & 0.334 & . & . & 4 & 0.019 & . & & 4 & 0.28 & 0.322 & 4 & 31,789 & 0.74 \\
\hline New Zealand & 0.312 & & - & 2 & 0.034 & . & & 2 & 0.21 & 0.207 & 3 & 23,413 & 0.77 \\
\hline Nicaragua & & 0.414 & 0.083 & 4 & 0.004 & 4 & 0.036 & 4 & 0.01 & 0.124 & 1 & 3,634 & 0.65 \\
\hline Niger & . & 0.1 & 0.031 & 1 & 0.045 & 1 & 0.061 & 1 & 0.07 & 0.058 & 1 & 779 & \\
\hline Nigeria & & . & . & . & & . & & & 0.36 & 0.379 & 4 & 1,154 & 0.61 \\
\hline Norway & 0.267 & . & . & 2 & 0.011 & . & & 2 &. & 0.078 & 1 & 38,454 & 0.81 \\
\hline Oman & & . & 0.068 & & & 2 & 0.013 & 1 & 0.22 & 0.204 & 3 & 15,259 & 0.59 \\
\hline Pakistan & & & 0.012 & & & 1 & 0.033 & 1 & 0.1 & 0.167 & 2 & 2,225 & 0.55 \\
\hline Panama & & 0.371 & 0.165 & 3 & 0.027 & 3 & 0.059 & 3 & 0.01 & 0.009 & 1 & 7,278 & 0.70 \\
\hline Papua New Guinea & . & . & . & . & . & . & . & . & 0.1 & 0.096 & 1 & 2,543 & . \\
\hline Paraguay & . & 0.448 & 0.142 & 4 & 0.030 & 4 & 0.034 & 4 & 0.18 & 0.29 & 3 & 4,813 & 0.67 \\
\hline Peru & & 0.328 & 0.125 & 3 & 0.016 & 3 & 0.020 & 3 & 0.18 & 0.158 & 2 & 5,678 & 0.66 \\
\hline Philippines & & & 0.082 & . & & 2 & 0.000 & 1 & 0.2 & 0.191 & 3 & 4,614 & 0.76 \\
\hline Poland & 0.357 & 0.336 & 0.088 & 4 & 0.082 & 3 & 0.025 & 3 & 0.19 & 0.213 & 3 & 12,974 & 0.68 \\
\hline Portugal & 0.404 & 0.508 & . & 4 & 0.103 & 4 & 0.085 & 4 & 0.11 & 0.107 & 2 & 19,629 & 0.70 \\
\hline Romania & . & 0.277 & . & 2 & 0.032 & 2 & 0.018 & 2 & 0.1 & 0.08 & 1 & 8,480 & 0.69 \\
\hline Russian Federation & . & 0.286 & . & 2 & 0.041 & 2 & 0.027 & 2 & 0.49 & 0.453 & 4 & 9,902 & 0.69 \\
\hline Rwanda & & 0.41 & 0.104 & 4 & 0.008 & 4 & 0.019 & 4 & 0.06 & 0.041 & 1 & 1,263 &. \\
\hline Samoa & & . & . & . & . & . & . & & 0.17 & & 2 & 5,613 & \\
\hline San Marino & & . & . & & & . & & & 0.09 & 0.073 & 1 & & \\
\hline Sao Tome/Principe & & . & . & . & 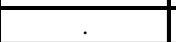 & . & & & 0 & 0 & 1 & 1,231 & \\
\hline Saudi Arabia & & . & . & . & . & . & & & 0.19 & 0.192 & 3 & 13,825 & 0.57 \\
\hline Senegal & & . & 0.048 & . & . & 1 & 0.002 & 1 & . & & 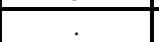 & 1,713 & \\
\hline
\end{tabular}




\begin{tabular}{|c|c|c|c|c|c|c|c|c|c|c|c|c|c|}
\hline \multicolumn{14}{|c|}{ Appendix 2 Cont'd - Final Cluster Analysis for Women in Leadership Dependent Variables } \\
\hline \multirow[t]{2}{*}{ 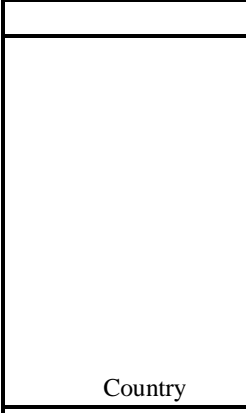 } & \multicolumn{8}{|c|}{ Women in Business Leadership } & \multicolumn{3}{|c|}{ Women in Political Leadership } & \multirow[b]{2}{*}{\begin{tabular}{|} 
GDP per \\
capita (PPP \\
US\$) 2004*
\end{tabular}} & \multirow[b]{2}{*}{$\begin{array}{c}\text { Global } \\
\text { Gender } \\
\text { Gap } \\
\text { Index } \\
2007\end{array}$} \\
\hline & $\begin{array}{c}\text { Firms with } \\
\text { Female } \\
\text { Employers \& } \\
\text { Own Account } \\
\text { Workers } \\
\text { Developed N } \\
=29 \\
\end{array}$ & \begin{tabular}{|c|} 
\\
Firms With \\
Females in \\
Ownership \\
Developing N \\
$=76$
\end{tabular} & $\begin{array}{c}\text { Women in } \\
\text { Senior } \\
\text { Positions } \\
\text { Developing } \\
\mathrm{N}=66 \\
\end{array}$ & \begin{tabular}{|c|} 
K-Mean \\
Cluster \\
Firms With \\
Women \\
Owners \\
Developed \& \\
Developing \\
$\mathrm{N}=95$ \\
\end{tabular} & \begin{tabular}{|c|} 
Distance of \\
Country from \\
Cluster Center \\
K-Mean Cluster \\
Firms With \\
Women \\
Owners \\
Developed \& \\
Developing \\
\end{tabular} & \begin{tabular}{|c|} 
\\
K-Means \\
Firms with \\
Women \\
Owners and \\
Senior \\
Positions \\
$\mathrm{N}=97$ \\
\end{tabular} & \begin{tabular}{|c|} 
Distance of \\
Country from \\
Cluster Center \\
K-Means \\
Firms with \\
Women \\
Owners and \\
Senior \\
Positions \\
\end{tabular} & \begin{tabular}{|c|} 
\\
Women in \\
Business \\
Leadership 4- \\
cluster \\
variable \\
$\mathrm{N}=115$ \\
\end{tabular} & $\begin{array}{c}\text { Proportion of } \\
\text { seats held by } \\
\text { women in } \\
\text { national } \\
\text { parliament } \\
\text { WDI } \\
\end{array}$ & \begin{tabular}{|c|} 
Proportion of \\
seats in \\
parliament \\
held by \\
women \\
UNDP \\
\end{tabular} & \begin{tabular}{|c|} 
K-Means \\
Cluster \\
Political \\
Leadership N \\
$=181$ \\
\end{tabular} & & \\
\hline$\overline{\text { Serbia }}$ & \begin{tabular}{|l|}
. \\
\end{tabular} & \begin{tabular}{|l|}
0.25 \\
\end{tabular} & 0.071 & \begin{tabular}{|l|}
2 \\
\end{tabular} & \begin{tabular}{|l|}
0.006 \\
\end{tabular} & \begin{tabular}{|l|}
2 \\
\end{tabular} & \begin{tabular}{|l|}
0.014 \\
\end{tabular} & 2 & \begin{tabular}{|l|l}
0.08 & \\
\end{tabular} & & \begin{tabular}{l|l}
1 & \\
\end{tabular} & &. \\
\hline Serbia/Montenegro & . & $\cdot$ & . &. & . &. & . &. & 0.29 & 0.294 & 3 & & . \\
\hline Seychelles & . &. &. &. &. & . & . &. & 0.15 & 0.145 & 2 & 16,652 & \\
\hline Sierra Leone & . &. & . & . &. & . & . & . & 0.16 & 0.189 & 2 & 561 & \\
\hline Singapore & & & . &. &. &. &. &. & 0.19 & 0.167 & 2 & 28,077 & 0.66 \\
\hline Slovak Republic & 0.259 & 0.182 & . & 2 & 0.065 & 1 & 0.022 & 1 & 0.12 & 0.108 & 2 & 14,623 & 0.68 \\
\hline Slovenia & 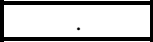 & 0.345 &. & 3 & 0.001 & 3 & 0.002 & 3 & 0 & 0 & 1 & 20,939 & 0.68 \\
\hline Solomon Islands & & 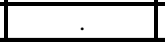 & . & . &. & . & & & 0.3 & 0.328 & 4 & 1,814 & \\
\hline South Africa & & 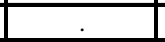 & 0.023 & . & . & 1 & 0.023 & 1 & 0.28 & 0.305 & 3 & 11,192 & 0.72 \\
\hline Spain & 0.281 & 0.341 &. & 3 & 0.053 & 3 & 0.003 & 3 & 0.04 & 0.049 & 1 & 25,047 & 0.74 \\
\hline Sri Lanka &. &. & 0.023 & . & . & 1 & 0.022 & 1 & 0.13 & 0 & 1 & 4,390 & 0.72 \\
\hline St. Kitts and Nevis & . & . & . & . & . & . & . & . & 0.11 & 0.172 & 2 & 12,702 &. \\
\hline St. Lucia &. & . & . & . & . & . & . & . & 0.23 & 0.182 & 3 & 6,324 & - \\
\hline St.Vincent/Grenadines & . & . & . & . & . & . & . & . & 0.1 & 0.136 & 2 & 6,398 & . \\
\hline Sudan & & . & . & . & . & . & . & . & 0.18 & 0.255 & 3 & 1,949 & \\
\hline Suriname & & & . & . & . & . & . & . & 0.11 & 0.168 & 2 & 6,552 & 0.68 \\
\hline Swaziland & & 0.286 & 0.124 & 2 & 0.041 & 2 & 0.050 & 2 & 0.45 & 0.453 & 4 & 5,638 & \\
\hline Sweden & 0.243 &. & . & 3 & 0.015 & . & . & 3 & 0.25 & 0.248 & 3 & 29,541 & 0.82 \\
\hline Switzerland & 0.378 & . & . & 4 & 0.025 & . &. & 4 & 0.12 & 0.12 & 2 & 33,040 & 0.69 \\
\hline Syrian Arab Republic & &. & 0.004 & . & . & 1 & 0.041 & 1 & 0.13 & 0.196 & 2 & 3,610 & 0.62 \\
\hline Tajikistan & & 0.218 & . & 2 & 0.026 & 2 & 0.041 & 2 & 0.21 & 0.304 & 3 & 1,202 & 0.66 \\
\hline Tanzania & & 0.309 & 0.037 & 3 & 0.035 & 2 & 0.067 & 3 & 0.09 & 0.107 & 1 & 674 & 0.70 \\
\hline Thailand & &. & 0.02 & . &. & 1 & 0.026 & 1 & 0.26 & 0.253 & 3 & 8,090 & 0.68 \\
\hline Timor-Leste & . &. &. &. &. &. &. & . & 0.07 & 0.086 & 1 & 1,033 &. \\
\hline Togo & . & . & . & . & . & . & . & . & 0 & 0.033 & 1 & 1,536 & . \\
\hline Tonga & . & . &. & . &. &. & . & . & 0.19 & 0.254 & 3 & 7,870 & \\
\hline Trinidad and Tobago & & & . & . & . & . & . & . & 0.12 & 0.193 & 2 & 12,182 & 0.69 \\
\hline Tunisia & & & . & . & & . & & & 0.04 & 0.044 & 1 & 7,768 & 0.63 \\
\hline Turkey & 0.099 & 0.089 & . & 1 & 0.056 & 1 & 0.071 & 1 & 0.26 & 0.16 & 3 & 7,753 & 0.58 \\
\hline
\end{tabular}




\begin{tabular}{|c|c|c|c|c|c|c|c|c|c|c|c|c|c|}
\hline \multicolumn{14}{|c|}{ Appendix 2 Cont'd - Final Cluster Analysis for Women in Leadership Dependent Variables } \\
\hline \multirow[b]{2}{*}{ Country } & \multicolumn{8}{|c|}{$\begin{array}{c}\text { Women in Business Leadership } \\
\end{array}$} & \multicolumn{3}{|c|}{ Women in Political Leadership } & \multirow[b]{2}{*}{\begin{tabular}{|c|} 
\\
GDP per \\
capita (PPP \\
US\$) 2004*
\end{tabular}} & \multirow[b]{2}{*}{$\begin{array}{c}\text { Global } \\
\text { Gender } \\
\text { Gap } \\
\text { Index } \\
2007\end{array}$} \\
\hline & $\begin{array}{c}\text { Firms with } \\
\text { Female } \\
\text { Employers \& } \\
\text { Own Account } \\
\text { Workers } \\
\text { Developed N } \\
=29\end{array}$ & $\begin{array}{c}\text { Firms With } \\
\text { Females in } \\
\text { Ownership } \\
\text { Developing N } \\
=76\end{array}$ & $\begin{array}{l}\text { Women in } \\
\text { Senior } \\
\text { Positions } \\
\text { Developing } \\
\mathrm{N}=66\end{array}$ & \begin{tabular}{|c|} 
K-Mean \\
Cluster \\
Firms With \\
Women \\
Owners \\
Developed \& \\
Developing \\
$\mathrm{N}=95$
\end{tabular} & \begin{tabular}{|c|} 
Distance of \\
Country from \\
Cluster Center \\
K-Mean Cluster \\
Firms With \\
Women \\
Owners \\
Developed \& \\
Developing
\end{tabular} & \begin{tabular}{|c|} 
\\
K-Means \\
Firms with \\
Women \\
Owners and \\
Senior \\
Positions \\
$\mathrm{N}=97$ \\
\end{tabular} & \begin{tabular}{c|} 
Distance of \\
Country from \\
Cluster Center \\
K-Means \\
Firms with \\
Women \\
Owners and \\
Senior \\
Positions \\
\end{tabular} & \begin{tabular}{|c|} 
\\
Women in \\
Business \\
Leadership 4- \\
cluster \\
variable \\
$\mathrm{N}=115$ \\
\end{tabular} & $\begin{array}{c}\text { Proportion of } \\
\text { seats held by } \\
\text { women in } \\
\text { national } \\
\text { parliament } \\
\text { WDI }\end{array}$ & $\begin{array}{c}\text { Proportion of } \\
\text { seats in } \\
\text { parliament } \\
\text { held by } \\
\text { women } \\
\text { UNDP }\end{array}$ & $\begin{array}{c}\text { K-Means } \\
\text { Cluster } \\
\text { Political } \\
\text { Leadership N } \\
=181\end{array}$ & & \\
\hline Turkmenistan &. & \begin{tabular}{|l|l|l|l}
. &
\end{tabular} &. & \begin{tabular}{|l|l|l|l}
. & 1
\end{tabular} & \begin{tabular}{|l|l|l|l}
. & \\
\end{tabular} & 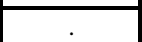 & \begin{tabular}{|l|l|l}
. & 1
\end{tabular} &. & \begin{tabular}{|l|l|l|l}
0.25 & \\
\end{tabular} & \begin{tabular}{|l|l|l}
0.288 &
\end{tabular} & \begin{tabular}{|l|l|l|l}
3 &
\end{tabular} & \begin{tabular}{|l|l}
4,584 & \\
\end{tabular} &. \\
\hline Uganda & & 0.347 & 0.065 & 3 & 0.003 & 3 & 0.048 & 3 & 0.05 & 0.071 & 1 & 1,478 & 0.68 \\
\hline Ukraine & & 0.349 & . & 3 & 0.004 & 3 & 0.005 & 3 & 0 & 0 & 1 & 6,394 & 0.68 \\
\hline United Arab Emirates & &. & . & . & & . & & & 0.18 & 0.185 & 2 & 24,056 & 0.62 \\
\hline United Kingdom & 0.269 &. & . & 2 & 0.009 & . & . & 2 & 0.14 & 0.15 & 2 & 30,821 & 0.74 \\
\hline United States & 0.371 & . & . & 4 & 0.018 & . & . & 4 & 0.12 & 0.108 & 2 & 39,676 & 0.70 \\
\hline Uruguay & & 0.416 & 0.146 & 4 & 0.002 & 4 & 0.029 & 4 & 0.07 & 0.164 & 2 & 9,421 & 0.66 \\
\hline Uzbekistan & & 0.172 & 0.104 & 1 & 0.027 & 1 & 0.060 & 1 & 0.02 & 0.038 & 1 & 1,869 & 0.69 \\
\hline Vanuatu & &. &. & $\dot{.}$ & 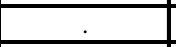 & . & & & 0.1 & 0.18 & 2 & 3,051 & \\
\hline Venezuela, RB & & . & . & . & & . & & & 0.27 & 0.273 & 3 & 6,043 & 0.68 \\
\hline Vietnam & & 0.274 & . & 2 & 0.030 & 2 & 0.015 & 2 & . & & & 2,745 & 0.69 \\
\hline West Bank and Gaza & . & 0.18 & . & 1 & 0.035 & 1 & 0.021 & 1 & 0 & 0.007 & 1 & . & . \\
\hline Yemen, Rep. & &. & & & & - & & & 0.12 & 0.127 & 2 & 879 & 0.45 \\
\hline Zambia & . & . & 0.016 & . & . & 1 & 0.029 & 1 & 0.1 & 0.208 & 2 & 943 & 0.63 \\
\hline Zimbabwe & & . & . & . & . & . & & & . & & & 2,065 & 0.65 \\
\hline
\end{tabular}




\begin{tabular}{|c|c|c|c|c|c|c|c|c|c|c|c|c|c|c|c|c|}
\hline \multicolumn{2}{|r|}{ Appendix 3 Correlation Table } & $\mu$ & $\delta$ & & 1 & 2 & 3 & 4 & 5 & 6 & 7 & 8 & 9 & 10 & 11 & 12 \\
\hline \multirow[t]{2}{*}{1} & \multirow[t]{2}{*}{ KmeansClusterPoliticalLeadership } & 1.994 & 0.969 & $r$ & & & & & & & & & & & & \\
\hline & & & & N & 181 & & & & & & & & & & & \\
\hline \multirow[t]{2}{*}{2} & \multirow[t]{2}{*}{ WomenInBusinessLeadershipClusters } & 2.261 & 1.125 & $r$ & $.346^{*+}$ & & & & & & & & & & & \\
\hline & & & & N & 110 & 115 & & & & & & & & & & \\
\hline \multirow[t]{2}{*}{3} & \multirow[t]{2}{*}{ GiftGivingtoGetanOperatingLicense } & 18.554 & 20.736 & $r$ & -.165 & -.249 & & & & & & & & & & \\
\hline & & & & $\mathrm{N}$ & 57 & 53 & & & & & & & & & & \\
\hline \multirow[t]{2}{*}{4} & \multirow[t]{2}{*}{ GiftGivingtoGetanElectricalConnection } & 17.137 & 17.148 & $r$ & $-.358^{*}$ & $-.263^{*}$ & $.784 *$ & & & & & & & & & \\
\hline & & & & N & 65 & 61 & 58 & & & & & & & & & \\
\hline \multirow[t]{2}{*}{5} & \multirow[t]{2}{*}{ PayinglnformalPaymentToGetThingsDone } & 38.507 & 22.076 & $r$ & -.344 & $-.285^{\star \star}$ & $.481^{\#}$ & $.646^{* *}$ & & & & & & & & \\
\hline & & & & N & 88 & 89 & 53 & 60 & & & & & & & & \\
\hline \multirow[t]{2}{*}{64} & \multirow[t]{2}{*}{ AverageNumberofTemporanWorkers } & 27.573 & 51.393 & $r$ & -.005 & $-.258^{*}$ & -.158 & -.120 & .106 & & & & & & & \\
\hline & & & & N & 97 & 95 & 58 & 65 & 91 & & & & & & & \\
\hline \multirow[t]{2}{*}{$7 A$} & \multirow[t]{2}{*}{ AverageNumberofSkilledProductionWorkers } & 55.007 & 56.921 & $r$ & .002 & $-.299 *$ & -.024 & -.121 & -.002 & $.316^{*}$ & & & & & & \\
\hline & & & & N & 97 & 96 & 55 & 64 & 91 & 99 & & & & & & \\
\hline \multirow[t]{2}{*}{8} & \multirow[t]{2}{*}{ AwerageNumberofUnskilledProductionWorkers } & 41.576 & 61.678 & $r$ & -.004 & $-.285^{*}$ & -.180 & -.178 & .010 & $.502^{\star *}$ & $.471^{\#}$ & & & & & \\
\hline & & & & N & 97 & 96 & 55 & 64 & 91 & 99 & 101 & & & & & \\
\hline \multirow[t]{2}{*}{$9 /$} & \multirow[t]{2}{*}{ AverageNumberofNonProductionWorkrs } & 17.030 & 20.187 & $r$ & .092 & -.134 & -.231 & -.227 & -.081 & $.423^{\sharp t}$ & $.298^{\#}$ & $.705^{\star *}$ & & & & \\
\hline & & & & N & 94 & 94 & 54 & 62 & 88 & 96 & 98 & 98 & & & & \\
\hline \multirow[t]{2}{*}{10} & \multirow{2}{*}{ YearsofExperienceoftheTopManagemorking } & 12.428 & 4.912 & $r$ & .058 & $.423^{\star *}$ & -.208 & -.213 & $-.309^{*}$ & -.234 & -.143 & -.220 & -.006 & & & \\
\hline & & & & N & 58 & 60 & 49 & 55 & 54 & 60 & 60 & 60 & 59 & & & \\
\hline 11 & LaborSkillLevelAsAMajorConstraint & 19.325 & 10.799 & $r$ & -.087 & -.070 & $-.410^{* t}$ & -.236 & $-.207^{*}$ & $.196^{*}$ & -.133 & $.327^{* t}$ & $.359 *$ & .135 & & \\
\hline & & & & N & 99 & 97 & 58 & 67 & 93 & 102 & 101 & 101 & 98 & 61 & & \\
\hline 12 & FirmsofferingFormalTraining & 42.089 & 17.364 & $r$ & .119 & $228^{*}$ & -.242 & $-.264^{*}$ & $-.223^{*}$ & -.010 & -.054 & $.197^{*}$ & .158 & .021 & .113 & \\
\hline & & & & N & 99 & 97 & 58 & 67 & 93 & 102 & 101 & 101 & 98 & 61 & 104 & \\
\hline 13 & CustomsTradeRegsAsAMajorConstraint & 19.057 & 11.110 & $r$ & $-.340^{* t}$ & $-.351 \div$ & .118 & $254^{*}$ & $.319 *$ & .140 & -.036 & .097 & -.025 & $-.264^{*}$ & $.394^{*}$ & -.105 \\
\hline & & & & N & 99 & 97 & 58 & 67 & 93 & 102 & 101 & 101 & 98 & 61 & 104 & 104 \\
\hline 14 & DealingwithLicensesTime & 224.468 & 150.019 & $r$ & -.114 & -.141 & .160 & .136 & $.373^{\star \star}$ & $.318^{* t}$ & .098 & .079 & -.034 & .046 & -.035 & -.028 \\
\hline & & & & N & 165 & 114 & 58 & 67 & 93 & 102 & 101 & 101 & 98 & 61 & 104 & 104 \\
\hline 15 & EnforcingContractsProcedures & 37.721 & 6.572 & $r$ & $-.322^{*}$ & $-.462^{\star \star}$ & $.404 \div$ & $.445^{\star \pi}$ & $.329 \div$ & .079 & .002 & -.009 & -.040 & -.142 & .070 & $-.479 *$ \\
\hline & & & & N & 166 & 114 & 58 & 67 & 93 & 102 & 101 & 101 & 98 & 61 & 104 & 104 \\
\hline 16 & TaxAdministrationAsAMajorConstraint & 28.519 & 15.585 & $r$ & $-.326^{*}$ & $-.239^{*}$ & $.293^{*}$ & $.405^{\star *}$ & $.329 *$ & .119 & -.134 & -.005 & -.013 & -.032 & $.277^{*+}$ & -.117 \\
\hline & & & & N & 99 & 97 & 58 & 67 & 93 & 102 & 101 & 101 & 98 & 61 & 104 & 104 \\
\hline 17 & TypicalFirmReportsLessThanTotalSales & 48.827 & 18.844 & $r$ & -.019 & -.094 & $341^{*}$ & $.367^{* t}$ & $.513^{\star *}$ & -.035 & $-.238^{*}$ & -.167 & -.083 & $-.309^{*}$ & -.001 & $-.260^{*}$ \\
\hline & & & & N & 92 & 92 & 55 & 64 & 90 & 95 & 95 & 95 & 92 & 57 & 97 & 97 \\
\hline 18 & AccessCostofFinanceAsMajorConstraint & 31.648 & 17.308 & $r$ & -.177 & -.082 & .083 & $.285^{*}$ & $.386^{*}$ & .002 & $-.305^{\star \star}$ & -.072 & -.067 & -.183 & $.250^{*}$ & $-.287^{*}$ \\
\hline & & & & N & 99 & 97 & 58 & 67 & 93 & 102 & 101 & 101 & 98 & 61 & 104 & 104 \\
\hline 19 & GlobalCompetitivenessIndex & 4.161 & 0.695 & $r$ & $.311^{\star t}$ & $.284^{*}$ & -.194 & $-.406^{* t}$ & $-.464 *$ & -.061 & .108 & .176 & $.293^{\star \pi}$ & .096 & -.111 & $.360^{*+}$ \\
\hline & & & & N & 125 & 100 & 45 & 54 & 77 & 86 & 86 & 86 & 84 & 51 & 88 & 88 \\
\hline
\end{tabular}




\begin{tabular}{|c|c|c|c|c|c|c|c|c|c|c|c|c|c|c|c|c|}
\hline \multicolumn{2}{|r|}{ Appendix 3 Cont'd Correlation Table } & $\mu$ & $\delta$ & & 1 & 2 & 3 & 4 & 5 & 6 & 7 & 8 & 9 & 10 & 11 & 12 \\
\hline \multirow[t]{2}{*}{20} & \multirow[t]{2}{*}{ GlobalCompetitivenessLaborMarketEfficiency } & 4.338 & 0.511 & $r$ & $.240^{* \pi}$ & $.293^{\star \pi}$ & -.187 & -.129 & -.016 & -.029 & .084 & .135 & .076 & $-.305^{\star}$ & -.265 & $.391^{* 1}$ \\
\hline & & & & N & 125 & 100 & 45 & 54 & 77 & 86 & 86 & 86 & 84 & 51 & 88 & 88 \\
\hline \multirow[t]{2}{*}{21} & \multirow[t]{2}{*}{ GlobalCompetitivenessFinancialmktSophistication } & 4.377 & 0.847 & $r$ & $.334 *$ & $.304^{* \pi}$ & $-.328^{*}$ & $-.401^{\#+}$ & $-.542 *$ & -.120 & .099 & .041 & .190 & .011 & -.002 & $296^{\star *}$ \\
\hline & & & & N & 125 & 100 & 45 & 54 & 77 & 86 & 86 & 86 & 84 & 51 & 88 & 88 \\
\hline \multirow[t]{2}{*}{22} & \multirow[t]{2}{*}{ RespectForlndividaulistic\&InnovativeEntrepreneurs } & 2.800 & 0.714 & $r$ & -.123 & .237 & .003 & .151 & .095 & .342 & -.197 & .292 & .168 & & .519 & -.069 \\
\hline & & & & N & 29 & 26 & 6 & 7 & 10 & 13 & 12 & 12 & 12 & 6 & 13 & 13 \\
\hline \multirow[t]{2}{*}{23} & \multirow[t]{2}{*}{ SocialAcceptanceRespectforEntrepreneurs } & 3.333 & 0.547 & $r$ & $-.467^{*}$ & .208 & $.817^{*}$ & .613 & $.642^{*}$ & .371 & -.433 & .385 & .183 & -.800 & .195 & .255 \\
\hline & & & & $N$ & 29 & 26 & 6 & 7 & 10 & 13 & 12 & 12 & 12 & 6 & 13 & 13 \\
\hline \multirow[t]{2}{*}{24} & \multirow[t]{2}{*}{ PositivelmpressionOfGovtSupportEship } & 2.633 & 0.615 & $r$ & .220 & $.450^{*}$ & -.064 & -.064 & -.095 & .376 & .128 & .264 & .138 & -.177 & -.172 & .295 \\
\hline & & & & N & 29 & 26 & 6 & 7 & 10 & 13 & 12 & 12 & 12 & 6 & 13 & 13 \\
\hline \multirow[t]{2}{*}{25} & \multirow[t]{2}{*}{ AccessibleAffordableBusinessServicesSuppliers } & 3.067 & 0.365 & $r$ & .120 & $476^{*}$ & & .125 & & .209 & .164 & .006 & .173 & .456 & -.357 & -.151 \\
\hline & & & & N & 29 & 26 & 6 & 7 & 10 & 13 & 12 & 12 & 12 & 6 & 13 & 13 \\
\hline \multirow[t]{2}{*}{26} & \multirow[t]{2}{*}{ StrongIntellectualPropertyRights } & 3.200 & 0.761 & $r$ & .258 & $479^{*}$ & -.096 & -.207 & -.167 & .172 & -.002 & .139 & .010 & -.177 & -.441 & .184 \\
\hline & & & & N & 29 & 26 & 6 & 7 & 10 & 13 & 12 & 12 & 12 & 6 & 13 & 13 \\
\hline \multirow[t]{2}{*}{27} & \multirow[t]{2}{*}{ GoodMarketOpportunityandControls } & 2.900 & 0.305 & $r$ & -.013 & .207 & .504 & .337 & .450 & .017 & $-.597^{*}$ & -.111 & .071 & .020 & -.124 & .124 \\
\hline & & & & N & 29 & 26 & 6 & 7 & 10 & 13 & 12 & 12 & 12 & 6 & 13 & 13 \\
\hline \multirow[t]{2}{*}{28} & \multirow[t]{2}{*}{ GoodAvailableEntrepreneurshipTraining } & 2.767 & 0.504 & $r$ & -.166 & .286 & -.768 & -.594 & $-.742^{*}$ & -.197 & .128 & -.277 & -.276 & 488 & .200 & .243 \\
\hline & & & & N & 29 & 26 & 6 & 7 & 10 & 13 & 12 & 12 & 12 & 6 & 13 & 13 \\
\hline \multirow[t]{2}{*}{29} & \multirow[t]{2}{*}{ EmployeeServicesFemale } & 70.932 & 17.624 & $r$ & $.483^{* \star}$ & $.560^{* *}$ & -.208 & -.416 & $-.690^{*}$ & -.095 & $-.398^{* 4}$ & -.282 & .004 & $.543^{*}$ & .263 & $.304^{*}$ \\
\hline & & & & $N$ & 68 & 60 & 15 & 21 & 39 & 44 & 44 & 44 & 42 & 19 & 45 & 45 \\
\hline 30 & EstimatedEearnedIncomeFemale & 7148.713 & 8403.331 & $r$ & $457^{+\pi}$ & $.376^{* *}$ & $-.321^{*}$ & $-.499 *$ & $-.452^{*}$ & -.114 & -.016 & -.090 & -.029 & .255 & -.182 & $.435^{*+}$ \\
\hline & & & & $N$ & 159 & 110 & 57 & 65 & 88 & 97 & 97 & 97 & 94 & 58 & 99 & 99 \\
\hline 31 & LaborforceParticipationMale & 81.407 & 6.455 & $r$ & -.052 & -.132 & -.001 & .122 & $.331 \%$ & .095 & -.129 & .162 & .131 & -.124 & $.370^{*+}$ & $-.343^{\star \pi}$ \\
\hline & & & & N & 168 & 112 & 58 & 66 & 90 & 99 & 98 & 98 & 95 & 59 & 101 & 101 \\
\hline 32 & UnemploymentFemale & 10.542 & 7.149 & $r$ & -.082 & $-.256^{*}$ & $-.506^{*}$ & -.254 & -.246 & -.080 & -.013 & -.003 & .140 & .310 & .253 & -.045 \\
\hline & & & & $N$ & 71 & 66 & 20 & 24 & 44 & 49 & 48 & 48 & 46 & 23 & 50 & 50 \\
\hline 33 & GenderRelatedDevelopmentIndexValue & 0.706 & 0.189 & $r$ & $.313^{\star *}$ & $.337^{* t}$ & -.117 & $-.392^{*}$ & $-.519 *$ & -.190 & .061 & -.083 & -.057 & $.344^{*}$ & -.109 & $.456^{\star *}$ \\
\hline & & & & N & 136 & 100 & 49 & 57 & 79 & 87 & 87 & 87 & 84 & 51 & 89 & 89 \\
\hline 34 & GenderEmpowermentMeasureValue & 0.588 & 0.169 & $r$ & .793 & $.411^{\#}$ & -.141 & -.504 & $-.516^{*}$ & -.156 & $-.303^{*}$ & -.230 & -.013 & .088 & -.147 & $.391 \div$ \\
\hline & & & & $N$ & 75 & 62 & 21 & 25 & 41 & 48 & 47 & 47 & 46 & 23 & 48 & 48 \\
\hline 35 & GenderGaplndex & 0.667 & 0.057 & $r$ & $.642^{\star *}$ & $.395^{* *}$ & -.254 & $-.398^{*+}$ & $-.426 *$ & .152 & $.251^{*}$ & .036 & .039 & .143 & -.160 & $477^{*+}$ \\
\hline & & & & N & 126 & 97 & 45 & 53 & 74 & 83 & 83 & 83 & 81 & 48 & 85 & 85 \\
\hline 36 & GenderGapPoliticalEmpowerment & 0.139 & 0.108 & $r$ & $.701^{\star *}$ & $.224^{*}$ & -.188 & $-.278^{*}$ & $-.299 *$ & .167 & $.274^{*}$ & .062 & .076 & .005 & -.034 & .069 \\
\hline & & & & $N$ & 126 & 97 & 45 & 53 & 74 & 83 & 83 & 83 & 81 & 48 & 85 & 85 \\
\hline 37 & AdultLiteracyRateAges15andolder & 81.649 & 20.124 & $r$ & $.249 \#$ & $.297^{\star *}$ & -.045 & -.294 & $-.463^{* t}$ & -.055 & .132 & .022 & .035 & 209 & -.073 & $.485^{* t}$ \\
\hline & & & & N & 172 & 110 & 57 & 65 & 88 & 97 & 97 & 97 & 94 & 58 & 99 & 99 \\
\hline 38 & AdultLiteracyFemalesAge15andolder & 79.188 & 24.096 & $r$ & $.292^{\star *}$ & $.341 *$ & -.083 & $-.348^{*+}$ & $-.480^{*}$ & -.043 & .125 & .006 & .024 & .230 & -.127 & $.481 \div$ \\
\hline & & & & N & 146 & 103 & 51 & 59 & 82 & 90 & 90 & 90 & 87 & 53 & 92 & 92 \\
\hline
\end{tabular}




\begin{tabular}{|c|c|c|c|c|c|c|c|c|c|c|c|c|c|c|c|c|}
\hline \multicolumn{2}{|r|}{ Appendix 3 Cont'd Correlation Table } & $\mu$ & $\delta$ & & 1 & 2 & 3 & 4 & 5 & 6 & 7 & 8 & 9 & 10 & 11 & 12 \\
\hline \multirow[t]{2}{*}{39} & \multirow[t]{2}{*}{ AdultLiteracyMalesAge15andOlder } & 86.971 & 16.142 & $r$ & $.263^{\star \pi}$ & $.271^{\star *}$ & .020 & $-.293^{\star}$ & $-.429 *$ & -.089 & .192 & .026 & .062 & .194 & -.148 & $.428^{* 1}$ \\
\hline & & & & N & 132 & 97 & 46 & 54 & 76 & 84 & 84 & 84 & 81 & 48 & 86 & 86 \\
\hline \multirow[t]{2}{*}{40} & \multirow[t]{2}{*}{ EducationCombinedPrimsecTermales } & 70.701 & 16.519 & $r$ & $.275^{\star *}$ & $.355^{\star \star}$ & -.050 & $-.262^{*}$ & $-.489 * \pi$ & -.048 & .126 & -.001 & .046 & 249 & .018 & $.502^{\star \star}$ \\
\hline & & & & N & 163 & 107 & 55 & 63 & 85 & 94 & 94 & 94 & 91 & 56 & 96 & 96 \\
\hline \multirow[t]{2}{*}{41} & \multirow[t]{2}{*}{ PublicSpendingonEducationTotal } & 4.808 & 1.900 & $r$ & $.276^{*+}$ & .334 & -.252 & $-.376^{*}$ & $-.412^{*+}$ & -.130 & -.230 & .007 & .218 & -.197 & .048 & $.321^{*}$ \\
\hline & & & & N & 105 & 75 & 30 & 37 & 53 & 61 & 61 & 61 & 58 & 36 & 62 & 62 \\
\hline \multirow[t]{2}{*}{42} & \multirow[t]{2}{*}{ GlobalCompetitivHigherEducationTraining } & 3.977 & 0.982 & $r$ & $.339 \div$ & $.318^{*}$ & -.166 & $-.398 *$ & $-.511 \div$ & -.125 & .109 & .012 & .164 & .146 & -.158 & $.459^{* 1}$ \\
\hline & & & & N & 125 & 100 & 45 & 54 & 77 & 86 & 86 & 86 & 84 & 51 & 88 & 88 \\
\hline \multirow[t]{2}{*}{43} & \multirow[t]{2}{*}{ Populationages65andaboveoftotal } & 61.706 & 6.788 & $r$ & $.369 *$ & $.312^{* \pi}$ & -.067 & -.228 & $-.296^{*}$ & -.116 & .059 & -.140 & -.057 & $.266^{*}$ & $-.332^{*}$ & $.465^{\star *}$ \\
\hline & & & & N & 169 & 112 & 58 & 66 & 90 & 99 & 98 & 98 & 95 & 59 & 101 & 101 \\
\hline \multirow[t]{2}{*}{44} & \multirow[t]{2}{*}{ Ruralpopulationoftotalpopulation } & 45.352 & 24.194 & $r$ & $-.187^{*}$ & $-.308^{* 1}$ & .192 & $.329 \div$ & $.461^{\#}$ & $.260^{*}$ & .158 & $.269^{* \pi}$ & .144 & $-.521 *$ & -.110 & $-.292^{\star *}$ \\
\hline & & & & N & 181 & 113 & 58 & 66 & 91 & 100 & 99 & 99 & 96 & 59 & 102 & 102 \\
\hline \multirow[t]{2}{*}{45} & \multirow[t]{2}{*}{ HumanDevelopmentlndex } & 0.711 & 0.178 & $r$ & $.270^{*+}$ & $.322^{* *}$ & -.096 & $-.334^{* t}$ & $-.515^{*+1}$ & -.171 & .070 & -.070 & -.054 & $.324^{*}$ & -.057 & $.470^{*+}$ \\
\hline & & & & N & 172 & 110 & 57 & 65 & 88 & 97 & 97 & 97 & 94 & 58 & 99 & 99 \\
\hline \multirow[t]{2}{*}{46} & \multirow[t]{2}{*}{ OutOfPocketHealthExpenditure } & 80.295 & 21.318 & $r$ & $-.204 *$ & $-.290^{\star *}$ & $.468^{\star 4}$ & $.422^{\star *}$ & $.407^{*}-$ & $-.291 *$ & -.050 & $-.285^{\star *}$ & $-.345^{\star 4}$ & -.188 & $-.351^{\star t}$ & * -.137 \\
\hline & & & & N & 177 & 111 & 56 & 64 & 89 & 98 & 98 & 98 & 95 & 57 & 100 & 100 \\
\hline \multirow[t]{2}{*}{47} & \multirow[t]{2}{*}{ PrevalenceofUndernourishmentofPopulation } & 14.883 & 15.528 & $r$ & -.130 & -.164 & .261 & $.287^{*}$ & $.334^{* *}$ & .056 & -.110 & .018 & .012 & -.221 & -.036 & $-.360^{*+}$ \\
\hline & & & & N & 165 & 110 & 57 & 65 & 88 & 97 & 96 & 96 & 93 & 57 & 99 & 99 \\
\hline \multirow[t]{2}{*}{$48 \mid$} & \multirow[t]{2}{*}{ IndexofEconomicFreedom } & 3.000 & 0.717 & $r$ & $-.313^{* 1}$ & -.414 & $.347^{*}$ & $.383^{\star \star}$ & $.428 * \pi$ & .114 & $228^{*}$ & .144 & .093 & -.103 & -.034 & $-.342^{*}$ \\
\hline & & & & N & 148 & 106 & 52 & 60 & 84 & 93 & 93 & 93 & 90 & 53 & 95 & 95 \\
\hline 49 & GDPperCapitaConstantUS $\$$ & 6307.627 & 9706.085 & $r$ & $.373^{\star *}$ & $.336^{* \pi}$ & -.230 & $-.452^{\star \pi}$ & $-.431=$ & -.120 & -.095 & -.117 & -.031 & $.363^{* \pi}$ & -.068 & $.267^{*+1}$ \\
\hline & & & & N & 171 & 113 & 58 & 67 & 91 & 100 & 99 & 99 & 96 & 61 & 102 & 102 \\
\hline 50 & GDPperCapitaPPPconstantIntI\$ & 9571.787 & 10178.077 & $r$ & $.394^{* t}$ & $.366^{* \pi}$ & $-.306^{*}$ & $-.519 *$ & $-.485^{* \pi}$ & -.122 & -.031 & -.091 & -.026 & .256 & -.119 & $.382^{\star \pi}$ \\
\hline & & & & N & 164 & 109 & 57 & 65 & 87 & 96 & 96 & 96 & 93 & 58 & 98 & 98 \\
\hline 51 & GDPperCapitaPPPUS $\$$ & 10098.214 & 10970.954 & $r$ & $.372^{\star *}$ & $.365^{\star *}$ & $-.316^{*}$ & $-.518^{*}$ & $-.482^{\star \star}$ & -.129 & -.034 & -.091 & -.028 & $.265^{*}$ & -.114 & $.389 *$ \\
\hline & & & & N & 172 & 110 & 57 & 65 & 88 & 97 & 97 & 97 & 94 & 58 & 99 & 99 \\
\hline 52 & GovtConsumptionExpenditureofGDP & 16.354 & 7.190 & $r$ & $.290^{* \pi}$ & .113 & -.253 & -.230 & $-.325^{*}$ & -.099 & -.135 & -.077 & -.005 & -.127 & .017 & .170 \\
\hline & & & & N & 155 & 111 & 54 & 63 & 88 & 97 & 96 & 96 & 94 & 58 & 99 & 99 \\
\hline 53 & BankNonPerfomingLoans & 7.734 & 7.301 & $r$ & 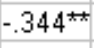 & $-.265^{\star}$ & .062 & .219 & $.292^{*}$ & $.368^{*}$ & $.277^{*}$ & .182 & $.254^{*}$ & -.124 & .016 & $-.310^{\#+}$ \\
\hline & & & & N & 98 & 82 & 34 & 40 & 61 & 68 & 67 & 67 & 65 & 39 & 69 & 69 \\
\hline 54 & DomesticCreditProvidedBy日ankingSector & 59.058 & 54.145 & $r$ & $.246^{* \pi}$ & $204^{*}$ & -.205 & -.229 & $-.387^{+*}$ & .017 & -.027 & $252^{*}$ & .159 & .068 & $.222^{*}$ & $.275^{\star *}$ \\
\hline & & & & N & 167 & 111 & 57 & 66 & 89 & 98 & 97 & 97 & 94 & 60 & 100 & 100 \\
\hline 55 & Domestic CreditToPrivateSector & 46.410 & 43.538 & $r$ & $.317^{*+}$ & $.281 *$ & $-.279^{*}$ & $-.316^{*}$ & $-.397^{+t}$ & .024 & -.019 & $254^{*}$ & .159 & .035 & .092 & $312^{*}$ \\
\hline & & & & N & 167 & 111 & 57 & 66 & 89 & 98 & 97 & 97 & 94 & 60 & 100 & 100 \\
\hline 56 & HighestMarginalTaxRate & 31.464 & 12.916 & $r$ & $.307^{\star *}$ & .115 & .158 & .107 & -.169 & -.087 & .086 & .204 & .220 & -.137 & -.235 & .175 \\
\hline & & & & N & 92 & 69 & 27 & 32 & 52 & 57 & 56 & 56 & 54 & 33 & 58 & 58 \\
\hline 57 & ForeignDirectlnvestmentlnflows & 5.576 & 19.008 & $r$ & .068 & -.049 & .144 & .204 & .014 & -.043 & -.050 & -.139 & -.133 & .046 & -.183 & -.063 \\
\hline & & & & $N$ & 162 & 109 & 56 & 64 & 87 & 96 & 96 & 96 & 93 & 57 & 98 & 98 \\
\hline
\end{tabular}




\begin{tabular}{|c|c|c|c|c|c|c|c|c|c|c|c|c|c|c|c|c|}
\hline \multicolumn{2}{|r|}{ Appendix 3 Cont'd Correlation Table } & $\mu$ & $\delta$ & & 1 & 2 & 3 & 4 & 5 & 6 & 7 & 8 & 9 & 10 & 11 & 12 \\
\hline \multirow[t]{2}{*}{$58 \mid$} & \multirow[t]{2}{*}{ ImportsOfGoods\&ServicesConstant2000US\$ } & 66244035781 & 182965752904 & $r$ & .105 & .185 & .058 & -.149 & .029 & .115 & -.009 & $.300^{* 1}$ & .226 & -.066 & -.066 & .138 \\
\hline & & & & N & 135 & 103 & 51 & 58 & 81 & 89 & 88 & 88 & 86 & 53 & 91 & 91 \\
\hline \multirow[t]{2}{*}{59} & \multirow[t]{2}{*}{ ExportsOfGoodsAndServicesofGDP } & 44.828 & 29.765 & $r$ & .027 & .037 & -.102 & -.116 & -.126 & -.050 & .050 & .022 & -.010 & -.161 & -.078 & $.300^{* t}$ \\
\hline & & & & N & 159 & 112 & 56 & 65 & 90 & 99 & 98 & 98 & 95 & 59 & 101 & 101 \\
\hline \multirow[t]{2}{*}{60} & \multirow[t]{2}{*}{ CommercialServiceExports } & 14554797781 & 37351914448 & $r$ & .152 & .187 & -.027 & -.154 & -.134 & .069 & .005 & .199 & $.276^{*}$ & -.047 & -.113 & .143 \\
\hline & & & & N & 144 & 100 & 50 & 57 & 78 & 87 & 86 & 86 & 84 & 52 & 88 & 88 \\
\hline \multirow[t]{2}{*}{61} & \multirow[t]{2}{*}{ ComputerCommunications\&OtherServices } & 31.639 & 20.902 & $r$ & .096 & .012 & .079 & .167 & $.324^{\star *}$ & .061 & .038 & .065 & .019 & -.138 & -.037 & -.053 \\
\hline & & & & N & 142 & 99 & 50 & 57 & 77 & 86 & 85 & 85 & 83 & 52 & 87 & 87 \\
\hline \multirow[t]{2}{*}{62} & \multirow[t]{2}{*}{ FoodExports } & 21.606 & 22.467 & $r$ & .091 & .154 & -.134 & .008 & -.044 & -.030 & $-.354 \stackrel{ }{\#}$ & -.040 & .121 & .180 & $.249^{*}$ & -.140 \\
\hline & & & & N & 126 & 94 & 41 & 49 & 70 & 78 & 79 & 79 & 77 & 46 & 80 & 80 \\
\hline \multirow[t]{2}{*}{63} & \multirow[t]{2}{*}{ GlobalCompetitivenessBasicInfrastructure } & 3.661 & 1.285 & $r$ & $.327^{*+}$ & $.295^{\star *}$ & -.294 & $-.404 \stackrel{*}{*}$ & $-.536^{\star *}$ & -.114 & -.055 & .106 & .202 & .071 & -.065 & $.241^{*}$ \\
\hline & & & & N & 125 & 100 & 45 & 54 & 77 & 86 & 86 & 86 & 84 & 51 & 88 & 88 \\
\hline \multirow[t]{2}{*}{64} & \multirow[t]{2}{*}{ ElectricPowerConsumption } & 3854.854 & 4812.565 & $r$ & $.388^{*}$ & $.222^{*}$ & -.140 & -.250 & 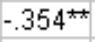 & -.115 & -.001 & -.083 & -.034 & .192 & $-.243^{*}$ & $.421^{\text {t* }}$ \\
\hline & & & & N & 125 & 94 & 41 & 46 & 70 & 78 & 78 & 78 & 76 & 43 & 80 & 80 \\
\hline \multirow[t]{2}{*}{65} & \multirow[t]{2}{*}{ TelephoneMainlines } & 211.791 & 201.799 & $r$ & $.361^{*}$ & $.336^{\star *}$ & -.117 & $-.333^{\star t}$ & $-.413^{* t}$ & $-.224^{*}$ & -.044 & -.157 & -.045 & $.273^{*}$ & $-.262^{*}$ & $.413^{*}$ \\
\hline & & & & N & 163 & 108 & 55 & 64 & 86 & 95 & 94 & 94 & 91 & 58 & 97 & 97 \\
\hline \multirow[t]{2}{*}{66} & \multirow[t]{2}{*}{ FixedLineAndMobilePhoneSubscribers } & 608.887 & 531.100 & $r$ & $.356^{\star *}$ & $.310^{* *}$ & -.225 & $-.421 *$ & $-.430 *$ & -.181 & -.003 & -.131 & -.036 & .183 & -.193 & $467^{*+}$ \\
\hline & & & & N & 163 & 108 & 55 & 64 & 86 & 95 & 94 & 94 & 91 & 58 & 97 & 97 \\
\hline \multirow[t]{2}{*}{671} & \multirow[t]{2}{*}{ MobilePhoneSubscribers } & 376.049 & 348.795 & $r$ & $.333^{\star *}$ & $.303^{*}$ & $-.273^{*}$ & $-.430^{\star \star}$ & $-.436 *$ & -.124 & .016 & -.086 & -.001 & .121 & -.089 & $471^{* t}$ \\
\hline & & & & N & 178 & 113 & 58 & 67 & 91 & 100 & 99 & 99 & 96 & 60 & 102 & 102 \\
\hline \multirow[t]{2}{*}{68 । } & \multirow[t]{2}{*}{ InternationallnternetBandwidth } & 1729.102 & 4461.483 & $r$ & $.433^{* \pi}$ & $.286^{*}$ & -.216 & $-.360^{*}$ & $-.277^{*}$ & -.101 & -.067 & -.138 & -.058 & $.385^{*}$ & -.227 & .236 \\
\hline & & & & N & 122 & 81 & 37 & 44 & 60 & 68 & 67 & 67 & 65 & 41 & 69 & 69 \\
\hline 69 & PersonalComputers & 161.001 & 213.783 & $r$ & $.409^{\#}$ & $.378^{\star *}$ & -.241 & $-.418^{*}$ & $-.409 *$ & -.134 & -.048 & -.138 & -.055 & .139 & -.190 & 494 \\
\hline & & & & $N$ & 148 & 101 & 51 & 59 & 77 & 87 & 86 & 86 & 83 & 54 & 88 & 88 \\
\hline 70 & PoliticalRights & 24.353 & 12.841 & $r$ & $-.166^{*}$ & -.073 & .139 & .092 & -.066 & -.126 & -.068 & -.010 & .034 & .132 & .000 & -.023 \\
\hline & & & & N & 164 & 104 & 54 & 63 & 86 & 94 & 94 & 94 & 91 & 56 & 96 & 96 \\
\hline 71 & CivilLiberties & 37.741 & 15.973 & $r$ & -.137 & -.007 & .175 & .102 & -.077 & -.135 & -.100 & -.036 & .002 & .154 & -.010 & -.015 \\
\hline & & & & N & 164 & 104 & 54 & 63 & 86 & 94 & 94 & 94 & 91 & 56 & 96 & 96 \\
\hline 72 & FutureOrientationSocietyPactice & 3.819 & 0.461 & $r$ & $.307^{*}$ & .124 & 402 & .186 & -.136 & .040 & .278 & .200 & .297 & -.307 & -.037 & -.146 \\
\hline & & & & N & 55 & 45 & 15 & 18 & 26 & 33 & 32 & 32 & 31 & 19 & 33 & 33 \\
\hline 73 & FutureOrientationSocietyalues & 5.504 & 0.398 & $r$ & $-.493^{*}$ & $-.432^{* \star}$ & .013 & -.063 & -.201 & .105 & .115 & -.089 & -.181 & -.001 & $.348^{*}$ & -.235 \\
\hline & & & & N & 55 & 45 & 15 & 18 & 26 & 33 & 32 & 32 & 31 & 19 & 33 & 33 \\
\hline 74 & PerformanceorientationSocietyalues & 5.953 & 0.317 & $r$ & .187 & .221 & -.216 & -.186 & $-.516^{* *}$ & -.154 & -.157 & -.288 & -.197 & .374 & .312 & .078 \\
\hline & & & & $\mathrm{N}$ & 55 & 45 & 15 & 18 & 26 & 33 & 32 & 32 & 31 & 19 & 33 & 33 \\
\hline
\end{tabular}




\begin{tabular}{|c|c|c|c|c|c|c|c|c|c|c|c|c|c|c|c|c|}
\hline \multicolumn{2}{|r|}{ Appendix 3 Cont'd Correlation Table } & $\mu$ & $\delta$ & & 1 & 2 & 3 & 4 & 5 & 6 & 7 & 8 & 9 & 10 & 11 & 12 \\
\hline \multirow[t]{2}{*}{75} & \multirow[t]{2}{*}{ AssertivenessSocietyalues } & 3.852 & 0.660 & $r$ & -.169 & -.120 & .168 & .171 & .207 & .322 & $.368^{*}$ & $.404^{*}$ & $.524 *$ & -.332 & -.074 & .142 \\
\hline & & & & N & 55 & 45 & 15 & 18 & 26 & 33 & 32 & 32 & 31 & 19 & 33 & 33 \\
\hline \multirow[t]{2}{*}{761} & \multirow[t]{2}{*}{ InGroupCollectivismSocietyPractice } & 5.172 & 0.724 & \multicolumn{3}{|c|}{$r-.611 *-.410 *$} & .398 & .386 & $.507^{*}$ & $.399^{*}$ & .297 & .100 & .168 & -.025 & .035 & -.189 \\
\hline & & & & N & 55 & 45 & 15 & 18 & 26 & 33 & 32 & 32 & 31 & 19 & 33 & 33 \\
\hline \multirow[t]{2}{*}{771} & \multirow[t]{2}{*}{ InGroupCollectivismSocietyalues } & 5.689 & 0.341 & $r$ & .080 & .121 & -.326 & -.371 & -.269 & -.023 & -.030 & -.357 & -.247 & .328 & .175 & -.096 \\
\hline & & & & N & 55 & 45 & 15 & 18 & 26 & 33 & 32 & 32 & 31 & 19 & 33 & 33 \\
\hline \multirow[t]{2}{*}{781} & \multirow[t]{2}{*}{ UncertaintyAwoidanceValues } & 4.642 & 0.584 & $r$ & $-.597 *$ & 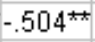 & .048 & -.101 & .216 & .281 & .175 & $.371^{*}$ & .271 & -.321 & .232 & .008 \\
\hline & & & & N & 55 & 45 & 15 & 18 & 26 & 33 & 32 & 32 & 31 & 19 & 33 & 33 \\
\hline \multirow[t]{2}{*}{79} & \multirow[t]{2}{*}{ PowerDistanceSocietyPractice } & 5.187 & 0.399 & $r$ & $-.500^{* *}$ & -.308 & -.077 & .137 & .071 & .095 & -.007 & -.157 & -.217 & -.099 & -.024 & -.149 \\
\hline & & & & N & 55 & 45 & 15 & 18 & 26 & 33 & 32 & 32 & 31 & 19 & 33 & 33 \\
\hline \multirow[t]{2}{*}{80} & \multirow[t]{2}{*}{ HumaneOrientationSocietyPractice } & 4.078 & 0.468 & $r$ & .049 & .126 & -.127 & -.213 & -.244 & -.283 & -.206 & .012 & .052 & .106 & -.019 & .000 \\
\hline & & & & N & 55 & 45 & 15 & 18 & 26 & 33 & 32 & 32 & 31 & 19 & 33 & 33 \\
\hline \multirow[t]{2}{*}{81} & \multirow[t]{2}{*}{ TeamorientedLeadership } & 5.796 & 0.219 & $r$ & -.083 & .107 & -.230 & -.189 & -.123 & -.128 & -.031 & -.278 & -.206 & .164 & .138 & .095 \\
\hline & & & & N & 55 & 45 & 15 & 18 & 26 & 33 & 32 & 32 & 31 & 19 & 33 & 33 \\
\hline \multirow[t]{2}{*}{82} & \multirow[t]{2}{*}{ ParticipativeLeadership } & 5.357 & 0.410 & $r$ & $.506^{\star *}$ & $.395^{*}$ & $-.557^{*}$ & -.339 & -.347 & -.065 & -.313 & -.173 & -.221 & .034 & $.368^{*}$ & .241 \\
\hline & & & & N & 55 & 45 & 15 & 18 & 26 & 33 & 32 & 32 & 31 & 19 & 33 & 33 \\
\hline \multirow[t]{2}{*}{83} & \multirow[t]{2}{*}{ HumaneorientedLeadership } & 4.899 & 0.408 & $r$ & -.222 & -.239 & -.016 & .191 & .016 & .174 & 291 & .314 & $.362^{*}$ & -.251 & .201 & -.134 \\
\hline & & & & N & 55 & 45 & 15 & 18 & 26 & 33 & 32 & 32 & 31 & 19 & 33 & 33 \\
\hline \multirow[t]{2}{*}{84} & \multirow[t]{2}{*}{ AutonomousLeadership } & 3.904 & 0.504 & $r$ & .050 & -.127 & .250 & .260 & .340 & .296 & .102 & .115 & .212 & .329 & -.131 & -.062 \\
\hline & & & & N & 55 & 45 & 15 & 18 & 26 & 33 & 32 & 32 & 31 & 19 & 33 & 33 \\
\hline \multirow[t]{2}{*}{85} & \multirow[t]{2}{*}{ SelfProtectiveLeadership } & 3.460 & 0.412 & $r$ & $-.612^{* \star}$ & $-.532^{\star \pi}$ & .433 & .376 & .372 & .032 & .104 & .305 & .339 & .035 & .077 & -.134 \\
\hline & & & & $N$ & 55 & 45 & 15 & 18 & 26 & 33 & 32 & 32 & 31 & 19 & 33 & 33 \\
\hline 86 & SocialCynism & 2.968 & 0.215 & $r$ & -.198 & -.205 & .355 & .286 & -.005 & -.073 & -.452 & -.184 & -.265 & .102 & -.206 & .024 \\
\hline & & & & N & 38 & 32 & 6 & 7 & 17 & 22 & 22 & 22 & 22 & 8 & 22 & 22 \\
\hline 87 & SocialComplexity & 4.027 & 0.154 & $r$ & $.398^{*}$ & .208 & -.347 & .135 & .033 & -.044 & .004 & -.063 & .039 & -.139 & -.124 & .042 \\
\hline & & & & N & 38 & 32 & 6 & 7 & 17 & 22 & 22 & 22 & 22 & 8 & 22 & 22 \\
\hline 88 & RewardforApplication & 3.721 & 0.268 & $r$ & $-.372^{*}-$ & $-.496^{\star \pi}$ & .506 & .313 & .420 & .284 & .307 & .226 & .323 & -.087 & .070 & $-.480^{*}$ \\
\hline & & & & N & 38 & 32 & 6 & 7 & 17 & 22 & 22 & 22 & 22 & 8 & 22 & 22 \\
\hline 89 & Religiosity & 3.176 & 0.490 & $r$ & $-.413^{\star}$ & $-.435^{\star}$ & -.136 & -.246 & .419 & .035 & .315 & .150 & .238 & -.365 & .084 & $-.478^{*}$ \\
\hline & & & & $N$ & 38 & 32 & 6 & 7 & 17 & 22 & 22 & 22 & 22 & 8 & 22 & 22 \\
\hline 90 & FateControl & 2.651 & 0.265 & $r$ & $-.417^{* t}$ & -.272 & .237 & .211 & $.659^{*}$ & .282 & .070 & 401 & .320 & -.543 & .005 & -.041 \\
\hline & & & & $N$ & 38 & 32 & 6 & 7 & 17 & 22 & 22 & 22 & 22 & 8 & 22 & 22 \\
\hline
\end{tabular}




\begin{tabular}{|c|c|c|c|c|c|c|c|c|c|c|c|c|c|c|c|c|c|}
\hline \multicolumn{2}{|r|}{ Appendix 3 Cont'd Correlation Table } & & 13 & 14 & 15 & 16 & 17 & 18 & 19 & 20 & 21 & 22 & 23 & 24 & 25 & 26 & 27 \\
\hline \multirow[t]{2}{*}{1} & \multirow[t]{2}{*}{ KmeansClusterPoliticalLeadership } & $r$ & & & & & & & & & & & & & & & \\
\hline & & N & & & & & & & & & & & & & & & \\
\hline \multirow[t]{2}{*}{2} & \multirow[t]{2}{*}{ WomenInBusinessLeadershipClusters } & $r$ & & & & & & & & & & & & & & & \\
\hline & & N & & & & & & & & & & & & & & & \\
\hline \multirow[t]{2}{*}{3} & \multirow[t]{2}{*}{ GiftGivingtoGetanoperatingLicense } & $r$ & & & & & & & & & & & & & & & \\
\hline & & N & & & & & & & & & & & & & & & \\
\hline \multirow[t]{2}{*}{4} & \multirow{2}{*}{ GiftGivingtoGetanElectricalConnection } & $r$ & & & & & & & & & & & & & & & \\
\hline & & N & & & & & & & & & & & & & & & \\
\hline \multirow[t]{2}{*}{5} & \multirow[t]{2}{*}{ PayingInformalPaymentToGetThingsDone } & $r$ & & & & & & & & & & & & & & & \\
\hline & & N & & & & & & & & & & & & & & & \\
\hline \multirow[t]{2}{*}{6} & \multirow[t]{2}{*}{ AverageNumberofTemporaryworkers } & $r$ & & & & & & & & & & & & & & & \\
\hline & & N & & & & & & & & & & & & & & & \\
\hline \multirow[t]{2}{*}{7} & \multirow[t]{2}{*}{ AverageNumberofSkilledProductionWorkers } & $r$ & & & & & & & & & & & & & & & \\
\hline & & $N$ & & & & & & & & & & & & & & & \\
\hline \multirow[t]{2}{*}{8} & \multirow[t]{2}{*}{ AverageNumberofUnskilledProductionWorkers } & $r$ & & & & & & & & & & & & & & & \\
\hline & & N & & & & & & & & & & & & & & & \\
\hline \multirow[t]{2}{*}{9} & \multirow[t]{2}{*}{ AverageNumberofNonProductionWorkrs } & $r$ & & & & & & & & & & & & & & & \\
\hline & & N & & & & & & & & & & & & & & & \\
\hline \multirow[t]{2}{*}{10} & \multirow[t]{2}{*}{ YearsofExperienceoftheTopManagerWorking } & $r$ & & & & & & & & & & & & & & & \\
\hline & & N & & & & & & & & & & & & & & & \\
\hline 11 & LaborSkillLevelAsAMajorConstraint & $r$ & & & & & & & & & & & & & & & \\
\hline & & N & & & & & & & & & & & & & & & \\
\hline 12 & FirmsofferingFormalTraining & $r$ & & & & & & & & & & & & & & & \\
\hline & & N & & & & & & & & & & & & & & & \\
\hline 13 & CustomsTradeRegsAsAMajorConstraint & $r$ & & & & & & & & & & & & & & & \\
\hline & & N & & & & & & & & & & & & & & & \\
\hline 14 & DealingwithLicensesTime & $r$ & .177 & & & & & & & & & & & & & & \\
\hline & & N & 104 & & & & & & & & & & & & & & \\
\hline 15 & EnforcingContractsProcedures & $r$ & $.374^{* t}$ & .046 & & & & & & & & & & & & & \\
\hline & & N & 104 & 171 & & & & & & & & & & & & & \\
\hline 16 & TaxAdministrationAsAMajorConstraint & $r$ & $.737^{\star *}$ & .189 & $.327^{* \pi}$ & & & & & & & & & & & & \\
\hline & & N & 104 & 104 & 104 & & & & & & & & & & & & \\
\hline 17 & TypicalFirmReportsLessThanTotalSales & $r$ & .184 & .058 & $256^{*}$ & .076 & & & & & & & & & & & \\
\hline & & N & 97 & 97 & 97 & 97 & & & & & & & & & & & \\
\hline 18 & AccessCostofFinanceAsMajorConstraint & $r$ & $.587^{\star *}$ & .085 & $.344 \div$ & $.576^{*}$ & .213 & & & & & & & & & & \\
\hline & & N & 104 & 104 & 104 & 104 & 97 & & & & & & & & & & \\
\hline 19 & GlobalCompetitivenessIndex & $r$ & $-465^{*+1}$ & $.440^{* *}$ & $-.481 \div$ & $-344^{* \pi}$ & $402^{*}$ & $.560 *$ & & & & & & & & & \\
\hline & & N & 88 & 122 & 122 & 88 & 81 & 88 & & & & & & & & & \\
\hline
\end{tabular}




\begin{tabular}{|c|c|c|c|c|c|c|c|c|c|c|c|c|c|c|c|c|c|}
\hline \multicolumn{2}{|r|}{ Appendix 3 Cont'd Correlation Table } & & 13 & 14 & 15 & 16 & 17 & 18 & 19 & 20 & 21 & 22 & 23 & 24 & 25 & 26 & 27 \\
\hline \multirow[t]{2}{*}{20} & \multirow[t]{2}{*}{ GlobalCompetitivenessLaborMarketEfficiency } & $r$ & $-.272^{\star}-$ & $-.330^{* t}$ & -.424 & $-.351 \star$ & -.055 & $-.354^{* *}$ & $.670^{* t}$ & & & & & & & & \\
\hline & & N & 88 & 122 & 122 & 88 & 81 & 88 & 128 & & & & & & & & \\
\hline \multirow[t]{2}{*}{21} & \multirow[t]{2}{*}{ GlobalCompetitivenessFinancialMktSophistication } & $r$ & $-.343^{\star \star 4}-$ & -.424 & $-.547^{t+1}$ & $-.360^{* t}$ & $-.318^{*}$ & $-.417^{\star t}$ & $.848^{* \pi}$ & $.649^{*}$ & & & & & & & \\
\hline & & $N$ & 88 & 122 & 122 & 88 & 81 & 88 & 128 & 128 & & & & & & & \\
\hline \multirow[t]{2}{*}{22} & \multirow[t]{2}{*}{ RespectForIndividaulistic\&InnovativeEntrepreneurs } & $r$ & 270 & -.221 & -.079 & .332 & -.004 & .300 & .090 & .367 & .099 & & & & & & \\
\hline & & N & 13 & 30 & 30 & 13 & 11 & 13 & 30 & 30 & 30 & & & & & & \\
\hline \multirow[t]{2}{*}{23} & \multirow[t]{2}{*}{ SocialAcceptanceRespectforEntrepreneurs } & $r$ & .467 & -.036 & .044 & 479 & .535 & .478 & -.002 & .252 & -.075 & $.618^{* \pi}$ & & & & & \\
\hline & & N & 13 & 30 & 30 & 13 & 11 & 13 & 30 & 30 & 30 & 30 & & & & & \\
\hline \multirow[t]{2}{*}{24} & \multirow[t]{2}{*}{ PositivelmpressionOfGovtSupportEship } & $r$ & -.341 & $-.426^{*}$ & $-.450^{*}$ & -.223 & -.508 & -.427 & $.675^{*}$ & $477^{* t}$ & $.648^{*}$ & .141 & .171 & & & & \\
\hline & & N & 13 & 30 & 30 & 13 & 11 & 13 & 30 & 30 & 30 & 30 & 30 & & & & \\
\hline \multirow[t]{2}{*}{25} & \multirow[t]{2}{*}{ AccessibleAffordableBusinessServicesSuppliers } & $r$ & $-.746^{*+}-$ & $-.478^{* x}$ & -.284 & $-.783^{\star \star}$ & $-.630^{*}$ & $-.706^{\star *}$ & $.383^{*}$ & $454^{*}$ & .343 & $449^{*}$ & $.403^{*}$ & .266 & & & \\
\hline & & N & 13 & 30 & 30 & 13 & 11 & 13 & 30 & 30 & 30 & 30 & 30 & 30 & & & \\
\hline \multirow[t]{2}{*}{26} & \multirow[t]{2}{*}{ StrongIntellectualPropertyRights } & $r$ & $-.507-$ & $-.552^{\star *}$ & $-.536^{*+}$ & -.373 & -.419 & $-692^{\star *}$ & $.761^{\star *}$ & $.536^{*+}$ & $.722^{*}$ & 203 & .166 & $.678^{*}$ & $.447^{*}$ & & \\
\hline & & N & 13 & 30 & 30 & 13 & 11 & 13 & 30 & 30 & 30 & 30 & 30 & 30 & 30 & & \\
\hline \multirow[t]{2}{*}{27} & \multirow[t]{2}{*}{ GoodmarketopportunityandControls } & $r$ & -.120 & -.299 & -.034 & .274 & .608 & .253 & .336 & .359 & .211 & .063 & .207 & .165 & .062 & .238 & \\
\hline & & N & 13 & 30 & 30 & 13 & 11 & 13 & 30 & 30 & 30 & 30 & 30 & 30 & 30 & 30 & \\
\hline \multirow[t]{2}{*}{28} & \multirow[t]{2}{*}{ GoodAvailableEntrepreneurshipTraining } & $r$ & -.089 & -.300 & -.231 & .088 & -.357 & -.099 & $.393^{*}$ & .251 & $.395^{*}$ & $.536^{*}$ & .292 & $.382^{*}$ & .275 & .306 & .067 \\
\hline & & N & 13 & 30 & 30 & 13 & 11 & 13 & 30 & 30 & 30 & 30 & 30 & 30 & 30 & 30 & 30 \\
\hline \multirow[t]{2}{*}{29} & \multirow[t]{2}{*}{ EmployeeServicesFemale } & $r$ & -.223 & $-.258^{*}$ & $-.392^{* t}$ & -.005 & -.255 & -.056 & $.574 \div$ & $.334^{* t}$ & $.674^{* *}$ & .305 & .176 & $.546^{*}$ & $.463^{*}$ & $.539^{\star \star}$ & -.012 \\
\hline & & N & 45 & 63 & 63 & 45 & 43 & 45 & 66 & 66 & 66 & 24 & 24 & 24 & 24 & 24 & 24 \\
\hline 30 & EstimatedEearnedIncomeFemale & $r$ & $-.498^{*+}$ & $-.225 \ldots$ & $-.516^{*+1}-$ & $-.337^{\star \star}$ & $-.275^{*}$ & $-.501 *$ & $.819 *$ & $.554^{* *}$ & $.781^{*}$ & .069 & -.042 & $.557^{*+}$ & .344 & $.771^{*}$ & $.362^{*}$ \\
\hline & & N & 99 & 152 & 153 & 99 & 92 & 99 & 122 & 122 & 122 & 30 & 30 & 30 & 30 & 30 & 30 \\
\hline 31 & LaborforceParticipationMale & $r$ & $.365^{\star *}$ & .003 & $.185^{*}$ & $.303^{\star *}$ & $.303^{* t}$ & $.466^{* \pi}$ & -.140 & -.004 & -.072 & $.371^{*}$ & .187 & .014 & -.012 & -.007 & -.112 \\
\hline & & $\mathbb{N}$ & 101 & 160 & 161 & 101 & 94 & 101 & 126 & 126 & 126 & 30 & 30 & 30 & 30 & 30 & 30 \\
\hline 32 & UnemploymentFemale & $r$ & .256 & -.037 & $.289^{*}$ & .170 & -.084 & .221 & $-.457^{* t}$ & -.454 & $-.352^{*}$ & -.068 & -.202 & -.148 & -.177 & $-.445^{*}$ & $-.731 *$ \\
\hline & & $N$ & 50 & 68 & 68 & 50 & 47 & 50 & 71 & 71 & 71 & 23 & 23 & 23 & 23 & 23 & 23 \\
\hline 33 & GenderRelatedDevelopmentIndexvalue & $r$ & $-.522^{\star+4}-$ & $-.299 *$ & $-.420^{* t+}-$ & $-.395^{\star *}$ & $-.249^{*}$ & $-.696^{\star *}$ & $.820^{* t}$ & $.470^{*}$ & $.682^{*}$ & -.035 & -.209 & .355 & .226 & $.596^{\star *}$ & .332 \\
\hline & & N & 89 & 131 & 131 & 89 & 82 & 89 & 112 & 112 & 112 & 28 & 28 & 28 & 28 & 28 & 28 \\
\hline 34 & GenderEmpowermentMeasureValue & $r$ & $-.512^{\star \star}$ & $-.295^{*}$ & $-.511^{\star \star}-$ & $-.372^{\star \star}$ & $-.312^{*}$ & -.232 & $.676^{* t}$ & $.483^{*}$ & $.694^{*}$ & .053 & -.118 & $.631^{\star *}$ & .363 & $.734^{* t}$ & .218 \\
\hline & & $N$ & 48 & 72 & 72 & 48 & 42 & 48 & 72 & 72 & 72 & 25 & 25 & 25 & 25 & 25 & 25 \\
\hline 35 & GenderGaplndex & $r$ & $-.452^{\star \star t}$ & -.150 & $-.505^{*-1}-$ & $-.425^{\star t}$ & -.199 & $-.528 *$ & $.490^{* t}$ & $.462^{*}$ & $.494^{*}$ & -.166 & $-.380^{*}$ & .329 & .086 & $.454^{*}$ & .029 \\
\hline & & $N$ & 85 & 121 & 121 & 85 & 79 & 85 & 117 & 117 & 117 & 29 & 29 & 29 & 29 & 29 & 29 \\
\hline 36 & GenderGapPoliticalEmpowerment & $r$ & $-.295^{\star \star}$ & $-.206^{*}$ & $-.388^{+11-}$ & $-.302 *$ & -.126 & $-.245^{\star}$ & $.402^{*}$ & $.254^{\sharp t}$ & $.475^{* \pi}$ & -.141 & $-.401^{*}$ & .296 & -.031 & .314 & -.104 \\
\hline & & $N$ & 85 & 121 & 121 & 85 & 79 & 85 & 117 & 117 & 117 & 29 & 29 & 29 & 29 & 29 & 29 \\
\hline 37 & AdultLiteracyRateAges15andolder & $r$ & $-.458^{* t}$ & -.154 & $-.338^{*+1}-$ & $-.387^{* t}$ & $-.243^{\star *}$ & $-.727 *$ & $.543^{\star *}$ & $.377^{* t}$ & $.458^{* *}$ & -.123 & -.291 & 244 & .165 & $419^{*}$ & .236 \\
\hline & & N & 99 & 162 & 163 & 99 & 92 & 99 & 126 & 126 & 126 & 30 & 30 & 30 & 30 & 30 & 30 \\
\hline 38 & AdultLiteracyFemalesAge15andolder & $r$ & $-.495^{\star \star}$ & -.144 & -.404 & $-.410^{\star 1}$ & -.212 & $-.710^{\star *}$ & $.543^{*}$ & $.422^{\star *}$ & $.469 *$ & -.113 & -.314 & .232 & .180 & $405^{*}$ & .173 \\
\hline & & N & 92 & 138 & 138 & 92 & 85 & 92 & 118 & 118 & 118 & 29 & 29 & 29 & 29 & 29 & 29 \\
\hline
\end{tabular}




\begin{tabular}{|c|c|c|c|c|c|c|c|c|c|c|c|c|c|c|c|c|c|}
\hline \multicolumn{2}{|r|}{ Appendix 3 Cont'd Correlation Table } & & 13 & 14 & 15 & 16 & 17 & 18 & 19 & 20 & 21 & 22 & 23 & 24 & 25 & 26 & 27 \\
\hline \multirow[t]{2}{*}{39} & \multirow[t]{2}{*}{ AdultLiteracyMalesAge15andolder } & $r$ & $-.472^{\star \pi}$ & -.135 & $-.394^{*+1}-$ & $-.406^{+\pi}$ & -.189 & $-.751^{\star \star}$ & $.539 \div$ & $.389 \div$ & $.451^{\star 1}$ & -.105 & -.241 & .282 & 274 & $475^{*}$ & .308 \\
\hline & & N & 86 & 125 & 125 & 86 & 80 & 86 & 109 & 109 & 109 & 29 & 29 & 29 & 29 & 29 & 29 \\
\hline \multirow[t]{2}{*}{40} & \multirow[t]{2}{*}{ EducationCombinedPrimSecTermales } & $r$ & $-.392^{* *}$ & $-.174^{*}$ & $-.448 *$ & $-.276^{\star *}$ & $-.288^{\star \pi}$ & $-.661 *$ & $.722^{\star *}$ & $.380^{*}$ & $.612^{* *}$ & -.031 & -.273 & $.469^{*}$ & -.022 & $.596^{\star *}$ & .265 \\
\hline & & N & 96 & 154 & 155 & 96 & 89 & 96 & 121 & 121 & 121 & 29 & 29 & 29 & 29 & 29 & 29 \\
\hline \multirow[t]{2}{*}{41} & \multirow[t]{2}{*}{ PublicSpendingonEducationTotal } & $r$ & -.102 & $-.350^{* *}$ & $-.232 *$ & -.162 & $-.315^{*}$ & -.037 & $.538^{\star *}$ & $.321^{*}$ & $.527^{\star *}$ & -.197 & -.217 & .118 & .045 & $.429^{*}$ & .182 \\
\hline & & N & 62 & 99 & 100 & 62 & 56 & 62 & 82 & 82 & 82 & 25 & 25 & 25 & 25 & 25 & 25 \\
\hline \multirow[t]{2}{*}{42} & \multirow[t]{2}{*}{ GlobalCompetitivHigherEducationTraining } & $r$ & $-.470^{* 4}$ & $-.363^{*+}$ & $-.516^{*+}$ & $-.328^{\star *}$ & $-.392^{*}$ & $-.595^{*}$ & $.935^{* t}$ & $.588^{*}$ & $.810^{* *}$ & -.018 & -.184 & $.533^{\star *}$ & .252 & $.750^{* 4}$ & .357 \\
\hline & & N & 88 & 122 & 122 & 88 & 81 & 88 & 128 & 128 & 128 & 30 & 30 & 30 & 30 & 30 & 30 \\
\hline \multirow[t]{2}{*}{43} & \multirow[t]{2}{*}{ Populationages65andaboveoftotal } & $r$ & $-.435^{*+}$ & -.102 & $-.469 *$ & $-.251^{*}$ & $-.296^{*}$ & $-.507 *$ & $.626^{* t}$ & $.345^{*}$ & $.525^{\star \star *}$ & -.294 & -.322 & .196 & .116 & $.364^{*}$ & .314 \\
\hline & & N & 101 & 161 & 162 & 101 & 94 & 101 & 126 & 126 & 126 & 30 & 30 & 30 & 30 & 30 & 30 \\
\hline \multirow[t]{2}{*}{44} & \multirow[t]{2}{*}{ Ruralpopulationoftotalpopulation } & $r$ & $235^{*}$ & .130 & $.349 *$ & .110 & .198 & $290^{*}$ & $-.668 *$ & $-.326^{*+}$ & $-.586^{* t}$ & -.052 & .165 & -.059 & -.128 & -.269 & .012 \\
\hline & & N & 102 & 169 & 170 & 102 & 95 & 102 & 126 & 126 & 126 & 30 & 30 & 30 & 30 & 30 & 30 \\
\hline \multirow[t]{2}{*}{45} & \multirow[t]{2}{*}{ HumanDevelopmentlndex } & $r$ & $-.478^{*+1}$ & $-.273^{*}$ & $-.368^{* 1}$ & $-.364 \stackrel{*}{*}$ & $-.273^{* t}$ & $-698 *$ & $.802^{*}$ & $.439 *$ & $.672^{* \pi}$ & -.008 & -.172 & .361 & .226 & $.589 *$ & .332 \\
\hline & & N & 99 & 162 & 163 & 99 & 92 & 99 & 126 & 126 & 126 & 30 & 30 & 30 & 30 & 30 & 30 \\
\hline \multirow[t]{2}{*}{46} & \multirow[t]{2}{*}{ OutofPocketHealthExpenditure } & $r$ & .135 & -.030 & $243^{\star}$ & .111 & .170 & .050 & -.142 & -.081 & $-.178^{*}$ & -.272 & -.184 & -.169 & -.261 & .127 & .087 \\
\hline & & N & 100 & 165 & 166 & 100 & 93 & 100 & 123 & 123 & 123 & 29 & 29 & 29 & 29 & 29 & 29 \\
\hline \multirow[t]{2}{*}{47} & \multirow[t]{2}{*}{ PrevalenceofUndernourishmentofPopulation } & $r$ & $.205^{*}$ & $246^{\star *}$ & $.188^{*}$ & .103 & $.273^{*}$ & $.380^{* \pi}$ & $-.634^{* t}$ & $-.229 *$ & $-.509 *$ & -.085 & 237 & $-.500^{\star *}$ & -.159 & $-.551 \%$ & -.257 \\
\hline & & N & 99 & 157 & 158 & 99 & 92 & 99 & 122 & 122 & 122 & 28 & 28 & 28 & 28 & 28 & 28 \\
\hline \multirow[t]{2}{*}{48} & \multirow[t]{2}{*}{ IndexofEconomicFreedom } & $r$ & $.257^{*}$ & $.376^{* t}$ & $.441 \%$ & $.241^{*}$ & .143 & $.216^{*}$ & $-.734 *$ & $-.620 *$ & $-.782 *$ & -.261 & -.064 & $-.597^{* t}$ & $-.382^{*}$ & $-.699 \div$ & $-.391^{*}$ \\
\hline & & $\mathbb{N}$ & 95 & 141 & 141 & 95 & 88 & 95 & 123 & 123 & 123 & 30 & 30 & 30 & 30 & 30 & 30 \\
\hline 49 & GDPperCapitaConstantUS\$ & $r$ & $-.357^{* 1}$ & $-.234 *$ & -.422 & -.234 & -.220 & -.380 & .808 & .572 & .738 & .145 & .052 & .517 & .379 & .743 & .345 \\
\hline & & $\mathbb{N}$ & 102 & 168 & 169 & 102 & 95 & 102 & 127 & 127 & 127 & 30 & 30 & 30 & 30 & 30 & 30 \\
\hline 50 & GDPperCapitaPPPconstantInt|\$ & $r$ & $-.486^{*+}$ & $-.242^{*+}$ & $-.452^{\star \star}$ & $-.344^{* t}$ & $-.278^{*}$ & $-.492^{*}$ & $.844 \approx$ & $.551^{\star}$ & $.796^{* *}$ & .135 & .012 & $.590^{*+}$ & $.386^{*}$ & $.782^{\star \star t}$ & .336 \\
\hline & & N & 98 & 160 & 161 & 98 & 91 & 98 & 122 & 122 & 122 & 30 & 30 & 30 & 30 & 30 & 30 \\
\hline 51 & GDPperCapitaPPPUS\$ & $r$ & $-.481 \div$ & -.234 & $-.469 *$ & $-.343^{*}$ & $-.276^{*+}$ & $-.491 \div$ & $.823^{\star *}$ & $.531 \%$ & $.779^{* *}$ & .142 & .041 & $607^{*}$ & $.392^{*}$ & $.782^{\star t}$ & .329 \\
\hline & & $\mathbb{N}$ & 99 & 162 & 163 & 99 & 92 & 99 & 126 & 126 & 126 & 30 & 30 & 30 & 30 & 30 & 30 \\
\hline 52 & GovtConsumptionExpenditureofGDP & $r$ & .018 & -.100 & .023 & -.155 & -.153 & -.009 & $.178^{*}$ & .058 & $.211^{*}$ & $-.376^{*}$ & -.362 & .091 & -.210 & .142 & .124 \\
\hline & & $\mathbb{N}$ & 99 & 153 & 154 & 99 & 92 & 99 & 125 & 125 & 125 & 30 & 30 & 30 & 30 & 30 & 30 \\
\hline 53 & BankNonPerfomingLoans & $r$ & $.322^{* \pi}$ & $.295^{*}$ & $.265^{\star *}$ & $247^{*}$ & -.087 & $.299 *$ & $-.437^{* 1}$ & $-.426^{* t}$ & $-.499 *$ & -.079 & .141 & -.206 & -.176 & -.354 & .137 \\
\hline & & N & 69 & 98 & 98 & 69 & 62 & 69 & 92 & 92 & 92 & 29 & 29 & 29 & 29 & 29 & 29 \\
\hline 54 & DomesticCreditProvidedByBankingSector & $r$ & -.163 & $-.205^{* *}$ & $-.310^{* t+}$ & $-.201^{*}$ & $-.244^{*}$ & $-.332 *$ & $.722^{*}$ & $.460^{*}$ & $.653^{* *}$ & $.445^{*}$ & 225 & $.544^{* 1}$ & $.456^{*}$ & $418^{*}$ & .033 \\
\hline & & N & 100 & 163 & 164 & 100 & 93 & 100 & 124 & 124 & 124 & 30 & 30 & 30 & 30 & 30 & 30 \\
\hline 55 & DomesticCreditToPrivateSector & $r$ & $-.278^{* 1}$ & -.282 & $-.407^{+1+}$ & $-.330^{* t}$ & $-.319 *$ & $-.426^{\star *}$ & $.798^{\star *}$ & $.567^{*}$ & $.737^{* *}$ & $433^{*}$ & .213 & $.579 *$ & $.495^{\star *}$ & $.503^{\star *}$ & .072 \\
\hline & & $\mathbb{N}$ & 100 & 163 & 164 & 100 & 93 & 100 & 124 & 124 & 124 & 30 & 30 & 30 & 30 & 30 & 30 \\
\hline 56 & HighestMarginalTaxRate & $r$ & $-.332^{*}$ & -.140 & $-.279^{* \pi}$ & -.086 & -.045 & -.193 & $.323^{*}$ & .108 & $.294 *$ & $-.426^{*}$ & $-.407^{*}$ & .144 & -.240 & -.132 & .156 \\
\hline & & N & 58 & 86 & 86 & 58 & 52 & 58 & 82 & 82 & 82 & 27 & 27 & 27 & 27 & 27 & 27 \\
\hline 57 & ForeignDirectlnvestmentlnflows & $r$ & -.151 & -.022 & -.120 & -.078 & .048 & -.135 & .071 & .067 & .146 & 238 & .124 & -.053 & .241 & .123 & .115 \\
\hline & & $N$ & 98 & 157 & 158 & 98 & 91 & 98 & 118 & 118 & 118 & 30 & 30 & 30 & 30 & 30 & 30 \\
\hline
\end{tabular}




\begin{tabular}{|c|c|c|c|c|c|c|c|c|c|c|c|c|c|c|c|c|c|}
\hline \multicolumn{2}{|r|}{ Appendix 3 Cont'd Correlation Table } & & 13 & 14 & 15 & 16 & 17 & 18 & 19 & 20 & 21 & 22 & 23 & 24 & 25 & 26 & 27 \\
\hline \multirow[t]{2}{*}{58} & \multirow[t]{2}{*}{ ImportsOfGoods\&ServicesConstant2000US\$ } & $r$ & -.201 & -.157 & -.236 & -.084 & -.058 & $-.237^{*}$ & $.519 \div$ & $.359^{+1}$ & $.367^{+4}$ & $427^{*}$ & $.593^{*}$ & .316 & $.513^{\pi+}$ & 252 & .124 \\
\hline & & N & 91 & 133 & 134 & 91 & 84 & 91 & 110 & 110 & 110 & 29 & 29 & 29 & 29 & 29 & 29 \\
\hline \multirow[t]{2}{*}{59} & \multirow[t]{2}{*}{ ExportsOfGoodsAndServicesofGDP } & $r$ & $-.289 *$ & -.107 & $-.295^{\star \star}$ & $-.418^{*}$ & .059 & $-.370^{*}$ & $.314^{*}$ & $.373^{\star *}$ & $.376^{\star t}$ & .090 & .217 & .258 & .247 & $.366^{*}$ & .139 \\
\hline & & N & 101 & 157 & 158 & 101 & 94 & 101 & 124 & 124 & 124 & 30 & 30 & 30 & 30 & 30 & 30 \\
\hline \multirow[t]{2}{*}{60} & \multirow[t]{2}{*}{ CommercialServiceExports } & $r$ & $-.239 *$ & -.159 & $-.295^{\star \star}$ & -.105 & -.200 & $-.271^{*}$ & $.586^{\star 4}$ & $.378^{\star *}$ & $.448^{* 1}$ & 297 & $.443^{*}$ & $.368^{*}$ & $.431^{*}$ & .255 & .106 \\
\hline & & N & 88 & 138 & 138 & 88 & 81 & 88 & 114 & 114 & 114 & 30 & 30 & 30 & 30 & 30 & 30 \\
\hline \multirow[t]{2}{*}{61} & \multirow[t]{2}{*}{ ComputerCommunications\&OtherServices } & $r$ & .033 & .007 & -.123 & .050 & .166 & .149 & $.358^{\star *}$ & $.232^{*}$ & $.338^{*}$ & .026 & .302 & $.574^{*}$ & .131 & $.498^{\star \pi}$ & .331 \\
\hline & & N & 87 & 136 & 136 & 87 & 80 & 87 & 112 & 112 & 112 & 30 & 30 & 30 & 30 & 30 & 30 \\
\hline \multirow[t]{2}{*}{62} & \multirow[t]{2}{*}{ FoodExports } & $r$ & .060 & -.078 & .163 & .008 & .236 & $.370^{* *}$ & $-.465^{*}$ & -.162 & $-.300^{* *}$ & .272 & -.063 & -.285 & -.232 & $-.378^{*}$ & .141 \\
\hline & & N & 80 & 120 & 120 & 80 & 73 & 80 & 106 & 106 & 106 & 30 & 30 & 30 & 30 & 30 & 30 \\
\hline \multirow[t]{2}{*}{63} & \multirow[t]{2}{*}{ GlobalCompetitivenessBasicInfrastructure } & $r$ & $-.467^{+t}$ & $-.403^{\star *}$ & $-.470^{* t}$ & $-.383^{*}$ & $-.401 *$ & $-.505^{*}$ & $.935^{*}$ & $.614 *$ & $.830^{*}$ & .060 & -.079 & $.597^{* *}$ & $.414^{*}$ & $.665^{*}$ & .251 \\
\hline & & N & 88 & 122 & 122 & 88 & 81 & 88 & 128 & 128 & 128 & 30 & 30 & 30 & 30 & 30 & 30 \\
\hline \multirow[t]{2}{*}{64} & \multirow[t]{2}{*}{ ElectricPowerConsumption } & $r$ & $-.439 *$ & $-.273^{\star *}$ & $-.341 *$ & $-.351 *$ & $-.377^{*}$ & $-.526^{*}$ & $.693^{\star *}$ & $.541^{\star *}$ & $.643^{*}$ & .177 & -.048 & .137 & .254 & .529 & .221 \\
\hline & & N & 80 & 119 & 119 & 80 & 73 & 80 & 110 & 110 & 110 & 29 & 29 & 29 & 29 & 29 & 29 \\
\hline \multirow[t]{2}{*}{65} & \multirow[t]{2}{*}{ TelephoneMainlines } & $r$ & 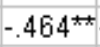 & $-.246^{\star *}$ & $-.432 *$ & $-.297^{\star *}$ & $-.232^{*}$ & $-.526^{*}$ & $.816^{* \pi}$ & $.540^{\star *}$ & $.733^{\star *}$ & .019 & -.088 & $.393^{*}$ & .333 & $.637^{* t}$ & $422^{*}$ \\
\hline & & N & 97 & 155 & 156 & 97 & 90 & 97 & 121 & 121 & 121 & 30 & 30 & 30 & 30 & 30 & 30 \\
\hline \multirow[t]{2}{*}{66} & \multirow[t]{2}{*}{ FixedLineAndMobilePhoneSubscribers } & $r$ & $-.480^{* 1}$ & $-.252^{\star+}$ & $-.476^{*+}$ & $-.343^{*}$ & $-.277^{* t}$ & $-.544 *$ & $.825^{*}$ & $.527^{* t}$ & $.781^{\star t}$ & -.040 & -.189 & $.384^{*}$ & .230 & $.644 * t$ & .332 \\
\hline & & N & 97 & 155 & 156 & 97 & 90 & 97 & 121 & 121 & 121 & 30 & 30 & 30 & 30 & 30 & 30 \\
\hline \multirow[t]{2}{*}{67} & \multirow[t]{2}{*}{ MobilePhoneSubscribers } & $r$ & $-.437^{* t}$ & $-.223^{\star *}$ & $-.449 \div$ & $-.314 *$ & $-.291 \%$ & $-.481 \div$ & $.783^{*}$ & $.476^{* t}$ & $.773^{*}$ & -.075 & -.235 & .336 & .137 & $.576^{*}$ & .236 \\
\hline & & N & 102 & 167 & 168 & 102 & 95 & 102 & 126 & 126 & 126 & 30 & 30 & 30 & 30 & 30 & 30 \\
\hline \multirow[t]{2}{*}{68} & \multirow[t]{2}{*}{ InternationallnternetBandwidth } & $r$ & $-.361 *$ & $-.201^{*}$ & $-.374^{* *}$ & $-.258^{*}$ & -.232 & $-.319 *$ & $.587^{* 1}$ & $.450^{* \pi}$ & $.559 \#$ & -.320 & -.199 & .285 & .052 & .267 & .231 \\
\hline & & N & 69 & 115 & 116 & 69 & 62 & 69 & 92 & 92 & 92 & 28 & 28 & 28 & 28 & 28 & 28 \\
\hline 69 & PersonalComputers & $r$ & $-.420^{* t}$ & $-.237^{\star *}$ & $-.464^{\star \star}$ & $-.295^{\star *}$ & $-.264^{*}$ & $-.433^{*}$ & $.856^{* *}$ & $.654^{* t}$ & $.782^{*}$ & .088 & .025 & $.522^{\star \star}$ & $.429^{*}$ & $.744^{*}$ & .364 \\
\hline & & $N$ & 88 & 142 & 143 & 88 & 82 & 88 & 113 & 113 & 113 & 29 & 29 & 29 & 29 & 29 & 29 \\
\hline 70 & PoliticalRights & $r$ & .135 & .013 & .092 & .116 & .077 & -.023 & .098 & -.023 & -.007 & .263 & .060 & -.176 & -.044 & -.116 & -.041 \\
\hline & & N & 96 & 154 & 155 & 96 & 89 & 96 & 118 & 118 & 118 & 26 & 26 & 26 & 26 & 26 & 26 \\
\hline 71 & CivilLiberties & $r$ & .118 & -.025 & .059 & .105 & .062 & -.016 & .113 & .010 & .005 & .241 & .015 & -.119 & -.046 & -.019 & .029 \\
\hline & & $N$ & 96 & 154 & 155 & 96 & 89 & 96 & 118 & 118 & 118 & 26 & 26 & 26 & 26 & 26 & 26 \\
\hline 72 & FutureOrientationSocietyPactice & $r$ & .014 & $-.279^{*}$ & $-.421 *$ & -.207 & .062 & -.246 & $.587^{\star *}$ & $.478^{* \pi}$ & $.637^{\star *}$ & .073 & .127 & $495^{*}$ & .181 & $.536^{*}$ & .173 \\
\hline & & N & 33 & 55 & 55 & 33 & 29 & 33 & 55 & 55 & 55 & 24 & 24 & 24 & 24 & 24 & 24 \\
\hline 73 & FutureorientationSocietyalues & $r$ & .306 & $288^{*}$ & $299^{*}$ & .082 & .089 & .212 & $-.632^{\star \star}$ & $-.468 \div$ & 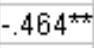 & .275 & .227 & $-.437^{*}$ & -.017 & -.295 & -.357 \\
\hline & & N & 33 & 55 & 55 & 33 & 29 & 33 & 55 & 55 & 55 & 24 & 24 & 24 & 24 & 24 & 24 \\
\hline 74 & PerformanceorientationSocietyalues & $r$ & .106 & .150 & .108 & -.031 & .141 & .124 & $-.419 *$ & $-.336^{*}$ & -.215 & -.021 & .072 & $-.495^{*}$ & -.029 & -.297 & -.156 \\
\hline & & N & 33 & 55 & 55 & 33 & 29 & 33 & 55 & 55 & 55 & 24 & 24 & 24 & 24 & 24 & 24 \\
\hline
\end{tabular}




\begin{tabular}{|c|c|c|c|c|c|c|c|c|c|c|c|c|c|c|c|c|c|}
\hline \multicolumn{2}{|r|}{ Appendix 3 Cont'd Correlation Table } & & 13 & 14 & 15 & 16 & 17 & 18 & 19 & 20 & 21 & 22 & 23 & 24 & 25 & 26 & 27 \\
\hline \multirow[t]{2}{*}{75} & \multirow[t]{2}{*}{ AssertivenessSocietyalues } & $r$ & -.007 & .087 & -.013 & -.335 & .038 & -.197 & .015 & .254 & .037 & .339 & .517 & .293 & $.488^{*}$ & 400 & .048 \\
\hline & & N & 33 & 55 & 55 & 33 & 29 & 33 & 55 & 55 & 55 & 24 & 24 & 24 & 24 & 24 & 24 \\
\hline \multirow[t]{2}{*}{76} & \multirow[t]{2}{*}{ InGroupCollectivismSocietyPractice } & $r$ & .305 & $.367^{\star *}$ & $.425^{\sharp}$ & .284 & .194 & .146 & \multicolumn{2}{|c|}{$-.687^{*+}-.480^{*}$} & $-.680^{*}$ & .135 & .286 & -.307 & -.098 & $-.407^{*}$ & -.310 \\
\hline & & N & 33 & 55 & 55 & 33 & 29 & 33 & 55 & 55 & 55 & 24 & 24 & 24 & 24 & 24 & 24 \\
\hline \multirow[t]{2}{*}{77} & \multirow[t]{2}{*}{ InGroupCollectivismSocietyalues } & $r$ & -.025 & .043 & -.008 & -.197 & .006 & .011 & -.383 & -.230 & -.248 & -.101 & -.107 & -.335 & .157 & .009 & -.233 \\
\hline & & $\mathbb{N}$ & 33 & 55 & 55 & 33 & 29 & 33 & 55 & 55 & 55 & 24 & 24 & 24 & 24 & 24 & 24 \\
\hline \multirow[t]{2}{*}{78} & \multirow[t]{2}{*}{ UncertaintyAwoidanceValues } & $r$ & .337 & $.331^{*}$ & $.470^{* \pi}$ & .204 & .099 & .186 & \multicolumn{3}{|c|}{$-.734 \%-.483^{\star \star}-.714 \%$} & .012 & .098 & $-.508^{*}$ & -.216 & \multicolumn{2}{|c|}{$-.568^{\star \star}-.413^{*}$} \\
\hline & & N & 33 & 55 & 55 & 33 & 29 & 33 & 55 & 55 & 55 & 24 & 24 & 24 & 24 & 24 & 24 \\
\hline \multirow[t]{2}{*}{79} & \multirow[t]{2}{*}{ PowerDistanceSocietyPractice } & $r$ & -.051 & $.309^{*}$ & $268^{*}$ & .136 & -.044 & .126 & \multicolumn{2}{|c|}{$-.454^{* t}-.447^{*}$} & $-.440^{* 1}$ & -.071 & .046 & -.410 & -.184 & -.377 & -.148 \\
\hline & & N & 33 & 55 & 55 & 33 & 29 & 33 & 55 & 55 & 55 & 24 & 24 & 24 & 24 & 24 & 24 \\
\hline \multirow[t]{2}{*}{80} & \multirow[t]{2}{*}{ HumaneOrientationSocietyPractice } & $r$ & -.177 & -.008 & -.120 & -.110 & -.185 & .101 & -.108 & -.080 & -.026 & -.065 & .156 & .375 & .171 & .291 & -.002 \\
\hline & & N & 33 & 55 & 55 & 33 & 29 & 33 & 55 & 55 & 55 & 24 & 24 & 24 & 24 & 24 & 24 \\
\hline \multirow[t]{2}{*}{81} & \multirow[t]{2}{*}{ TeamorientedLeadership } & $r$ & .085 & .212 & .261 & .060 & $.513^{\star *}$ & -.121 & $-.432 *$ & -.231 & $-.282^{*}$ & .233 & .173 & -.324 & -.207 & -.203 & .040 \\
\hline & & N & 33 & 55 & 55 & 33 & 29 & 33 & 55 & 55 & 55 & 24 & 24 & 24 & 24 & 24 & 24 \\
\hline \multirow[t]{2}{*}{82} & \multirow[t]{2}{*}{ ParticipativeLeadership } & $r$ & .171 & -.151 & -.245 & .079 & .201 & .321 & .207 & .048 & $.303^{*}$ & .035 & .028 & .146 & -.102 & .022 & $.486^{*}$ \\
\hline & & N & 33 & 55 & 55 & 33 & 29 & 33 & 55 & 55 & 55 & 24 & 24 & 24 & 24 & 24 & 24 \\
\hline \multirow[t]{2}{*}{83} & \multirow[t]{2}{*}{ HumaneOrientedLeadership } & $r$ & .267 & .176 & .103 & .022 & .317 & -.143 & -.287 & .006 & -.068 & $.493^{\star \pi}$ & .446 & .116 & .260 & .215 & -.107 \\
\hline & & $N$ & 33 & 55 & 55 & 33 & 29 & 33 & 55 & 55 & 55 & 24 & 24 & 24 & 24 & 24 & 24 \\
\hline \multirow[t]{2}{*}{84} & AutonomousLeadership & $r$ & -.109 & .250 & -.089 & -.095 & -.122 & -.214 & -.075 & .075 & -.035 & .021 & -.180 & .192 & $.440^{*}$ & .344 & .245 \\
\hline & & N & 33 & 55 & 55 & 33 & 29 & 33 & 55 & 55 & 55 & 24 & 24 & 24 & 24 & 24 & 24 \\
\hline 85 & SelfProtectiveLeadership & $r$ & .285 & $.343^{*}$ & $.472^{*}$ & .303 & .347 & .002 & $-.554^{*}$ & -.291 & $-.586^{*}$ & .112 & .214 & $-.476^{*}$ & -.036 & $-.476^{*}$ & -.280 \\
\hline & & $N$ & 33 & 55 & 55 & 33 & 29 & 33 & 55 & 55 & 55 & 24 & 24 & 24 & 24 & 24 & 24 \\
\hline 86 & SocialCynism & $r$ & -.139 & .011 & .183 & -.008 & -.067 & -.062 & $-.363^{*}$ & -.246 & $-.351^{*}$ & -.196 & -.224 & -.154 & -.096 & -.224 & -.007 \\
\hline & & N & 22 & 38 & 38 & 22 & 18 & 22 & 37 & 37 & 37 & 17 & 17 & 17 & 17 & 17 & 17 \\
\hline 87 & SocialComplexity & $r$ & -.218 & $-.417^{* \pi}$ & -.416 & -.190 & .023 & -.221 & $.629 \approx$ & .290 & $.515^{\star *}$ & -.304 & -.272 & $.541^{*}$ & .193 & 298 & -.045 \\
\hline & & N & 22 & 38 & 38 & 22 & 18 & 22 & 37 & 37 & 37 & 17 & 17 & 17 & 17 & 17 & 17 \\
\hline 88 & RewardforApplication & $r$ & .140 & .218 & $.450^{* 1}$ & -.113 & .242 & -.084 & $-.341^{*}$ & -.048 & -.191 & .223 & .311 & .143 & .309 & .244 & .131 \\
\hline & & $N$ & 22 & 38 & 38 & 22 & 18 & 22 & 37 & 37 & 37 & 17 & 17 & 17 & 17 & 17 & 17 \\
\hline 89 & Religiosity & $r$ & .329 & .257 & $.336^{*}$ & .225 & .465 & .205 & $-.457^{\#}$ & -.049 & -.262 & $.570^{*}$ & $.599^{*}$ & -.253 & .208 & .056 & .439 \\
\hline & & N & 22 & 38 & 38 & 22 & 18 & 22 & 37 & 37 & 37 & 17 & 17 & 17 & 17 & 17 & 17 \\
\hline 90 & FateControl & $r$ & .043 & .253 & .211 & -.120 & .074 & -.174 & -.310 & -.025 & $-.356^{\star}$ & .093 & .185 & .225 & .078 & -.141 & .261 \\
\hline & & $\mathbb{N}$ & 22 & 38 & 38 & 22 & 18 & 22 & 37 & 37 & 37 & 17 & 17 & 17 & 17 & 17 & 17 \\
\hline
\end{tabular}




\begin{tabular}{|c|c|c|c|c|c|c|c|c|c|c|c|c|c|c|c|c|}
\hline \multicolumn{2}{|r|}{ Appendix 3 Cont'd Correlation Table } & & 28 & 29 & 30 & 31 & 32 & 33 & 34 & 35 & 36 & 37 & 38 & 39 & 40 & 41 \\
\hline \multirow[t]{2}{*}{20} & \multirow[t]{2}{*}{ GlobalCompetitivenessLabormarketEfficiency } & $r$ & & & & & & & & & & & & & & \\
\hline & & N & & & & & & & & & & & & & & \\
\hline \multirow[t]{2}{*}{21} & \multirow[t]{2}{*}{ GlobalCompetitivenessFinancialmktSophistication } & $r$ & & & & & & & & & & & & & & \\
\hline & & $\mathbb{N}$ & & & & & & & & & & & & & & \\
\hline \multirow[t]{2}{*}{22} & \multirow{2}{*}{ RespectF orIndividaulistic\&InnovativeEntrepreneurs } & $r$ & & & & & & & & & & & & & & \\
\hline & & N & & & & & & & & & & & & & & \\
\hline \multirow[t]{2}{*}{23} & \multirow[t]{2}{*}{ SocialAcceptanceRespectforEntrepreneurs } & $r$ & & & & & & & & & & & & & & \\
\hline & & N & & & & & & & & & & & & & & \\
\hline \multirow[t]{2}{*}{24} & \multirow[t]{2}{*}{ PositivelmpressionofGovtSupportEship } & $r$ & & & & & & & & & & & & & & \\
\hline & & N & & & & & & & & & & & & & & \\
\hline \multirow[t]{2}{*}{25} & \multirow[t]{2}{*}{ AccessibleAffordableBusinessServicesSuppliers } & $r$ & & & & & & & & & & & & & & \\
\hline & & N & & & & & & & & & & & & & & \\
\hline \multirow[t]{2}{*}{26} & \multirow[t]{2}{*}{ StrongIntellectualPropertyRights } & $r$ & & & & & & & & & & & & & & \\
\hline & & N & & & & & & & & & & & & & & \\
\hline \multirow[t]{2}{*}{27} & \multirow[t]{2}{*}{ GoodmarketOpportunityandControls } & $r$ & & & & & & & & & & & & & & \\
\hline & & N & & & & & & & & & & & & & & \\
\hline \multirow[t]{2}{*}{28} & \multirow[t]{2}{*}{ GoodAvailableEntrepreneurshipTraining } & $r$ & & & & & & & & & & & & & & \\
\hline & & N & & & & & & & & & & & & & & \\
\hline \multirow[t]{2}{*}{29} & \multirow[t]{2}{*}{ EmployeeServicesFemale } & $r$ & 201 & & & & & & & & & & & & & \\
\hline & & N & 24 & & & & & & & & & & & & & \\
\hline 30 & EstimatedEearnedIncomeFemale & $r$ & .307 & $.663^{*}$ & & & & & & & & & & & & \\
\hline & & N & 30 & 66 & & & & & & & & & & & & \\
\hline 31 & LaborforceParticipationMale & $r$ & -.110 & .094 & $-.223^{\star \star}$ & & & & & & & & & & & \\
\hline & & N & 30 & 70 & 159 & & & & & & & & & & & \\
\hline 32 & UnemploymentFemale & $r$ & -.098 & -.117 & $-.378^{* \$}$ & -.055 & & & & & & & & & & \\
\hline & & N & 23 & 61 & 71 & 74 & & & & & & & & & & \\
\hline 33 & GenderRelatedDevelopmentIndexvalue & $r$ & .335 & $.743^{\star *}$ & $.745^{\star *}$ & $-.389 *$ & $-.250^{*}$ & & & & & & & & & \\
\hline & & N & 28 & 61 & 136 & 135 & 66 & & & & & & & & & \\
\hline 34 & GenderEmpowermentMeasurevalue & $r$ & .074 & $.737^{* *}$ & $.844^{* t}$ & .036 & -.228 & $.714^{*}$ & & & & & & & & \\
\hline & & N & 25 & 55 & 75 & 75 & 54 & 70 & & & & & & & & \\
\hline 35 & GenderGaplndex & $r$ & -.084 & $.527^{\star *}$ & $.570^{\star *}$ & $-.195^{\star}$ & -.217 & $.580^{\star 4}$ & $.817^{*}$ & & & & & & & \\
\hline & & N & 29 & 65 & 123 & 127 & 69 & 115 & 74 & & & & & & & \\
\hline 36 & GenderGapPoliticalEmpowerment & $r$ & -.124 & $.484^{\star *}$ & $.503^{\star \star}$ & .050 & -.113 & $.324 *$ & $.673^{* *}$ & $.728^{\star *}$ & & & & & & \\
\hline & & N & 29 & 65 & 123 & 127 & 69 & 115 & 74 & 127 & & & & & & \\
\hline 37 & AdultLiteracyRateAges15andolder & $r$ & .284 & $444 \div$ & $.531^{\star \prime}$ & $-.457^{\star \star}$ & $-.247^{*}$ & $.860^{* *}$ & $.614^{* *}$ & $.653^{* t}$ & $.221^{*}$ & & & & & \\
\hline & & N & 30 & 68 & 160 & 167 & 72 & 136 & 75 & 126 & 126 & & & & & \\
\hline 38 & AdultLiteracyFemalesAge15andolder & $r$ & .325 & $.553^{\star *}$ & $.542^{\star 4}$ & $-.437^{\star *}$ & -.121 & $861^{\star 4}$ & $.647^{*+}$ & $.696^{* *}$ & $.238^{\star *}$ & $.992^{\star *}$ & & & & \\
\hline & & $\mathbb{N}$ & 29 & 65 & 141 & 144 & 68 & 136 & 73 & 121 & 121 & 146 & & & & \\
\hline
\end{tabular}




\begin{tabular}{|c|c|c|c|c|c|c|c|c|c|c|c|c|c|c|c|c|}
\hline \multicolumn{2}{|r|}{ Appendix 3 Cont'd Correlation Table } & & 28 & 29 & 30 & 31 & 32 & 33 & 34 & 35 & 36 & 37 & 38 & 39 & 40 & 41 \\
\hline \multirow[t]{2}{*}{39} & \multirow[t]{2}{*}{ AdultLiteracylualesAge15andolder } & $r$ & .228 & $.360^{* 4}$ & $.516^{\star *}$ & $-.427^{* 1}$ & -.164 & $.843^{\star+}$ & $.530^{* \pi}$ & $.599 \div$ & $.226^{*}$ & $984^{* 4}$ & $.958^{\star *}$ & & & \\
\hline & & N & 29 & 63 & 128 & 130 & 66 & 123 & 67 & 112 & 112 & 132 & 132 & & & \\
\hline \multirow[t]{2}{*}{40} & \multirow[t]{2}{*}{ EducationCombinedPrimSecTermales } & $r$ & .344 & $.602^{\star *}$ & $.681 *$ & $-.382^{\star *}$ & $-.370^{*+}$ & $.863^{\star *}$ & $.683^{*}$ & $.595^{\star *}$ & $.353^{\star *}$ & $.767^{\star *}$ & $.777^{\star *}$ & $.759 *$ & & \\
\hline & & N & 29 & 66 & 154 & 159 & 71 & 136 & 72 & 123 & 123 & 164 & 141 & 127 & & \\
\hline \multirow[t]{2}{*}{41} & \multirow[t]{2}{*}{ PublicSpendingonEducationTotal } & $r$ & -.322 & $.354^{*}$ & $458 *$ & -.171 & -.251 & $469 *$ & $.590^{* *}$ & $406^{*+}$ & $.321 *$ & $.379 \div$ & $.410 \div$ & $.398^{\star *}$ & $.349^{* *}$ & \\
\hline & & N & 25 & 52 & 98 & 102 & 55 & 86 & 54 & 83 & 83 & 103 & 90 & 84 & 103 & \\
\hline \multirow[t]{2}{*}{42} & \multirow[t]{2}{*}{ GlobalCompetitivHigherEducationTraining } & $r$ & .358 & $613^{*}$ & $.819 *$ & $-.254^{* t}$ & $-.406^{\star *}$ & $.888^{*}$ & $.733^{*}$ & $.598^{\star *}$ & $.415^{*}$ & $.680^{*}$ & $.680^{*}$ & $.657^{*}$ & $.837^{\star *}$ & $.624 \stackrel{*}{*}$ \\
\hline & & N & 30 & 66 & 122 & 126 & 71 & 112 & 72 & 117 & 117 & 126 & 118 & 109 & 121 & 82 \\
\hline \multirow[t]{2}{*}{43} & \multirow[t]{2}{*}{ Populationages65andaboveoftotal } & $r$ & .070 & .384 & .734 & $-.455^{\star *}$ & $-.278^{*}$ & $.760 *$ & $.616^{*}$ & $.587^{*}$ & $.376^{*}$ & $.627 *$ & $.637^{*}$ & $.611 *$ & $.706^{\star *}$ & $.306^{*}$ \\
\hline & & N & 30 & 70 & 159 & 172 & 74 & 135 & 75 & 127 & 127 & 167 & 144 & 130 & 159 & 102 \\
\hline \multirow[t]{2}{*}{44} & \multirow[t]{2}{*}{ Ruralpopulationoftotalpopulation } & $r$ & $-.362^{*}$ & $-.689 *$ & $-.586^{*}$ & $.229 *$ & .171 & $-.697^{*}$ & $-.456^{*}$ & $-.354^{*}$ & $-.188^{*}$ & $-.494^{*}$ & $-.510^{* *}$ & $-.538 *$ & $-.560^{*}$ & $-.214^{*}$ \\
\hline & & N & 30 & 71 & 160 & 172 & 74 & 136 & 75 & 127 & 127 & 173 & 146 & 132 & 164 & 107 \\
\hline \multirow[t]{2}{*}{45} & \multirow[t]{2}{*}{ HumanDevelopmentlndex } & $r$ & .343 & $.726^{\star *}$ & $.734^{*}$ & $-.396^{* *}$ & $-.363^{*+}$ & $9995^{\star H}$ & $.712^{\star \star}$ & $.563^{\star *}$ & $.317^{*}$ & $.859 *$ & $.851^{\star *}$ & $.837^{*}$ & $.859 \star *$ & $.407^{*}$ \\
\hline & & $N$ & 30 & 68 & 160 & 167 & 72 & 136 & 75 & 126 & 126 & 173 & 146 & 132 & 164 & 103 \\
\hline \multirow[t]{2}{*}{46} & \multirow[t]{2}{*}{ OutofPocketHealthExpenditure } & $r$ & $-.508^{\star *}$ & $-.248^{*}$ & $-.179 *$ & .095 & -.110 & -.088 & -.097 & -.162 & -.081 & -.098 & -.154 & -.103 & -.143 & .018 \\
\hline & & N & 29 & 68 & 156 & 167 & 71 & 134 & 74 & 124 & 124 & 169 & 143 & 129 & 161 & 104 \\
\hline \multirow[t]{2}{*}{47} & \multirow[t]{2}{*}{ PrevalenceofUndernourishmentofPopulation } & $r$ & $-.521 *$ & $-.425 * \pi$ & $-.505^{*}$ & $.370^{*}$ & $.275^{\star}$ & $-.735^{*+}$ & $-.441 \div$ & $-.342^{*}$ & -.173 & $-.557^{* 1}$ & $-.530^{* *}$ & $-.518^{*}$ & $-.632 *$ & $-.391 *$ \\
\hline & & N & 28 & 67 & 151 & 162 & 72 & 129 & 74 & 123 & 123 & 162 & 138 & 125 & 156 & 99 \\
\hline \multirow[t]{2}{*}{48} & \multirow[t]{2}{*}{ IndexofEconomicFreedom } & $r$ & $-.449^{*}$ & $-.614 *$ & $-.765^{\star *}$ & $.183^{*}$ & $.364 *$ & $-.677^{*+}$ & $-.719 *$ & $-.462^{*+}$ & $-.374 *$ & $-.437^{* 1}$ & $-.444 *$ & $-.378^{\star \star}$ & $-.545^{\star \star}$ & $-.394 *$ \\
\hline & & $N$ & 30 & 68 & 144 & 149 & 72 & 125 & 75 & 123 & 123 & 149 & 133 & 122 & 143 & 94 \\
\hline 49 & GDPperCapitaConstantUS $\$$ & $r$ & .297 & .632 & .947 & -.062 & -.413 & .671 & .726 & .453 & .455 & .436 & $.444^{\star *}$ & $.425^{\star *}$ & $.580^{* *}$ & $.305^{*}$ \\
\hline & & N & 30 & 67 & 157 & 166 & 72 & 135 & 75 & 126 & 126 & 167 & 142 & 129 & 159 & 103 \\
\hline 50 & GDPperCapitaPPPconstantInt|\$ & $r$ & $.396^{*}$ & $.664 *$ & $979 *$ & $-.198^{*}$ & $-.384^{* *}$ & $.775^{\star *}$ & $.782^{\star *}$ & $491 *$ & $.438 \div$ & $.538 \div$ & $.552^{\star *}$ & $.530^{*}$ & $.675^{\star *}$ & $.396^{\star *}$ \\
\hline & & $N$ & 30 & 66 & 156 & 159 & 71 & 135 & 75 & 125 & 125 & 163 & 140 & 127 & 157 & 101 \\
\hline 51 & GDPperCapitaPPPUS $\$$ & $r$ & $404^{*}$ & $.654^{*}$ & $978^{\star *}$ & $-.184^{*}$ & $-.359 *$ & $.757^{\star *}$ & $.775^{\star *}$ & $469 *$ & $.420 \approx$ & $.522 *$ & $.528 *$ & $.506^{*}$ & $.653^{\star \star}$ & $.378^{*}$ \\
\hline & & $N$ & 30 & 68 & 160 & 167 & 72 & 136 & 75 & 126 & 126 & 173 & 146 & 132 & 164 & 103 \\
\hline 52 & GovtConsumptionExpenditureofGDP & $r$ & -.135 & $.326^{*}$ & $.300^{*}$ & $-.173^{*}$ & .104 & $.360^{\star *}$ & $.514 *$ & $.352^{\star *}$ & $.256^{* *}$ & .156 & .354 & $.314^{*}$ & .154 & $.541 \%$ \\
\hline & & $N$ & 30 & 67 & 146 & 155 & 72 & 127 & 73 & 122 & 122 & 154 & 136 & 125 & 147 & 99 \\
\hline 53 & BankNonPerfomingLoans & $r$ & -.217 & $-.574 *$ & $-.534 *$ & .184 & .123 & $-.562^{*}$ & $-.536^{*}$ & $-.451^{* t}$ & $-.334 *$ & $-.495^{\star *}$ & $-.501 *$ & $-.421 *$ & $-.516^{*}$ & -.236 \\
\hline & & $N$ & 29 & 56 & 98 & 99 & 60 & 89 & 64 & 91 & 91 & 98 & 93 & 87 & 94 & 68 \\
\hline 54 & DomesticCreditProvidedBy日ankingSector & $r$ & $.487^{*}$ & $450^{*+}$ & $.629 \div$ & .012 & $-.246^{*}$ & $.629 \div$ & $.462^{*}$ & $.299 \div$ & $.276^{\star *}$ & $.404 \div$ & $418^{*}$ & $.393^{*}$ & $.507^{* *}$ & $.325^{\star *}$ \\
\hline & & N & 30 & 69 & 155 & 164 & 74 & 132 & 75 & 123 & 123 & 166 & 140 & 127 & 159 & 102 \\
\hline 55 & DomesticCreditToPrivateSector & $r$ & $.444^{*}$ & $.514 *$ & $.739 * 4$ & -.050 & $-.318^{*+}$ & $.658^{\star *}$ & $.557^{*}$ & $.374 *$ & $.347^{*+}$ & $.456^{* \pi}$ & $.448 \div$ & $.427^{*+}$ & $.569 *$ & $.399^{*}$ \\
\hline & & $N$ & 30 & 69 & 155 & 164 & 74 & 132 & 75 & 123 & 123 & 166 & 140 & 127 & 159 & 102 \\
\hline 56 & HighestMarginalTaxRate & $r$ & -.083 & .044 & $.369 *$ & -.170 & -.025 & $403^{\star 4}$ & $.496^{\star *}$ & $.341^{*}$ & $.285^{*}$ & $.377^{* *}$ & $.471^{\star *}$ & $.501 *$ & $.428^{\star *}$ & $.330^{*}$ \\
\hline & & $N$ & 27 & 56 & 91 & 92 & 58 & 82 & 58 & 81 & 81 & 93 & 85 & 80 & 90 & 65 \\
\hline 57 & ForeignDirectlnvestmentInflows & $r$ & .182 & -.082 & $.347^{\star \star}$ & -.089 & -.054 & .108 & -.051 & .020 & -.038 & .104 & .101 & .094 & .080 & -.103 \\
\hline & & N & 30 & 66 & 153 & 160 & 71 & 130 & 71 & 120 & 120 & 161 & 138 & 125 & 154 & 101 \\
\hline
\end{tabular}




\begin{tabular}{|c|c|c|c|c|c|c|c|c|c|c|c|c|c|c|c|c|}
\hline \multicolumn{2}{|r|}{ Appendix 3 Cont'd Correlation Table } & & 28 & 29 & 30 & 31 & 32 & 33 & 34 & 35 & 36 & 37 & 38 & 39 & 40 & 41 \\
\hline \multirow{2}{*}{58} & \multirow[t]{2}{*}{ ImportsOfGoods\&ServicesConstant2000US\$ } & $r$ & $494^{* \pi}$ & $.316^{*}$ & $473^{*}$ & -.015 & -.210 & $357^{*+}$ & $.318^{\star 4}$ & .173 & .100 & $241^{\star 1}$ & $.231^{*}$ & $230^{*}$ & $322^{\star 1}$ & .145 \\
\hline & & N & 29 & 62 & 130 & 135 & 69 & 115 & 69 & 113 & 113 & 135 & 121 & 111 & 130 & 86 \\
\hline \multirow[t]{2}{*}{59} & \multirow[t]{2}{*}{ ExportsofGoodsAndServicesofGDP } & $r$ & .096 & .067 & $298 \div$ & -.123 & -.203 & .259 & .025 & .076 & -.075 & $299 *$ & $.285^{*}$ & $.282^{\star *}$ & .160 & .098 \\
\hline & & N & 30 & 67 & 148 & 156 & 72 & 128 & 72 & 122 & 122 & 157 & 137 & 126 & 150 & 99 \\
\hline \multirow[t]{2}{*}{60} & \multirow[t]{2}{*}{ CommercialServiceExports } & $r$ & $.495^{\star *}$ & $.332^{\star *}$ & $.587^{*}$ & -.047 & -.207 & $413^{\star *}$ & $.408^{* 1}$ & $.242^{*}$ & .206 & $266^{\star *}$ & $.270^{* *}$ & $273^{\star *}$ & $.369 *$ & .115 \\
\hline & & N & 30 & 66 & 136 & 141 & 70 & 117 & 72 & 113 & 113 & 145 & 125 & 115 & 139 & 90 \\
\hline \multirow[t]{2}{*}{61} & \multirow[t]{2}{*}{ ComputerCommunications\&OtherServices } & $r$ & .347 & $384 *$ & $.340^{* *}$ & .036 & -.217 & .020 & $411^{*}$ & $.196^{*}$ & $291^{\star}$ & -.030 & -.061 & .008 & -.045 & .056 \\
\hline & & N & 30 & 65 & 134 & 139 & 69 & 115 & 71 & 111 & 111 & 143 & 123 & 113 & 137 & 89 \\
\hline \multirow[t]{2}{*}{62} & \multirow[t]{2}{*}{ FoodExports } & $r$ & -.039 & .086 & $-.302^{\star \star}$ & $.396^{*}$ & .059 & $-.389 *$ & .054 & .022 & .021 & $-.196^{*}$ & $-.211^{*}$ & $-336^{\star \star}-$ & $-.306^{* t}$ & .152 \\
\hline & & N & 30 & 65 & 119 & 123 & 68 & 106 & 71 & 107 & 107 & 125 & 112 & 104 & 122 & 85 \\
\hline \multirow[t]{2}{*}{63} & \multirow{2}{*}{ GlobalCompetitivenessBasicInfrastructure } & $r$ & $.381^{*}$ & $.586^{\star *}$ & $811^{*}$ & -.112 & $-.372^{*}$ & $.760^{*}$ & $.620^{*}$. & $.425^{*}$ & $.356^{*}$ & $.477^{* *}$ & $.491 \%$ & $477^{*}$ & $.640^{* *}$ & $.495^{* \pi}$ \\
\hline & & $N$ & 30 & 66 & 122 & 126 & 71 & 112 & 72 & 117 & 117 & 126 & 118 & 109 & 121 & 82 \\
\hline \multirow[t]{2}{*}{64} & \multirow{2}{*}{ ElectricPowerConsumption } & $r$ & .064 & $.514^{*}$ & $.825^{* *}$ & -.029 & $-.345^{\star \star}$ & $.650^{* *}$ & $638^{*}$ & $.474^{*}$ & $453^{*}$ & $.445^{* \pi}$ & $.446^{* *}$ & $.432^{*}$ & $.554^{\star *}$ & $.470^{* \pi}$ \\
\hline & & N & 29 & 63 & 123 & 127 & 67 & 111 & 72 & 111 & 111 & 125 & 117 & 107 & 119 & 75 \\
\hline \multirow[t]{2}{*}{65} & \multirow[t]{2}{*}{ TelephoneMainlines } & $r$ & .204 & $597^{* 1}$ & $.896^{* \prime}-$ & $-.301^{*}$ & $-.419 *$ & $.850 *$ & $.724^{*}$ & $.546^{*}$ & $402^{*}$ & $.648^{* *}$ & $.656^{*}$ & $617^{*}$ & $.748^{*}$ & $.342^{* t}$ \\
\hline & & N & 30 & 70 & 148 & 157 & 73 & 129 & 74 & 123 & 123 & 159 & 138 & 126 & 152 & 98 \\
\hline \multirow[t]{2}{*}{66} & \multirow{2}{*}{ FixedLineAndMobilePhoneSubscribers } & $r$ & .209 & $606^{* *}$ & $.898 *-$ & $-.325^{\star \star}$ & $-.381^{*}$ & $.867^{*}$ & $.723^{*}$ & $.537^{* 1}$ & $.385^{*}$ & $.653^{* *}$ & $.669 *$ & $621^{*}$ & $.753^{*}$ & $.352^{*}$ \\
\hline & & $N$ & 30 & 70 & 148 & 157 & 73 & 129 & 74 & 123 & 123 & 159 & 138 & 126 & 152 & 98 \\
\hline \multirow[t]{2}{*}{67} & \multirow{2}{*}{ MobilePhoneSubscribers } & $r$ & .190 & $.575^{*}$ & $841^{*-}-$ & $-.291^{\star *}$ & $-.291^{*}$ & $784^{* 1}$ & $674^{*}$ & $495^{*}$ & $.365^{*}$ & $.561^{*}$ & $.572^{*}$ & $.543^{\#}$ & $.658^{* *}$ & $.284^{* \pi}$ \\
\hline & & N & 30 & 71 & 159 & 169 & 74 & 135 & 75 & 127 & 127 & 171 & 145 & 131 & 163 & 105 \\
\hline \multirow[t]{2}{*}{68} & \multirow{2}{*}{ InternationallnternetBandwidth } & $r$ & -.153 & $.369^{* 4}$ & $631 \%$ & -.017 & $-.288^{*}$ & $.414^{* *}$ & $603^{*}$ & $.464^{*}$ & $493^{*}$ & $.272^{\star *}$ & $272^{*}$ & $.244^{*}$ & $423^{*}$ & $.353^{* \pi}$ \\
\hline & & N & 28 & 57 & 110 & 118 & 59 & 96 & 63 & 94 & 94 & 118 & 104 & 97 & 113 & 77 \\
\hline 69 & PersonalComputers & $r$ & .336 & $.595^{\star *}$ & $.903^{* *}$ & $-.182^{*}$ & $-.415^{\star \star}$ & $.706^{*}$ & $.708^{*}$ & $.515^{\star *}$ & $.442^{*}$ & $.509 *$ & $521^{*}$ & $479 \#$ & $649 \div$ & $.336^{*}$ \\
\hline & & N & 29 & 68 & 137 & 144 & 70 & 120 & 71 & 113 & 113 & 145 & 126 & 116 & 142 & 97 \\
\hline 70 & PoliticalRights & $r$ & .176 & .048 & .026 & .059 & .110 & .094 & .026 & -.131 & -.180 & .043 & .033 & .022 & .017 & .186 \\
\hline & & N & 26 & 61 & 147 & 156 & 65 & 125 & 66 & 117 & 117 & 158 & 135 & 122 & 150 & 97 \\
\hline 71 & CivilLiberties & $r$ & .160 & .081 & .046 & .047 & .070 & .116 & .078 & -.083 & -.135 & .056 & .063 & .034 & .022 & .187 \\
\hline & & N & 26 & 61 & 147 & 156 & 65 & 125 & 66 & 117 & 117 & 158 & 135 & 122 & 150 & 97 \\
\hline 72 & FutureOrientationSocietyPactice & $r$ & .129 & $.406^{*}$ & $440^{* 4}$ & .253 & -.222 & .194 & $435^{*}$ & $.267^{*}$ & $.372^{\star 4}$ & .090 & .092 & .149 & .261 & .300 \\
\hline & & N & 24 & 39 & 56 & 56 & 38 & 51 & 42 & 55 & 55 & 56 & 54 & 52 & 53 & 42 \\
\hline 73 & FutureOrientationSocietyalues & $r$ & .342 & $-.497^{* 1+}$ & $-683^{*}$ & .047 & .045 & $-.607^{\star \star}$ & $.688^{\star *}-$ & $-.519^{*}$ & $.429 *$ & $-.506^{*}$ & $-488^{* 1+}$ & $.482^{\star \star}-$ & $-.600 *$ & $.438^{*}$ \\
\hline & & N & 24 & 39 & 56 & 56 & 38 & 51 & 42 & 55 & 55 & 56 & 54 & 52 & 53 & 42 \\
\hline 74 & PerformanceorientationSocietyvalues & $r$ & .232 & .214 & -.234 & .071 & .108 & $-.305^{\star}$ & .025 & .066 & .075 & -.247 & -.170 & -.229 & $-.327^{*}$ & .093 \\
\hline & & N & 24 & 39 & 56 & 56 & 38 & 51 & 42 & 55 & 55 & 56 & 54 & 52 & 53 & 42 \\
\hline
\end{tabular}




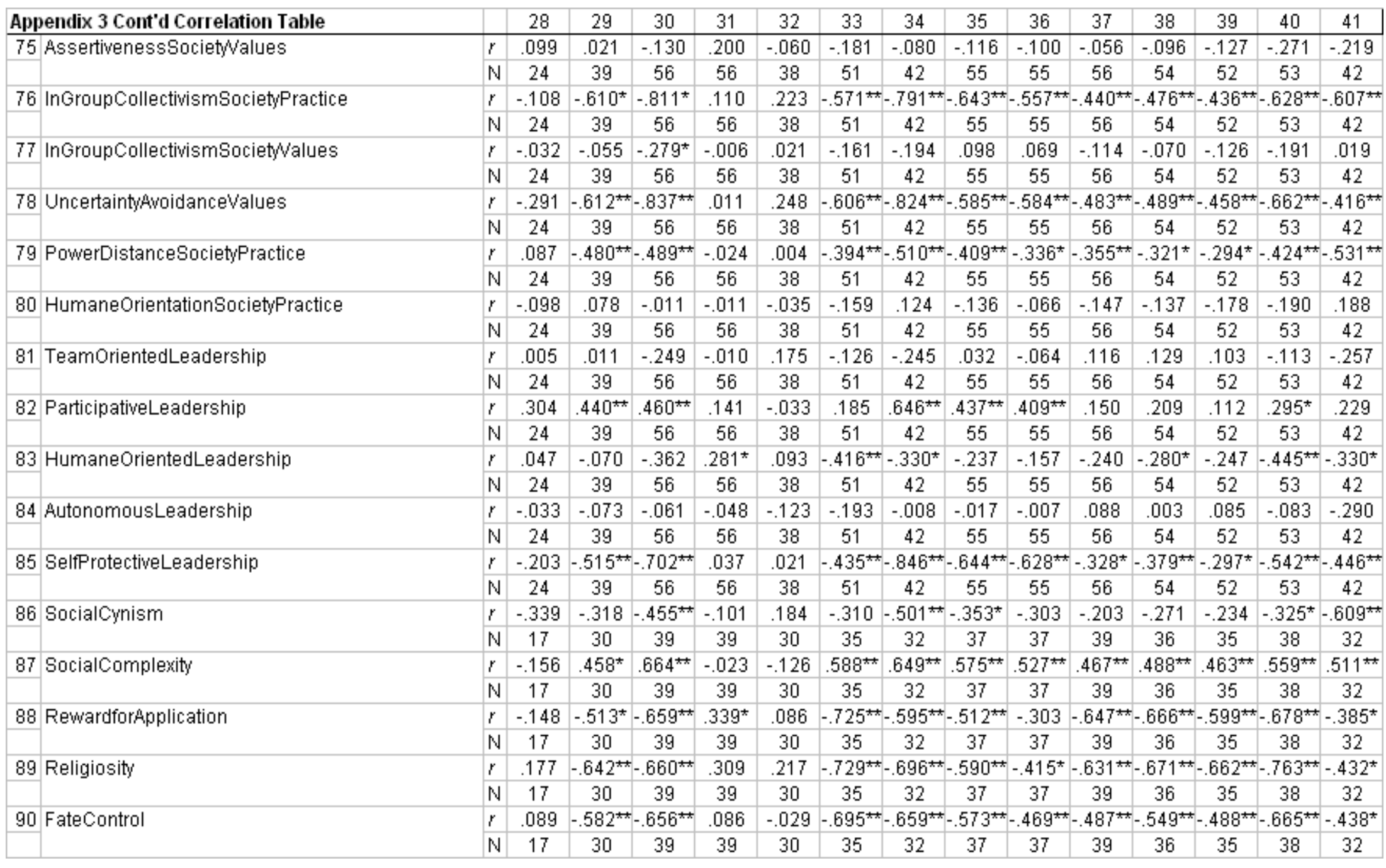




\begin{tabular}{|c|c|c|c|c|c|c|c|c|c|c|c|c|c|c|c|c|c|}
\hline \multicolumn{2}{|r|}{ Appendix 3 Cont'd Correlation Table } & & 42 & 43 & 44 & 45 & 46 & 47 & 48 & 49 & 50 & 51 & 52 & 53 & 54 & 55 & 56 \\
\hline \multirow[t]{2}{*}{39} & \multirow[t]{2}{*}{ AdultLiteracymalesAge15andolder } & $r$ & & & & & & & & & & & & & & & \\
\hline & & $N$ & & & & & & & & & & & & & & & \\
\hline \multirow[t]{2}{*}{40} & \multirow[t]{2}{*}{ EducationCombinedPrimSecTermales } & $r$ & & & & & & & & & & & & & & & \\
\hline & & N & & & & & & & & & & & & & & & \\
\hline \multirow[t]{2}{*}{41} & \multirow[t]{2}{*}{ PublicSpendingonEducationTotal } & $r$ & & & & & & & & & & & & & & & \\
\hline & & N & & & & & & & & & & & & & & & \\
\hline \multirow[t]{2}{*}{42} & \multirow[t]{2}{*}{ GlobalCompetitivHigherEducationTraining } & $r$ & & & & & & & & & & & & & & & \\
\hline & & N & & & & & & & & & & & & & & & \\
\hline \multirow[t]{2}{*}{43} & \multirow[t]{2}{*}{ Populationages65andaboveoftotal } & $r$ & $.736^{*}$ & & & & & & & & & & & & & & \\
\hline & & N & 126 & & & & & & & & & & & & & & \\
\hline \multirow[t]{2}{*}{44} & \multirow[t]{2}{*}{ Ruralpopulationoftotalpopulation } & $r$ & $-699 * \pi$ & $-.496^{* x}$ & & & & & & & & & & & & & \\
\hline & & N & 126 & 173 & & & & & & & & & & & & & \\
\hline \multirow[t]{2}{*}{45} & \multirow[t]{2}{*}{ HumanDevelopmentlndex } & $r$ & $.873^{*}$ & $.739 *$ & $-.659 *$ & & & & & & & & & & & & \\
\hline & & N & 126 & 167 & 173 & & & & & & & & & & & & \\
\hline \multirow[t]{2}{*}{46} & \multirow[t]{2}{*}{ OutOfPocketHealthExpenditure } & $r$ & -.089 & .002 & .057 & -.057 & & & & & & & & & & & \\
\hline & & N & 123 & 168 & 179 & 169 & & & & & & & & & & & \\
\hline \multirow[t]{2}{*}{47} & \multirow[t]{2}{*}{ PrevalenceofUndernourishmentofPopulation } & $r$ & $-.673^{*+}$ & $-.559 * 1$ & $.564 *$ & $-.741 *$ & .087 & & & & & & & & & & \\
\hline & & N & 122 & 162 & 167 & 162 & 164 & & & & & & & & & & \\
\hline \multirow[t]{2}{*}{48} & \multirow[t]{2}{*}{ IndexofEconomicFreedom } & $r$ & $-.721^{\star+}$ & $-.571^{\star x}$ & $.503^{\star \star-}$ & $-.638^{\star *}$ & $.184^{*}$ & $.485^{\star *}$ & & & & & & & & & \\
\hline & & $\mathbb{N}$ & 123 & 149 & 150 & 149 & 147 & 144 & & & & & & & & & \\
\hline 49 & GDPperCapitaConstantUS\$ & $r$ & $.754^{*}$ & $.606^{* 1}$ & $-.574^{\star \star}$ & $.662^{*}$ & -.149 & $-.431^{\star \star}$ & $-.719 *$ & & & & & & & & \\
\hline & & $\mathbb{N}$ & 127 & 167 & 174 & 167 & 169 & 161 & 145 & & & & & & & & \\
\hline 50 & GDPperCapitaPPPconstantInt|\$ & $r$ & $.823^{*}$ & $.696^{* 1}$ & $-.639 *$ & $.764 \%$ & $-.192^{*}$ & $-.535^{\star \star}$ & $-.781^{\star \star}$ & $.962^{*}$ & & & & & & & \\
\hline & & $\mathrm{N}$ & 122 & 160 & 166 & 163 & 162 & 154 & 143 & 166 & & & & & & & \\
\hline 51 & GDPperCapitaPPPUS\$ & $r$ & $.800^{*}$ & $.685^{*}$ & $-.591^{\star \star t}$ & $.744 *$ & $-.193^{*}$ & $-.513^{\star \star}$ & $-.753^{\star \star}$ & $.956^{\star *}$ & $.995^{* \pi}$ & & & & & & \\
\hline & & N & 126 & 167 & 173 & 173 & 169 & 162 & 149 & 167 & 163 & & & & & & \\
\hline 52 & GovtConsumptionExpenditureofGDP & $r$ & $.251 *$ & $.183^{*}$ & -.117 & .141 & $-.195^{\star}$ & -.102 & $-.300^{*}$ & $.167^{*}$ & $.266^{\star *}$ & $.201^{*}$ & & & & & \\
\hline & & N & 125 & 155 & 159 & 154 & 154 & 150 & 139 & 158 & 150 & 154 & & & & & \\
\hline 53 & BankNonPerfomingLoans & $r$ & $-.430^{*}$ & $-.437^{*+1}$ & $.425^{*}$ & $-.559 *$ & .126 & $.332^{\star 4}$ & $.569^{* *}$ & $-.480^{*+}$ & $-.533^{*+}$ & $-.519 *$ & $-.225^{*}$ & & & & \\
\hline & & N & 92 & 99 & 99 & 98 & 96 & 97 & 97 & 100 & 97 & 98 & 99 & & & & \\
\hline 54 & DomesticCreditProvidedByBankingSector & $r$ & $.664^{*}$ & $.472^{*}$ & $-.387^{* *}$ & $.592^{*}$ & -.118 & $-.325^{*}$ & $-.607 *$ & $.601 \%$ & $.622^{\star *}$ & $.635^{\star *}$ & $.275^{\star *}$ & $-.294 * t$ & & & \\
\hline & & $\mathbb{N}$ & 124 & 165 & 170 & 166 & 165 & 158 & 144 & 169 & 162 & 166 & 154 & 99 & & & \\
\hline 55 & Domestic CreditToPrivateSector & $r$ & $.725^{*}$ & $.547^{* t}$ & $-.467^{* t}$ & $.659 *$ & $-.179^{*}$ & $-.468 *$ & $-.692 \pi$ & $.740^{* t}$ & $.745^{\star *}$ & $.740^{* *}$ & $.237^{* t}$ & -.364 & $.866^{\star *}$ & & \\
\hline & & $\mathbb{N}$ & 124 & 165 & 170 & 166 & 165 & 158 & 144 & 169 & 162 & 166 & 154 & 99 & 172 & & \\
\hline 56 & HighestMarginalTaxRate & $r$ & $.402^{*}$ & $.412^{\star t}$ & .091 & $.315^{\star *}$ & -.023 & -.087 & -.174 & $.256^{*}$ & $.267^{*}$ & $.296^{*}$ & $.265^{*}$ & -.165 & $.325^{\star *}$ & $.288^{\star *}$ & \\
\hline & & N & 82 & 92 & 95 & 93 & 91 & 87 & 87 & 91 & 91 & 93 & 88 & 70 & 92 & 92 & \\
\hline 57 & ForeignDirectlnvestmentInflows & $r$ & .017 & .088 & -.115 & .116 & .008 & -.037 & -.168 & $.310^{* *}$ & $.334^{*}$ & $.405^{\star *}$ & -.056 & -.115 & .063 & .068 & .027 \\
\hline & & $\mathrm{N}$ & 118 & 160 & 164 & 161 & 160 & 155 & 140 & 161 & 157 & 161 & 150 & 96 & 159 & 159 & 87 \\
\hline
\end{tabular}




\begin{tabular}{|c|c|c|c|c|c|c|c|c|c|c|c|c|c|c|c|c|c|}
\hline \multicolumn{2}{|r|}{ Appendix 3 Cont'd Correlation Table } & & 42 & 43 & 44 & 45 & 46 & 47 & 48 & 49 & 50 & 51 & 52 & 53 & 54 & 55 & 56 \\
\hline \multirow[t]{2}{*}{58} & \multirow[t]{2}{*}{ ImportsOfGoods\&ServicesConstant2000US\$ } & $r$ & $.418^{\#+1}$ & $.350^{*}$ & $-.274^{* 1}$ & $.359^{\#-}$ & $-.261^{\star \prime}$ & $-.230 \div$ & $-.345^{* \prime \prime}$ & $.500^{\#}$ & $.468 \div$ & $.467^{\text {tht}}$ & .078 & $-.204^{*}$ & $.560^{\#+}$ & $.572^{\text {t }}$ & .200 \\
\hline & & N & 110 & 135 & 138 & 135 & 133 & 133 & 126 & 137 & 133 & 135 & 136 & 94 & 134 & 134 & 80 \\
\hline \multirow[t]{2}{*}{59} & \multirow[t]{2}{*}{ ExportsOfGoodsAndServicesofGDP } & $r$ & $.280^{\star *}$ & .108 & $-.303^{\star *}$ & $.293^{\star *}$ & .000 & $-.259 *$ & $-.320^{*+}$ & $.318^{\star t}$ & $.366^{*}$ & $.359 \star 3$ & -.020 & -.137 & .093 & $.225^{\star *}$ & -.179 \\
\hline & & N & 124 & 156 & 163 & 157 & 158 & 153 & 139 & 162 & 155 & 157 & 159 & 100 & 158 & 158 & 89 \\
\hline \multirow[t]{2}{*}{60} & \multirow[t]{2}{*}{ CommercialServiceExports } & $r$ & $.496^{\star \pi}$ & $.453^{\pi}$ & $-.316^{\star *}$ & $.399 *$ & $-.235^{\star \star}$ & $-.270^{\star \star}$ & $-.422^{\star \Delta}$ & $.608^{*}$ & $.582^{\text {\# }}$ & $.577^{\star *}$ & .148 & $-.257^{*}$ & $.574^{*}$ & $.610^{\star \star *}$ & $.265^{\star}$ \\
\hline & & $N$ & 114 & 141 & 146 & 145 & 142 & 138 & 130 & 144 & 141 & 145 & 134 & 93 & 145 & 145 & 84 \\
\hline \multirow[t]{2}{*}{61} & \multirow{2}{*}{ ComputerCommunications\&OtherServices } & $r$ & $.308^{* t}$ & .185 & -.042 & .015 & -.027 & -.097 & $-.190^{*}$ & $.339 *$ & $.286^{* t}$ & $.319 *$ & .130 & -.184 & $.178^{*}$ & $.217^{* \pi}$ & .183 \\
\hline & & N & 112 & 139 & 144 & 143 & 140 & 136 & 128 & 142 & 139 & 143 & 132 & 92 & 143 & 143 & 83 \\
\hline \multirow[t]{2}{*}{62} & \multirow[t]{2}{*}{ FoodExports } & $r$ & $-.424^{* t}$ & $-.345^{\star \pi}$ & $.346^{* t}$ & $-.352^{* \pi}$ & -.007 & $.398^{*}$ & .170 & $-.285^{\star \star}$ & $-.337^{* t}$ & $-.327^{* t}$ & .056 & .075 & -.128 & $-.191 *$ & -.115 \\
\hline & & $N$ & 106 & 123 & 128 & 125 & 124 & 121 & 115 & 126 & 124 & 125 & 120 & 88 & 126 & 126 & 82 \\
\hline \multirow[t]{2}{*}{63} & \multirow[t]{2}{*}{ GlobalCompetitivenessBasicInfrastructure } & $r$ & $.865^{\star *}$ & $.600^{*}$ & $-.618^{* *}$ & $.739^{*}$ & $-.213^{*}$ & $-.536^{*}$ & $-.737^{* t}$ & $.815^{\star t}$ & $.852^{*}$ & $.830 *$ & $.196^{*}$ & $-.426 *$ & $.762^{*}$ & $.826^{\star \star}$ & $.329 *$ \\
\hline & & N & 128 & 126 & 126 & 126 & 123 & 122 & 123 & 127 & 122 & 126 & 125 & 92 & 124 & 124 & 82 \\
\hline \multirow[t]{2}{*}{64} & \multirow{2}{*}{ ElectricPowerConsumption } & $r$ & $.704^{\star *}$ & $.490^{*}$ & $-.535^{\star *}$ & $.645^{\star \prime}$ & -.134 & $-.436^{*}$ & $-.620^{*+}$ & $.838^{\star \Delta}$ & $.836^{*}$ & $.818^{\star x}$ & $477^{* t}$ & $-.441 *$ & $.484 *$ & $.576^{\star *}$ & .142 \\
\hline & & N & 110 & 127 & 127 & 125 & 124 & 123 & 122 & 124 & 121 & 125 & 120 & 95 & 121 & 121 & 81 \\
\hline \multirow[t]{2}{*}{65} & \multirow[t]{2}{*}{ TelephoneMainlines } & $r$ & $.865^{\star \star *}$ & $.821^{\text {t }}$ & $-.606^{\star \star}$ & $.835^{\star \star}$ & -.059 & $-.604 *$ & $-.746^{\star \pi}$ & $.814^{* t}$ & $.875^{\star \star *}$ & $.856^{\star \star}$ & $.281^{*}$ & $-.509 *$ & $.671^{\star *}$ & $.760^{* t}$ & $.316^{* \pi}$ \\
\hline & & N & 121 & 158 & 167 & 159 & 161 & 152 & 140 & 160 & 155 & 159 & 149 & 99 & 160 & 160 & 89 \\
\hline \multirow[t]{2}{*}{66} & \multirow[t]{2}{*}{ FixedLineAndMobilePhoneSubscribers } & $r$ & $.872^{*}$ & $.794^{*}$ & $-.659 *$ & $.853^{\star *}$ & -.061 & $-.629 *$ & $-.808^{\star \prime}$ & $.822^{\star t}$ & $.906^{*}$ & $.891^{\star}$ & $.289 \div$ & $-.519 \#$ & $.618^{*}$ & $.726^{* t}$ & $272^{*}$ \\
\hline & & $N$ & 121 & 158 & 167 & 159 & 161 & 152 & 140 & 160 & 155 & 159 & 149 & 99 & 160 & 160 & 89 \\
\hline \multirow[t]{2}{*}{67} & \multirow[t]{2}{*}{ MobilePhoneSubscribers } & $r$ & $.821^{\#}$ & $.745^{\#}$ & $-.637^{\star \star}$ & .768 & -.095 & -.591 \# & $-.800^{* 1}$ & $.780^{\star \prime}$ & $.871^{\#}$ & $.847^{\star *}$ & $.301^{*}$ & $-.490 *$ & $.528^{* \prime}$ & $.673^{\star \star}$ & $.211^{*}$ \\
\hline & & $N$ & 126 & 170 & 182 & 171 & 175 & 164 & 148 & 173 & 165 & 171 & 158 & 99 & 170 & 170 & 94 \\
\hline \multirow[t]{2}{*}{681} & \multirow{2}{*}{ InternationallnternetBandwidth } & $r$ & $.578^{*}$ & $.457^{\star *}$ & $-.360^{* t}$ & $.417^{\star \star}$ & -.092 & $-.250^{*}$ & $-.520^{\star x}$ & $.623^{\star \Delta}$ & $.588^{\star \prime}$ & $.572^{\star *}$ & $.257^{*}$ & $-.337^{\star H}$ & $.422^{\star \pi}$ & $.525^{\star \star}$ & $.337^{\star \prime}$ \\
\hline & & $N$ & 92 & 119 & 125 & 118 & 119 & 114 & 106 & 120 & 115 & 118 & 112 & 82 & 121 & 121 & 70 \\
\hline 69 & PersonalComputers & $r$ & $.826^{*}$ & $.655^{*}$ & $-.574^{* t}$ & $.695^{\star \star}$ & $-.203^{*}$ & $-.468 *$ & $-.755^{\star \star}$ & $.893^{\#+}$ & $.892^{*}$ & $.875^{*}$ & $.289 \div$ & $-.512^{\star \star}$ & $.648^{* 1}$ & $.757^{\star *}$ & $.335^{\#-1}$ \\
\hline & & N & 113 & 144 & 151 & 145 & 146 & 140 & 128 & 149 & 144 & 145 & 138 & 90 & 145 & 145 & 83 \\
\hline 70 & PoliticalRights & $r$ & .084 & .029 & $-.180^{*}$ & .083 & .054 & -.107 & .037 & .085 & .092 & .056 & -.036 & .024 & .068 & .044 & -.062 \\
\hline & & N & 118 & 157 & 168 & 158 & 161 & 151 & 137 & 159 & 151 & 158 & 145 & 91 & 156 & 156 & 87 \\
\hline 71 & CivilLiberties & $r$ & .108 & .047 & -.187 & .094 & .079 & -.090 & .015 & .110 & .112 & .073 & -.027 & .000 & .039 & .034 & -.084 \\
\hline & & N & 118 & 157 & 168 & 158 & 161 & 151 & 137 & 159 & 151 & 158 & 145 & 91 & 156 & 156 & 87 \\
\hline 72 & FutureOrientationSocietyPactice & $r$ & $.480^{* 1}$ & .125 & -.196 & .226 & -.098 & -.183 & $-.453^{\star *}$ & $.519 *$ & $.431^{\star *}$ & $.441 *$ & .144 & -.167 & $.539 *$ & $.581^{\star \star}$ & .095 \\
\hline & & N & 55 & 56 & 56 & 56 & 54 & 54 & 55 & 56 & 56 & 56 & 56 & 52 & 56 & 56 & 47 \\
\hline 73 & FutureorientationSocietyalues & $r$ & $-.669 *$ & $-.625 *$ & $.320^{*}$ & $-.602^{*}$ & .015 & $.469 *$ & $.539 *$ & $-.632^{*+}$ & $-.632^{* \pi}$ & $-.633^{*+}-$ & $-.377^{*}$ & $.444^{* \pi}$ & $-.466^{\star *}$ & $-.536^{* t}$ & $-.361^{*}$ \\
\hline & & N & 55 & 56 & 56 & 56 & 54 & 54 & 55 & 56 & 56 & 56 & 56 & 52 & 56 & 56 & 47 \\
\hline 74 & PerformanceorientationSocietyalues & $r$ & $-.367^{* t}$ & $-.298^{*}$ & .181 & $-.316^{*}$ & -.184 & .373 & .188 & $-.289^{*}$ & -.255 & -.256 & .010 & .167 & -.349 & $-.309^{*}$ & .023 \\
\hline & & N & 55 & 56 & 56 & 56 & 54 & 54 & 55 & 56 & 56 & 56 & 56 & 52 & 56 & 56 & 47 \\
\hline
\end{tabular}




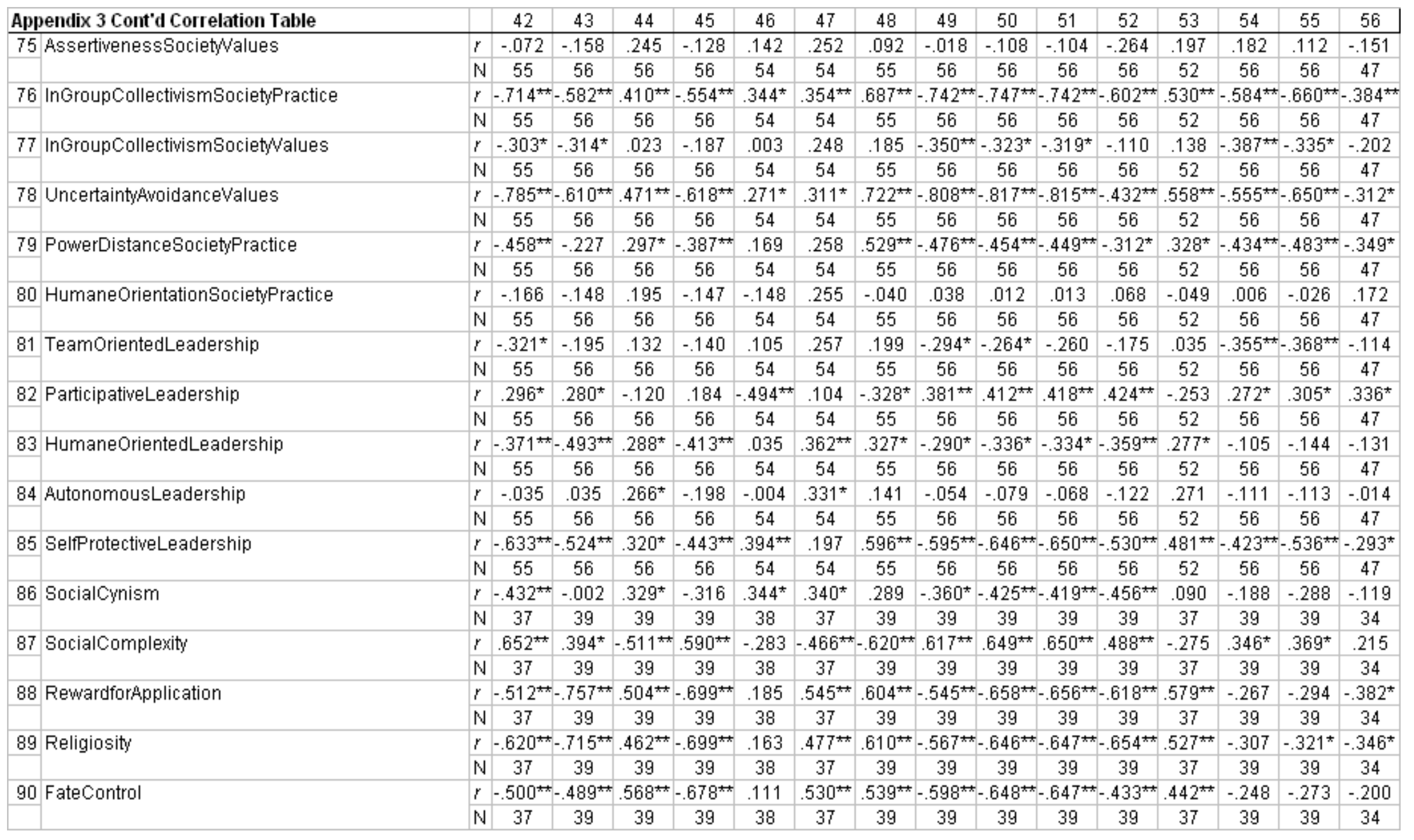




\begin{tabular}{|c|c|c|c|c|c|c|c|c|c|c|c|c|c|c|c|c|c|c|c|}
\hline \multicolumn{2}{|r|}{ Appendix 3 Cont'd Correlation Table } & & 57 & 58 & 59 & 60 & 61 & 62 & 63 & 64 & 65 & 66 & 67 & 68 & 69 & 70 & 71 & 72 & 73 \\
\hline \multirow{2}{*}{\multicolumn{2}{|c|}{58 ImportsOfGoods\&ServicesConstant2000US\$ }} & $r$ & -.040 & & & & & & & & & & & & & & & & \\
\hline & & N & 135 & & & & & & & & & & & & & & & & \\
\hline \multirow[t]{2}{*}{59} & \multirow[t]{2}{*}{ ExportsOfGoodsAndServicesofGDP } & $r$ & $.360^{*}$ & -.059 & & & & & & & & & & & & & & & \\
\hline & & N & 153 & 137 & & & & & & & & & & & & & & & \\
\hline \multirow[t]{2}{*}{60} & \multirow[t]{2}{*}{ CommercialServiceExports } & $r$ & .009 & $.948^{*+}$ & -.027 & & & & & & & & & & & & & & \\
\hline & & N & 138 & 116 & 137 & & & & & & & & & & & & & & \\
\hline \multirow[t]{2}{*}{61} & \multirow[t]{2}{*}{ ComputerCommunications\&OtherServices } & $r$ & $.175^{*}$ & $.279^{\star *}$ & .163 & $.309^{* \pi}$ & & & & & & & & & & & & & \\
\hline & & N & 137 & 115 & 135 & 144 & & & & & & & & & & & & & \\
\hline \multirow[t]{2}{*}{62} & \multirow[t]{2}{*}{ FoodExports } & $r$ & -.052 & $-.248^{*}$ & -.171 & $-.263^{\sharp \pi}$ & $-.187^{*}$ & & & & & & & & & & & & \\
\hline & & N & 124 & 108 & 120 & 116 & 115 & & & & & & & & & & & & \\
\hline \multirow[t]{2}{*}{63} & \multirow[t]{2}{*}{ GlobalCompetitivenessBasicInfrastructure } & $r$ & .109 & $.511^{*}$ & $.347^{t+t}$ & $.577^{* \pi}$ & $.300^{*}$ & $-.379^{*+}$ & & & & & & & & & & & \\
\hline & & N & 118 & 110 & 124 & 114 & 112 & 106 & & & & & & & & & & & \\
\hline \multirow[t]{2}{*}{64} & \multirow[t]{2}{*}{ ElectricPowerConsumption } & $r$ & $.226^{*}$ & $.307^{* t}$ & $.215^{\star}$ & $.360^{*}$ & $.246^{\star *}$ & -.184 & $.684^{* *}$ & & & & & & & & & & \\
\hline & & N & 119 & 111 & 120 & 113 & 111 & 105 & 110 & & & & & & & & & & \\
\hline \multirow[t]{2}{*}{65} & \multirow[t]{2}{*}{ TelephoneMainlines } & $r$ & .133 & $.475^{\star *}$ & $.249 *$ & $.526^{\star *}$ & $.179^{*}$ & $-.305^{* 1}$ & $.820^{*}$ & $.745^{\#}$ & & & & & & & & & \\
\hline & & N & 152 & 133 & 153 & 138 & 136 & 123 & 121 & 122 & & & & & & & & & \\
\hline \multirow[t]{2}{*}{66} & \multirow[t]{2}{*}{ FixedLineAndMobilePhoneSubscribers } & $r$ & .210 & $.379 \$$ & $.371^{* t}$ & $.464 * \pi$ & .168 & $-.343^{\star \pi}$ & $.827^{* \pi}$ & $.757^{* \pi}$ & $.932^{*}$ & & & & & & & & \\
\hline & & N & 152 & 133 & 153 & 138 & 136 & 123 & 121 & 122 & 168 & & & & & & & & \\
\hline \multirow[t]{2}{*}{67} & \multirow[t]{2}{*}{ MobilePhoneSubscribers } & $r$ & $.223^{*}$ & $.311^{*}$ & $.408^{*}$ & $.405^{*}$ & .151 & $-.339 *$ & $.785^{\star *}$ & $.714^{\star *}$ & $.837^{* t}$ & $.978^{*}$ & & & & & & & \\
\hline & & N & 163 & 138 & 163 & 145 & 143 & 128 & 126 & 126 & 168 & 168 & & & & & & & \\
\hline \multirow[t]{2}{*}{68} & \multirow[t]{2}{*}{ InternationallnternetBandwidth } & $r$ & .005 & $239^{*}$ & .170 & $.373^{*}$ & $.375^{*}$ & -.178 & $.559 *$ & $.416^{*}$ & $.582^{\star \star}$ & $.564 \approx$ & $.520^{* *}$ & & & & & & \\
\hline & & N & 113 & 105 & 115 & 101 & 99 & 97 & 92 & 94 & 126 & 126 & 126 & & & & & & \\
\hline 69 & PersonalComputers & $r$ & .161 & $.510^{* t}$ & $.242^{*}$ & $.591^{*}$ & $.345^{\star *}$ & $-.319^{*+}$ & $.818^{*}$ & $.741^{*}$ & $.860^{* *}$ & $.823^{*}$ & $.752^{\star \star}$ & $.655^{\star *}$ & & & & & \\
\hline & & N & 141 & 123 & 141 & 124 & 122 & 119 & 113 & 110 & 145 & 145 & 152 & 112 & & & & & \\
\hline 70 & PoliticalRights & $r$ & .090 & .108 & .062 & .078 & -.030 & .003 & .090 & .025 & -.009 & .014 & .041 & -.033 & .001 & & & & \\
\hline & & N & 148 & 123 & 149 & 133 & 131 & 112 & 118 & 114 & 150 & 150 & 164 & 111 & 135 & & & & \\
\hline 71 & CivilLiberties & $r$ & .098 & .092 & .081 & .067 & -.079 & .004 & .103 & .066 & .012 & .034 & .053 & -.003 & .027 & $.967^{\star *}$ & & & \\
\hline & & $N$ & 148 & 123 & 149 & 133 & 131 & 112 & 118 & 114 & 150 & 150 & 164 & 111 & 135 & 170 & & & \\
\hline 72 & 2 FutureOrientationSocietyPactice & $r$ & .006 & $271^{*}$ & $.388^{* t}$ & $.296^{\star}$ & $.514^{*}$ & $-.367^{* \pi}$ & $.555^{\star \star}$ & $.366^{\star *}$ & $.377^{* \pi}$ & $.343^{*}$ & $.298^{*}$ & $.515^{\star \star}$ & $.567^{\text {t\#}}$ & -.095 & -.089 & & \\
\hline & & N & 55 & 55 & 55 & 52 & 52 & 53 & 55 & 56 & 56 & 56 & 56 & 48 & 53 & 49 & 49 & & \\
\hline 73 & 3 FutureorientationSocietyalues & $r$ & .076 & $-.293^{*}$ & .016 & $-.347^{*}$ & $-.398^{*}$ & $.288^{*}$ & $-.538^{\star t}$ & $-.518^{*}$ & $-.721 *$ & $-.627^{*+}$ & $-.524^{* \star}$ & $-.671^{* x}$ & $-.685^{*+}$ & -.135 & -.243 & $-.375^{* *}$ & \\
\hline & & N & 55 & 55 & 55 & 52 & 52 & 53 & 55 & 56 & 56 & 56 & 56 & 48 & 53 & 49 & 49 & 56 & \\
\hline 74 & 4 PerformanceorientationSocietyalues & $r$ & -.156 & -.160 & -.153 & -.156 & -.108 & .301 & $-.331^{*}$ & -.185 & $-.314^{*}$ & $-.303^{*}$ & $-.274^{*}$ & -.281 & $-.346^{*}$ & .077 & .077 & -.168 & $.419 *$ \\
\hline & & N & 55 & 55 & 55 & 52 & 52 & 53 & 55 & 56 & 56 & 56 & 56 & 48 & 53 & 49 & 49 & 56 & 56 \\
\hline
\end{tabular}




\begin{tabular}{|c|c|c|c|c|c|c|c|c|c|c|c|c|c|c|c|c|c|c|c|}
\hline \multicolumn{2}{|r|}{ Appendix 3 Cont'd Correlation Table } & & 57 & 58 & 59 & 60 & 61 & 62 & 63 & 64 & 65 & 66 & 67 & 68 & 69 & 70 & 71 & 72 & 73 \\
\hline \multirow[t]{2}{*}{75} & \multirow[t]{2}{*}{ AssertivenessSocietyalues } & $r$ & .214 & .175 & .223 & .117 & .014 & -.213 & -.023 & -.071 & -.163 & -.179 & -.176 & -.179 & -.042 & .102 & .043 & .219 & .049 \\
\hline & & N & 55 & 55 & 55 & 52 & 52 & 53 & 55 & 56 & 56 & 56 & 56 & 48 & 53 & 49 & 49 & 56 & 56 \\
\hline \multirow[t]{2}{*}{76} & \multirow[t]{2}{*}{ InGroupCollectivismSocietyPractice } & $r$ & .224 & $-.340^{*}$ & .081 & $-.433^{* *}$ & $-.471^{\star *}$ & .062 & $-.686^{*+}$ & $-.667^{\star *}$ & $-.737^{* 1}$ & $-657^{\star t}$ & $\star-.561 \star \star$ & $-673^{*+}$ & $-.820^{* *}$ & .094 & .013 & $-.428^{*}$ & $.637^{+t}$ \\
\hline & & N & 55 & 55 & 55 & 52 & 52 & 53 & 55 & 56 & 56 & 56 & 56 & 48 & 53 & 49 & 49 & 56 & 56 \\
\hline \multirow[t]{2}{*}{77} & \multirow[t]{2}{*}{ InGroupCollectivismSocietyalues } & $r$ & -.157 & -.245 & -.195 & -.267 & $-.406^{* *}$ & $.470^{*+}$ & $-.371^{\star \star}$ & -.204 & $-.299^{*}$ & $-.320^{*}$ & $-.310^{*}$ & -.267 & $-.328^{*}$ & $-.293^{*}$ & -.251 & $\star-.359 * \star$ & $.474^{\star t}$ \\
\hline & & N & 55 & 55 & 55 & 52 & 52 & 53 & 55 & 56 & 56 & 56 & 56 & 48 & 53 & 49 & 49 & 56 & 56 \\
\hline \multirow[t]{2}{*}{78} & \multirow[t]{2}{*}{ UncertaintyAwoidanceValues } & $r$ & .141 & $-.338^{*}$ & -.102 & $-.446^{*+}$ & $-.553^{\star \star}$ & .150 & $-.701^{* t}$ & -.709 & $-.783^{*}$ & $-.728 *$ & $\star-.642^{* *}$ & $-.659 *$ & $-.847^{\star t}$ & .049 & -.046 & $-.523^{* \star}$ & $.681 \%$ \\
\hline & & N & 55 & 55 & 55 & 52 & 52 & 53 & 55 & 56 & 56 & 56 & 56 & 48 & 53 & 49 & 49 & 56 & 56 \\
\hline \multirow[t]{2}{*}{79} & \multirow[t]{2}{*}{ PowerDistanceSocietyPractice } & $r$ & .031 & -.136 & -.123 & -.143 & -.209 & .120 & $-.351^{* t}$ & $-.413^{*}$ & $-.414 \approx$ & $-.384 *$ & $-.338^{*}$ & $-647^{* t}$ & $-.578 *$ & .073 & .039 & $-.510^{* *}$ & $.650^{\#+}$ \\
\hline & & N & 55 & 55 & 55 & 52 & 52 & 53 & 55 & 56 & 56 & 56 & 56 & 48 & 53 & 49 & 49 & 56 & 56 \\
\hline \multirow[t]{2}{*}{80} & \multirow[t]{2}{*}{ HumaneOrientationSocietyPractice } & $r$ & -.174 & -.007 & -.072 & -.051 & -.063 & .010 & -.021 & .045 & -.025 & -.083 & -.113 & -.144 & -.023 & -.142 & -.137 & -.122 & .003 \\
\hline & & N & 55 & 55 & 55 & 52 & 52 & 53 & 55 & 56 & 56 & 56 & 56 & 48 & 53 & 49 & 49 & 56 & 56 \\
\hline \multirow[t]{2}{*}{81} & \multirow[t]{2}{*}{ TeamorientedLeadership } & $r$ & -.038 & -.260 & -.108 & -.246 & -.173 & $.275^{*}$ & $-.423^{\star x}$ & -.210 & -.248 & -.207 & -.167 & -.164 & $-.310^{*}$ & -.077 & -.107 & -.136 & $297^{*}$ \\
\hline & & N & 55 & 55 & 55 & 52 & 52 & 53 & 55 & 56 & 56 & 56 & 56 & 48 & 53 & 49 & 49 & 56 & 56 \\
\hline \multirow[t]{2}{*}{82} & \multirow[t]{2}{*}{ ParticipativeLeadership } & $r$ & $-.268^{*}$ & .191 & -.135 & $.311^{*}$ & $297^{*}$ & $.316^{*}$ & $.320^{*}$ & $.353^{*}$ & $.385^{* \star}$ & $.289^{*}$ & .210 & $.309^{*}$ & $.346^{*}$ & -.002 & .079 & .209 & -.251 \\
\hline & & N & 55 & 55 & 55 & 52 & 52 & 53 & 55 & 56 & 56 & 56 & 56 & 48 & 53 & 49 & 49 & 56 & 56 \\
\hline \multirow[t]{2}{*}{83} & \multirow[t]{2}{*}{3 Hun } & $r$ & .066 & -.043 & .126 & -.059 & -.055 & .109 & $-.299^{*}$ & -.241 & $-.369 *$ & $-.425 *$ & $-.429 \div$ & $-.285^{\star}$ & $-.305^{*}$ & -.107 & -.213 & .220 & 394 \\
\hline & & N & 55 & 55 & 55 & 52 & 52 & 53 & 55 & 56 & 56 & 56 & 56 & 48 & 53 & 49 & 49 & 56 & 56 \\
\hline \multirow[t]{2}{*}{84} & \multirow[t]{2}{*}{ AutonomousLeadership } & $r$ & .188 & -.040 & .131 & .012 & .016 & -.119 & -.041 & -.039 & -.055 & -.083 & -.093 & -.008 & .050 & -.097 & -.082 & .013 & -.048 \\
\hline & & N & 55 & 55 & 55 & 52 & 52 & 53 & 55 & 56 & 56 & 56 & 56 & 48 & 53 & 49 & 49 & 56 & 56 \\
\hline \multirow[t]{2}{*}{85} & 5 SelfProtectiveLeadership & $r$ & .162 & -.208 & -.036 & $-.330^{*}$ & $-.421^{\star *}$ & .036 & $-.599 *$ & $-.549 *$ & $-.607 * \pi$ & $-.589 *$ & $-.536^{*}$ & $-.565^{\star \star}$ & $-.613^{* *}$ & .084 & -.041 & $-.350^{* *}$ & $.497^{\star t}$ \\
\hline & & $\mathrm{N}$ & 55 & 55 & 55 & 52 & 52 & 53 & 55 & 56 & 56 & 56 & 56 & 48 & 53 & 49 & 49 & 56 & 56 \\
\hline 86 & SocialCynism & $r$ & .251 & -.187 & .003 & -.239 & $-.374^{*}$ & .062 & -.214 & -.464 & -.254 & -.289 & -.283 & $-.415^{\star}$ & $-.368^{*}$ & -.183 & -.150 & -.315 & .009 \\
\hline & & $N$ & 39 & 38 & 38 & 37 & 37 & 38 & 37 & 39 & 39 & 39 & 39 & 34 & 37 & 35 & 35 & 30 & 30 \\
\hline 87 & SocialComplexity & $r$ & -.016 & .302 & .135 & $.326^{*}$ & .253 & -.117 & $.592^{\star \star *}$ & $.612^{\star \pi}$ & $.644^{* t}$ & $.645^{\#+}$ & $.590^{* *}$ & $.499 \approx$ & $.604^{*}$ & .021 & .041 & .336 & $-.533^{\star \star}$ \\
\hline & & $N$ & 39 & 38 & 38 & 37 & 37 & 38 & 37 & 39 & 39 & 39 & 39 & 34 & 37 & 35 & 35 & 30 & 30 \\
\hline 88 & RewardforApplication & $r$ & -.115 & -.191 & .054 & -.275 & -.245 & -.044 & $-.376^{*}$ & -.431 & $-617^{*}$ & $-.705^{\star *}$ & $-.693^{*}$ & $-.600^{*}$ & -.474 & -.021 & -.065 & .146 & $475^{\star+}$ \\
\hline & & $N$ & 39 & 38 & 38 & 37 & 37 & 38 & 37 & 39 & 39 & 39 & 39 & 34 & 37 & 35 & 35 & 30 & 30 \\
\hline 89 & Religiosity & $r$ & -.007 & -.220 & .137 & -.296 & -.162 & .044 & -.469 & -.502 & $-630 *$ & $=-.682$ & $-653^{*}$ & $-.426^{*}$ & $-.537^{t+1}$ & -.006 & -.073 & .143 & $.558^{* *}$ \\
\hline & & $N$ & 39 & 38 & 38 & 37 & 37 & 38 & 37 & 39 & 39 & 39 & 39 & 34 & 37 & 35 & 35 & 30 & 30 \\
\hline 90 & FateControl & $r$ & .016 & -.145 & .109 & -.263 & -.063 & -.138 & -.316 & -.581 & $-.564 *$ & $-.589 *$ & $-.553^{*}$ & $-.364 *$ & $-.413^{*}$ & -.197 & -.192 & -.065 & .334 \\
\hline & & $N$ & 39 & 38 & 38 & 37 & 37 & 38 & 37 & 39 & 39 & 39 & 39 & 34 & 37 & 35 & 35 & 30 & 30 \\
\hline
\end{tabular}




\begin{tabular}{|c|c|c|c|c|c|c|c|c|c|c|c|c|c|c|c|c|c|c|}
\hline \multicolumn{2}{|r|}{ Appendix 3 Cont'd Correlation Table } & & 74 & 75 & 76 & 77 & 78 & 79 & 80 & 81 & 82 & 83 & 84 & 85 & 86 & 87 & 88 & 89 \\
\hline \multirow[t]{2}{*}{75} & \multirow[t]{2}{*}{ AssertivenessSocietyalues } & $r$ & -.026 & & & & & & & & & & & & & & & \\
\hline & & N & 56 & & & & & & & & & & & & & & & \\
\hline \multirow[t]{2}{*}{76} & \multirow[t]{2}{*}{ InGroupCollectivismSocietyPractice } & $r$ & .166 & $.264^{*}$ & & & & & & & & & & & & & & \\
\hline & & N & 56 & 56 & & & & & & & & & & & & & & \\
\hline \multirow[t]{2}{*}{77} & \multirow[t]{2}{*}{ InGroupCollectivismSocietyalues } & $r$ & $.556^{*}$ & -.046 & .184 & & & & & & & & & & & & & \\
\hline & & N & 56 & 56 & 56 & & & & & & & & & & & & & \\
\hline \multirow[t]{2}{*}{78} & \multirow[t]{2}{*}{ UncertaintyAwoidanceValues } & $r$ & .206 & .181 & $.802^{* *}$ & .261 & & & & & & & & & & & & \\
\hline & & N & 56 & 56 & 56 & 56 & & & & & & & & & & & & \\
\hline \multirow[t]{2}{*}{79} & \multirow[t]{2}{*}{ PowerDistanceSocietyPractice } & $r$ & $.309^{*}$ & -.050 & $.592^{* \pi}$ & $.290^{*}$ & $.551^{\star \prime}$ & & & & & & & & & & & \\
\hline & & N & 56 & 56 & 56 & 56 & 56 & & & & & & & & & & & \\
\hline \multirow[t]{2}{*}{80} & \multirow[t]{2}{*}{ HumaneOrientationSocietyPractice } & $r$ & .151 & .182 & .000 & .050 & .026 & -.012 & & & & & & & & & & \\
\hline & & N & 56 & 56 & 56 & 56 & 56 & 56 & & & & & & & & & & \\
\hline \multirow[t]{2}{*}{81} & \multirow[t]{2}{*}{ TeamorientedLeadership } & $r$ & $.436^{* *}$ & .037 & $.311^{*}$ & $.346^{*}$ & .182 & .100 & -.144 & & & & & & & & & \\
\hline & & N & 56 & 56 & 56 & 56 & 56 & 56 & 56 & & & & & & & & & \\
\hline \multirow[t]{2}{*}{82} & \multirow[t]{2}{*}{ ParticipativeLeadership } & $r$ & $.344^{*}$ & $-.272^{*}$ & $-.516^{*+}$ & .061 & $-.556^{*}$ & -.117 & .033 & .131 & & & & & & & & \\
\hline & & N & 56 & 56 & 56 & 56 & 56 & 56 & 56 & 56 & & & & & & & & \\
\hline \multirow[t]{2}{*}{83} & \multirow[t]{2}{*}{ HumaneorientedLeadership } & $r$ & .231 & $428 *$ & $.388^{*}$ & .088 & $.322^{*}$ & .082 & .009 & $.392^{* t}$ & -.120 & & & & & & & \\
\hline & & N & 56 & 56 & 56 & 56 & 56 & 56 & 56 & 56 & 56 & & & & & & & \\
\hline \multirow[t]{2}{*}{84} & \multirow[t]{2}{*}{ AutonomousLeadership } & $r$ & -.117 & .208 & .104 & -.091 & -.039 & -.025 & .070 & -.017 & -.127 & .140 & & & & & & \\
\hline & & N & 56 & 56 & 56 & 56 & 56 & 56 & 56 & 56 & 56 & 56 & & & & & & \\
\hline \multirow[t]{2}{*}{85} & \multirow[t]{2}{*}{ SelfProtectiveLeadership } & $r$ & -.048 & .273 & $.710^{* t}$ & .015 & $.768^{\star *}$ & .252 & .017 & .180 & $-.742^{\star *}$ & $.441 \%$ & .131 & & & & & \\
\hline & & $\mathbb{N}$ & 56 & 56 & 56 & 56 & 56 & 56 & 56 & 56 & 56 & 56 & 56 & & & & & \\
\hline 86 & SocialCynism & $r$ & $-.368^{*}$ & -.021 & $.405^{*}$ & -.339 & $.399^{*}$ & $.489 *$ & .056 & -.258 & -.317 & .009 & $.412^{*}$ & $.404^{*}$ & & & & \\
\hline & & $N$ & 30 & 30 & 30 & 30 & 30 & 30 & 30 & 30 & 30 & 30 & 30 & 30 & & & & \\
\hline 87 & SocialComplexity & $r$ & -.084 & -.135 & $-.592 \pi$ & -.156 & $-.741^{\star *}$ & $-.476^{*+}$ & .348 & -.131 & $.426^{*}$ & -.293 & -.098 & $-.607 *$ & $-.461^{\#}$ & & & \\
\hline & & $\mathrm{N}$ & 30 & 30 & 30 & 30 & 30 & 30 & 30 & 30 & 30 & 30 & 30 & 30 & 39 & & & \\
\hline 88 & RewardforApplication & $r$ & .152 & .318 & $.623^{* \pi}$ & .242 & $.574 *$ & $.419^{*}$ & -.052 & .080 & $-.434^{*}$ & $.572^{\star \pi}$ & .356 & $.607^{* t}$ & $.319^{*}$ & $-.464 \approx$ & & \\
\hline & & $N$ & 30 & 30 & 30 & 30 & 30 & 30 & 30 & 30 & 30 & 30 & 30 & 30 & 39 & 39 & & \\
\hline 89 & Religiosity & $r$ & .241 & .274 & $.574 *$ & .188 & $.556^{*}$ & .249 & -.149 & .311 & -.348 & $.681 *$ & .188 & $.577^{\star *}$ & .172 & $-.566^{\star *}$ & $.778^{\star *}$ & \\
\hline & & $N$ & 30 & 30 & 30 & 30 & 30 & 30 & 30 & 30 & 30 & 30 & 30 & 30 & 39 & 39 & 39 & \\
\hline 90 & FateControl & $r$ & -.197 & .159 & $.546^{*}$ & -.178 & $.573^{* *}$ & $.362^{*}$ & -.121 & -.228 & $-.577^{* t}$ & .339 & $.464^{*}$ & $.654^{\star *}$ & $.487^{\star t}$ & $-.510^{* \star}$ & $.625^{*}$ & $.620^{* *}$ \\
\hline & & $\mathrm{N}$ & 30 & 30 & 30 & 30 & 30 & 30 & 30 & 30 & 30 & 30 & 30 & 30 & 39 & 39 & 39 & 39 \\
\hline
\end{tabular}


VITA

\section{AMANDA M. BULLOUGH \\ EDUCATION}

Florida International University, Miami, Florida

Doctoral Candidate in Business Administration, Management and International Business (August 2004 - December 2008) - Research focus: Leadership, Entrepreneurship, and International Small Business Development, and Women's Roles in the Economic Development of Developing Countries

Master of Arts, International Studies (August 2004) - Research Focus: Globalization, International Business, Emerging Economic Markets, International Political Economy, Women's Issues

University of South Florida, Tampa, FL

Bachelor of Science, Business Administration (August 1997) - Major: Marketing

\section{ACADEMIC WORK EXPERIENCE}

Thunderbird School of Global Managment

Assistant Professor of Entrepreneurship / Academic Director, Goldman Sachs Women Entrepreneurs Program (Present)

Florida International University

Instructor (January 2005-December 2008)

Teaching/Research Assistant (August 2004-April 2005, August 2007-Present)

Lead Researcher (August 2005-August 2007)

Florida International University Women-Led Businesses Survey Research Project

Teaching Experience

Student Evaluations Weighted Average: 4.33 out of 5

Graduate MBA Courses:

Organizational Design \& Behavior: (Summer 2008)

Undergraduate Courses:

Organizational Behavior: (Summer/Fall 2005, Summer 2008)

International Business: (Spring 2008)

Entrepreneurship: (Spring 2006 - Fall 2007)

Organization \& Management: (Spring \& Summer 2005)

\section{DISSERTATION}

Bullough, Amanda. "Factors Affecting Women's Participation in Leadership: A Theory Global Levels," In Progress - September 2008 Targeted Final Defense 


\section{RESEARCH PAPERS AND PROJECTS}

Bullough, Amanda. "Leadership and Entrepreneurship in Developing Countries: There May Be More Room for Women Than We Thought," Under Review at Gender in Management: an International Journal (formerly Women in Management Review)

Zanakis, Stelios, Maija Renko, Amanda Bullough. "Where Do New Businesses Come From? The Logic of Effectuation and Transition to Entrepreneurship," Working on a Revise and Resubmit for The Journal of Business Venturing.

Kroeck, K. Galen, Amanda Bullough, Paul Reynolds. "Entrepreneurship and Differences in Locus of Control," In Progress

Kroeck, K. Galen, Amanda Bullough, Maija Renko. "Expectancy Theory's Predictive Ability for Entrepreneurship" In Progress

Elam, Joyce, Amanda Bullough, Mayra Beers. "Florida's Women-Led Businesses 2006 Report", The Center for Leadership at Florida International University, May 2006

\section{CONFERENCE PRESENTATIONS}

Zanakis, Stelios, Maija Renko, Amanda Bullough. "Survival of Nascent Entrepreneurs: In Search of an Explanation," ICSB 2007 World Conference, Turku, Finland, June 1316,2007

Bullough, Amanda. "Leadership and Entrepreneurship in Developing Countries: There May Be More Room for Women Than We Thought," Gallup Leadership Institute Summit, Washington, D.C., October 7-9, 2006

Bullough, Amanda. "The Effect of Women Entrepreneurs Economic Development," Paper presented at the Academy of International Business, Southeast USA Chapter 2006 Annual Conference, Clearwater Beach, FL, October 25-27, 2006

Bullough, Amanda. "The Role of Governments \& Institutions in Promoting Global Entrepreneurship: International Business Theories Applied," Competitive Paper presented at the 2006 Annual Academy of International Business Conference, Beijing, China, June 23-25, 2006

Kroeck, K. Galen, Amanda Bullough, Paul D. Reynolds. "Cognitive Aspects of Entrepreneurship Revisited: Differences in Locus of Control," Paper presented at the 2005 Annual Academy of Management Conference: A New Vision of Management In The 21st Century, Honolulu, Hawaii, August 5-10, 2005

Bullough, Amanda. "Sex Slavery in Asia: Exploring Patriarchy and the Economic Effects of Globalization," Paper presented at the International Studies Association Southeast Conference, Miami, October 2005, at the Florida International University Women's Studies Conference, Miami, April 2005, and at the Florida Atlantic University Women's Studies Conference, Boca Raton, April 2005 